Portland State University

PDXScholar

Winter 4-18-2018

\title{
Is Therapy Going to the Dogs? Evaluating Animal Assisted Therapy for Early Identified At-Risk Children
}

Leah Faith Brookner

Portland State University

Follow this and additional works at: https://pdxscholar.library.pdx.edu/open_access_etds

Part of the Animal-Assisted Therapy Commons, and the Social Work Commons Let us know how access to this document benefits you.

\section{Recommended Citation}

Brookner, Leah Faith, "Is Therapy Going to the Dogs? Evaluating Animal Assisted Therapy for Early Identified At-Risk Children" (2018). Dissertations and Theses. Paper 4338.

https://doi.org/10.15760/etd.6231

This Dissertation is brought to you for free and open access. It has been accepted for inclusion in Dissertations and Theses by an authorized administrator of PDXScholar. Please contact us if we can make this document more accessible: pdxscholar@pdx.edu. 
Is Therapy Going To The Dogs?

Evaluating Animal Assisted Therapy for Early Identified At-Risk Children

\author{
by \\ Leah Faith Brookner
}

A dissertation submitted in partial fulfillment of the requirements for the degree of

\author{
Doctor of Philosophy \\ in \\ Social Work and Social Research
}
Dissertation Committee:
Maria Talbott, Chair
Vicki Cotrell
Michael Taylor
Eric Mankowski

Portland State University

2018 


\begin{abstract}
This study explores the historical context of human-animal relationships and examines the important ways that humans benefit from various types of interactions with domesticated animals. Therapeutic approaches that incorporate animals have been shown to have multiple benefits, including improved physical and mental health. Although this area of study is still largely overlooked in scientific fields of study, including social work, Animal Assisted Therapy (AAT) has become increasingly prevalent in various mental health settings. Despite its popularity and anecdotal support, research on the benefits of AAT with children is minimal; there are no studies examining the ways in which this approach impacts children under the age of five.

Thirteen pre-school-aged children from a community-based early intervention program participated in a 16-week pilot study on AAT. The children were considered atrisk for potential behavioral, emotional and psychological challenges due to a constellation of factors, including developmental delays, poverty and early childhood trauma. This research includes case studies for each of the participants, with detailed information about the children as well as an account of their therapeutic experiences during the 16-week program. Thematic Analysis was used to analyze the data. Broad themes emerged in two main areas: demographic factors and intervention strategies. Each of these themes is explored in depth to highlight the most salient features of the cases and effective therapeutic processes.

Findings indicate that the population studied shared various characteristics, including poverty, trauma history and complex family sessions. Preschool-aged children
\end{abstract}


with risk factors do benefit from Animal Assisted Therapy in different ways based upon their histories and presenting behaviors. Children who present with internalizing behaviors, fear and disengagement, respond favorably to therapeutic cross-talking and physical touch; children with aggression and externalizing behaviors respond positively to clear limits, identifying feelings in the therapy dog and physical touch; and children who present more typically for the age and development, respond well to various forms of therapeutic interventions that incorporate the dog. Recommendations for therapeutic animal-based approaches are made based on the findings of this research. 


\section{Table of Contents}

Abstract $\quad$ i

List of Tables $\quad$ V

List of Figures $\quad$ vi

Chapter 1 - Introduction and Overview

Significance and Context for Study 2

Purpose of Study 4

Overview 5

Chapter 2 - Review of the Literature $\quad 7$

$\begin{array}{ll}\text { Theory } & 7\end{array}$

Applicable Theories $\quad 8$

Moving Beyond Theory: Evidence $\quad 19$

Pet Ownership and Social Support $\quad 21$

History and Literature Review of Animal Assisted Therapy 23

Humane Education 33

Animal Cruelty 35

Cultural and Social Barriers in Research on the Human-Animal Bond 37

Challenges in Studying the Emotional Connections to Pets 39

Who is “At-risk”?

Support for Further Study $\quad 42$

Chapter 3 - Methodology $\quad 46$

Significance of the Study 46

Research Questions $\quad 46$

Design 47

Intervention $\quad 48$

Therapeutic Techniques 49

Sample 58

$\begin{array}{ll}\text { Data Collection } & 61\end{array}$

$\begin{array}{ll}\text { Ethical Issues } & 63\end{array}$

Analysis $\quad 64$

Chapter 4 - Findings $\quad 69$ 
$\begin{array}{ll}\text { Cases Studies } & 69\end{array}$

Thematic Analysis 182

$\begin{array}{ll}\text { Therapeutic Themes } & 187\end{array}$

Chapter 5 - Discussion 197

$\begin{array}{ll}\text { My Role } & 197\end{array}$

$\begin{array}{ll}\text { Personal and Professional Interest } & 199\end{array}$

Summary and Discussion of Findings 200

Implications for Social Work 203

Implications for Theory 206

Implications for Practice $\quad 208$

$\begin{array}{ll}\text { Strengths of this Study } & 209\end{array}$

$\begin{array}{ll}\text { Limitations } & 211\end{array}$

$\begin{array}{ll}\text { Future Research Directions } & 214\end{array}$

$\begin{array}{ll}\text { References } & 217\end{array}$

Appendix A - Animal Assisted Therapy 237

Appendix B - Animal-Assisted Therapy Evaluation Instrument (AATEI) 238

Appendix C - Animal Assisted Therapy Progress Note 242

Appendix D - Animal-Assisted Individual Therapy Program 245

Appendix E - Photo/Media/Research Release 247

Appendix F - Human Subjects Review Committee Permission Letter 248 


\section{List of Tables}

Table 1. Client Demographic and Referral Information

Table 2. Theme Groups 


\section{List of Figures}

$\begin{array}{ll}\text { Figure 1. Ay-Attention. } & 79\end{array}$

Figure 2. Ay-Engagement. $\quad 80$

Figure 3. Ay-Emotional regulation. $\quad 80$

Figure 4. Ay-Age-appropriate behavior. $\quad 81$

Figure 5. Ay-Cognitive "Yes" scores (Raters $1 \& 2)$ ). 81

Figure 4. Ay-Social-emotional "Yes" scores (Raters 1 \& 2). 82

Figure 7. Ay-Verbal "Yes" scores (Raters 1 \& 2). 83

$\begin{array}{ll}\text { Figure 8. Bri-Attention. } & 88\end{array}$

Figure 9. Bri-Engagement. $\quad 89$

Figure 10. Bri-Emotional regulation. $\quad 89$

Figure 11. Bri-Age-appropriate behavior. $\quad 90$

Figure 12. Bri-Cognitive "Yes" scores (Raters 1 \& 2). 90

Figure 13. Bri-Social-emotional "Yes" scores (Raters 1 \& 2). 91

Figure 14. Bri-Verbal "Yes" scores (Raters 1 \& 2). 91

Figure 15. Guy-Attention. 96

Figure 16. Guy_Engagement.

Figure 17. Guy-Age-appropriate behavior. $\quad 97$

Figure 18. Guy—Social-emotional indicators. $\quad 97$

Figure 19. Guy-Cognitive "Yes" scores (Raters 1 \& 2). 98

Figure 20. Guy—Social-emotional "Yes" scores (Raters 1 \& 2). 98

Figure 21. Guy_Verbal "Yes" scores (Raters 1 \& 2). 99

$\begin{array}{ll}\text { Figure 22. JJ-Attention. } & 104\end{array}$

$\begin{array}{ll}\text { Figure 23. JJ—Engagement. } & 105\end{array}$ 
Figure 24. JJ-Emotional regulation. 105

Figure 25. JJ-Age-appropriate behavior. 106

Figure 26. JJ-Cognitive "Yes" scores (Raters 1 \& 2). 106

Figure 27. JJ-Social-emotional "Yes" scores (Raters 1 \& 2). 107

Figure 28. JJ-Verbal "Yes" scores (Raters 1 \& 2). 107

Figure 29. Jav-Attention. 111

Figure 30. Jav-Engagement. 112

Figure 31. Jav-Emotional regulation. 112

Figure 32. Jav-Age-appropriate behavior. 113

Figure 33. Jav-Cognitive "Yes" scores (Raters $1 \&$ 2). 113

Figure 34. Jav-Social-emotional "Yes" scores (Raters 1 \& 2). 114

Figure 35. Jav—Verbal "Yes" scores (Raters 1 \& 2). 114

$\begin{array}{lr}\text { Figure 36. Kai-Attention. } & 118\end{array}$

Figure 37. Kai-Engagement. 119

Figure 38. Kai-Emotional regulation. 119

Figure 39. Kai-Age-appropriate behavior. 120

Figure 40. Kai-Cognitive "Yes" scores (Raters 1 \& 2). 120

Figure 41. Kai-Social-emotional "Yes" scores (Raters 1 \& 2). 121

Figure 42. Kai-Verbal "Yes" scores (Raters 1 \& 2). 121

$\begin{array}{lr}\text { Figure 43. May-Attention. } & 128\end{array}$

$\begin{array}{lr}\text { Figure 44. May_Engagement. } & 128\end{array}$

$\begin{array}{ll}\text { Figure 45. May_Emotional regulation. } & 129\end{array}$

$\begin{array}{ll}\text { Figure 46. May-Age-appropriate behavior. } & 129\end{array}$

Figure 47. May—Cognitive "Yes" scores (Raters $1 \& 2)$. 
Figure 48. May-Social-emotional "Yes" scores (Raters 1 \& 2). 130

Figure 49. May_Verbal "Yes" scores (Raters 1 \& 2). 131

$\begin{array}{ll}\text { Figure 50. Mik-Attention. } & 138\end{array}$

Figure 51. Mik-Engagement. 139

Figure 52. Mik-Emotional regulation. 139

Figure 53. Mik-Age-appropriate behavior. $\quad 140$

Figure 54. Mik-Cognitive "Yes" scores (Raters 1 \& 2). 140

Figure 55. Mik—Social-emotional "Yes" scores (Raters 1 \& 2). 141

Figure 56. Mik—Verbal "Yes" scores (Raters 1 \& 2). 141

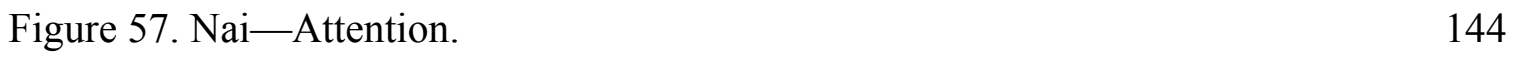

$\begin{array}{ll}\text { Figure 58. Nai-Engagement. } & 145\end{array}$

Figure 59. Nai-Emotional regulation. 145

Figure 60. Nai-Age-appropriate behavior. 146

Figure 61. Nai-Cognitive "Yes" scores (Raters $1 \&$ 2). 146

Figure 62. Nai-Social-emotional "Yes" scores (Raters 1 \& 2). 147

Figure 63. Nai-Verbal "Yes" scores (Raters 1 \& 2). 147

Figure 64. Ren-Attention. 151

Figure 65. Ren-Engagement. 152

Figure 66. Ren-Emotional regulation. 152

Figure 67. Ren-Age-appropriate behavior. 153

Figure 68. Ren-Cognitive "Yes" scores (Raters 1 \& 2). 153

Figure 69. Ren-Social-emotional "Yes" scores (Raters 1 \& 2). 154

Figure 62. Ren-Verbal "Yes" scores (Raters 1 \& 2). 154

Figure 71. Tah-Attention. 159 
$\begin{array}{ll}\text { Figure 72. Tah-Engagement. } & 160\end{array}$

Figure 73. Tah-Emotional regulation. 160

Figure 74. Tah-Age-Appropriate behavior. $\quad 161$

Figure 75. Tah-Cognitive "Yes" scores (Raters 1 \& 2). 161

Figure 76. Tah-Social-emotional "Yes" scores (Raters 1 \& 2). 162

Figure 77. Tah—Verbal "Yes" scores (Raters $1 \& 2)$.

Figure 78. Vin-Attention. 167

Figure 79. Vin-Engagement. 167

Figure 80. Vin-Emotional regulation. 168

$\begin{array}{ll}\text { Figure 81. Vin-Age-appropriate behavior. } & 168\end{array}$

Figure 82. Vin-Cognitive "Yes" scores (Raters 1 \& 2). 169

Figure 83. Vin-Social-emotional "Yes" scores (Raters 1 \& 2). 169

Figure 84. Vin-Verbal "Yes" scores (Raters 1 \& 2). 170

$\begin{array}{ll}\text { Figure 85. Vivi-Attention. } & 175\end{array}$

Figure 86. Vivi-Engagement. 176

Figure 87. Vivi-Emotional regulation. 176

$\begin{array}{ll}\text { Figure 88. Vivi-Age-appropriate behavior. } & 177\end{array}$

Figure 89. Vivi-Cognitive "Yes" scores (Raters $1 \&$ 2). 177

Figure 90. Vivi-Social-emotional "Yes" scores (Raters 1 \& 2). 178

Figure 91. Vivi-Verbal "Yes" scores (Raters $1 \& 2)$.

Figure 92. Individual change scores for each client (16.2 average score). 180

Figure 93. Thematic web for intervention type and technique. 191 


\section{Chapter 1}

\section{Introduction and Overview}

The relationships humans have with animals, domestic and wild, positive and negative, are as dynamic and multifaceted as human-to-human relationships. The significance of the interdependent relationship between humans and animals has been best captured in research on the Human-Animal Bond (HAB), pet guardianship and Animal Assisted Therapy (AAT). Findings from research on AAT, pet ownership and Humane Education Programs indicate that animals play a very important role in the overall healthy development of children. However, not a single theory used in the understanding or practice of social work specifically includes animals as active contributors to human development or socialization. Studies in these areas have been impaired by the absence of strong, cohesive theoretical explanations, methodological inconsistency and small, disparate samples.

This research study explores the benefits of a therapeutic animal intervention program with 13 children determined to be "at risk" for the development of later psycho/social/emotional disorders. This study builds from research and theory-supported ideas about the Human Animal Bond (HAB) by providing Animal Assisted Therapy to a novel population - at-risk children of pre-school age - to better understand the effects of the intervention and propose future directions for study in this area. To date, there has been no published research on the impact or potential benefits of AAT on the specific population of focus in this study. 


\section{Significance and Context for Study}

The complex social relationship between people and animals extends back to prehistoric times. Biological interdependency, an argument stemming from research on urban animal management, asserts that human animals evolved with and because of their relationships with other species (Paxton, 1998, 2000). Certain species developed a partnership to increase the potential of both species' procreation and success. This partnership is especially clear with human beings and canines. Dogs quickly became the first domesticated pet for a variety of reasons: they supported human survival, are social creatures, can reproduce easily in captivity, can subsist on food offered to them by humans, do not consider human flesh a source of food, and are relatively small in size compared to many other species; additionally, they are physically attractive to most humans because of their facial symmetry and markings (Anderson, 2008).

Since the rise of agriculture, human beings have become removed from wild, untamed settings. Many decades of technological advancements, industry, urban development and commerce, as well as a steadily growing population, have spurred the separation of humans from other animal species. This growing divide may be one of the essential reasons why pets have become such central features in the lives of Westernized people.

Animals exist in almost every aspect of human life, functioning as pets, sources of entertainment, transportation, clothing and food; there are few people who are not somehow directly affected by and through animals. This is not to say that all humananimal relationships are positive; in fact, often one species may benefit while the other 
suffers. For example, in dog fighting, circuses, and zoos - the animals are a means for entertainment and may be regarded as objects or commodities. The same is true for animals used as a food source. Though these relationships between humans and animals are not wholly positive for the animals in question, there is no denying the reliance that humans have upon animals. Often, this reliance is grossly under- or unrecognized.

In recent years, the relationship between humans and their animals, namely dogs, has been the focus of many movies and books. Much attention is paid to the HumanAnimal Bond in contemporary or "pop" culture; the media reflects this with wildly popular movies like 101 Dalmatians, Scooby Doo, and Beverly Hills Chihuahua. Animals have always been central characters in children's toys, literature, and television (Serpell, 1999). But no longer are animals simply the content of children's genres; Marley and Me and Best in Show are movies specifically targeting adult audiences. Further, there are more best-selling books published on the relationship between dogs and their owners than ever before. The value placed on animals, and the frequency with which people are able to share their feelings of love, joy, and sorrow about their dogs, has increased dramatically in just 10 years. The Washington Post had a front-page story, complete with large color photos, reporting on the many Senators in office who bring their dogs with them to work "on the hill" (June 2010); that same publication reported the benefits of pet ownership and positive interactions with animals as recently as July 2017 in an article entitled "Therapy animals are everywhere. Proof that they help is not." Dogs have not only made their way into contemporary media, they have literally entered into schools and hospitals to improve and enhance the lives of the people within (Hines, 2003). The 
examples of pets helping humans through therapeutic services and activities are nearly endless (Delta Society, 2010); examples and anecdotal evidence abound while scientific "proof" is much more challenging to generate.

The important role of animals in the lives of American people is further evidenced through consumer habits. The American Pet Products Association, the "leading not-forprofit trade association serving the interests of the pet products industry" calculated that Americans spent $\$ 66.75$ billion on their household pets in 2016 (this figure does not include money spent on farm animals). According to the 2017 National Pet Owners Survey, 84.6 million American homes include at least one pet, which is $68 \%$ of the U.S. population; of those, 60.2 million homes include at least one dog. Dogs are the most popular American pet, followed by cats. Clearly, there is not only a high prevalence of family pets, there is also a high value placed upon them. The majority of pet owners $(95 \%)$ regard their pets as their friends while $87 \%$ of pet owners consider their pets family members (Walsh, 2009). Interestingly, research on family intimacy indicates that a higher percentage of pet owners feel closer to their cat or dog than they do to their fathers (Pew Research Center, 2006)!

\section{Purpose of Study}

To date, there has been no research done to specifically address the influence that animals have on early childhood development; further, there has been no attention paid to the potential therapeutic impact that Animal Assisted Therapy may have on young children who present with various risk factors. While social work "has experienced a boom in interest in non-talk-based therapies to address trauma . . . in children," none have 
specifically focused on creating an evidence base using AAT for this particular population (Dunlop \& Tsantefski, 2017,p. 1). Adverse childhood experiences, including trauma, parental loss and neglect, have been shown to have negative long-term effects on development and social wellbeing into adulthood, including criminality, poor educational achievement and increased medical and mental illness (Varese et al., 2012). Primary prevention and early intervention services are extremely valuable in helping to mitigate the effects of early adversity (Read \& Bentall, 2012). This study aims to provide support for incorporating therapy dogs into programs for at-risk pre-school-aged childrenthrough an increased understanding of the population and greater insight into the therapeutic techniques being tested, additional information about the benefits and challenges of this unique intervention are better articulated.

\section{Overview}

The following chapter explores substantial literature and existing theoretical support for therapeutic interventions that incorporate animals. A partial explanation for the lack of research and study in this area, especially in early childhood development, may be due to the lack of well-established theories that support and guide the practice of Animal Assisted Therapy. Other limitations to studying this type of intervention are due to cultural and social values placed upon animals (for example, some animals are treated as beloved pets while others are consumed for food), the relative novelty of this field, and the fluidity with which the intervention is applied by varying practitioners and therapists. The aim of this study is to: build a foundation for future research and study by establishing a sound theoretical base, deeply examine a population of young children 
before and during the delivery of a therapeutic pilot program, and evaluate the components of AAT that have impact on the sample group to understand which children benefit and why.

Chapter 2 synthesizes several major theories of human development and behavior to provide a solid theoretical foundation for Animal Assisted Therapy with children. Chapter 2 also reviews the literature on AAT and HAB, which establish that AAT is a promising intervention, and lays the foundation for studying this intervention with very young children. Chapter 3 describes this intervention in an early childhood program serving children experiencing various challenges and risks by delivering a 16-week treatment program to 13 pre-school aged children using individualized Animal Assisted Therapy. Chapter 4 presents the findings from this study using primarily case study and thematic analyses. Chapter 5 discusses the findings, their implications, strengths and weaknesses of the study and provides direction for future research. 


\section{Chapter 2}

\section{Review of the Literature}

\section{Theory}

The pursuit of a single unifying theory that explains the human-animal relationship proves challenging, for there are biological, historical, evolutionary, spiritual, social, emotional and developmental arguments that link some aspect of the human experience to the influence of non-human beings.

Why does theory even matter? Social work has long struggled to be recognized as a profession based on scientifically supported research. In the past, the profession was "in crisis" due to a "dearth of empirically based studies of practice outcomes" (Thyer, 2001, p. 9). Social work struggles to gain professional recognition as a hard science for a variety of reasons, one of which is the limitation that theory has in predicting pro-social outcomes. Explanatory research is "supposedly predicated on a theory" and such a theory should be "driving the research" and/or "defining the question" (Thyer, 2001, p. 14). But what if theories lack complexity or adaptability? What happens when the profession seeks to build research on a theoretical foundation that is too simple, too dated, too inflexible or simply culturally insensitive? Social work as a field has struggled to explain how interventions work using a clear theoretical framework. Thyer critiques social work's struggle succinctly, he writes: "Our field's preoccupation with the development of a unique, discipline-specific theoretical foundation is in large part driven by the assumption that the possession of such knowledge is considered to be a prerequisite for obtaining "professional status"” (2001, p. 23). The struggle is this: we (professionals, 
providers and practitioners) must adhere to rigorous scientific testing while also demonstrating allegiance to theoretical assumptions. But what if there is no concise or even complex theory currently available that explains how and why certain phenomena exist? Herein lies the struggle to define and measure the Human-Animal Bond; the struggle is not only evidenced by a lack of theory but also helps to explain why research and quantitative data are missing from this field. The field of mental health "has been slow to recognize the importance of [human-animal] bonds in clinical theory, research and practice" (Walsh, 2009, p. 462). Theory fuels research but without a concrete theory, or simply, a clear place to start, how can we research dynamic, complex or even enigmatic experiences?

\section{Applicable Theories}

There are a number of well-established theories both within and outside of social work that help to explain how and why human beings develop strong bonds with their pets. Though there is room within the theories to allow for the expansion of principles such that pets may be included as social supporters and environmental contributors, relational theories in social work do not explicitly examine the role of animals in the lives

of humans. In the following section, I propose adaptations to Ecological Systems Theory and Attachment Theory so that they include the Human Animal Bond and introduce Biophilia, a theoretical hypothesis, which may be used to guide the expansion of social work to include animals.

The Ecological Systems Theory perspective in social work examines the personin-environment but the "environment" is focused on the individual and social (human) 
environment. This mode of thinking limits the extent to which a person is seen as having a relationship with nature and with other non-human species. Bronfenbrenner's ecosystem model includes the micro, meso, exo and macro system (as well as chronosystem) that, taken together, help to explain development and subsequent behavior in children (1979). The microsystem is the innermost layer, which includes the people and constructs most closely related to an individual; those with whom the individual has direct contact and interactions. Elements of one's home environment are included in the microsystem. For children with pets, the nature and strength of this relationship (between child and pet) is certainly an important consideration when looking at the microsystem. Often, the ecosystem model ignores the crucial role that animals play in the microsystems of children; pets may be perceived as peers, siblings, friends or constant companions (Melson, 2001). The mesosystem focuses on the connections and relationships within the greater system. Conceptually, the mesosystems are the relationships between the many people and constructs in an individual's life. For a child with a pet, mesosystem examples are the connection between child's pet and parent and/or pet and sibling; all of these relationships are mutually influential and affect the system as a whole. The macrosystem includes cultural, political and social ideology; forces such as racism, stigma and bias are macrosystem concepts thought to have significant impact upon developing children. In order to understand psychological development and health, Bronfenbrenner encourages a deep examination of the multiple systems at play and an in-depth understanding of how these systems interact (1979). The Ecological model or theory leaves room for the role of animals and does suggest that early relationships are pivotal to childhood development. 
However, the specific nature of and importance of pet animals in the lives of children is missing from the theory.

Many, if not most, theories on human development are relational models, in that they include a shared principle that human growth is shaped by relationships and connections that individuals have with others. All phases of growth and maturation, which include mental, psychological, physical and spiritual, exist in the context of extensive connections. Early relational interactions serve as a significant foundation for later social and emotional development; the continuous connectedness of self with others creates a flow of reciprocity, which in Psychology and social work has been examined only at the human-to-human level.

Attachment Theory does not specifically focus on the impacts of pets or animals on childhood development but it is a malleable enough theory to allow for the stretching of its concepts to explain the human-animal bond. Development, according to Attachment-based theories, is situated within important early relationships and the lasting effects of such. Attachment has been defined as the "lasting psychological connectedness between human beings" (Bowlby, 1969). John Bowlby, the pioneer of Attachment Theory, believed that children are "born with an inherent predisposition to form and maintain attachments to their ...caregivers because the development of attachment relationships is key to the continuation of the species and thus intrinsic to survival" (Slade, 2004, p. 271). This idea that attachment is survival-based echoes biological and historical principles indicating that interdependency (between not only the human species but also between species of differing types) is essential for longevity and evolution. The 
principles behind Attachment Theory are not only emotional and psychological; the theory is rooted in an ethological foundation (and originally studied in non-humans). Ethology is concerned with studying the adaptive behaviors that promote survival. Konrad Lorenz's acclaimed research in this area centered on baby geese and their ability to form lasting attachments to a mother figure. Lorenz noted the ability of geese and other species as well, to form a strong attachment to mother-figures of another species (namely humans). Imprinting is now considered a form of adaptive learning that happens early in life. Geese and dogs can become attached to humans; so too can humans become attached to members of equally dissimilar species.

There are a number of unexamined theoretical assumptions within Attachment Theory: that because a person's first attachment is to another human all future attachment figures must necessarily be human. The need for attachment and bonding does not disappear when an individual grows from an infant to child to adult; if anything, relationships become more complex and dynamic. Figures of attachment change and individuals are capable of having multiple attachment figures; more may be necessary over time as to meet a constellation of emotional needs. In cases where unhealthy attachment occurs between infant and caregiver, for example, the infant may grow to compensate for unmet needs (in the case of neglect) or traumatic experiences (characterized by abuse) by selecting a new attachment figure that may be perceived to be less threatening or more consistent (Fairchild, 2009; Main \& Weston, 1982; Zimberoff \& Hartman, 2002). One's first primary attachment is often paramount to any future relationships. However, choosing a new attachment figure is possible and may help to 
mitigate the negative effects of a disturbed early relationship. For example, in homes characterized by chaos and unpredictability, children often seek out family pets for stability and unconditional acceptance; to counter feelings of fear and loneliness, children rely on their "companion animals" (Turner, 2005, p. 14). Self-care children (that is, children who come home to an empty house after school and are required to spend greater-than-average time alone) who "come home to a companion animal feel a greater sense of security" and experience a reduced sense of isolation (Turner, 2005, p. 14). There is a growing body of research demonstrating the evolution of children's choice of attachment figures; pets are often the primary non-parent attachment figures in homes where they exist (Anderson, 2007; Triebenbacher, 1999). Supporting this, Harm conducted a study that "indicates that children's attachment to a companion animal is positively correlated to their sense of self-esteem" $(2005$, p. 4). The effects of early connections with animals, though overlooked by conventional theories and models, may include aspects of growth and maturation related to empathy building, patterns of socialization, emotional functioning, communication and bonding similar to those described by Attachment Theory but specifically applicable to the human-animal relationship (American Veterinary Medical Association, 1997; Melson, 2003; Wolf, 2000).

Children's very early relationships with attachment figures have lasting impact. Pets have been found, for some children, to be significant attachment figures that impact the development of positive working models in children (Bretherton \& Munholland, 1999; Parish-Plass, 2008; Rynearson, 1978). Dogs are highly attentive to the needs of 
humans and offer consistent love and attention, both crucial aspects in developing a secure attachment style (Wilson \& Turner, 1998). Research findings on the psychological benefits of pets are strongest when people are "strongly attached" to a companion animal (Garrity et al., 1989). Social support and/or a social network contribute to how a child develops and influence the trajectory of such development; for example, considerable evidence shows that effective social support "contributes to mental health" and additional evidence indicates that it may provide a buffering or "protective function against psychosocial stress" (Cochran \& Brassard, 1979; Cohen \& Willis, 1985; Endenburg \& Baarda, 1995, p. 7).

Proponents of using AAT with children suggest that animals, especially for children who have experienced trauma at the hands of parents or caregivers, can approximate attachment relationships in healthy new ways. Children can experiment with "doing relationships differently" and test out some of the behaviors learned within their family of origin (Dunlop \& Tsantefksi, 2017, p. 2). This type of therapy has the capacity to influence a child's internal working model (a key concept in the development of attachment patterns), especially for very young children (Dunlop \& Tsantefski, 2017).

Ecological Systems Theory and Attachment Theory suggest that multiple factors and layers of environmental influence contribute to an individual's development. Both theories leave latitude for the contributing influence that companion animals may provide, yet they do not explicitly state it.

Biophilia, a biosocial hypothesis first suggested by researcher E. O. Wilson suggests that humans have an innate and predetermined tendency to relate to and "deeply 
affiliate" with other non-human life forms (Besthorn \& Saleebey, 2003; Wilson, 1984, 1993). Biophilia claims that human beings have an inherent need to interact with other species (and other aspects of natural settings), and that this need is not only biologically based but also deeply emotional and intimate. According to Biophilia, it is imperative that human beings "connect with nature in order to maximize their potential and lead productive, fulfilling lives" (Besthorn \& Saleebey, 2003).

Given the history of humans as subsistence hunters and gatherers, it is implausible and naïve to believe that the natural environment did not shape the cognitive, emotional and social capacities shared by modern human beings. Genetic "pre-dispositions arose within natural settings ... and contexts, and ... the [human] species [has] been intimately tied to a variety of natural environments" such that an integral aspect of healthy development is dependent upon opportunities to interact with and connect with nature or features of nature (Besthorn \& Saleebey, 2003, p. 2). The current tendency to affiliate with natural settings and aspects of nature (such as animals) is one that likely enhanced the fitness of Homo Sapiens in the past (Gullone, 2000). Therefore, the relationship between humans and other species is one not of preference but instead a hardwired need that underlies the survival, success and healthy development of our species. Without a relationship with nature, or features of it, human beings become deprived of an essential feature of what it means to be living, breathing creatures amongst many others. Our modern lifestyle moves the human species further away from nature, through industrialization, technology, cultural changes, and population growth; this modern lifestyle "manifests a large discrepancy between who we are and how we 
live...[and] this discrepancy may be responsible for increases in psychopathology evidenced in the modern world" (Gullone, 2000, p. 311). The further apart we become from others, the more significant the need for and presence of companion animals.

Nine perspectives have been outlined that describe humans' relationships with the natural world. Kellert argues that these perspectives are all "biologically based ... [and allow for] physical, emotional and intellectual fulfillment" (Gullone, 2000, p. 304). His extensive "cross-cultural research [proves] that our eon's old affiliation with nature has conferred advantages in our species survival throughout history" (Besthorn \& Saleebey, 2003, p. 2). Based upon such research, the nine perspectives account for the multiple features of humans' relationship with nature. These perspectives advanced Biophilia by expounding upon the encompassing notion of human-animal interdependency; each point illustrates a distinct domain of connectedness with or reliance upon nature or animals. The nine perspectives are: (1) Utilitarian, (2) Naturalistic, (3) Ecologistic-scientific , (4) Aesthetic, (5) Symbolic, (6) Humanistic, (7) Moralistic, (8) Dominionistic, (9) Negativistic valuations of nature (see Kellert, 1993).

The perspective that best accounts for the Human-Animal Bond and supports the notion that this dynamic can have positive effects on development and be utilized as an intervention is Humanistic. The Humanistic perspective purports that humans require and are sustained by emotional connections to others- human and non-human. Relationships are foundational for psychological growth and development. If the perspectives (based upon research conducted in fields such as biology, psychology, and anthropology) are accepted as legitimate traits for the majority of modern humanity, any intervention or 
program that increases the opportunity to practice or develop any one of the above is, in essence, providing the chance for individuals to become more human, respecting and building upon a deeply innate (biological) trait that might otherwise be marginalized and therefore neglected. If healthy development is contingent upon Biophilic principles, which can be broken down into essential features and commonalities tracing back to humanity's earliest history, the recognition of these principles and adherence to them may offer deeper insight into the evolution of psychology.

Relationships between humans and non-humans are often very often positive and fulfilling; however, this is not always the case. The theory argues that ambivalent relationships with non-human others are due to the unnatural divide between and separation from natural settings (and what, or who, exists in those settings). A lack of connections or opportunities to relate to non-human others may create a void that does not outwardly impair one's emotional well-being or relationships; however, for some this void may progress into outwardly negative behaviors indicative of mental illness or social maladaptation. Biophilia assumes that relationships between human and non-humans are as dynamic and complex as human-to-human relationships. For that reason, human-toanimal relationships, even those with negative characteristics, must be regarded and investigated closely, as would any human-to-human interaction. Sometimes fear or aversion to animals is simply due to lack of exposure, as is often the case with children reared in highly urban, low-income neighborhoods; animals, including pets, are not as frequently encountered in these settings. Dislike of specific animals may also be rooted in evolution; certain animals once presented a threat to human survival and, as such, some 
people still have an inborn disdain for certain creatures (for example, snakes and spiders). Finally, in a small percentage of the population, feelings of apathy or revulsion can trigger anger or acts of violence toward non-threatening animals, which would be indicative of psychopathology. It is estimated that $1.8 \%$ of U.S. adult males have committed intentional acts of cruelty toward animals (Vaughn et al., 2009). Cruelty toward animals is significantly associated with other maladaptive behavior patterns, such as alcoholism, conduct disorder, antisocial personality disorder, obsessive-compulsive disorder, histrionic personality disorders, pathological gambling, family history of antisocial behavior, and domestic violence within the family system (Vaughn et al., 2009).

Social work should challenge the assumptions, theories and practices of anthropocentric thinking. It must go further and attend to the gaps or areas of concern that arise when human beings are either alienated from or superior to other forms of life. The term "Green" or progressive social work is that which seeks to address the relational connection between humans and nature. Currently, Green social work is not a field unto itself; it's a sub-discipline in social work that is gaining momentum alongside environmental justice and sustainability (Shaw, 2008). An article in Social Work implores the profession to recognize the "powerful" relationship between "humans and companion animals" (Risley-Curtiss, 2010, p. 38). Risley-Curtiss presents three important reasons why companion animals should be included in social work research, education and practice: (1) Most homes that include pets consider them to be family members. As such, these animal members of the family should be considered "subsystems within the 
complex family system" (2010, p. 39). (2) Cruelty toward animals is often correlated with chaotic or unstable home environments; it can also be predictive of future anti-social behaviors toward others (Dadds, Whiting, \& Hawes, 2006; Merz-Perez \& Heide, 2004). (3) Companion animals have been proven to have a beneficial effect on people across the lifespan, not just for those who live with the animals but also for those who interact with therapy animals inconsistently (through programs or services offered in multiple settings).

Social work that goes beyond a humanocentric focus is needed to "expand the lens to include the presence or absence of companion animals, and the nature of those relationships ... with regard to issues such as oppression, health, social support and violence" (Risley-Curtiss, 2010, p. 44). The American Sociological Association (ASA) created a "special section ... with the stated purpose to encourage and support the development of theory, research and teaching about the complex relationships that exist between humans and other animals" (Anderson, 2008, p. 18). Psychologists formed the group Psychologists for the Ethical Treatment of Animals (PSYETA), renamed Society and Animals in 2004, to promote the study of interspecies relationships. Though an interdisciplinary approach is necessary to study and better understand HAB, it has primarily been the field of veterinary medicine that has promoted this concept and led the examination of HAB (Hines, 2003).

Studying HAB and supporting intervention research on AAT requires a refined theoretical argument. Biophilia, Attachment Theory, Ecological Systems Theory and Green social work all borrow theoretical principles from well-accepted and scientifically- 
supported theories; however, this paper suggests shifting the focus from human-human relationships to human-animal relationships, while still adhering to the theories' assumptions about attachment, social support, layers of influence, connections to others (all others), and recognizing an individual's position within an intricate web of relationships. "Theory clarification" or development within social work is an important area that has gone largely unrecognized in this arena. The lack of an appropriate existing theoretical orientation has influenced how and what social workers study.

\section{Moving Beyond Theory: Evidence}

With a theoretical perspective or orientation in place, Animal Assisted Therapy as an intervention becomes an opportunity, and one worthy of further exploration. As stated above, any intervention or program that increases the opportunity to practice or develop aspects essential to healthy development (per Biophilic principles) should include the opportunity to interact with features of one's natural environment. The development of theory that pets serve as allies and attachment figures may be the launching pad that AAT needs to become more credible as an intervention based on theory. Animal Assisted Therapy as a research-supported and scientifically backed intervention might then be incorporated into a more holistic and humanistic treatment of clients in a multitude of settings.

One of the major reasons that AAT has not gained more scientific attention is because the research supporting it has been conducted on small-size samples and the results are largely qualitative, as such lacking generalizability. Furthermore, there have been minimal longitudinal studies on children to date, as all of the studies have assessed 
people within a relatively short time period. Thus, while the ostensible benefits of positive relationships with companion animals are clear, the lasting effects of Animal Assisted Therapy are not. The latter (AAT) is seen as a treatment or solution for a preexisting problem; the former (relationships with animals) is regarded as long-term, relationally based and incorporating development over a period of time. Between the two exists a space where animals may be incorporated during key periods in childhood to help support the development of prosocial behaviors and prevent the onset of mental illness or behavior problems in children. This research attempts to investigate how Animal Assisted Therapy can be used as a tool of prevention for preschool children who are most at-risk (due to a constellation of factors, to be explored). With enhanced understanding of the treatment responses, future interventions can be tailored specifically for the population served; this will reduce variability in service delivery, improve the operational definition of Animal Assisted Therapy and improve the measurements available to rate the intervention.

The multitude of benefits offered by animals to humans and captured in research can be conceptualized into three distinct yet overlapping areas: pet ownership, Animal Assisted Therapy and Humane Education. Much less scholarly attention has been paid to investigating how healthy interactions with animals or pets during early childhood may act as prevention against the development of later antisocial behaviors during adolescence and beyond. However, a great deal of research has demonstrated that connections exist between animal abuse and interpersonal violence (Vaughn et al., 2009). This research will build from the knowledge that supports the significance of the Human- 
Animal Bond, especially in the lives of children, and the research that shows the therapeutic effectiveness of Animal Assisted Therapy to build a rationale for the development of a prevention model for at-risk children.

\section{Pet Ownership and Social Support}

Social support has a substantial impact on human mental health and physical health (Kim \& Young, 2006; Serpell, 2011). Numerous studies have found that pets offer social support to their owner (Matchock, 2015). They serve as "bridges to fellow human beings" and, in some cases, "can replace the need for human relationships" (Peacock \& McCulloch, 1981, p. 24). There is research showing that pets may act as social catalysts for other human interactions, including romantic relationships (Cloutier \& Peetz, 2016; McNicholas \& Collis, 2000; Messent, 1983; Peacock \& McCulloch, 1981). The physiological and salutary benefits reaped by pet owners include lowered blood pressure, reduced heart rate, improved health, increased oxytocin and faster healing times after injury (Matchock, 2015; Miller et al., 2009; Nagasawa, Kikusui, Onaka, \& Ohta, 2009; Friedmann, Thomas, \& Eddy, 2000). Children who may have experienced neglect or trauma in their human relationships may relate more easily or quickly to their pets; the reason for this is the animal's nonthreatening and unconditional attention. This ability of pet to "fill in" for failed human relationships is thought to promote a child's psychological well-being (Serpell, 2011).

The field of mental health has "undervalued" the deep and unique bonds that people have with their pets (Kruger \& Serpell, 2006; Walsh, 2009, p. 467). Humans who identify their closest relationships as those they have with their companion animals are 
viewed as "strange or deficient" and it is widely presumed that the healthiest human relationships are those had among each other, never with animals (Walsh, 2009, p. 467). Researchers interested in the Human-Animal Bond have found, in their examination of the characteristics of pet lovers, that preferring a pet to a person is not uncommon. Most people who report strong connections with their companion animals also have strong attachments/bonds to their family and best friends, and these "pet lovers" show no greater levels of anxiety and avoidance than the regular population (Walsh, 2009, p. 468). In fact, "people with companion animals are frequently regarded as more socially accessible" (Anderson, 2008, p.36). Research also indicates that "persons who are not married and do not have children show a stronger attachment to companion animals" (Turner, 2005, p. 13). Multidisciplinary research has continued to demonstrate the significance of pets in providing social relationships and supporting healthy psychological development in children.

The following section focuses on the use of animals in the fields of mental health and childhood development; studies on this particular population consistently lack empirical support due to: limited research in this area, small samples, no control groups, design flaws, lack of randomization and procedural limitations (for example, a lack of clear understanding of the specific therapeutic techniques used during interventions and the lack of a treatment manual). The physical and medical benefits animals provide to humans will not be reviewed in depth in this paper. 


\section{History and Literature Review of Animal Assisted Therapy}

In 1641, the first animal welfare law was passed in North America to protect domestic animals from cruel or inhumane treatment. The mid to late 17th century marked a period of migration of Europeans from rural settings into more urban environments, along with industrialization and agricultural growth. Such lifestyle changes influenced the ways in which animals were treated and regarded during this time period. Pets grew in popularity and prevalence, probably largely because of the emerging middle class and the limited accessibility to wilderness.

The notion that animals offered people, especially children, the opportunity to form nurturing relationships and had a socializing function was first documented by British philosopher John Locke. Locke suggested, in 1699, that giving children the chance to "look after dogs, squirrels, birds or any such things" would develop feelings of concern, empathy and "tenderness," as well as encourage responsibility for others (Fine, 2000, p. 154). Concern and feelings of compassion toward domestic animals continued to evolve; at the same time, there was a growing opinion that animals could be utilized to support the development of "kindness and gentility . . in children" (Fine, 2006, p. 12).

The primary method for treating the disabled or emotionally disturbed in the 18th and 19th centuries involved long-term institutionalization; this is where the first documented use of animals for therapeutic purposes occurred. The York Retreat in England is believed to have first recorded the use of animals in the asylum setting. The York Retreat was distinctly progressive in that it encouraged patients to care for farm animals as a means to engage with their natural surroundings, which, in turn, had positive 
effects on improving patients' self-control (Cusack, 1988). Mental institutions throughout England included pets as common features (Fine, 2006). The positive effects of animals in institutions appears to have also extended to hospitals focused on the treatment of physical ailments during this period (late 1800s); Florence Nightingale wrote that "a small pet is often an excellent companion for the sick [and for] long chronic cases especially" (Nightingale, 1860, p.103).

The slow growth toward animal-assisted care in institutions was stymied by major scientific advancement in medicine and medical treatments. Hospitals began to require sterile environments with strict codes for treatment, rendering animal-related therapy nearly absent from an institutional context for approximately the next 50 years. The literature reflects this absence, as there is little to no documentation of progressive treatments incorporating animals between the late 1800 s and early 1900 s.

The first use of AAT in the United States was recorded in 1919 when Franklin K. Lane, Secretary of the Interior, suggested using dogs in therapy with psychiatric patients at Saint Elizabeth's Hospital in Washington, D.C. (Bustad, 1980). In 1942, at the Pawling Army Air Force Convalescent Hospital in New York, in an effort to rehabilitate veterans suffering from physical and emotional war trauma, patients were encouraged to nurture and care for various farm animals living on-site. Similar to the York Retreat, the therapeutic animal-focused activities were based on anecdotal and sentimental ideas about the human-animal relationship and data were not collected to quantify change or effectiveness (a trend in the field that continues to this day). 
The "father of Animal Assisted Therapy," Boris Levinson, was the first to track and report findings specific to the therapeutic benefits of contact between animals and human clients (children and adults). In 1953, Levinson accidentally discovered that the presence of his dog in his office triggered a previously severely withdrawn child to engage and communicate for the first time. He serendipitously found that his client became more relaxed and secure when Levinson's dog, Jingles, was present. Levinson used this accidental finding as a launching pad and soon began to incorporate pet therapy in treatment centers for emotionally disturbed youth. He also introduced animals into mental hospitals, training schools for handicapped children and adults, and schools for the blind and deaf (Levinson, 1997). Levinson observed that animals could be "transitional objects" for children engaged in therapy and suggested that they could help to build rapport and trust (McCulloch, 1981. p. 20). When Levinson presented his findings at the American Psychological Association Conference in 1961, they were met with skepticism by his colleagues due to lack of quantitative data. Undeterred and inspired by his findings, he continued to advocate for the utilization of animals in treatment settings and identified the need for research in this area. He also began to theorize why animals did and could have such a positive therapeutic effect. His book, Pets and Human Development, marks the beginning of attention to what would later be termed the "human-animal bond." In it, he theorized that "one of the chief reasons for man's present difficulties is his inability to come to terms with his inner self and to harmonize his culture with his membership in the world of nature" (Levinson, 1972, p. 6). 
Captivated by Levinson's work and his call for more "rigorous research," Samuel and Elizabeth Corson, psychiatrists at Ohio State University, began to "evaluate the technique of [using] pet dogs in psychotherapy in a hospital setting" (Bustad, 1990, p. 39). Findings from their research, the first scientific evaluation of AAT, indicated that a therapy pet serves as a "catalytic vehicle" in social interactions; further, they found that the animals caused a "widening circle of warmth and approval" to improve social interactions (McCulloch, 1981, p. 20). The Corsons proposed that Animal Assisted Therapy should be used as an adjunct to traditional therapy and that it should not replace conventional treatments used at that time. They went on to continue their research at a nursing home where they found that previously unresponsive patients benefited from the introduction of therapy dogs as evidenced by decreased loneliness, depression, boredom, lack of sensory stimulation and withdrawal (Beck \& Katcher, 1996). The Corsons' work helped to legitimize the budding field of Animal Assisted Therapy; their findings prompted multiple other health-related studies and also stimulated more theorizing about the "salutary effect of pets" (Fine, 2006, p. 15; Friedmann et al., 1980; Ryan \& Ziebland, 2015). Repeated studies have confirmed that companion animals are capable of providing people with a form of stress-reducing or stress-buffering social support (McNicholas \& Collis, 1995; Ryan \& Ziebland, 2015; Serpell, 1996; Siegel, 1990). Still the research conducted and the findings generated lacked a clear theoretical explanation; there was no clear theory guiding research and even with positive research outcomes, no single theory was capable of explaining such effects. 
The Delta Foundation was founded in Portland, Oregon, in 1977 by brothers Michael McCulloch, MD, and William McCulloch, DVM, who both witnessed firsthand the benefits that pets had on their human patients but they knew that anecdotal and qualitative evidence alone were not enough to convince the medical community to incorporate therapy animals into practice. In 1981 the name of the organization was changed to Delta Society to reflect a growing group of researchers and doctors interested in the bond between humans and animals. The American Veterinary Medical Association's Human-Animal Bond Task Force was initiated to collectivize the various professions involved in promoting and researching the human-animal bond. In 1987, the Delta Society established Anthrozoos, the only scientific journal dedicated to studying human-animal relationships and interactions. Delta Society published the first and currently most thorough set of guidelines for Animal Assisted Therapy in 1992 entitled "Standards or Practice in Animal-Assisted Activities and Animal-Assisted Therapy."

The early 1980s marked a time of increased attention to Animal Assisted Therapy. The first epidemiological report on pet ownership was published in 1983 and focused on the health and medical benefits pets afforded coronary patients. Investigators were surprised to learn that one variable responsible for increased survival rates in these patients was pet ownership: $94 \%$ of patients who were pet owners survived their first year after a myocardial infarction; only $72 \%$ of non-pet owners survived their first year (Friedmann et al., 1983). Years later, a similar study was conducted on one-year survival rates for patients in a Cardiac Arrhythmia Suppression Trial; controlling for other factors, 
dog ownership (above any other pet) was a significant finding in contributing to survival rates (Friedmann \& Thomas, 1995).

These studies fueled further investigation of the significant roles that pets have in the lives of their owners. Social support is defined as "information leading the subject to believe that he is cared for and loved, esteemed, and a member of a network of mutual obligations" (Cobb, 1976, p. 300). The importance of social support and its benefits to human health (physical, mental, and emotional) are well documented (Knight \& Edwards, 2008; Mills \& Dombeck, 2005; Wenz-Gross \& Siperstein, 1997; Wilkes, 2009). Medical literature confirms a strong positive link between social support and improved human health and survival (Eriksen, 1994; Esterling et al., 1994; House et al., 1988; Knight \& Edwards, 2008; Ostberg \& Lennartsson, 2007; Sherbourne et al., 1992; Vilhjalmsson, 1993). Unfortunately, social relationships have been defined as those existing between persons with close affiliations, such as partners, friends, and family members. The possibility that animal companions may offer some of the most unconditional and unadulterated forms of social support that yield the same strong positive feelings as healthy person-to-person relationships (feeling valued, cared for, loved and respected) is still largely overlooked by science. Kidd and Kidd (1985) found that $95 \%$ of children in their study reported that their pets loved them and $94 \%$ said that they loved their pets. Fine states that the "current inability or unwillingness of the medical establishment to address this topic seriously is a legacy of the same anthropocentrism that has dominated ... Western thinking since the Middle Ages" (2006, p. 17). With the medical establishment's lead role in creating scientifically supported 
facts and ideas, and in a current ideological climate that champions "hard science" over other ways of knowing, a narrow view of health and healing has continued. The biopsychosocial model is not incorporated into most contemporary medical research and treatment. For these reasons, both research and theory specific to the relationship between humans and animals continue to be (a) sparse and (b) presented in journals and publications outside of the mainstream.

In 1980, Dr. Aaron Katcher, a psychiatrist and Associate Director of the Center for Interaction of Animals and Society at the School of Veterinary Medicine, University of Pennsylvania, received a grant from the National Institutes of Health specifically to help bridge the gap between the human-health-focused and veterinary fields. The goal of his study was to explore the various health benefits that contact with companion animals confers on various populations. Katcher and his colleagues are largely responsible for sparking scholarly and scientific interest in the various ways in which, from a medical and professional standpoint, animals can benefit people. Physiological measurements provide concrete data on the benefits that interactions with animals have on people and support the notion that there exists an organic connection between people and (some) animals. Reduced heart rates and lowered blood pressure are common findings in repeated studies focused on the soothing effects that pets have on children and adults in hospital or treatment settings (Friedmann et al., 1983). Diverse populations ranging from children to the elderly have been the subject of multiple studies to assess the physiological and self-reported emotional support benefits experienced in the presence of companion animals. Pets have been found to have mood enhancing properties (Kaminski 
et al., 2002; Wells, 2009). Animals in nursing home settings have been found to increase verbalization in patients with dementia (Kogan, 2000). The presence of pets helps to improve palliative care in hospice settings and provide much needed companionship for dying patients (Ptak \& Howie, 2005). Animal Assisted Therapy has been found to increase pro-social behavior in psychiatric inpatients (Marr et al., 2000).

Growth in the study on the therapeutic benefits offered to humans by pets or therapy animals has steadily increased since the early 1980s. The field of study that examines human-animal interaction is referred to as Anthrozoology (de Mello, 2012). Within Anthrozoology lies scientific research on Animal Assisted Therapies, however this sub-group of study remains quite limited; only 10 journals have published more than five papers since 1993 on the subject of human-animal interactions, relationships or bonds (Hosey \& Melfi, 2014). The following section includes a literature review of findings for AAT, specific to children and youth.

Children with emotional and behavioral disorders have shown fewer signs of depression and anxiety when participating in Animal Assisted Activities and Therapy (Greenwald, 2001; Hughes, 2000; May et al., 2016). Further, children with histories of sexual abuse are more likely to report and discuss their abuse in the presence of a therapy animal (Reichert, 1998; Signal, 2017; Wilkes, 2009). The presence of animals in the lives of children has been shown to increase empathy toward animals and people; animals in therapeutic settings can support and enrich rapport-building and trusting relationships; animals can also decrease blood pressure, reduce anxiety and feelings of depression (Ascione \& Weber, 1996; Katcher \& Beck, 1983; May et al., 2016). Animal Assisted 
Therapy (AAT) has been shown to help clients self-regulate and socialize, and to improve focus and attention, reduce aggressive behaviors, and increase self-esteem (Friesen, 2010; Parish-Plass, 2008; Poresky, 1996; Taylor \& Kuo, 2009). Children in residential care experienced reduction in depressive symptoms and an increase in feelings of self-worth after participation in Animal Assisted Psychotherapy (Muela et al., 2017).

Repeatedly, studies have shown the presence of animals to contribute to a decrease in aggressive behaviors in children and an increase in anger management skills (Hanselman, 2001; Lange et al., 2006; May et al., 2016). Animals in outpatient settings have helped to expedite rapport building, increase client comfort, and decrease identified problem behaviors in clients. Studies on relationships between animals and people have conclusively demonstrated social, behavioral and interpersonal benefits in multiple fields. Conversely, individuals who commit intentional acts of cruelty toward animals demonstrate significantly more anti-social behaviors and higher likelihood of future violence toward other humans (Dadds et al., 2006; Merz-Perez \& Heide, 2004).

Animal-based services and therapies vary with the level of direction and structure in the interaction between client/human and pet. In general, there are two widely accepted terms to denote the difference between an animal visitation type of program and a therapeutic service involving an animal. Animal Assisted Activities (AAA) are those where a person is visited by an animal and has a casual encounter (petting, walking, or talking); AAA does not follow individual treatment plans and the interaction between person and pet varies. Animal Assisted Therapy (AAT) is far more structured. It involves treatment goals, and a regular schedule for visitation, and it is specifically designed to 
promote social, emotional, physical or cognitive functioning in individuals (Tucker, 2005). AAT is further described as "a goal oriented, planned and structured therapeutic intervention directed and/or delivered by heath, education and human service professionals" (Signal et al., 2017, p. 83). One of the challenges to completing a thorough review of literature pertaining to AAT is the variability in the way it is defined, implemented and studied. Several meta-analyses (Nimer \& Lundahl, 2007; Souter \& Miller, 2007) and systematic reviews (Kamioka et al., 2014; Maujean, Pepping, \& Kendall, 2015; Rossetti \& King, 2010) have established that AAT is a valuable therapeutic resource in the field of social work, clinical psychology and psychiatry. Linking empirically supported interventions with AAT continues to be a challenge: the most recent review of literature generated only six randomized-controlled studies on AAT for children in the last 20 years using a dog as the therapy animal (May et al., 2016).

Additional support for the notion that the relationship between people and animals is significant and has the potential to influence personal development comes from the field of Humane Education. Humane Education attempts to not only prevent cruelty toward animals but also promote the development of empathy and pro-social skills in children. The following section discusses the current trend in Humane Education Programs and expounds upon its current application to further support the argument that animals are not only therapeutic but also promote healthy human development. 


\section{Humane Education}

Two common traits in violent adult offenders are "lack of empathy and history of animal abuse during childhood" (Sprinkle, 2008, p. 48). Therefore, helping young children to develop a healthy respect for others, including non-humans, is "hypothesized to be the first step in inhibiting the development of . . . aggressive tendencies" (Sprinkle, 2008, p. 48). It is this hypothesis that fuels humane education programs for youth. Humane education is a type of "education that uses animal-related stories, lessons and activities to foster respect, kindness, and responsibility in children's relationships with both animals and people" (Faver, 2010, p. 365). Humane Education Programs (HEP) facilitate the "development of empathy and pro-social behavior," which are inversely related to aggression (Faver, 2010, p. 365; Miller \& Eisenberg, 1988). Deficits in empathy are considered to be at the root of childhood cruelty to animals (CTA); healthy development of empathy for animals is correlated with empathy toward people (Faver, 2010; Hargreaves-Cormany, 2017; Hastings et al., 2000). Humane education programs attempt to reach children in school and community settings in an effort to foster awareness and understanding of animals as well an increase the development of empathy, thus reducing the likelihood of aggression.

HEP is typically offered by animal welfare and non-profit animal-focused organizations to children in elementary and middle school. Content of the humane education programs vary widely in scope and methods, however all are focused on improving children's attitudes and behaviors toward living beings and instilling compassion for others (Ascione, 1993; Hargreaves-Cormany, 2017; Selby, 1995). HEP 
have repeatedly evidenced an increase in levels of empathy and effective violence prevention for participants (see Sprinkle, 2008). More research is needed to better understand how the unique needs of participants vary in accordance with social and economic features, family function, and special needs. Additionally, in a thorough review of humane education programs, recommendations for human service agencies and professionals to initiate these programs were stressed. Rather than relying on the animal welfare professionals to develop and conduct research, psychologists and social workers are needed to further the intervention effectively (Faver, 2010).

Younger children are the most likely to be positively impacted by empathy promotion and violence prevention programs (Bemak \& Keys, 2000; HargreavesCormany, 2017). Children from lower socioeconomic status have fewer protective factors in their natural environment and also experience a greater number of environmental stressors than their more affluent peers (Garmezy, 1993; Rutter, 1987). A study published in 2010 found that the earlier the age at the time of animal abuse onset (first act of cruelty) the more likely the individual is to commit later recurrent violent offenses. (Henderson, 2010; Onion, 2014). Role modeling and desensitization are two key mechanisms that help to explain why and how children become perpetual abusers and may graduate their acts of cruelty, especially when engaging in those behaviors at a young age. Children naturally learn to emulate the behaviors of others with whom they are in frequent contact and repeated exposure to acts of animal abuse (either as a witness or perpetrator) causes a desensitizing effect over time (Ascione, 1993; Duncan \& Miller, 2002). Further, the presence or absence of empathy will then influence whether the 
behavior will increase in severity (Bandura, 1973, 1986; Eisenberg, 1986; Kohlberg, 1969).

\section{Animal Cruelty}

Cruelty or abuse of animals is widely defined as "socially unacceptable behavior that intentionally causes unnecessary pain, suffering or distress to and/or the death of an animal" (Ascione, 1993, p. 228). Children who engage in intentional acts of cruelty toward animals often engage in other delinquent behaviors (Burchfield, 2016; MerzPerez, Heide, \& Silverman, 2001). Further, these delinquent behaviors often become more severe into adulthood. Childhood cruelty to animals has been associated with other maladaptive patterns of behavior. MacDonald (1961) was one of the first to identify the relationship between intentional violence toward animals and interpersonal aggression. Through his research, MacDonald discovered that animal cruelty often co-occurs with fire setting and enuresis; this discovery was coined the "McDonald triad" and has been used as a model to predict future antisocial behaviors, namely violence toward humans (MacDonald, 1963).

Since MacDonald's incipient research, more attention has been paid to studying the link between cruelty to animals and interpersonal violence. There continues to be a debate as to whether the "graduation hypothesis," which states that children who are cruel to animals will likely "graduate" into more serious acts of violence against humans, is clinically or statistically salient; research exists that both supports and undermines the predictive validity of this hypothesis (Arluke, Levin, Luke, \& Ascione, 1999; Beirne, 2004; Wright \& Hensley, 2003; Zilney \& Zilney, 2005). Numerous studies have 
validated the positive correlation between childhood cruelty to animals and adult aggression (Merz-Perez, Heide, \& Silverman, 2001; Miller, 2001; Miller \& Knutson, 1997; Wright \& Hensley, 2003). Recent media and scholarly attention has been paid to better understanding the causal link between childhood violence toward animals and later violence toward humans; to date, only a handful of studies have empirically tested the direct causal link between childhood animal cruelty and later interpersonal aggression (Henderson, 2010; Hensley et al., 2009; Hensley \& Tallichet, 2009; Tallichet \& Hensley, 2004). Although the direct causal relationship between animal cruelty and later interpersonal violence is still unclear, the correlation between animal cruelty and subsequent interpersonal aggression has been substantiated; often this progression also includes additional influences such as domestic violence (Merz-Perez \& Heide, 2004). Animal cruelty was added as a diagnostic criterion for Conduct Disorder to the Diagnostic and Statistical Manual of Mental Health Disorder in 1987; Conduct Disorder in children often continues into adulthood and then meets criteria for Antisocial Personality Disorder (American Psychiatric Association, 2013). Approximately a half century of research has established animal cruelty as an important indicator of mental illness and a possible factor contributing to adult violence against humans (Tallichet, Hensley, \& Singer, 1995). A select few studies examine the specific acts of cruelty (type of abuse) and corroborating factors (such as race and/or comorbid diagnoses) and later acts of interpersonal violence (Burchfield, 2016; Tallichet et al., 1995). Tallichet and Hensley (2004) found that repeated acts of cruelty toward animals and the more number of siblings a child had predicted later violence toward humans. A study in 2005 found 
that demographic and family differences plus type of animal abused (family pet vs. wild animal or stray) affected the frequency of childhood animal cruelty in the sample studied (Tallichet \& Hensley, 2004). In 2008, the same researchers found that abusing an animal for "fun" was the only predictor for later interpersonal violence (Hensley \& Tallichet, 2008). Which specific components of animal cruelty predict later antisocial behaviors are still largely unknown; this information is crucial in helping to better identify potential violent offenders and offer prevention/intervention services before the development of maladaptive behavior patterns.

The following section highlights the philosophical challenges inherent in studying interspecies relationships; these challenges have impeded research in each of the fields of study mentioned above (AAT, pet ownership, HEP and animal cruelty). Even after the National Institutes of Health highlighted the need to study the effects of pets on the development of children in 1987, cultural and social barriers continue to impede progress (McCardle et al., 2011).

\section{Cultural and Social Barriers in Research on the Human-Animal Bond}

A rationale for the dearth of theory and research pertaining to human-animal relationships and their effects may be due to the overwhelming cultural value that pervades Western thinking; the belief that human beings are superior to and apart from other animal species has profound consequences on a multitude of levels. The effects of the lack of research or "gap" include only partial explanations and understanding of human development, missed opportunities for advanced theoretical insight, a growing divide between humans and their animal counterparts, increased separation between 
humans and their natural environment, and ignorance of the true nature of humanity. Violence towards animals is correlated with later violence toward people; also, where there is violence toward animals there is often violence toward children (Wolf, 2000). Animal cruelty is a key predictor of future violent behavior in children (Burchfield, 2016; Knight \& Herzog, 2009; Wax \& Haddox, 1974).

Speciesism has been compared to other forms of discrimination that result from differential treatment due to out-group membership (Wolf, 2000). Not only does speciesism help to explain social work's narrow focus on human-to-human interaction and influence, but it also explains how and why certain types of animals are pets while others are commodified as sources of food or product. It is important to examine the effects of species discrimination, not only because of its implications for the treatment of animals, but also because the humans who passively participate in violence toward animals and show a general "disregard and indifference for their lives" may fuel a "similar lack of caring and compassion for ... the lives of other humans" (Anderson, 2008, p. ix). Since animals are an essential component of our environment and a key element in maintaining ecological balance, a person-in-environment orientation calls for an examination of our relationship with and treatment of animals.

Anthropocentrism, the overwhelming tendency of scholarly research to focus on the significance of human only attachments and relationships dominates all fields concerned with psychological development. A more "biocentric" view of child development includes non-humans and animals as important and influential attachment figures capable of influencing one's relational model (Kahn, 1999). As Melson has 
argued, the humanocentric paradigm has "impeded both theory and research into the developmental significance of animals" and does not accurately account for the complexity of real-life development (2003, p. 32).

\section{Challenges in Studying the Emotional Connections to Pets}

Besides the stigma associated with loving animals as family members, and aside from the dominant anthropocentric paradigm, the study of people's emotional connections to domestic animals and the therapeutic effect they may have on certain populations, is a difficult one to study for additional reasons. Experimental research on the topic of bonding with animals is difficult, nearly impossible, to contrive. To randomly assign an experimental group with a companion animal and restrict access to companions from a control group is a difficult proposition; and even if this assignment method were possible, the individual bonds between people and their pets remain highly complex and varied (Poresky, 1996).

The Human-Animal Bond is a difficult concept to concretize because vast cultural differences exist concerning the value and appropriate treatment of different species. In the U.S. dogs are widely considered pets and not food, yet pigs, who are more intelligent than dogs and display equally social behaviors, are consumed as food (Foer, 2009). A major reason for the increased attention to pets in most Western societies is that the division between farm animals and pets continues to widen as urbanization and technology remove humans from natural settings and regular interactions with multiple species. There exists a polarity between pets and animals valued simply for their utility. In his text Hunters, Herders, and Hamburgers, Bulliet chronicles the changing 
relationship between humans and multiple species; he explains that "people live far away, both physically and psychologically, from the animals that produce the food, fiber and hides they depend on ... yet they maintain very close relationships with companion animals - pets — often relating to them as if they were human" $(2005$, p. 3). This growing segregation promotes an ever-increasing focus on pets while eroding human connections to other species.

The degree of bonding and the social support that companion animals afford to their "guardians" has been measured through research and analysis of the relationship and the multiple benefits reaped by humans. The Human-Animal Bond and its key features can be identified by examining a diverse population of people in the U.S. who keep animals in their homes and distilling the factors that make this relationship significant and unique. However, if the Human-Animal Bond is defined and explained using data solely gathered through pet owners, then people living without pets in their homes are not represented, though this population may very well have the capacity to share the same qualities of bonding, support or socialization. It is non-pet owners that may actually be missing a key feature intrinsic to wellness and/or they may be receiving social support, offered to pet owners by their animals, through other means. It's important to examine what people without animals in their homes may be missing and in what ways they seek to fill this potential void. The Humanistic Principle (central to Biophilia) posits that humans need connections with other beings, both within and beyond their own species. If only $66 \%$ of the population is fulfilling the Humanistic need for connection with other 
species, namely pets, then the remainder might still benefit from the Human-Animal Bond in other ways that don't necessitate pet ownership.

The following section narrows the topic of study to focus specifically on a population of children considered to be "at risk" in their community. Studying the impact of $\mathrm{HAB}$ or AAT with this group of children is a novel direction for the field of social work and one worthy of greater attention.

\section{Who is "At-risk"?}

At-risk children have been broadly described as those who are associated with poor school performance, increased criminal behavior, poverty, violence, substance abuse, family discord, physical and/or emotional abuse and mental illness; however, there is no consistent definition available to operationalize this heterogeneous population. More often the term is used vaguely to refer to those with an increased likelihood of poor life outcomes in general and to experience long-term deficits marked by school failure, economic dependency, death, addiction or incarceration (Moore et al., 2006). Often, interventions for "at-risk" youth are not clear in explaining for what the children are atrisk (McCardle, 2011, p. 40).

The population of children determined to be at-risk in this study were those who may be more likely to develop psycho-social-emotional problems during later school years due to current and prolonged exposure to poverty, familial involvement with child protective services during their lifetime, and failure to meet typical expectations in social, emotional or behavioral domains. Factors such as poverty, mental illness in one's family of origin, parental absence and the presence of four or more children in the home have 
been correlated with increased risk for children to engage in criminal behavior, substance abuse or struggle with mental illness in adulthood (Armstrong \& Hill, 2001; Faver \& Strand, 2008; Henry, 2006; Magadi, 2010; Wright \& Hensley, 2003). Frequent moves, community violence, domestic abuse, poor parental attachment and drug addiction have also been found to negatively impact child outcomes to varying degrees and present future risk of poverty in adulthood (Jonson-Reid et al., 2009; Magadi, 2010). The identification and understanding of "alterable influences" on child development is at the nexus of early childhood education and prevention programs (Reynolds \& Ou, 2010). Early childhood intervention can have enduring protective effects on health, social behavior, socioeconomic status and educational achievement (Reynolds \& Ou, 2010).

This research will deeply examine the demographic details and case studies to gain a more nuanced and rich understanding of the sample group as a whole as well as the unique risk factors presented in the data for each child.

\section{Support for Further Study}

Children living in poverty tend to have minimal opportunity to own pets and positively interact with animals as a normal or natural feature of their environment (Louv, 2005). Increased urbanization and development continues to widen the separation between day-to-day life and nature. Environments where animals are scarce (e.g., urban centers, apartment buildings) and/or are used for intimidation purposes (e.g., guard dogs or police dogs) may perpetuate fear of animals and further deteriorate the relationship between children and animals or pets. While societal changes have caused life to become more "stressful and frenetic," pets have been called on to provide a sense of "relaxation 
and replenishment" (Walsh, 2009, p. 470). Companion animals help to meet the need for unconditional positive regard, social support, permanency and bonding (Walsh, 2009). Children who are reared with pets have "enhanced empathy, self-esteem, cognitive development, and greater participation in social...activities" (Walsh, 2009, p. 470). Children without pets may be more likely to be at-risk for later developmental, emotional or social delays if they are not provided with the opportunity to interact with animals and foster positive relationships with other species. The connection, or lack thereof, between a child and a pet has significant implications for social and emotional development. Additionally, early intervention of vulnerable children has demonstrated positive longterm effects for social and emotional development (Reynolds \& Ou, 2010). Even so, there are no Humane Education Programs available for children who are not yet school aged, nor are programs specially targeted to reach populations that may be more at-risk for engaging in animal cruelty or other pathological behaviors. Primary prevention may be offered only to youth who have already engaged in cruelty to animals or experienced (witnessed) it firsthand. The prevention then functions as an intervention, since cruelty behaviors or lack of empathy have already been evidenced.

Research on pet ownership and AAT with children evidences benefits, which include improved physical health, emotional well-being, stress management, social functioning and support, higher self-confidence and self-esteem, and development of secure attachment behaviors; similarly, research on humane education shares a number of positive benefits, including maintenance of pro-social behaviors, perception of increased social support and prevention of cruelty toward animals, which in turn decrease incidence 
of later interpersonal violence. Neither AAT nor HEP have been used with preschool aged children as primary prevention and therapeutic support to thwart the onset of emotional or behavioral disturbance.

A classification system that operationally defines Animal Assisted Therapy has yet to be developed. Thus the following terms have been used to denote animal-assisted activities and interventions: pet therapy, pet psychotherapy, pet-facilitated therapy, cotherapy with an animal, pet-human interaction therapy, Animal Assisted Activities, Animal Assisted Therapy, and Animal Assisted Intervention. Terms have been used interchangeably but often refer to very different treatment (LaJoie, 2003). Animal Assisted Therapy is best described as an intervention where the client and treatment provider work together with an animal to reach specific treatment goals (Barker \& Dawson, 1998). Because AAT and AAT-like interventions have been applied to a wide variety of clinical problems in disparate settings with diverse groups of clients, a more sophisticated understanding of intervention terms and systematic assessment of each intervention are necessary.

In her dissertation, LaJoie created a ranking system to structure the qualitative uses of AAT in an attempt to "widen the conceptual lens" (2003, p. 3). The ranking system was based on the degree of direct animal involvement wherein the lowest ranking denoted unstructured time spent with an animal; pet ownership was included at this level. Pet presence (having an animal in a therapist's office during a typical session yet not incorporating the animal directly into treatment), Pet-Facilitated Therapy (the animal helps to build rapport and foster communication between client and therapist), and 
Animal Assisted Therapy (goal directed intervention where the animal is an integral part of the process) were the subsequent rankings (LaJoie, 2003). None of the classifications address point of intervention and therefore do not inform therapeutic interactions with animals in early childhood to support healthy development and prevent later manifestation of mental or emotional illness, even though animals serve as a "buffer against adversity" (Beck et al., 1986; LaJoie, 2003, p. 18).

This study focuses on examining the provision of AAT for at-risk preschool-aged children. Children were labeled "at risk" for developing psycho/social/emotional problems later in childhood based upon program criteria (discussed in Sample section). This study aims to increase understanding about this population of children and their response to Animal Assisted Therapy. Insight into the variety of responses and reactions from children in the pilot group (discussed in following section) will help to inform future research in this area as well as support the standardization of AAT through the development of treatment manuals and guidelines for therapeutic procedures. The longterm goal of this research is to demonstrate the efficacy of need-specific AAT to at-risk young children to supplement their healthy development and prevent the onset of later disability or impairment. 


\section{Chapter 3}

\section{Methodology}

\section{Significance of the Study}

The goal of the research is two-fold: (1) Gain an in-depth understanding of the identified treatment group and (2) identify themes that inform experiences, potential predictors of positive responses to treatment and candidate outcomes for use in future research and to inform practice. The long-term potential benefits of this study include: improving the treatment options available to young children experiencing significant risk factors, increasing referrals for AAT programs for this particular population, and providing direction about measurable outcomes for use in program evaluation and in research in the field. Further, this research will generate future hypotheses about the use of AAT and help to direct studies in this field.

\section{Research Questions}

The primary objective of this study is to specify the characteristics of earlyidentified at-risk children receiving community-based prevention services and how they respond to individual Animal Assisted Therapy. The research will describe and assess

each child's social, emotional, behavioral and communication responses throughout the 16-week treatment period. Common experiences, potential predictors, and candidate outcomes for future assessment and evaluation will be identified across the population. These data will serve both future practice and research in the field of early childhood intervention and prevention of undesirable mental health outcomes. A better understanding of the interaction between children receiving the treatment and the 
therapeutic animal will also support the codifying of the treatment, specifically key components of treatment and means of evaluation. Further, recommendations for the incorporation of AAT as a prevention method with at-risk preschool-aged children may be made based on findings.

The research questions guiding this project are as follows:

1. What are the characteristics of these children and their environments?

2. How do preschool aged children identified as "at risk" in their community, per program standards (to be discussed), respond to a 16-week individualized Animal Assisted Therapy program individually and as a group?

3. What are the therapeutic interactions that occur during the course of AAT?

4. Are children's interactions with the therapeutic animal different based on the pre-intervention behavioral characteristics?

\section{Design}

This primarily qualitative secondary data analysis explores a pilot program that used Animal Assisted Therapy with children identified as at-risk enrolled in a community-based intervention program in a highly urbanized setting in the Pacific Northwest. In addition to qualitative analysis, a small descriptive, non-inferential quantitative component is included. Time series data are charted to track responses and changes in participants over the treatment period. The qualitative data and quantitative data together indicate various types of behavioral responses to the intervention over the course of the pilot. 
The pilot program took place in 2006. Each participant in the program received weekly sessions of AAT over 16 weeks. Weekly progress notes were completed by one of two therapists (of which, I was one) delivering AAT to the children as well as by the observer/animal handler. Extensive diagnostic and referral information was also collected on each child. Resulting data included these repeated measures at 16 data points in addition to pre and post treatment data (gathered immediately after the pilot concluded).

I was responsible for designing and delivering the pilot program, which included recruitment, data collection, interviews with program staff, file mining, coordinating sessions (ensuring that certified dog-handler teams were available each week, for example), maintaining records, and working closely with the other therapist to ensure consistency in therapy sessions. The initial intent of this pilot program was not to study the children and components of AAT; it was to provide a novel service to a specific population of children, per the agency's request. In building the program, I then discovered the incredible opportunity for further research.

\section{Intervention}

Individual AAT was provided for each child in a small office consisting of various play therapy toys, a couch, a desk, art supplies and a shelf of books. These children were not receiving individual therapy prior to this program. The therapist saw each client for 30 minutes at the same day and time each week (for 16 consecutive weeks). There were four teams of dog-and-handler: two of the dogs were Labradors, the other two were Golden Retrievers. Each child was paired with one "team" and saw only the same dog throughout the 16 weeks. 
As the child entered the office with the therapist, the therapy dog and its handler were waiting inside. The handler served as an observer and did not interact directly with the child unless, on rare occasion, the child solicited contact with the handler. Handlers were trained on their role in the therapeutic setting in advance of the program (see Data Collection section below). Therapeutic experiences varied based on the needs and responses of each child.

AAT considers the animal a catalyst for therapeutic growth or change. The intervention itself does not require a modification of the therapist's theoretical orientation or therapeutic approach; instead, the incorporation of the therapy dog is to assist the therapy and act as an adjunct to the process. The model for this pilot was to provide play therapy for children, with each session evolving uniquely over the treatment period for each participant.

\section{Therapeutic Techniques}

Various techniques were implemented in the treatment setting in an effort to test the client's responsiveness and direct the use of future techniques. Because there was no treatment manual for this pilot (or for any other program serving this particular population), various play-based and child-centered techniques that have been effective in other studies or settings were replicated here. The thematic analysis will attempt to more deeply analyze the respective techniques and draw connections between such efforts, demographic data and clinically significant behaviors.

Standard therapeutic techniques included: 
- Petting, therapeutic touching and guided touch: These terms were used in the course of treatment to describe the therapist's use of safe physical touch by the client toward the therapy dog. Using rhythm and counting to extend the contact between client and therapy dog, episodes of physically connecting with a therapy animal have been shown to decrease arousal and anxiety and promote trust-building (Chandler, 2017). In this study, a client's responsiveness to this technique was recorded both qualitatively and quantitatively. At times, clients who were fearful or insecure would be supported by "guided touch" or "guided petting" wherein the child would place his/her hand on top of the therapist's and engage in gentle touching. Guided petting would often lead to more independent petting in subsequent therapy sessions.

- Brushing, grooming or guided brushing: Brushing a dog's fur is one way to help children focus, calm their bodies, increase bonding and decrease anxiety (Elmacij \& Cevizci, 2015). Grooming also may help to improve selfregulation strategies and nurture caretaking (Dunlop \& Tsantefski, 2017). In the course of this study, children were offered opportunities to brush the therapy dog (with various brushes to select from). For children who showed apprehension, physical roughness or simply needed support, guided brushing was available to help children increase skill and comfort. In guided brushing, similar to guided touching or petting, the child would rest their hand on top of the therapist's while she engaged in brief periods of brushing. Often, while 
petting or brushing, other complementary therapeutic activities or skills were applied, such as cross-talking. Rhythm and counting were used to increase brushing episodes and lengthen the amount of time a child spent engaged in this activity.

- Feeding, treat giving: Hand-feeding treats or kibble to the dog was a technique often used to build trust and rapport. Children would be shown how to open their hands and have treats placed in the center of their palm; dogs were then given a command to gently take the treat from the child. This activity also includes a sensory component that many children immediately respond tofeeling the dog's mouth or tongue on their hand. Children demonstrated various responses to this simple technique, ranging from immediate recoil for one to sheer expression of joy and laughter from another. For children who enjoyed this activity, it was repeated in-session for extended periods and an entire meal could be delivered to the dog, one kibble at a time.

- Ball throwing: Ball throwing is a structured exercise that includes various steps; children pick up the ball, throw it in a single direction (repeatedly), the dog retrieves it and then gives it back to the child either by dropping the ball on the ground or allowing the children to take the ball from the dog's mouth. This activity is one that allows for variations based on the client's comfort level, skill and engagement. Ball throwing required that the client, therapist and dog exit the therapist's office and find a more open setting. For this pilot, ball throwing took place outside of the office in a hallway with very little (if 
any) foot traffic. This therapeutic activity requires gross motor control and motor planning.

- Walking: Dog walking has been shown to decrease stress, increase focus and provide various benefits to one's health (Taylor \& Kuo, 2009). For this study, children were given the opportunity to walk the therapy dog through the hallways in the building. During dog walks, a child held the dog's leash (either with assistance or without) and was supported in staying next to the dog. Pacing oneself is a major competent of this exercise; children also learn to limit pulling on the dog's leash (the consequences of pulling on the leash, such as hurting or scaring the dog are explained) and also to hold the leash tightly for the entirety of the walk. This activity also requires a significant amount of motor control, planning and attending behaviors.

- Cross-talking: This therapeutic technique was consistently used, to varying degrees, with each of the clients involved in this study. This approach is one where the therapist spoke to the dog, and occasionally to the dog's handler, in a way that allowed the client to overhear the conversation. Cross-talking allows for the therapist to communicate indirectly with the child and may help the child to feel more comfortable in the setting. Rather than talking directly to the child, cross-talking allows the therapist to model healthy communication and shift the focus away from the child. For children who were especially quiet or fearful during AAT, cross-talking was used to help defuse tension or de-center the child. For example, the therapist would sit with 
the child (either on her lap or close by) and comment, "We are here to see you [the dog] today. I wonder how you [the dog] are feeling . . . you might be happy to see us. Or maybe you're feeling a little confused. Sometimes when I feel confused, I need help understanding what's going to happen next. OK, doggy, we are just going to sit here for a while. I'll talk to you, maybe we'll play and maybe you'll even get some treats. I'm just going to sit here for a while with [client's name] and we can just spend some time getting more comfortable," or "Hey dog, this is my friend [client's name]. She and I are visiting you today and we'll keep coming to see you each week. It'll be our time together to try some new things and even have some fun. Right now, I'm just going to pet you and we can see how you feel about that."

Observational and non-directive learning have been studied in-depth, and are components of Social Learning Theory (Bandura, 1961). Especially effective with children, observational learning and modeling can help to produce new behaviors and encourage behavioral change (Bandura, 1961). The cross-talking technique, also referred to as lateral talking or therapeutic gossip (Watts, 2000), was modified based on child's age and level of comprehension. In many cases, cross-talking was the main therapeutic process employed during the initial stages of therapy; the reliance on this technique decreased as other skills and practices increased.

- Body part identification: Understanding the connections and common features that humans share with non-humans is an essential component in Humane 
Education. It helps to increase empathy and may also improve a child's ability to trust the therapy animal (Faver, 2010). In this pilot, children were guided in pointing to or touching certain parts of a dog's body; this activity continued with finding "matching" body parts between child and dog. For example, a simple activity would begin with "Can you see the dog's feet?" and if the child nodded yes, the therapist would follow with "Do you think you can touch one of those feet ... how about another one?" Depending on a child's response, this activity would continue to include other body parts. Folded in with this activity, the therapist would often share how the dog might be feeling about being touched: "I bet the dog likes being touched on the foot" or "It looks like doggy is happy that you are touching him so nicely." For children who responded positively, the skill would advance to include the child naming the feelings that they or the dog were having during this activity: "How do you think the dog feels when you are touching his ears?" or "How do you feel when you touch the dog's belly?" are common prompts a therapist would use during this therapeutic activity.

For children with little exposure to animals, this activity can be surprisingly educational. For other children with more comfort and knowledge, this activity can become more sophisticated to include not only body parts or feelings that are the same (between human and dog) but also aspects that are different. 
- Feelings identification: A major area of interest in this pilot study was in supporting clients in understanding how they were feeling and then being able to communicate those emotions. The process for learning how to identify feelings varied greatly due to a number of factors including the children's level of comprehension. Sometimes the therapist would take a more directive approach: "The dog feels happy when you play with him," or "His tail is wagging and he's excited to see you." Other times, the therapist might take a slightly less directive approach: "The dog's tail is wagging, I wonder how he is feeling?" or "Can you tell how the doggy feels right now?"

Children would be supported in learning about the dog's feelings and an attempt was often made to later identify one's own feelings, typically in connection with the dog. "How are you feeling right now?" was too direct or challenging a question for some of the children in this sample. Instead, photos and pictures were included that modeled different emotions, both in dogs and children. Simply looking at these expressions in picture form while the therapist explained them, connecting to causation, was an activity used in this pilot. Similar to other techniques, this approach paired well with other therapeutic techniques like cross-talking and petting.

- Drawing: Typical to therapeutic spaces for children, the office used for AAT included paper and drawing supplies. The intention use of these materials was not predetermined; however, leaving them out and available for children was a decision made prior to commencing AAT. As discussed in other sections, 
AAT is not a specific therapeutic approach but rather one that allows for therapists to utilize their own approaches and incorporate the therapy animal in personal and unique ways. For young children, many of whom are nonverbal or choose not to communicate, drawing can help to facilitate other forms of communication and self-expression (Birch \& Carmichael, 2009). Some children in the pilot gravitated toward drawing or coloring, therefore having this option available proved to be beneficial. Drawing pictures of dogs became a request of children in the sample group and some used their drawings to help illustrate stories or expression of feelings. Drawing is a form of play for children and therefore lends itself well to a play therapy setting (Birch \& Carmichael, 2009).

- Picture or photo taking: Children were asked if they would like a photo of their therapy dog and also asked if they would like to be in a photo with the dog. Most children were photographed with the dog, and these photos were displayed at the children's eye level in the therapist's office. As weeks progressed, more photos were steadily added. Some weeks, the photos were given to children to aid in their transition back to their classrooms (transitional object) and all children were given a photo during their last session with the $\operatorname{dog}$.

- Storytelling: A component of cross-talking, especially for non-verbal children, involved the therapist creating and sharing a story about the dog. Storytelling can act as a metaphor for clients to help overcome their own resistance or 
accept messages because they feel less threatening (Chandler, 2017). In her study on Animal Assisted Therapy with victims of sexual abuse, Signal writes, "the therapist and child may also incorporate the animal into stories that are not only less distressing for the child but also may be more developmentally appropriate for younger children" (Signal et al., 2016, p. 83). Children with greater vocabulary would sometimes ask for a story about the dog or attempt to make a story up of their own. Storytelling paired well with drawing, as the narrative was complemented with visual depictions of the story. Stories that involved feelings would help clients to connect cause and effect (for example: "When doggy was little, he needed a lot of help. He used to be a puppy and get scared when he couldn't find his grown up." and "Doggy loves to take walks outdoors in the sunshine. He gets really happy when it's time for his walks and wags his tail so fast!").

- Reading to the dog: A selection of children's books were included in the therapist's office. Many of the books featured animals, with dogs as the central figure. Reading directly to the therapy dogs was not a therapeutic intervention that was anticipated prior to the launching of the pilot program; however, during the course of the program, it was discovered by both therapists that children either pretending to or actually reading to the dog was common. When children initiated reading to a dog during one session, this was then offered to them as an option in subsequent sessions. The benefits of reading programs that incorporate dogs have shown that children increase 
confidence and improve reading performance (Hall et al., 2016; Linder et al., 2017); however, these were not the goals in this pilot and were not included in the measurement of outcomes. The practice of reading during AAT, for purposes of this pilot, was simply to enhance a child's comfort level and allow them to pursue activities that felt organic.

It's important to highlight that no two therapy sessions were alike. Children shifted greatly in their presentation from week to week; and between cases, interventions varied considerably. In general, therapists attempted to support and repeat therapeutic interactions where children appeared stable and successful. Given the age of most of the children, therapists were directive throughout the sessions while allowing for child-led activities whenever possible.

Therapeutic skills and interventions were commonly used in tandem with each other; often one skill was folded in with another, and some were more common combinations than others. This tendency to use certain approaches together with particular clients will be examined in depth in the Thematic Analysis. Further, some unanticipated activities (not described above) occurred organically during the course of treatment and those will be examined as well in the Thematic Analysis section.

\section{Sample}

This census included all children referred for AAT within a community-based program. The program's mission is to help reduce child abuse in communities affected by poverty by identifying high risk families and children and providing supportive services as early in a child's life as possible. Their mission is: Keep children safe and families 
strong. The program provides intensive out-of-home services for children in a school-like setting. Once accepted into the program, children attend the program five days a week for half-day periods, with groups of children attending either the morning or afternoon shift; the program is year-round and served close to one hundred families at the time of this study. The program also provides respite and emergency care when parents or caregivers need extra support. Most services are provided in the classroom and focus on social skills, communication, play and basic educational concepts. Certain children also receive early intervention services, such as occupational or speech therapy, during the day. Treatment plans are customized for each child based on individual needs and risks. Eligibility criteria for referral to AAT included established participation in the community-based intervention program and having been identified as "at risk," per the agency. Agency criteria for the at risk designation included all of the following: age three or under at the time of initial involvement with the program; family income at or below the poverty level; demonstrated delays or symptomatic behaviors in social, emotional, language or behavioral domains (one or more) as reported by family or legal guardian and supported through program assessment; and/or familial involvement during child's lifetime with the State's Child Protective Services.

The community-based program sought to provide more "experiential" and "holistic" interventions for certain children based on increased demonstrated risk factors and the program's perception of greater need. The program's case managers identified eligible children, made a recommendation for AAT, which was then vetted by the 
program director. Case managers were all educated and trained in early childhood development, education or psychology. The program manager held an MSW.

Children referred for AAT were more likely to demonstrate a combination of poor social skills, language delay, emotional lability, and/or inability to meet benchmarks for age-appropriate behavior, attention span and focus. Poor social skills were marked by difficulty engaging in play, lack of age-appropriate sharing, isolation, or aggression with peers or adults. All 13 referrals for the treatment group were accepted.

All referred children were then screened by me, who also served as the lead therapist, to assess for the following: whether the child was living with birth family or placed in substitute care, if the child had a pet in the home, had allergies to animal fur or dander, and had a history of cruelty to animals. None of these criteria were considered exclusive to involvement in the program. Each child's sex and age were also recorded as well as any known mental health diagnoses. All 13 children completed the full treatment (although to varying degrees, due to absences) and are therefore included in the analysis.

Nine females and five males were included in the sample. The average age of participants was 29 months (two years and five months old). The sample group had a diverse representation of races: five were Hispanic or Latino, five were White, two were Black/African American, and one was mixed race. Additional descriptive information about each of the participants, such as family composition, mental health diagnoses and trauma history, is explored in-depth in the case studies and thematic analysis. 


\section{Data Collection}

Progress notes, demographic information, diagnostics and referral information are included in this secondary data analysis. Case managers making a referral for a child completed a referral form including reason for referral. Case managers were also asked to rank each child in the areas of: social functioning, emotional stability, behavior, and language ability compared to other children in the program. See Appendix A for referral form. Additionally, therapists observed children in the classroom prior to the commencement of AAT and reviewed case files kept by the agency. Additional case information was made available by the agency hosting the pilot program through file mining.

The Animal-Assisted Therapy Evaluation Instrument (AATEI) was used for qualitative and quantitative evaluation of progress in specific domains and the agency's therapeutic progress notes provided additional qualitative information on the therapeutic interaction. The AATEI is not a standardized scale but is suggested by The Delta Society as a tracking instrument for use with clients receiving AAT (Delta Society, 2010). The AATEI (Appendix B) includes scaled ratings in the following domains: cognitive, social/emotional, physical, and verbal. Each domain contains concrete areas of observation with a 5 point "quality" rating. For example, the Social/Emotional section includes the following areas of observation (along with other areas): shows eye contact, show elevation in mood, expresses feelings, shows affect, uses touch to express interest.

Progress notes include scaled assessments for attention, engagement, emotional regulation, and age-appropriate behavior as well as categorical assessments related to 
appropriate touch and physical contact, social relatedness, and bonding and attachment observations. See Appendix C for the progress note form.

Both the AATEI and progress notes were completed immediately after each weekly session with the child. The AATEI was completed by both the therapist providing the intervention and by the animal's handler, who was not made aware of a child's demographic information or treatment goals during the study period. Progress notes were completed by the therapist only.

The animal's handler, serving as observer during the session, was trained in advance of the program on how to complete the AATEI. As the handlers were not trained in child development, each section of the evaluation tool was reviewed in depth, examples were given of what behaviors to note, and practice sessions were completed during which the observer completed the AATEI on a child not involved with the program to gain experience completing the measure. There were four animal handlers in the program. Three were matched with three children per week and one handler observed four children weekly.

Once completed, weekly progress notes were secured until the completion of the pilot program. Neither the therapist nor the observer had access to notes from previous weeks minimizing the potential for notes and rankings to be compared to previous data.

At the completion of the program, the therapist delivering AAT (of which I was one) wrote a brief interpretation summary of each child, the child's response to treatment, and areas of concern. In some cases, additional anecdotal data was shared by classroom teachers with either the therapist, case managers or lead investigator (me). 


\section{Ethical Issues}

All data were stored in a locked filing cabinet and computer files were passwordprotected and stored only on the principal investigator's computer. All progress reports and case notes have been de-identified for use in the secondary data analysis.

Protection for the clients and the assurance of confidentiality in this research includes the use of pseudonyms, the absence of identifying information in the case studies, randomly generated case numbers on progress notes and all subject-related information, and maintenance of files in a single, secured setting. The early intervention program sponsoring the AAT pilot study ensured that clinical treatment standards were met in accordance with the program policy and operation. All children were granted permission by their legal guardian prior to involvement in the pilot program and for use of their de-identified data in subsequent research. Legal guardians received information about Animal Assisted Therapy and the pilot program, potential risks and benefits to the participants were explained. See Appendix D for copy of the consent form. Further, consents for the collection of data and photo documentation were also obtained for each child. All permission slips and consents were returned with no one opting out of the pilot program or preventing the use of their data in research.

Potential risks to participants were minimal. Dogs used in the study had passed all behavioral and veterinary assessments per Dove Lewis and the Delta Society's Pet Partners Program. These approvals ensure that animals used for therapeutic purposes are safe, fully vaccinated, controllable and non-aggressive in any treatment setting. There was a theoretical risk to participants who had allergies; none were reported in the sample. 
Therapists and animal handlers ensured that children did not experience significant distress or fear when exposed to the dog. Potential benefits of AAT are outlined in detail in the above sections and include improved mood, social skills, emotional functioning, increased empathy and decrease in aggression. The Human Subjects Research Review Committee at Portland State University reviewed and approved this study (see Appendix F).

\section{Analysis}

The qualitative portion of this study includes a two-phase analysis plan in order to (1) fully understand the sample population and establish a baseline to track changes and (2) identify common experiences (aspects of the therapeutic process that evidence areas of improvement and/or areas that lack improvement).

A comparative multiple-case study analysis describes the sample population in context and establishes a baseline for individuals participating in the study. Each case was analyzed using a within-case analysis technique and includes the use of qualitative data as well as scores on subscales of the AATEI (Yin, 2009). The subscale data was used to establish a starting point for the children (as a group and individually) and then analyzed to track changes throughout the treatment period. Categorical aggregation informs common demographic features; the use of a matrix provides a simple framework for analyzing these qualitative demographic features. Because referrals for the AAT treatment group were made by the subjective recommendation of the case manager and program director, it is necessary to understand the group of children served before 
analyzing treatment effects. Scores on the AATEI help to provide descriptive data about the population.

An emergent Thematic Analysis allows for the exploration of the process of therapy for each participant by identifying common themes, as well as disparate experiences. The AATEI and progress notes have been designed to categorize observations in the following areas: cognitive, social-emotional, physical, and verbal. Despite this established structure, indicators of progress, response, outcome and experience emerged beyond these categories and within these categories. Based on the lack of research in this area, it was important to allow relevant themes and codes to arise from the data to account for variation within the treatment group, assess areas that may not be included in the outlined domains, and provide the rich description needed to increase understanding. Further, therapeutic methods, skills and tools were applied uniquely for each client, based upon age, development, responsiveness and need. These therapeutic techniques are also captured in the qualitative case notes and assessed.

Thematic analysis allows for a cross-case analysis through the creation of a "weblike illustration" that summarizes and connects findings using a visual illustration of networks (Attride-Stirling, 2011, p. 388). Ultimately, thematic network reveals the connectedness between the therapeutic approaches and the participants' varied responses.

Qualitative data gathered through referral forms, progress notes, the AnimalAssisted Therapy Evaluation Instrument (AATEI), brief interviews with program staff and a review of agency files are synthesized in the case study section of this paper. The material included in the case studies has been coded using Thematic Analysis to allow for 
maximum flexibility in identifying, analyzing and reporting themes. Because topics can be arranged broadly and include a range of different thematic possibilities, Thematic Analysis is applied with no specific or named process directing the assessment of data (Braun \& Clarke, 2006). For purposes of this study, given the various sources of information and the extent of differences amongst clients and within the therapeutic setting, Thematic Analysis was the best option to allow for the discovery of patterns and themes a posteriori. The central tenet of this qualitative research method is to allow themes to emerge from the data, quite organically, without an adherence to or reliance on a theoretical framework. The theoretical foundation of Animal Assisted Therapy is eclectic, as previously described, and not necessarily shared amongst practitioners of animal-centered therapies - and for this reason, the themes arising from this data are not coded with implicit theoretical underpinnings.

What counts as a theme? This is an important question to answer during the coding process, and not before. In their paper, which includes a step-by-step guide on this topic, Braun and Clarke describe a theme as "something important about the data in relation to the research question ... [with some degree] of patterned response" (2006, p. 82). The frequency in which the data item presents itself is what makes it a theme; however, there is no clear equation to determine whether the frequency of the data item should or should not be considered. The inductive coding process allows for the coding of data without trying to fit it into a preexisting theme or frame. For purposes of this study, and to offer some structure to the coding process, a frequent theme is one that 
arose at least three times within a single case or in at least three cases within the entire data set.

A six-step process was used to analyze the data using a Thematic Analysis approach, as recommended by Braun and Clarke (2006):

1. Transcribing the data and, in the process, gaining familiarity with the data.

2. Generating the initial codes across the data set.

3. Collating the codes into potential themes.

4. Reviewing the themes and assessing for patterns and frequencies.

5. Defining the themes.

6. Generating the report/map with a focus on vivid and compelling examples and quotes.

In their study on Thematic Analysis, Ando et al., (2014) found that a sample of 12 cases/interviews provided the necessary data to reach a saturation point within the analysis; no additional themes were discovered after a thorough coding of 12 disparate interviews. Given that the sample group for this study is 13 participants, the method of analysis is appropriate and endorsed by researchers as "rigorous and transparent" (Ando et al., 2014, p. 7).

In order to reduce interpretive bias in coding for themes and ensure trustworthiness, several mechanisms were put in place. The principal investigator employed a second coder to code for themes after all data were transcribed. Data was coded by both coders independently and differences in opinion were reconciled through regular discussions and meetings. Themes emerging from the data were then shared. 
Scaled data collected on the AATEI were used to create a quantitative descriptive chart for each child in the program. Four charts (one for each domain on the AATEI) were produced for each participant and included within the case studies for each client. These charts provide information about changes that occurred during the treatment period.

Data from weekly progress notes, reported by both raters (the therapist an observer) were included to track growth and change over the period of pilot study. These charts are embedded within the case studies. 


\section{Chapter 4}

\section{Findings}

The following section includes case studies for each of the 13 children included in the study. Demographic data, pre-study information gathered on each child about their family, diagnoses, identified behavioral or emotional concerns, and material from the AAT referral form were included in each of the case studies to help illustrate each case and how the clients presented prior to the intervention. After the initial description, each case study includes a Course of Treatment section to highlight the therapeutic tools used, client response, weekly changes or observations, and capture any additional information from case notes that directly related to the experience in the therapeutic setting. The Course of Treatment sections also include graphs and charts to depict the quantitative indicators of change based on progress notes and the AATEI. Those are embedded within each case study. Finally, Therapeutic Impressions are included for each case based on notes kept by the children's therapist during the course of treatment and immediately after. These Therapeutic Impressions are subjective and reflective, based not only on the individual child but also how each child's experience was unique based on the group as a whole.

\section{Cases Studies}

Table 1 includes demographic and referral information for each client involved in the study. Age, sex, race, and clinically relevant information gathered at the time of referral are presented to aid in the comparative analysis of cases and to illustrate the complexities of this population of study. 
Table 1

Client Demographic and Referral Information

\begin{tabular}{|c|c|c|c|c|}
\hline Client & $\begin{array}{c}\text { Age } \\
\text { (months) }\end{array}$ & Sex & Race & Referral Information \\
\hline Ay1 & 44 & $\mathrm{~F}$ & $\begin{array}{l}\text { Hispanic or } \\
\text { Latino }\end{array}$ & $\begin{array}{l}\text { Flat, withdrawn, "untouchable," "difficult to } \\
\text { relate to," silent, slow moving, avoided eye } \\
\text { contact, disengaged, remote, expressionless, } \\
\text { distant, avoidant }\end{array}$ \\
\hline Bri2 & 36 & $\mathrm{~F}$ & $\begin{array}{l}\text { Hispanic or } \\
\text { Latino }\end{array}$ & $\begin{array}{l}\text { No observable development in } 2 \text { years while } \\
\text { in program, Small, underdeveloped, delayed, } \\
\text { Physically attractive, Flat, expressionless }\end{array}$ \\
\hline Guy3 & 36 & M & White & $\begin{array}{l}\text { Poor social skills, Limited impulse control, } \\
\text { Aggression when frustrated, Not } \\
\text { affectionate, Complex parent-child } \\
\text { relationship }\end{array}$ \\
\hline $\mathrm{JJ} 4$ & 26 & M & $\begin{array}{l}\text { African } \\
\text { American }\end{array}$ & $\begin{array}{l}\text { Anxious upon leaving mother, Complex } \\
\text { parent-child relationship, Difficult to soothe, } \\
\text { Needed a lot of physical contact, Little } \\
\text { interest in peers and toys }\end{array}$ \\
\hline Jav5 & 39 & M & $\begin{array}{l}\text { Mixed } \\
\text { Race }\end{array}$ & $\begin{array}{l}\text { Lack of progress over past year, Ongoing } \\
\text { involvement with child welfare/concerns, } \\
\text { Unstable living situation, Comorbid factors, } \\
\text { Complex parent-child relationship, } \\
\text { Withdrawn, Poor hygiene and appearance, } \\
\text { Poor attendance prior to AAT (very poor } \\
\text { during pilot) }\end{array}$ \\
\hline Kai6 & 15 & $\mathrm{~F}$ & White & $\begin{array}{l}\text { Foster home with little involvement, Self- } \\
\text { isolative, Did not seek help or support from } \\
\text { adults, Withdrawn, Insecure and unsure, } \\
\text { Complex parent-child relationship, Ongoing } \\
\text { stressors and comorbid factors }\end{array}$ \\
\hline May7 & 28 & $\mathrm{~F}$ & $\begin{array}{l}\text { Hispanic or } \\
\text { Latino }\end{array}$ & $\begin{array}{l}\text { Suspected neglect in home, Highly } \\
\text { emotional- "meltdowns," tearful most } \\
\text { days, Physically attractive-well dressed, } \\
\text { attention paid to appearance, Complex } \\
\text { parent-child relationship, Clingy, needy, } \\
\text { anxious }\end{array}$ \\
\hline
\end{tabular}

Continued 
Table 1 - Continued

\begin{tabular}{|c|c|c|c|c|}
\hline Client & $\begin{array}{c}\text { Age } \\
\text { (months) }\end{array}$ & Sex & Race & Referral Information \\
\hline Mik8 & 30 & $\mathrm{~F}$ & $\begin{array}{l}\text { Hispanic or } \\
\text { Latino }\end{array}$ & $\begin{array}{l}\text { Avoidant, lack of engagement, Non-verbal, } \\
\text { Cultural context/concerns, Socially distant }\end{array}$ \\
\hline Nai9 & 13 & $\mathrm{~F}$ & $\begin{array}{l}\text { African } \\
\text { American }\end{array}$ & $\begin{array}{l}\text { Severely withdrawn, History of neglect (and } \\
\text { potentially current), Expressionless, Possible } \\
\text { FASD and developmental delays, No } \\
\text { communication, Under-reactive, Complex } \\
\text { parent-child relationship }\end{array}$ \\
\hline Ren10 & 28 & $\mathrm{~F}$ & White & $\begin{array}{l}\text { Complex parent-child relationship, Chronic } \\
\text { health and mental health concerns in parents, } \\
\text { Concerns about neglect, lack of care in } \\
\text { home, Emotional lability, Mood instability }\end{array}$ \\
\hline Tah11 & 25 & $\mathrm{~F}$ & White & $\begin{array}{l}\text { Withdrawn, Lack of stimulation at home, } \\
\text { Poor attachment, No other supports outside } \\
\text { of program, Complex parent-child } \\
\text { relationship }\end{array}$ \\
\hline Vin12 & 34 & M & White & $\begin{array}{l}\text { Aggression toward peers, Family discord } \\
\text { and instability, Poor hygiene, Poor } \\
\text { frustration tolerance, Emotional outbursts, } \\
\text { Receiving outside services for } \\
\text { speech/language, Complex parent-child } \\
\text { relationship }\end{array}$ \\
\hline Vivi13 & 31 & $\mathrm{~F}$ & $\begin{array}{l}\text { Hispanic or } \\
\text { Latino }\end{array}$ & $\begin{array}{l}\text { Aggression, Non-compliance, Inattention, } \\
\text { Impulsivity, Emotional dysregulation, } \\
\text { Concerns about home environment, } \\
\text { Complex parent-child relationship }\end{array}$ \\
\hline & \multirow{4}{*}{$\begin{array}{l}\text { Mean } \\
\text { Age: } \\
29.62 \\
\text { months }\end{array}$} & \multirow{4}{*}{$\begin{array}{l}9 \mathrm{~F} \\
4 \mathrm{M}\end{array}$} & \multicolumn{2}{|c|}{5 Hispanic/Latino } \\
\hline & & & \multicolumn{2}{|c|}{5 White } \\
\hline & & & \multicolumn{2}{|l|}{$2 \mathrm{AA} / \mathrm{Black}$} \\
\hline & & & \multicolumn{2}{|c|}{1 Mixed Race } \\
\hline
\end{tabular}


1. Ay. Ay, a Mexican female, was 44 months old at the time of referral. She had been involved with The Children's Program (TCP), a pseudonym for the agency hosting this pilot study, for two years but had yet to speak a single word out loud at TCP. She clearly understood what was going on around her and had average receptive language skills; Ay had recently been diagnosed with Selective Mutism though she spoke at home (but only in Spanish). Ay would not engage in play or activities with peers but seemed content to play alone.

Ay lived in small apartment with five siblings, all under the age of eight (her closest sibling was 10 months her junior). She lived in a home with her biological mother and father. Due to concerns perhaps about previous criminal involvement or immigration status, the family would not engage in services and never let staff from TCP into their home (which was unusual, given the program would do outreach in clients' homes as a regular component of services offered).

From the threshold of the doorway, her home environment was reported by case managers to be dark, under-stimulating and free of toys. The children reportedly watched a good deal of television and played with each other. Ay received little one-to-one attention from either of her parents; she provided care to younger siblings on a regular basis. Because of her family's reluctance to participate and her relative silence, there were many unanswered questions about this child and her lived experience. Some staff had guessed that she was parentified in the home, others assumed that her culture played a large part in her presentation at TCP. 
Compared to same-aged peers, Ay was scored by her classroom teacher as average in social functioning, above average in emotional stability and appropriate behavior, and below average in language ability. Her teacher indicated that Ay "seemed untouchable" and "difficult to relate to." Her teacher hoped that Ay might "open up" during AAT in a way that she had yet to in the TCP classroom.

Course of treatment. This child appeared very flat, disengaged, fearful, and "shut down" at the start of the study. She would not make eye contact with her therapist or the therapy dog. She was a slow-moving, easy-to-startle, quiet little girl who didn't show or speak of her emotions. She resisted any physical touch with the dog and seemed to prefer to sit on the therapist's lap and bow her head while watching the dog through raised eyelids. She would nod her responses at times, clearly understanding questions or what was being discussed ("cross-talking" with the dog was a therapeutic practice this pilot program used here regularly, as children often couldn't tolerate being spoken to directly, or some seemed confused by or intimated by direct feedback). Diagnosed with Selective Mutism, Ay had never uttered a word during her two years at TCP.

Her first three sessions included the therapist narrating the dog's behavior, encouraging Ay to try to brush the dog with the therapist's hand guiding the activity (because touching the dog directly with her hand was something she resisted strongly) and feeding the dog treats. Her interaction with the dog was limited; instead, she sat calmly for the duration of each session and appeared to simply listen to the therapist and watch the dog. Her face remained expressionless and her little body was nearly still, unless startled or during brief period of brushing or treat-giving. 
By week eight, Ay had already missed four sessions. However, during week nine, Ay was less nervous to enter the office and did not startle when the therapist moved closer to the dog (with Ay on therapist's lap, as this had become the typical structure for interaction). This time she agreed to throw the ball for the dog as well as brush and give treats. This was the first session where a "smile" was noted in case notes. Her communication continued to be behavioral, in the form of head nods.

Week 10 began typically-Ay was escorted into the office by the therapist and the two immediately sat down on the floor to greet the dog. The therapist began by greeting the dog and engaging in cross talk ("I wonder how you are feeling today, doggy?" "Do you feel a little excited to see us today?" "Should we just sit here together for a little bit until everyone is comfortable?"). Ay would often nod responses to questions if close-ended (yes/no). To more sophisticated questions, she would remain quiet but appear focused, always watching the dog. Still, there were no verbal responses given, nor were any expected given the client's diagnosis.

About half way through the session, the therapist misspoke by calling the dog by the child's name ("Come here, Ay!") and immediately, without any change in her posture, Ay blurted out: "I ain't no dog." These were the first words spoken during therapy and moreover, the first words ever uttered during her two-year enrollment in TCP. Appearing to not "make a big deal" over her verbalization, the therapist responded by saying, "Oh, you're right. Silly me.” Ay continued, as had become normal, with some brushing of the dog and giving treats, but did not speak any further. She remained seated on the therapist's lap and continued with no obvious emotional or behavioral shift. When 
asked, at the end of session, if she was ready to say goodbye, she nodded "no" and resisted leaving. She agreed to be carried out of the therapy office and waved on the way out (another first).

This child's verbalization indicated a major shift in her presentation and, from a clinical perspective, demonstrated significant progress in the therapeutic setting. It seemed important that the therapist not respond any differently after her verbalization or offer any feedback about her speaking. Often, children with this diagnosis can feel forced to speak and rewarded only for verbal progress (Muris \& Ollendick, 2015). The therapist was aware of the tendency to "push" children with Selective Mutism in ways that ultimately might be detrimental and cause her to retreat from the therapeutic alliance. Given that this is an anxiety-rooted disorder, the main goal for Ay was to help her feel comfortable in the treatment setting and allow her to engage with the therapy at her own pace.

After this remarkable session, the therapist let the classroom teachers and her case manager know about Ay's brief statement; all staff members were equally surprised and pleased to learn of her progress (one teacher even exclaimed, "No way! I cannot believe it!"). No changes in her classroom presentation were ever mentioned to the therapist after this session—she continued being silent in every other setting.

Ay presented with much more expressive affect during week 11. She entered the room without needing encouragement and smiled as the dog fetched and ate treats from her hand. She still appeared hesitant to touch the dog directly but grabbed the brush without being asked to and brushed without needing help. Again, Ay spent the entire 
session sitting squarely on the therapist's lap but showed no startle responses and was smiling and demonstrating more obvious pleasant emotion throughout. She again put her arms up at the end of the session, requesting through her nonverbal behavior, to be carried out of the office and back into her classroom (this had only been done once before, after the previous session). Ay did not speak during week 11.

Week 12 presented Ay with a new challenge: her therapist decided to sit in a new place in the office, which changed the predictable structure just a bit. At first, she seemed unfazed and walked into the room, sitting down on the therapist's lap without apprehension. The therapist, as had become standard, spoke to the dog about feelings and expectations for the session. The therapist asked the dog, "Would you like to try going for a walk today?" and the child nodded assertively and smiled with an open mouth, which seemed to indicate excitement over a new activity. The child was able to help get the dog ready for the walk (putting on his leash) and patted him on the head when he sat and waited. This was the first time where it was noted that Ay touched the dog on her own and without being asked. Ay was again silent throughout the session, including on the brief walk, but very compliant with instructions ("stay close," "try not to pull the leash too hard," "let's take him back into the room now."). At the end of the session, as the therapist was coaching Ay on saying goodbye to the dog, Ay spontaneously said, "wait!" followed by "I don't want to leave." She then asked the therapist to take a polaroid picture of her with the therapy dog ("take my picture?") and wanted to take the photo with her back to class. The photo seemed to act as a transitional object, as she exited the office with a smile on her face and skipped back to class. 
Case notes from this session repeatedly state "breakthrough!," "didn’t want to leave!," "voluntarily approached him [the dog]" and "showed affect!"

Week 13 was noteworthy from the beginning to the end of session. The moment Ay walked into the office, she was speaking in complete sentences (often the same exact sentences said by the therapist during previous sessions - "Hello today, doggy. How are you feeling? Are you excited to see me?"). She was verbally engaged with the dog and therapist throughout the session, asking clear questions about whether she could give a treat, go on a walk or read a book to the dog (something that had been offered as an option in the first three weeks of the pilot). About half way into the session, Ay began instructing her therapist to do certain things ("No, go like this" and "Can you do it that way?"). She sat on her own and moved around the room, two things she had not previously done. She also approached and touched the dog voluntarily. She asked for a "few minutes" more when told it was almost time to leave. She waved by to the dog and smiled at the very end of session.

It appears that the Ay made a significant shift in her presentation after week 10; both qualitative and quantitative markers support this. She was obviously more comfortable in the room and her rapport with both the dog and therapist had improved substantially. Week 13 confirmed that this child did have language skills and could communicate quite clearly her needs and wants. Interestingly, once back in the classroom after session, she would resume her silence and relatively flat affect. Her teachers continued to report that she would not speak in that setting. 
Weeks 14 and 15 (Ay’s final week) were drastically different from her initial weeks in the pilot program. Case notes indicate that she was extremely comfortable in the setting, asked for what she wanted, and even became "demanding and bossy" with the therapist. Clearly, she had strong ideas about how she wanted to spend her time and was able to communicate them. She showed no signs of fear or shyness. Ay seemed to test her power or control in these last two sessions. She requested that the therapist give commands to the dog and even said things like "You tell him to sit. I tell him 'good boy."" Ay kissed a photo of herself and the dog. She showed emotions that one might expect from a typically developed three-year-old in social, emotional, and verbal domains. These tremendous and obvious growth areas were confined to therapy.

Data points on the line graph indicate attendance, with a solid line joining consecutive attendance. Dash lines indicate missed weeks. The number along the $\mathrm{X}$-axis indicates weeks, with the final number indicating the last week of attendance.

Attention was measured weekly by the therapist using a five-point scale. This single rating was captured in the agency's case note and is one quantitative markers of change from week to week.

Engagement was measured weekly by the therapist using a five-point scale. This single rating was captured in the agency's case note and is one quantitative markers of change from week to week.

Emotional regulation was measured weekly by the therapist using a five-point scale. This single rating was captured in the agency's case note and is one quantitative markers of change from week to week. 
Age-appropriate behavior was measured weekly by the therapist using a five-

point scale. This single rating was captured in the agency's case note and is one quantitative markers of change from week to week.

Each of the four line charts is included for all of the case studies in the course of treatment section.

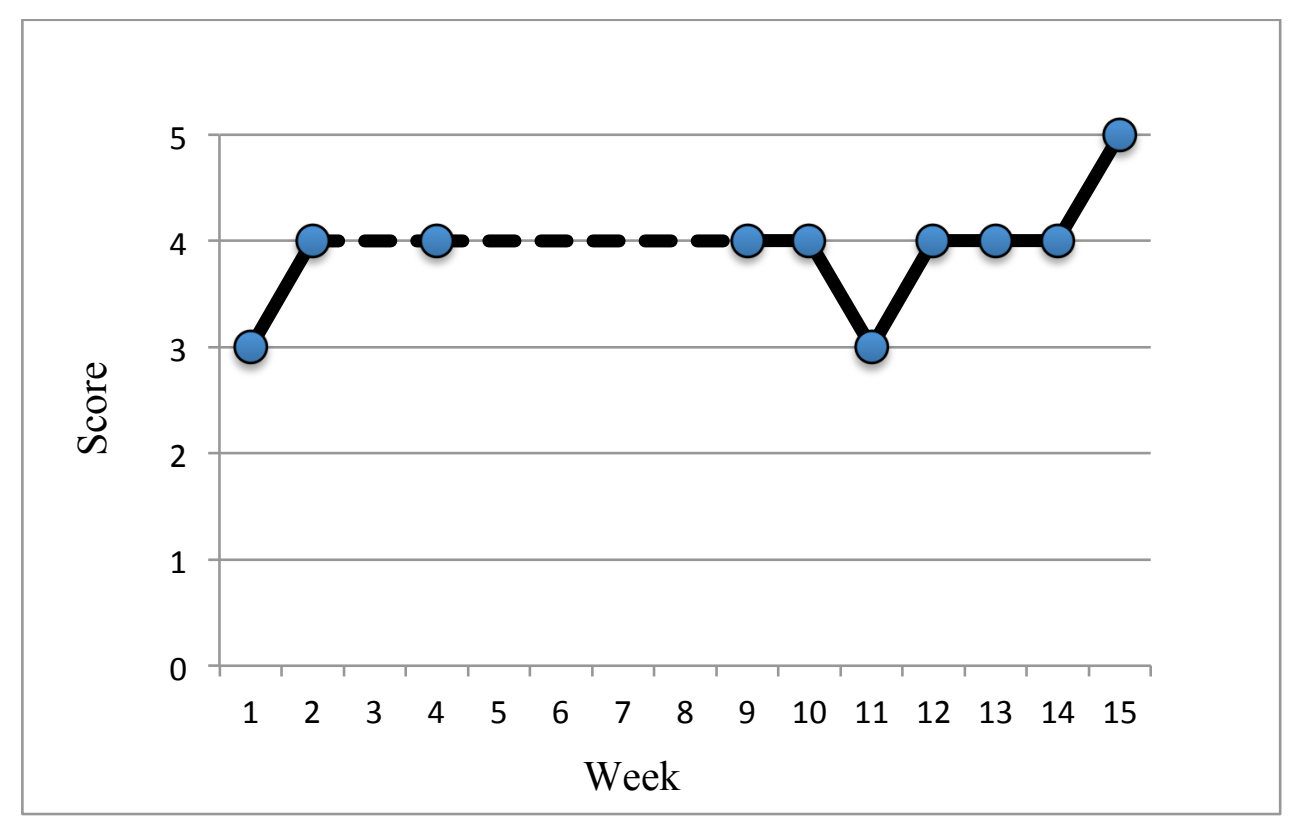

Figure 1. Ay-Attention. 


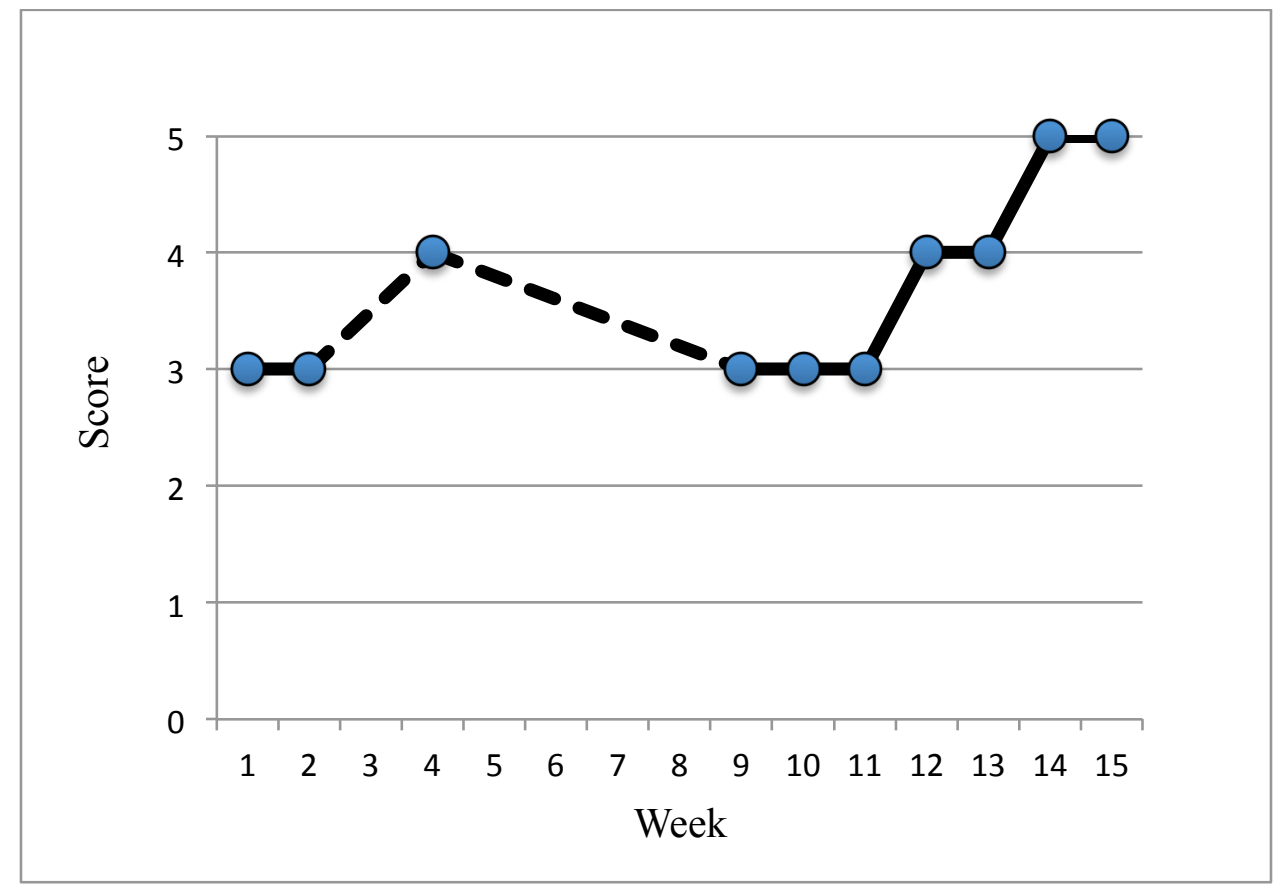

Figure 2. Ay-Engagement.

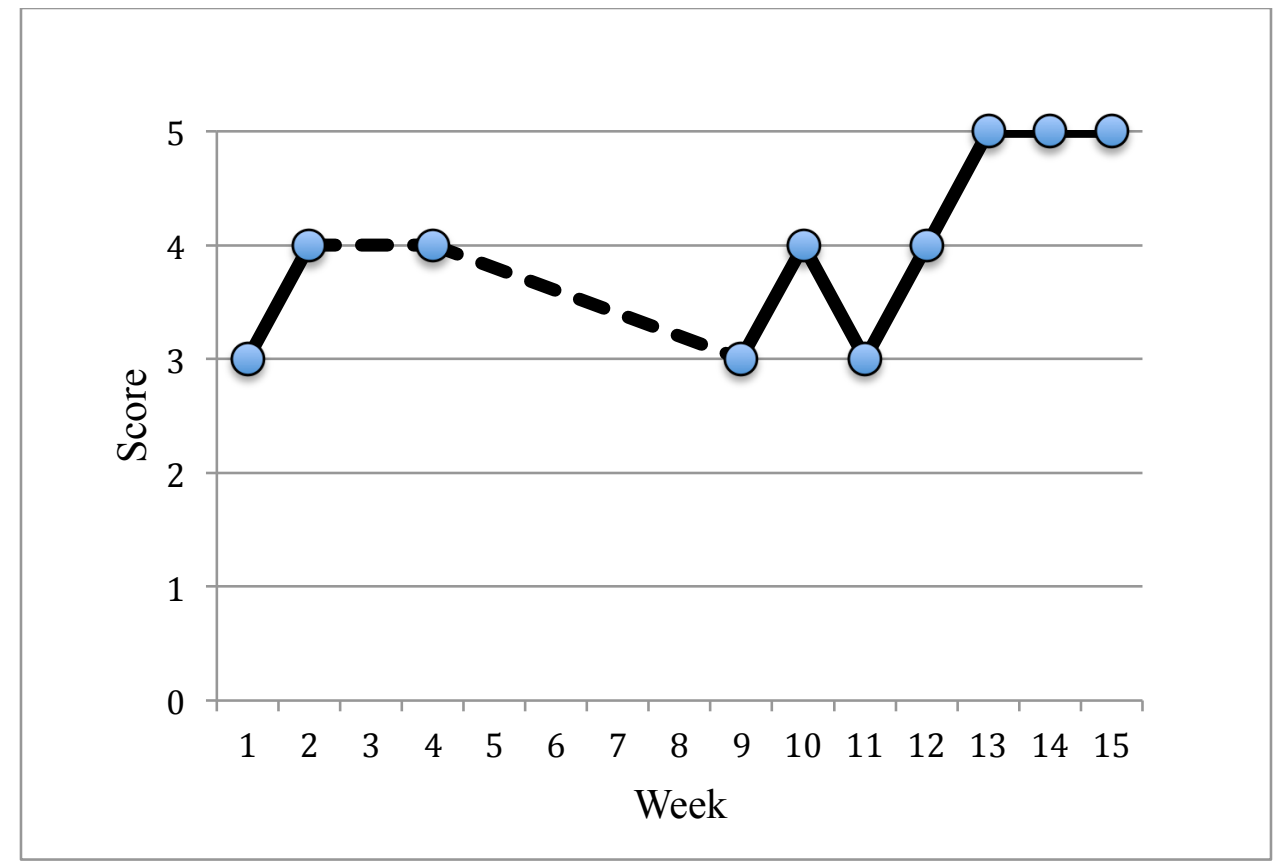

Figure 3. Ay-Emotional regulation. 


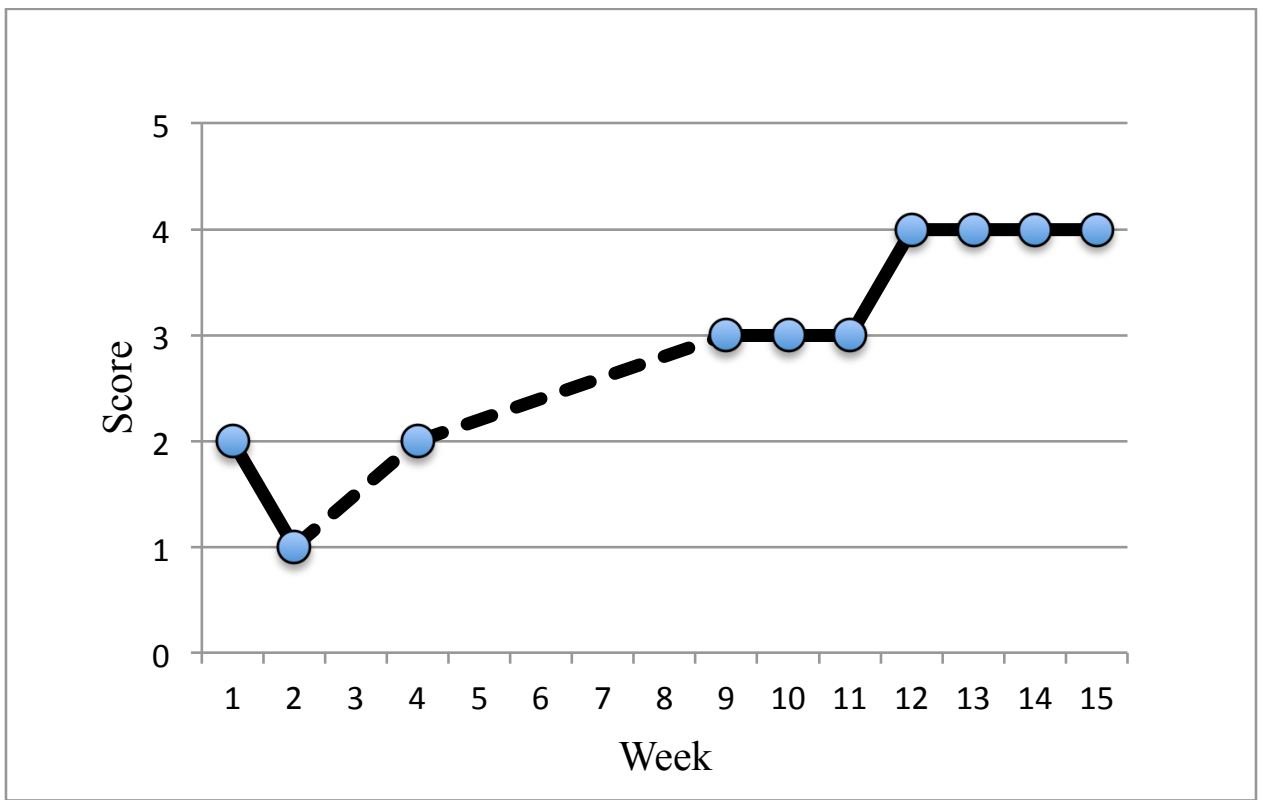

Figure 4. Ay-Age-appropriate behavior.

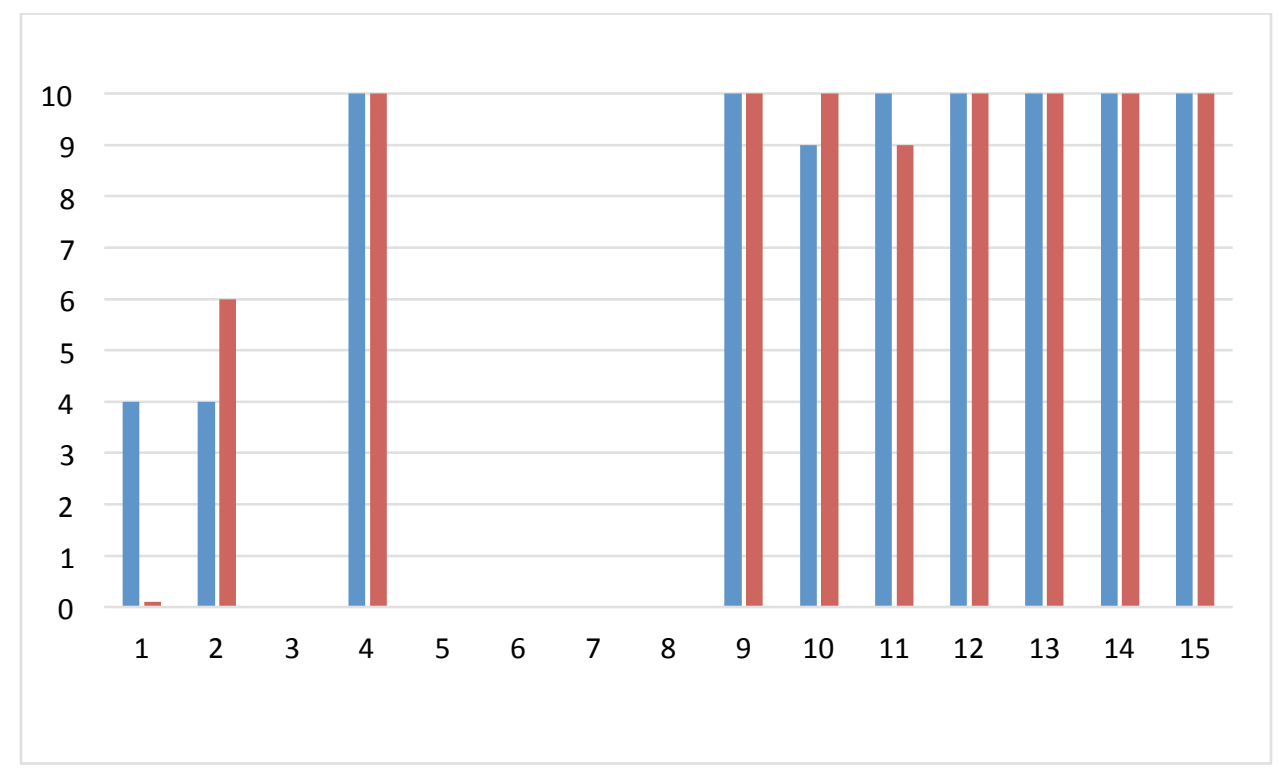

Figure 5. Ay-Cognitive "Yes" scores (Raters $1 \& 2$ ). 
Bar charts for cognitive, social-emotional, and verbal observable behaviors are based on the AATEI and measure the "yes" scores (indicating positive observations) from two raters - the therapist and observer. The cognitive domain on the AATEI has a maximum score of 10 . The social-emotional domain on the AATEI has a maximum score of 14 .

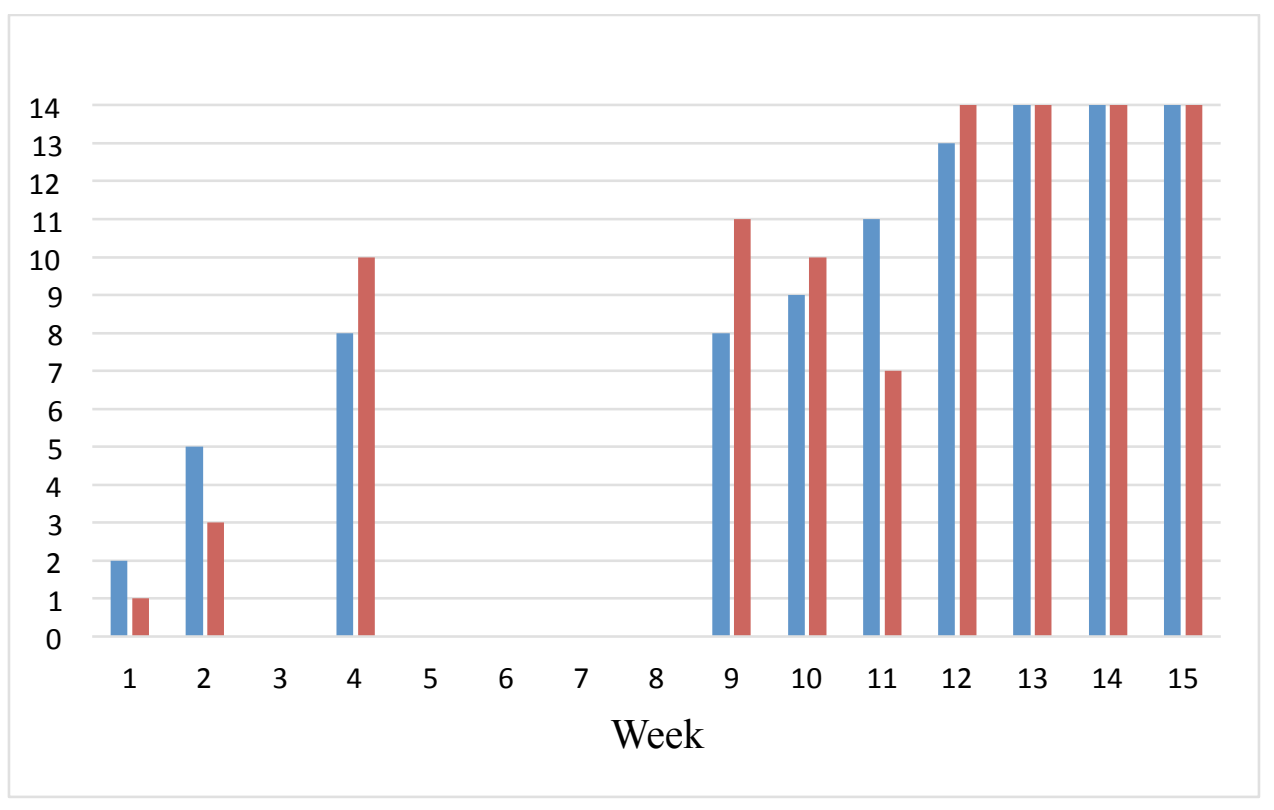

Figure 6. Ay-Social-emotional "Yes" scores (Raters 1 \& 2).

The verbal domain on the AATEI has a maximum score of six for verbal clients (or five for non-verbal clients). 


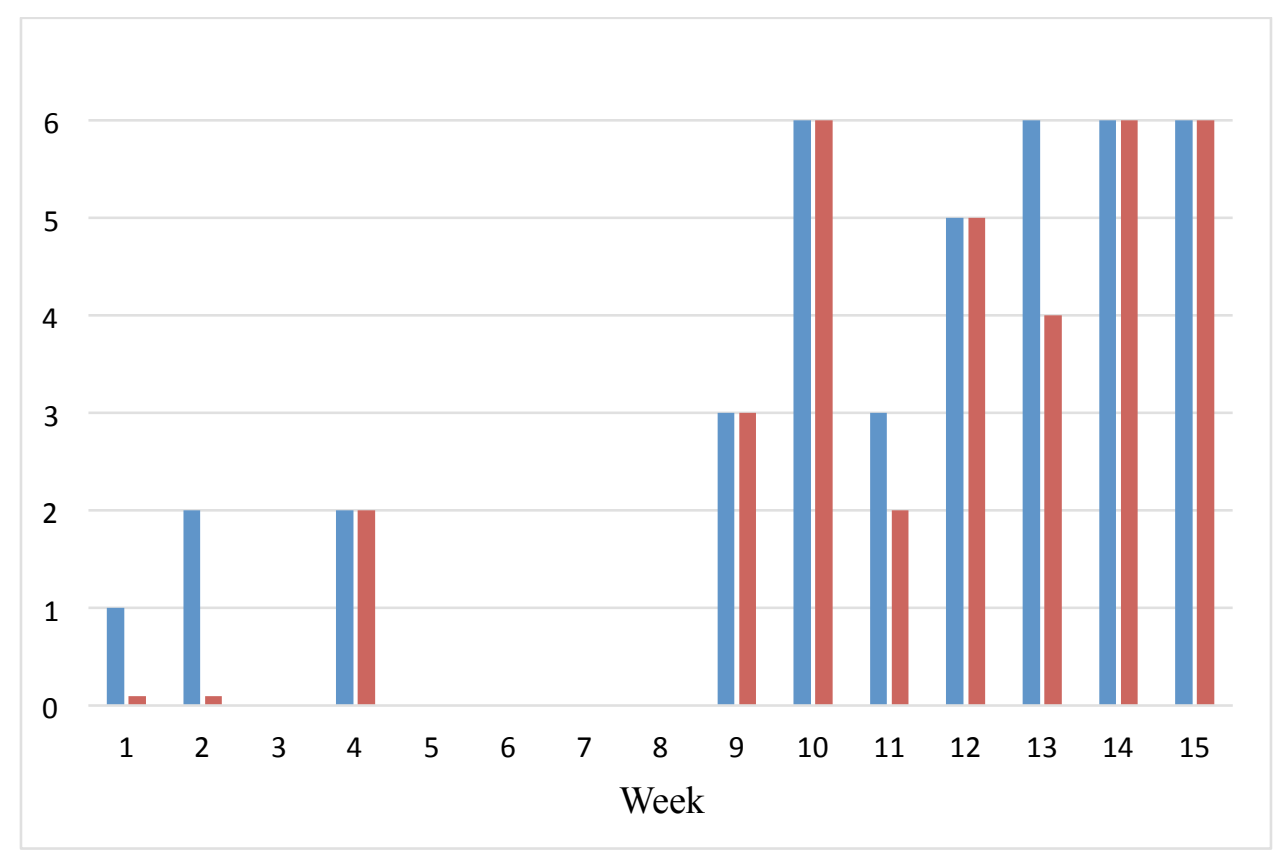

Figure 7. Ay-Verbal "Yes" scores (Raters 1 \& 2).

In addition to the figures above, the last quantitative measure included for each of the cases is a "change score" that was calculated using the child's "yes" scores from their last AAT session (which may function similarly to a post-test measure) and subtracting their "yes" scores from their first session (which may function similarly to a pre-test measure). Two raters contributed to this measurement - the therapist as well as the observer/animal handler. There were no pre- and post-test scores available; instead, the positive markers from the first session will serve as pre, and positive markers from the last session serve as post. Though this measurement is problematic, the change scores are useful in helping to understand how individual children progressed during the course of treatment. The average total change score for all cases was 16.92. A chart with the change scores for all children is included at the end of this section. 
Ay1's total change score was 65, the highest in the sample group. While all but two children had higher scores at the end of the study. Ay's change score was the highest by nearly 20 points.

Therapeutic impressions. The therapeutic implications of this one case study are important to explore. To date, there are no reports or research on the effectiveness of AAT with the diagnosis of Selective Mutism or other communication disorders (Muris \& Ollendick, 2015). The non-threatening nature of the human-animal relationship is one that can decrease anxiety, especially in treatment settings, and may be especially useful for children who do not speak in environments where fear, anxiety, lack-of-control or other influential power imbalances are present. Culture and language, for this particular child, are also important factors to consider given her family's language of origin (Spanish) and the private/closed culture of the home. Larger cultural impacts, such as the immigration experience of her parents, fear of deportation or arrest and other factors rooted in the family system would be valuable to explore, as they have the potential to contribute not only to the presentation of clients at the start of treatment but also to how they respond to treatment and what they respond to.

The "mistake" made by the therapist in week 10 seemed to shift the culture of the therapeutic relationship, perhaps also shifting the dynamic of therapist as "expert." The child had an opportunity to correct the mistake and gain power in the relationship in that moment. And the response of the therapist was also important, as it didn't reinforce the power dynamic but instead, offered the child a chance to be in a position of being right and recognized for that. In the last two sessions, her need for control and to be in charge 
was obvious; she finally seemed to revel in being able to "boss" not only the dog but therapist as well. And in the classroom setting, where again she was not able to be in control and had demands placed on her, she went silent. Also, it may be important to consider the fact that dogs don't have language and only respond to our verbalizationsthey are passive recipients of our language and aren't able to speak for themselves. This may have helped to decrease Ay's anxiety and lessen the demands being made of her in the therapeutic setting.

2. Bri. Bri was 36 months at the time of referral. She was identified as being of Mexican and Caucasian descent. Bri was referred for AAT by her classroom teacher because she had failed to show progress in the two years since she had started at TCP. She was well-liked at the program and described as "sweet" but reported to have severe language delays. Bri preferred to engage with adults and demonstrated limited interest in peers.

Bri lived in a very small home with five siblings, all under the age of seven-yearsold. Her mother and grandmother were the adults living in the home but there were reported to be multiple adult visitors at any given time. Bri had a younger sister enrolled at TCP as well (but not in the AAT program). In her file, it was noted that Bri's household spoke primarily Spanish. Her file also noted that Bri's home was very understimulating and that the "shades were always drawn" and that it was "very low light" inside the home.

Bri's teacher noted that Bri was below average in social functioning and language ability compared to similarly-aged peers but demonstrated average emotional stability 
and appropriate behavior. It was clear that program staff took special interest in Bri, largely because of her long-term enrollment and "baby-like" appearance. She was small, quite delayed (as mentioned) and, as one teacher reported, "beautiful in every moment."

The family reported no animals in the home and said Bri had very little contact with companion animals previously.

Course of treatment. Bri did not begin AAT until week three, as she was absent from the program for the first two weeks. She appeared very flat throughout the session but was able to demonstrate discomfort by reaching for her therapist and resting her head on the therapist's shoulder. Bri was quiet and did not show any other obvious signs of emotion or affect. Bri was obviously able to understand her therapist, as she touched the dog (with guided help) when asked if she would like to try that. Her gaze was downward and she only made brief eye contact with dog during the 30-minute session. By the end of the first session, Bri began pointing and gesturing at toward her jacket, showing she wanted to leave. Case notes indicate that Bri was "shut down" and "distant."

Bri continued to present with a very flat affect and expressed no emotion over the next two weeks. She was able to pet the dog with her therapist's help. She would turn away from the dog often and "stare into space" until her therapist was able to reengage her. She again focused on her coat and gesturing gently to leave the room. Week seven marked a subtle but important shift for Bri; she cried during session, which was her first open expression of emotion of any kind. She accepted comforting by the therapist. After observing the dog from a distance, Bri was able to point to body parts on her body that matched the dog's. She then progressed to pointing at the dog's body parts and eventually 
reached out to touch the dog's tail. Her movements were slow and deliberate throughout the session. Toward the end, she attempted some verbalizations/sounds but they were not intelligible. Helping Bri to connect to the dog by identifying similar body parts appeared to decrease her fear and increase her ability to engage. Still, her affect was flat and case notes indicate that she was "emotionless."

This client continued to present with apprehension at the start of her remaining sessions and would have brief periods of crying upon entering the room, which offered her therapist the opportunity to console and cross-talk. Bri became interested in the dog's ball and agreed to try throwing it for a game of fetch; this was the first time Bri stood up and didn't need to be held during the session. This new strategy seemed to empower Bri to try "experimental behaviors," such as moving closer to the dog (on her own) and then retreating, petting him and then running to the corner, stepping on his tail, and then picking up a stuffed dog toy and pointing out similar body parts. She then began hitting the stuffed dog, likely to test the reaction of the therapist. Bri showed fright and insecurity throughout sessions nine and 10 but would have brief periods of engagement (approach and retreat, approach and retreat). The therapist simply narrated what Bri was doing during these periods. Bri was responsive to encouragement and praise, as that seemed to help to increase her comfort. Still, her face presented no identifiable emotion and she was quiet throughout.

After missing a week, Bri came back to AAT during week 12 and entered the office on her own and even approached the dog casually. It was noted that she was “jumpy” but much more engaged. She looked at photos of dogs that were hung on the 
wall and was able to identify her therapy dog. She also saw photos of herself, which she looked at for an extended period. Bri appeared to enjoy listening to cross-talk (i.e., "You are a friendly dog and you like children. It makes you happy when people are kind.”) as this prompted her to move closer and eventually brush the dog (for the first time). Bri showed an ability to remember activities she had done in previous sessions (like throwing a ball and giving treats). This session, unfortunately, was to be her last. This session was also when she demonstrated the most comfort, engagement and a decrease in fear. She was self-directed, which was a trait lacking in other sessions.

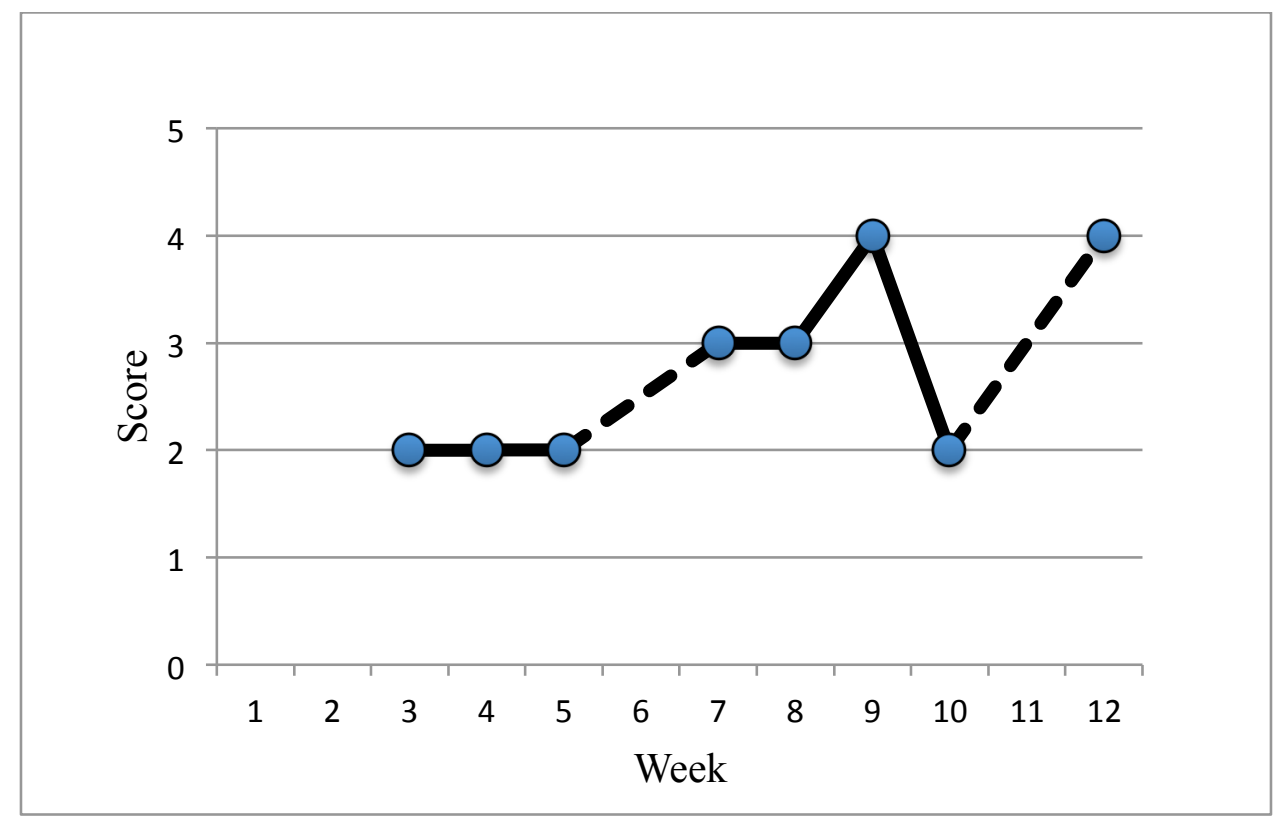

Figure 8. Bri-Attention. 


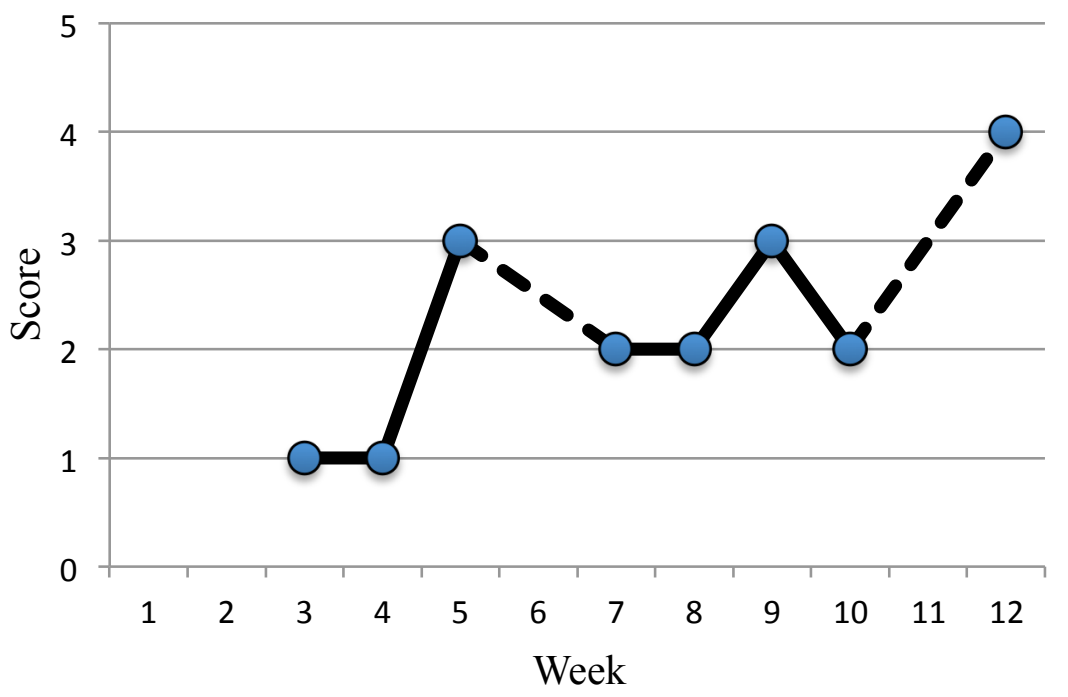

Figure 9. Bri_Engagement.

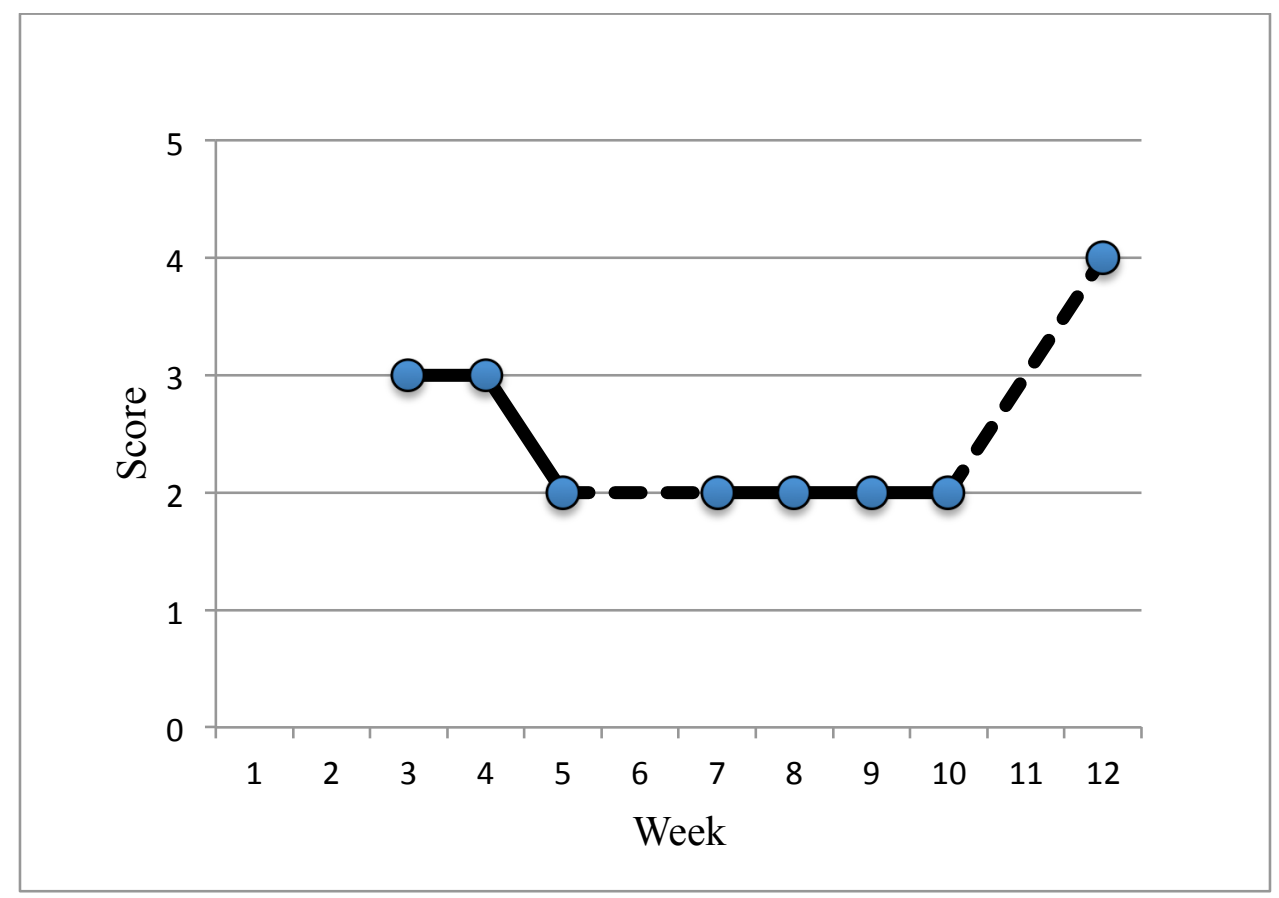

Figure 10. Bri-Emotional regulation. 


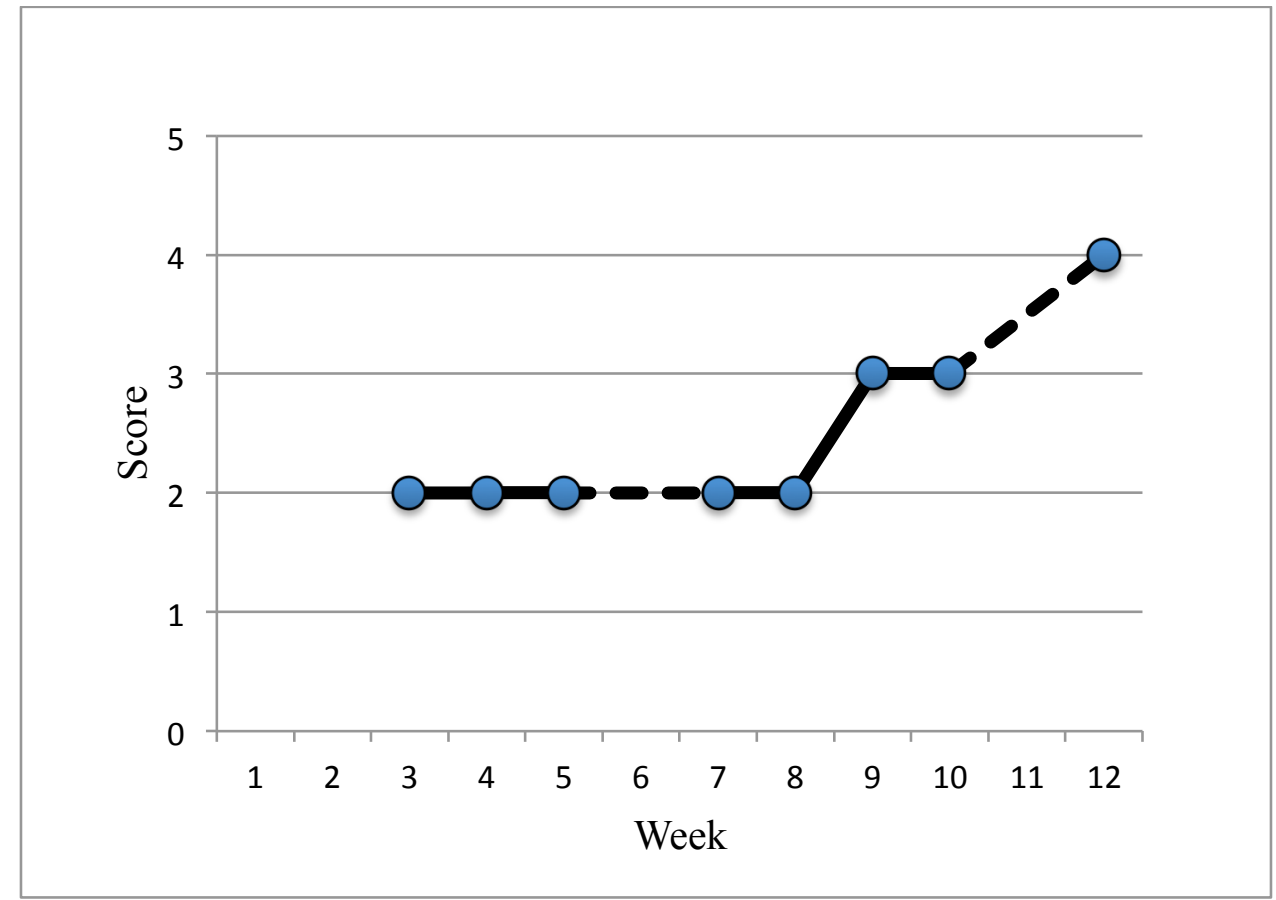

Figure 11. Bri-Age-appropriate behavior.

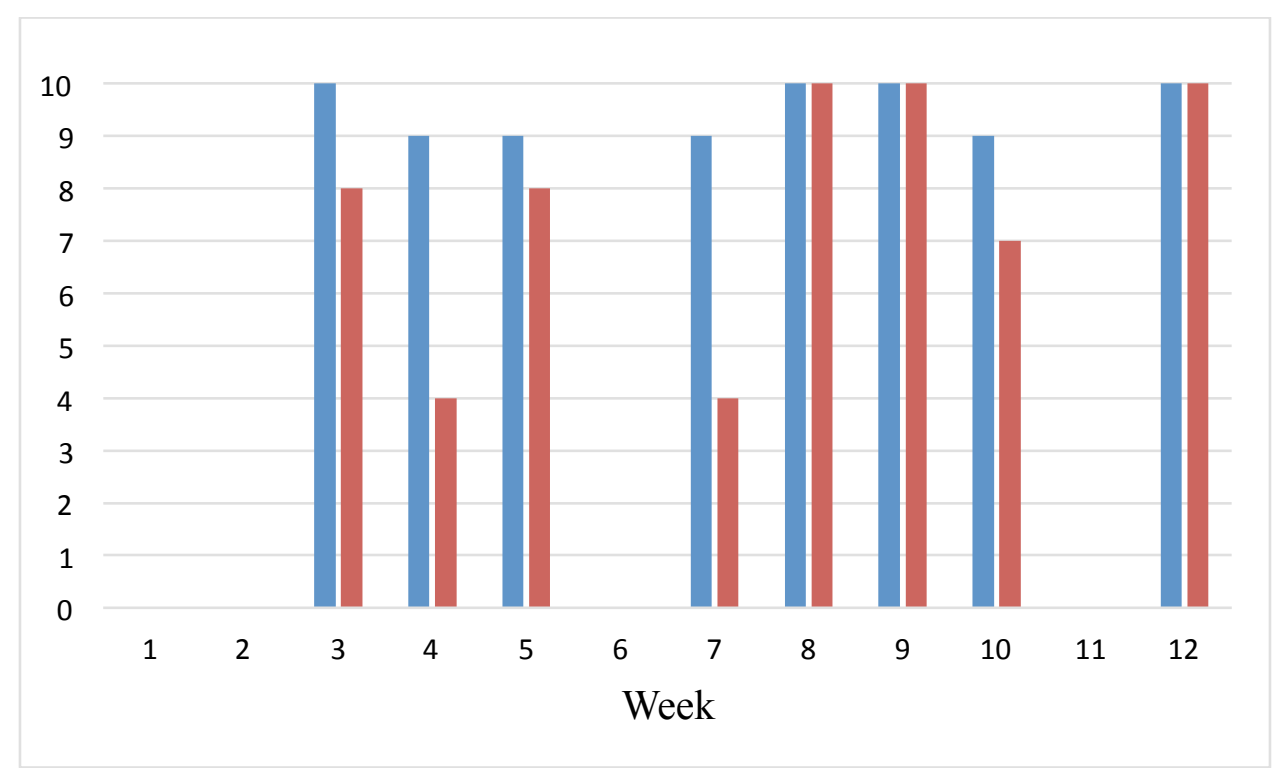

Figure 12. Bri-Cognitive "Yes" scores (Raters 1 \& 2).

Rater 1 is the therapist. Rater 2 is the animal handler/observer. 


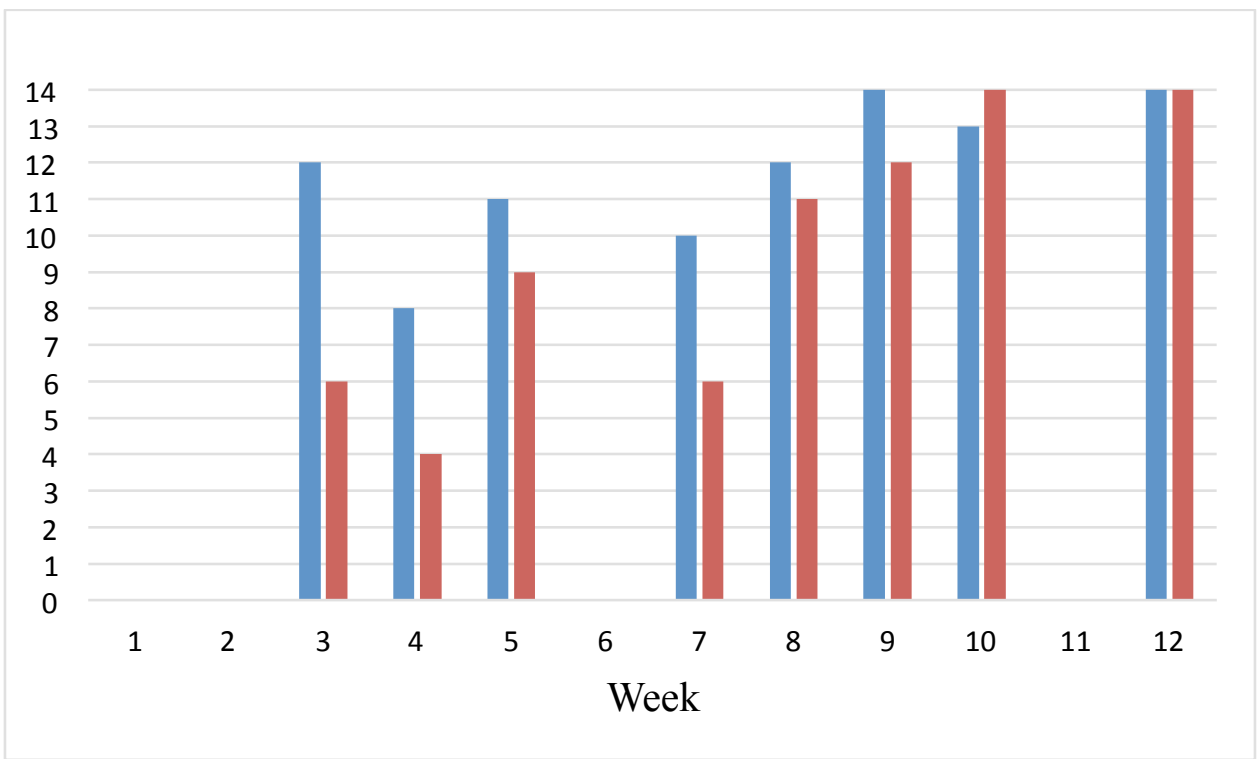

Figure 13. Bri-Social-emotional "Yes" scores (Raters 1 \& 2).

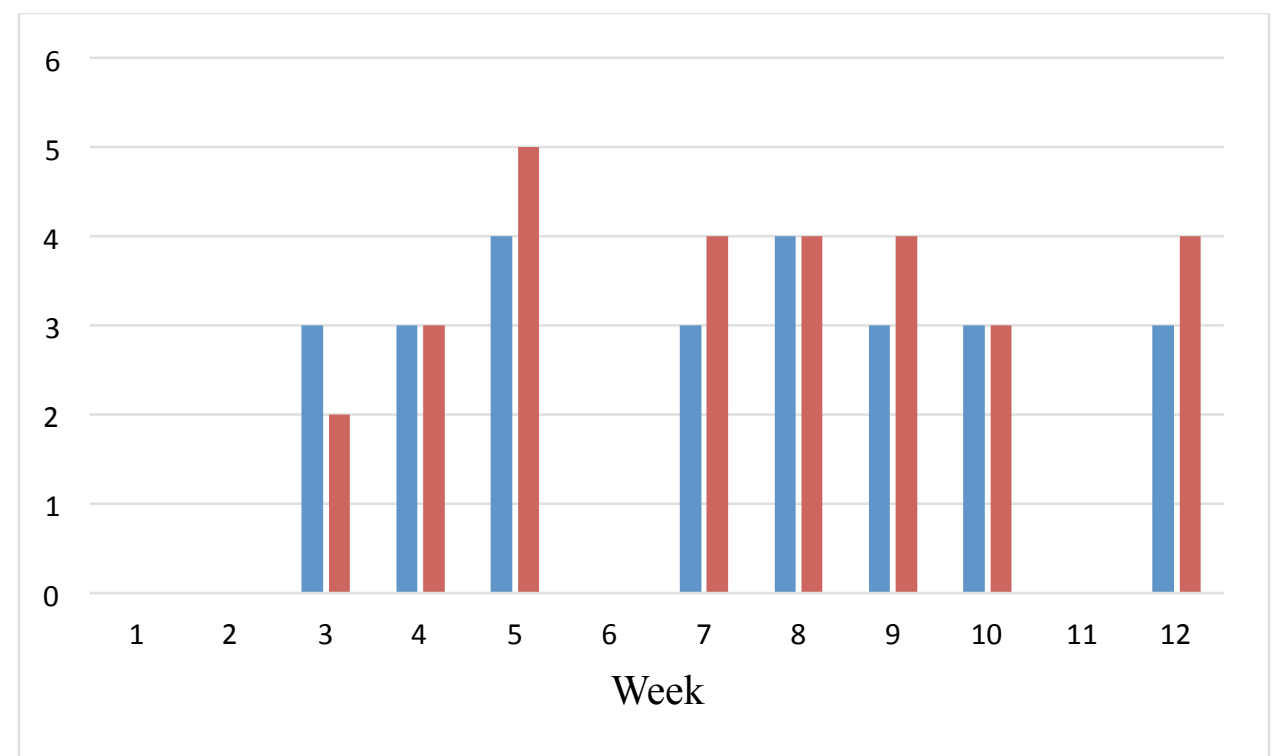

Figure 14. Bri-Verbal "Yes" scores (Raters 1 \& 2). 
Bri's change score was 17. Her last session, which occurred during week 12, was rated 17 points higher (essentially 17 more "yeses" were recorded) than her first session, which occurred during week three of the pilot.

Therapeutic impressions. Bri's presentation throughout AAT mirrored her presentation in the classroom. She was reserved, non-expressive, very mild tempered and extremely quiet. Her tearfulness, first expressed during week seven, should be considered a marker of growth or increase in communication, as she was typically not able to express any emotion, including fear or sadness. Often, crying is not considered a sign of progress, but for this client who was repeatedly reported to be "shut down," her expression of feeling is noteworthy. Bri appeared to be a highly insecure child with no ability to initiate new behaviors or activities.

Week 12 was when the most substantial shift happened for Bri. She showed initiative, drive, confidence and an ability to stay engaged with the dog throughout the session. She also remembered the rhythm of previous sessions, which indicates cognitive capacity. It was as if she finally trusted the environment (the dog, the therapist and the structure of AAT) enough to explore; this is significant given the concerns presented in the referral documentation and her general functioning in the program. Shifts in her functioning during AAT, though perhaps small, were not visible even after two years in the general classroom. The quantitative component of the case notes and the AATEI look for strong indicators and fail to capture the subtler changes that occur in children over the course of the treatment. Also, quantitative data is much narrower in its scope, therefore 
the quantitative markers for this client do not reflect the growth and change captured in the way that the qualitative case notes are able to do.

3. Guy. Guy was a 36-month-old Caucasian male referred to AAT after his case manager heard from his mother that he was "rough" with a pet guinea pig. Guy seemed not to understand how to relate to others, including animals, and often demonstrated poor social interactions. He did not know how to initiate play with peers and would attempt to "make friends" by "grabbing, pinching, or pulling" on other children. When redirected, Guy would escalate his behaviors and push or kick adults. He was easily frustrated and often "pretended to be a truck" during periods of stress. Guy was wary around new adults and shied away from one-on-one attention. He would become easily frustrated with simple tasks but failed to ask for help or support.

Guy lived with both of his parents. His mother worked in a school cafeteria and his father was not employed. Guy had two older brothers, both school-aged, and often got "beat up" by them. The family qualified for TCP due to living below the poverty level but they were self-referred (the only self-referred family in the treatment group). They had concerns that their son wasn't developing in the same way as their other children. Per his father, he was also the "least cute of my kids." Guy resisted physical affection and would become stiff if his parents insisted on a hug or kiss. He often avoided eye contact as well. Program staff wondered if Guy might be on the Autism spectrum but no formal assessment had ever been completed. 
Compared to similarly-aged peers, Guy's case manager rated him as below average in social functioning and emotional stability; and average in appropriate behavior and language ability.

There were no pets in the home at the time of the pilot. The family had to "get rid of" the guinea pig due to fear that Guy would hurt it.

Course of treatment. Guy received consistently high quantitative scores throughout AAT with very little variability from week to week, except in the communication domain/category, where his scores fluctuated. One of the main areas of concern for Guy was regarding his tendency toward rough physical interaction, but from the very first session, these behaviors were never observed. He was appropriate around the dog and even showed effort to not harm the dog; for example, during his first AAT session, Guy played with tractors next to the dog. As he was rolling a tractor and making loud noises, he intentionally steered his tractor around the nose and paw of the dog, who was lying right next to him. Guy did not want to leave after his first session but was able to transition out of the room with support from his therapist.

By week four (which was Guy's third therapy session), he showed noticeable improvement in his communication skills. He was talking and using multi-word sentences. He was very intentional in his interactions with the dog-he would show him toys and play ball for extended periods, showing focus and attention. When reminded how to gently show off his toys or throw the ball in the correct direction, Guy was able to follow through and respect limits. When the therapist attempted to introduce a new activity involving art, Guy resisted and asked to continue with the game of fetch. This 
became a pattern for all future sessions. He was soothed by the back-and-forth nature of catch and took turns without issue.

Some weeks (such as week seven) were highly verbal; he would explain his behavior to the dog ("I'm rolling this truck," and "I'm going to throw ball for you") and then stay engaged in a single task; then the following session, which was two weeks later due to an absence during week eight, he would not speak. His engagement skills continued to be strong and his focus on tasks were appropriate. Guy enjoyed all of the approaches his therapist attempted, from playing ball, to identifying the dog's body parts and feelings, to drawing pictures of the dog, to taking walks. As sessions progressed, Guy seemed able to read the dog's cues and adjust his behavior accordingly_ during week 11, he said "he doesn't want to play with that" and found a new toy for the dog. Guy was clearly able to articulate the dog's feelings and link to causation-during week 12, he said "the dog is crying and a walk will make him happy." These statements indicated a sophisticated level of emotional awareness and ability to empathize.

Guy's last four weeks in AAT (weeks 12-15) included him initiating reading to the dog. This was unguided and directed solely by him. He would find books featuring dogs and make up stories based on the pictures. With the dog lying next to him, he would carefully explain the illustrations. After a period of this type of interaction, Guy would shift into more physical activities, such as ball throwing and walking. When outside of the room on walks, Guy tended to become quiet and far less verbal; back in the room, he became highly articulate. 


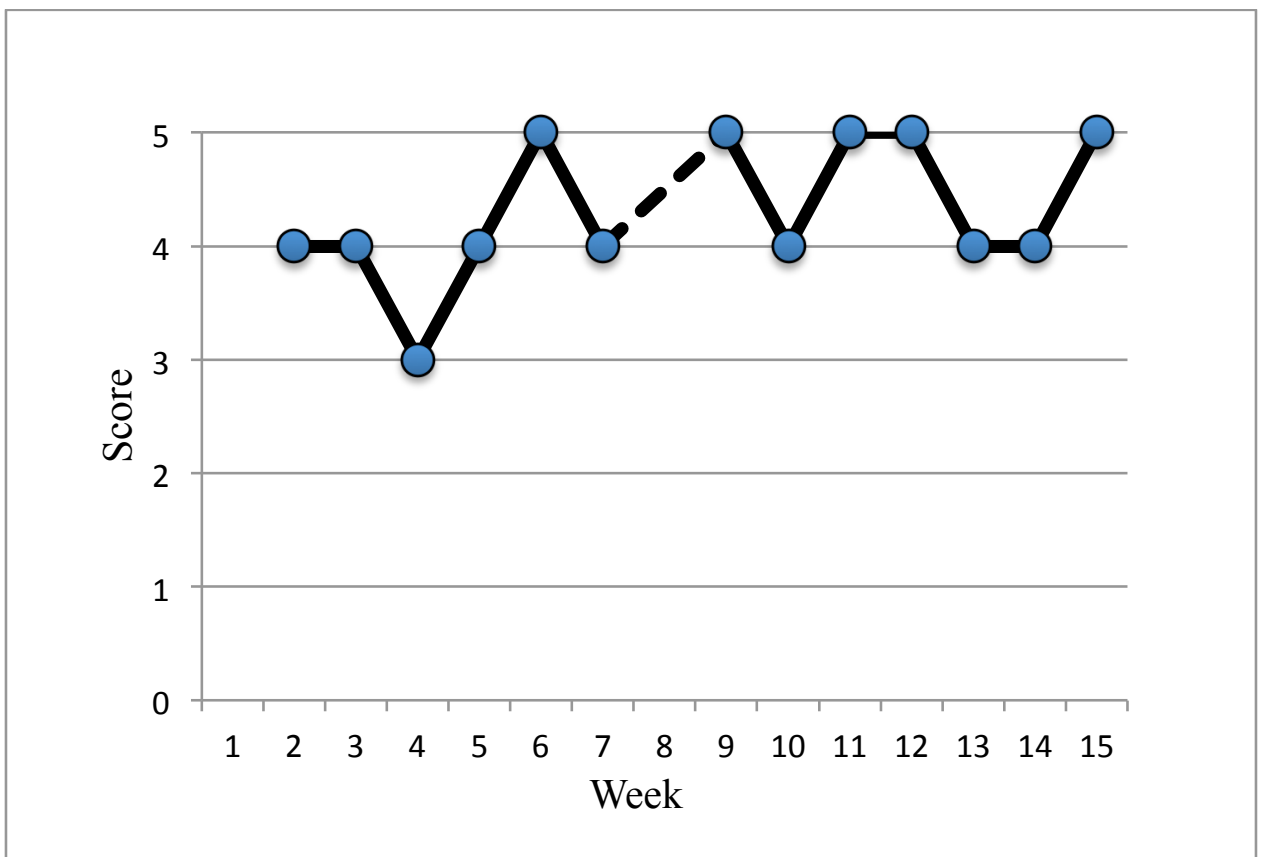

Figure 15. Guy-Attention.

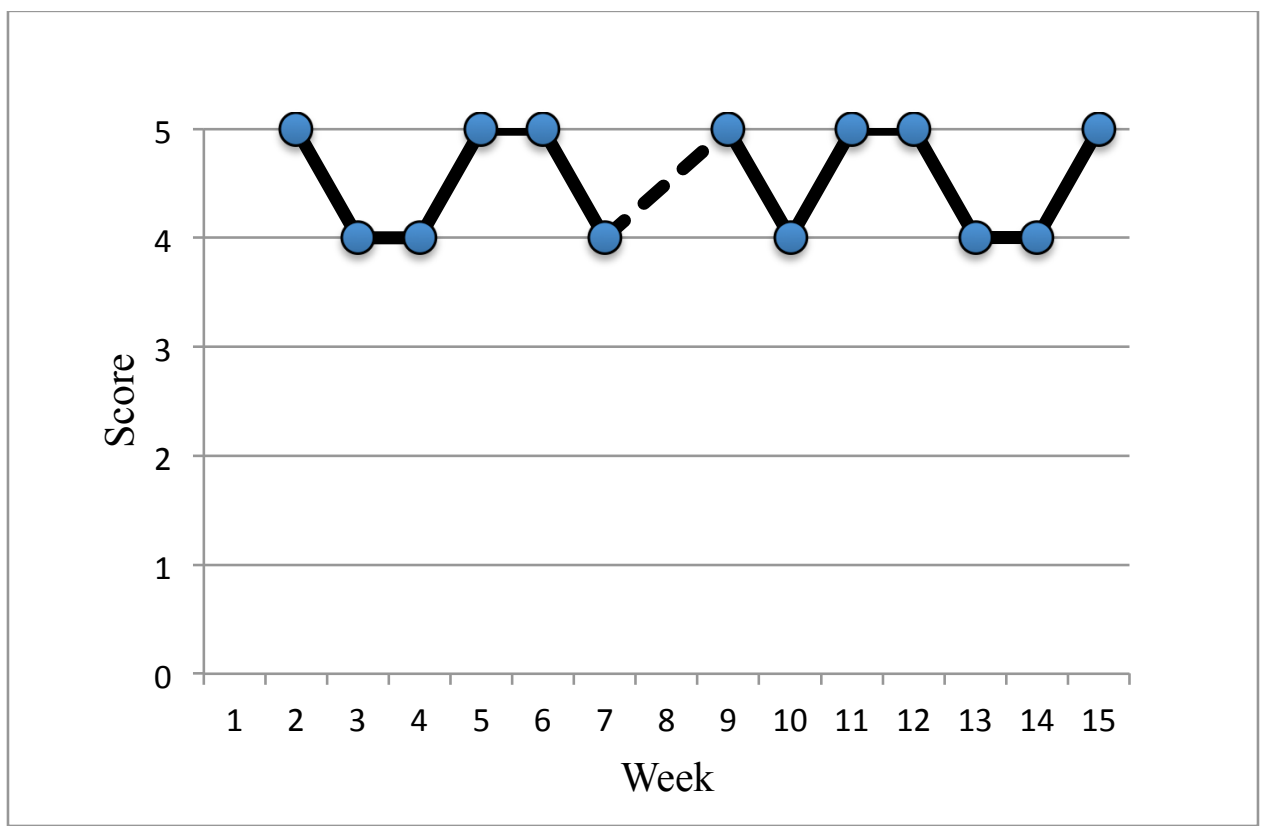

Figure 16. Guy_Engagement. 


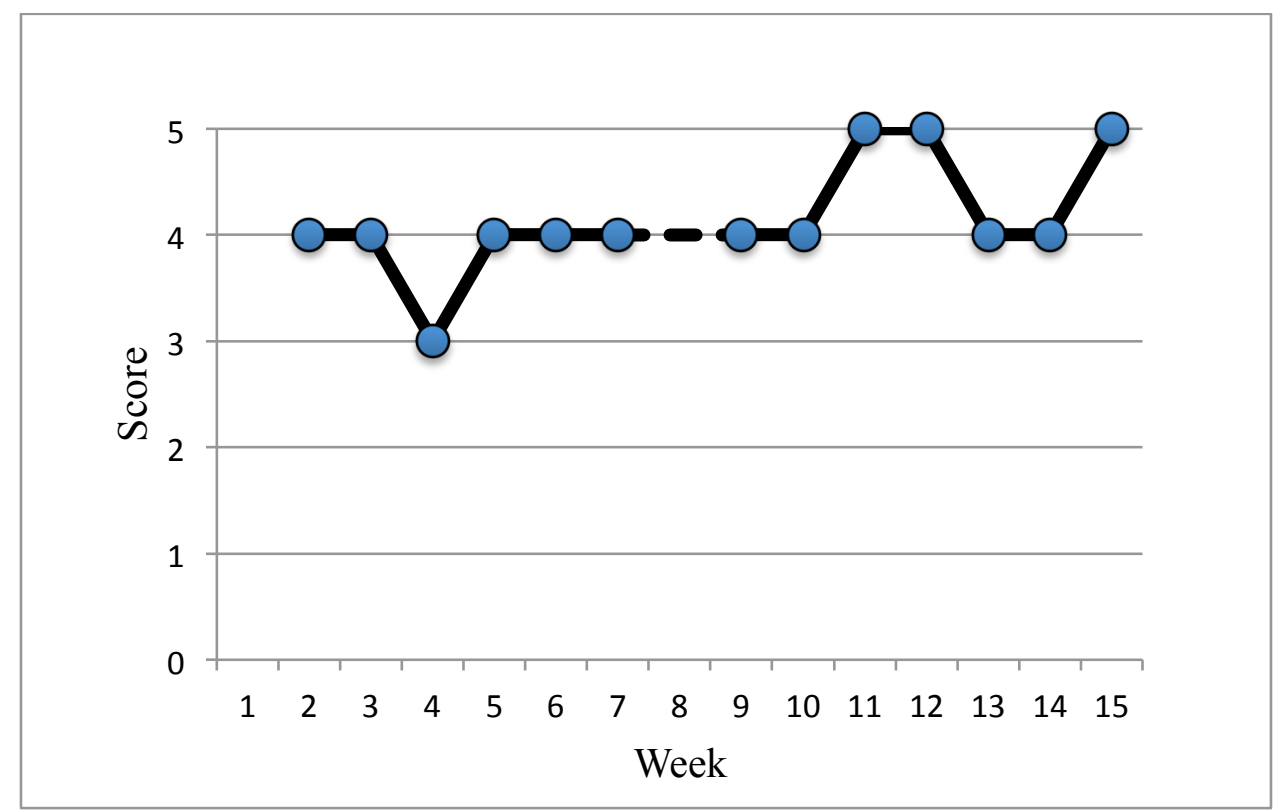

Figure 17. Guy-Age-appropriate behavior.

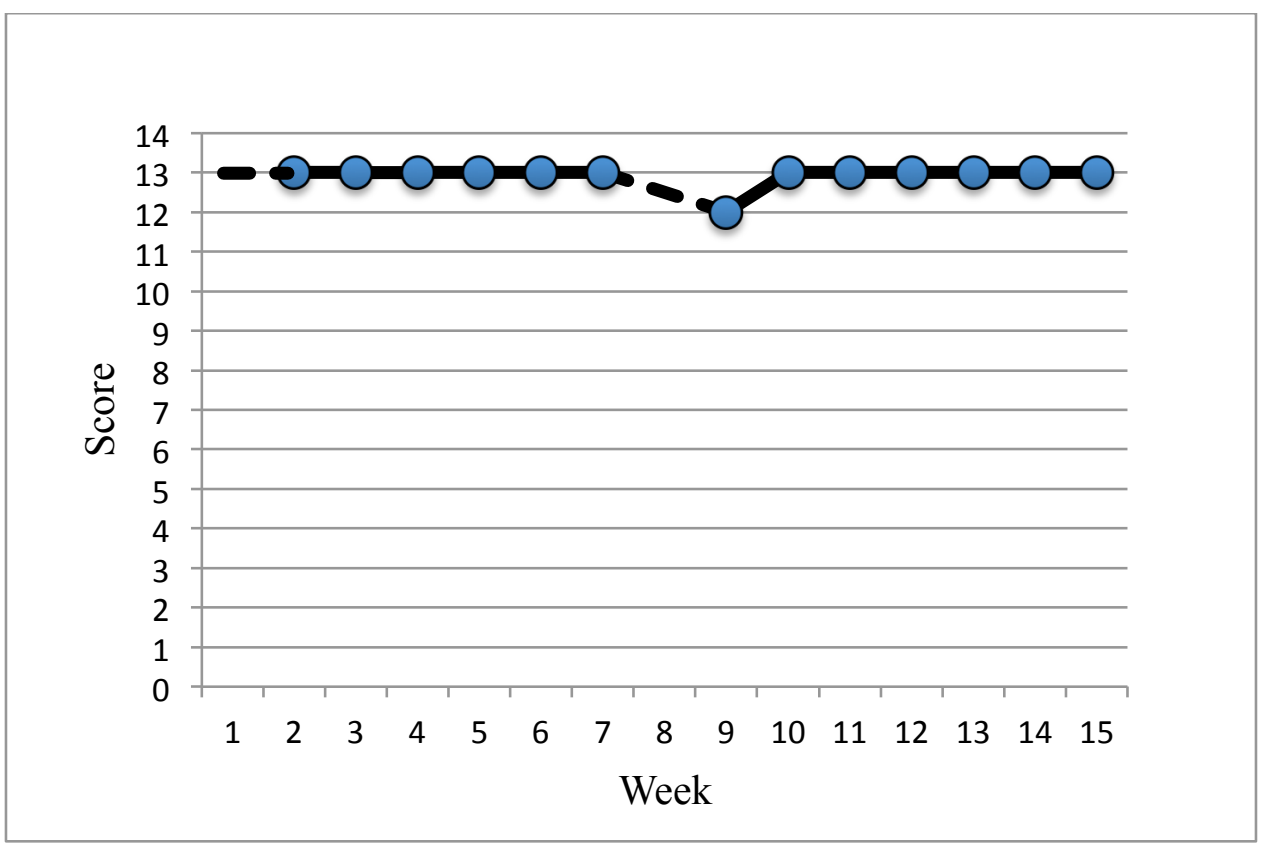

Figure 18. Guy-Social-emotional indicators. 


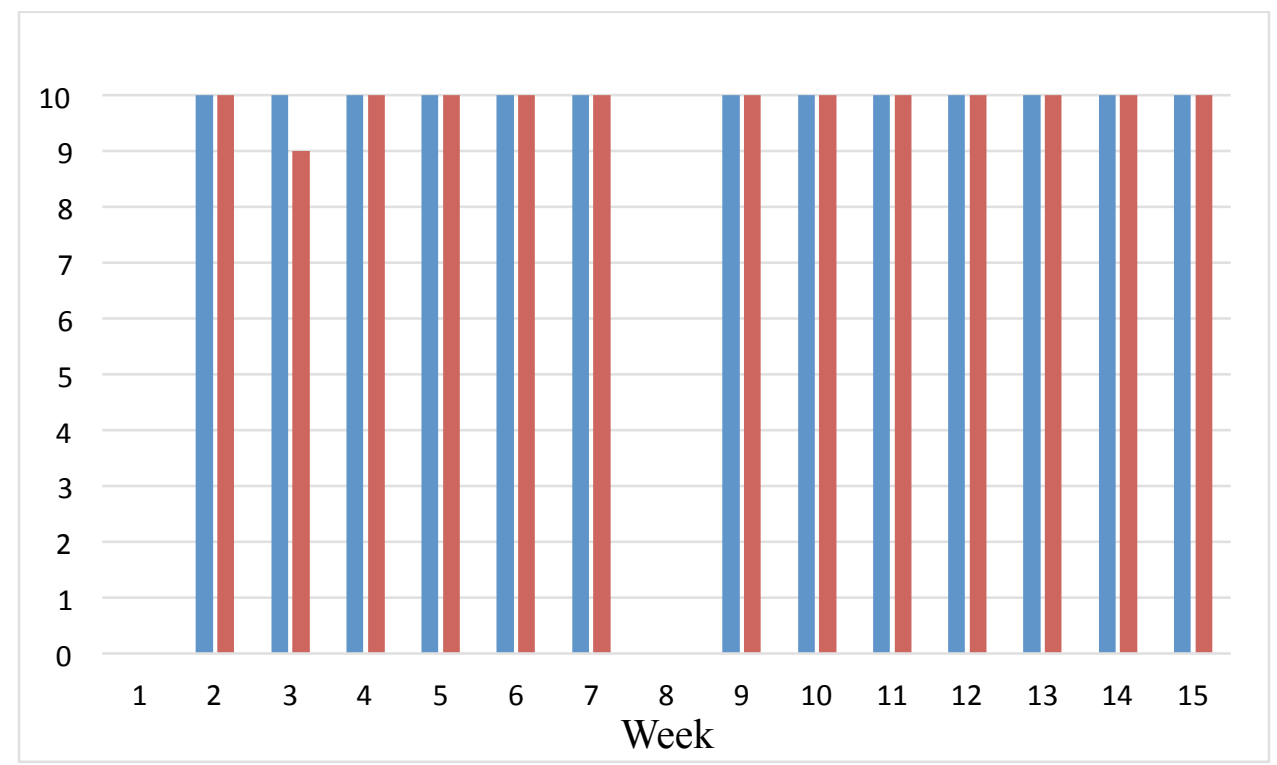

Figure 19. Guy-Cognitive "Yes" scores (Raters 1 \& 2).

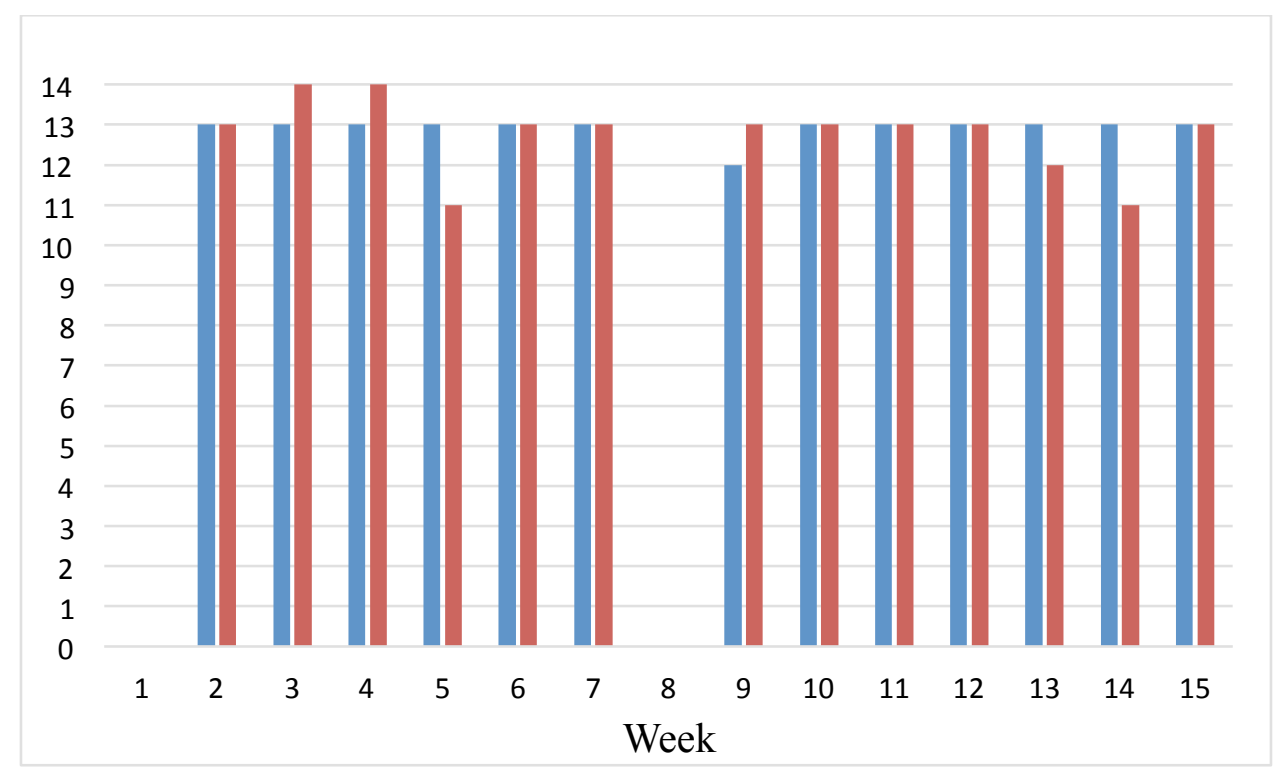

Figure 20. Guy—Social-emotional "Yes" scores (Raters 1 \& 2). 


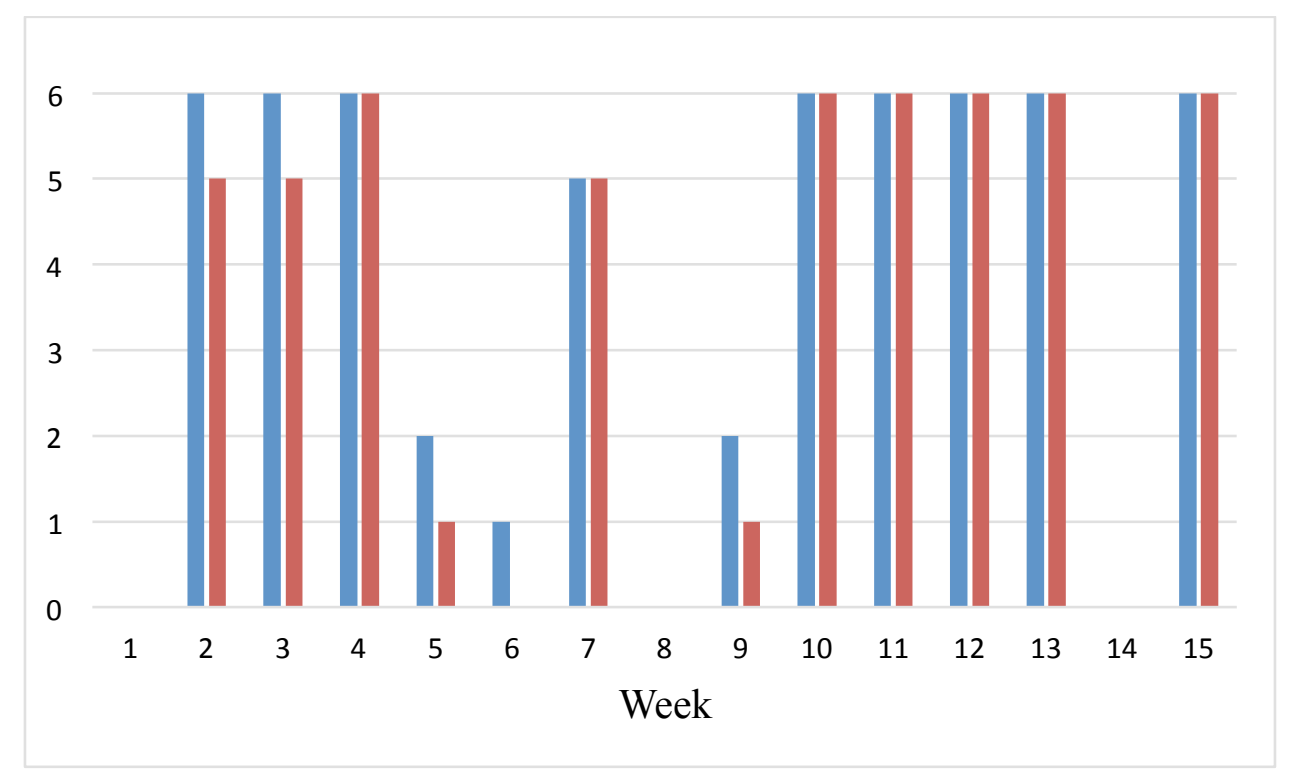

Figure 21. Guy_Verbal "Yes" scores (Raters 1 \& 2).

Guy4's change score was zero. His positive indicators were consistently high throughout the course of treatment.

Therapeutic impressions. Interestingly, none of the behaviors indicated on the referral forms were obvious during AAT. This child never became rough or aggressive with the dog; in fact, quite the opposite. He showed high levels of behavioral control around the dog and demonstrated empathy for how the dog might be feeling. He was receptive to feedback from his therapist about how to handle or approach the dog, and seemed to remember those lessons from week to week. Guy transitioned easily into and out of the therapy sessions, often expressing a desire to stay longer. He was not overtly physically affectionate toward the dog but showed great joy during their interactions.

Guy responded positively to the attention of his therapist and seemed, in a sense, to pass that along to the dog. He liked to "teach" the dog new things and read to him. His 
ability to clearly articulate and express feelings, both his own and the dog's, was unanticipated. His variable verbal presentation is something that could be explored in more depth, as clearly he had the skills necessary to communicate but chose not to in certain sessions (or during parts of sessions that occurred outside of the therapist's office). This particular child seemed to relish his time in AAT and benefit from the oneto-one attention he received (as well as the one-to-one attention he offered to the dog).

Based upon the data collected on this client, it would appear that Guy would benefit from an increase in personalized attention and the opportunity to engage in relationships where he is the central focus. Therapy dogs are easily able to provide the undivided attention and positive regard for clients that they may not receive outside of the therapeutic setting. This type of unadulterated relationship is central to the tenets of AAT and one of the central reasons why it has been shown effective with vulnerable populations.

4. JJ. JJ was 26 months old at the time of referral, identified as an African American male living with his mother after being reunified with her (following approximately four months in foster care when his mother was homeless). JJ had a history of delayed motor skills and wore leg braces for about six months when he was younger to correct a condition with his feet.

JJ had continued involvement with Child Protective Services; though he was living with his mother, a caseworker was still supervising his living situation to ensure safety. His mother was reported to have possible developmental delays and difficulty understanding his needs. There were no other adults or children living in the home. JJ and 
his mother lived in a studio apartment subsidized by a local non-profit organization. About once a week, JJ's mother would fail to pick him up and the program staff would have to drive him home.

JJ demonstrated a great deal of anxiety upon separating from his mother. He would protest loudly whenever she dropped him off at the program and had trouble calming down. Staff at TCP found that giving him one-on-one attention helped him to stay calm. He showed very little interest in toys, games or activities; instead, he wanted to be held or read to.

Compared to similarly-aged children, JJ was reported by his teacher to have average social functioning, appropriate behavior and language skills; he was ranked as below average in emotional stability.

JJ had no pets in his home.

Course of treatment. JJ appeared immediately comfortable with the dog and had no apprehension approaching or petting him. He was distracted by other objects and toys in the room - this became an obvious theme in case notes from the first session onward. JJ would approach the dog, interact for a short period of time, and then shift his attention elsewhere. Case notes indicate that the dog was "in the background [and] never the complete focus" during sessions. He was challenged by any activities that encouraged focus and generally had trouble following directions. Rather than focus on directiongiving, the therapist shifted to center sessions on healthy boundaries (of the dog) and empathy building through feeling recognition. Since he did not present with fear or hesitation around the dog, that relationship appeared very comfortable for JJ from the 
start. By week three, it became clear that this child had difficulty controlling his gross motor movements (especially when excited), and he would trip over, fall on, or attempt to lie on top of the dog. This presented a perfect opportunity to talk about healthy boundaries and feelings. It also helped $\mathrm{JJ}$ to focus on his coordination and make efforts not to hurt the dog (by accident).

During week five, JJ was presented with feelings cards and he was able to point to cards indicating how he felt (happy and excited) and how the dog felt (happy). JJ also pointed to body parts on the dog and then to similar body parts on himself. During this session, he began to communicate more verbally, per qualitative case notes, and it was discovered that he was best able to focus and control his movements when on a walk with the dog. He preferred walking the dog to petting or brushing.

Week six indicated some regression, as JJ did not want to pet or walk the dog and generally appeared distracted and unable to respond to communication efforts. He needed a lot of redirection and reminders about boundaries — case notes state that he was "relaxed and happy" but also had little interest in the dog and was very distractible.

Week seven and eight indicate a bit more focus on interactions with the dog-fine motor activities like petting and brushing were met with minimal interest or focus; but gross motor activities like walking and throwing the ball helped to improve his focus. He showed less distraction when engaged with gross motor activities. He seemed to "test" the dog by dropping the leash and throwing the ball at the dog but with some reminders about safety and boundaries, he reengaged more appropriately with the dog. JJ always maintained steady emotional regulation, despite lack of focus at times. 
By week nine, JJ seemed to have developed a rhythm to his AAT sessions. He would immediately greet the dog and ask to walk him. If the therapist attempted to first guide $\mathrm{JJ}$ into another activity, like identifying feelings or body parts, he would become distracted and lose focus. If allowed to do "what he wants to do" from the start of session, he would show engagement with less distraction. Given that JJ most enjoyed walking and throwing the ball, the therapist introduced the idea of tug-of-war with the dog, where the dog held one end of a rope and JJ held the other. It is noted that this activity is "not the best game" and caused some hyperarousal in the client. Given JJ's previous lack of coordination and distractibility, this activity was just too stimulating and he couldn't calm down afterward. He wanted to fall on top of the dog and had trouble recognizing the impact of those behaviors (that he could hurt himself or the dog).

By week 11, there were efforts being made in session to help JJ "slow down" and focus on simply watching the dog, noticing small movements, gentle petting and naming feelings - these were all things JJ was successful doing but only for short periods. When the dog arrived wearing a vest on week 14 (which he had never worn before), JJ took immediate notice. He spent time unbuckling the vest, taking it off, trying it on his own body and then putting it back on the dog. This initiation of a fine motor activity was surprising and unexpected. His clear recognition that something was different on the dog seemed to prompt his self-directed exploration. Because he was so comfortable with the dog and in the treatment setting, he was able to initiate and guide his own play for the longest stretch of time thus far in AAT. JJ also showed affection to the dog (hugging and 
kissing without any prompting) during this session, which continued into the last two remaining weeks.

Documentation for week 15 includes language like "perfect," "great job," and "very affectionate" while there is no mention of distracted behaviors or not respecting the dog's boundaries. It appears that his consistent attendance and familiarity with the dog over time allowed this client to develop a bit more emotional regulation and focus. His affection toward the dog also increased over time. During his last session, which was also his "best," JJ did the two things he most enjoyed: walking and throwing the ball, while he also drew some pictures of himself with the dog. He wanted to write on the picture he drew and asked the therapist to include the dog's name. He resisted leaving and wanted to continue to engage with the dog. The therapist took a polaroid photo of JJ with the dog and gave it to him. This helped to ease the transition and say goodbye. He showed a great deal of affection toward the dog and finally left the room.

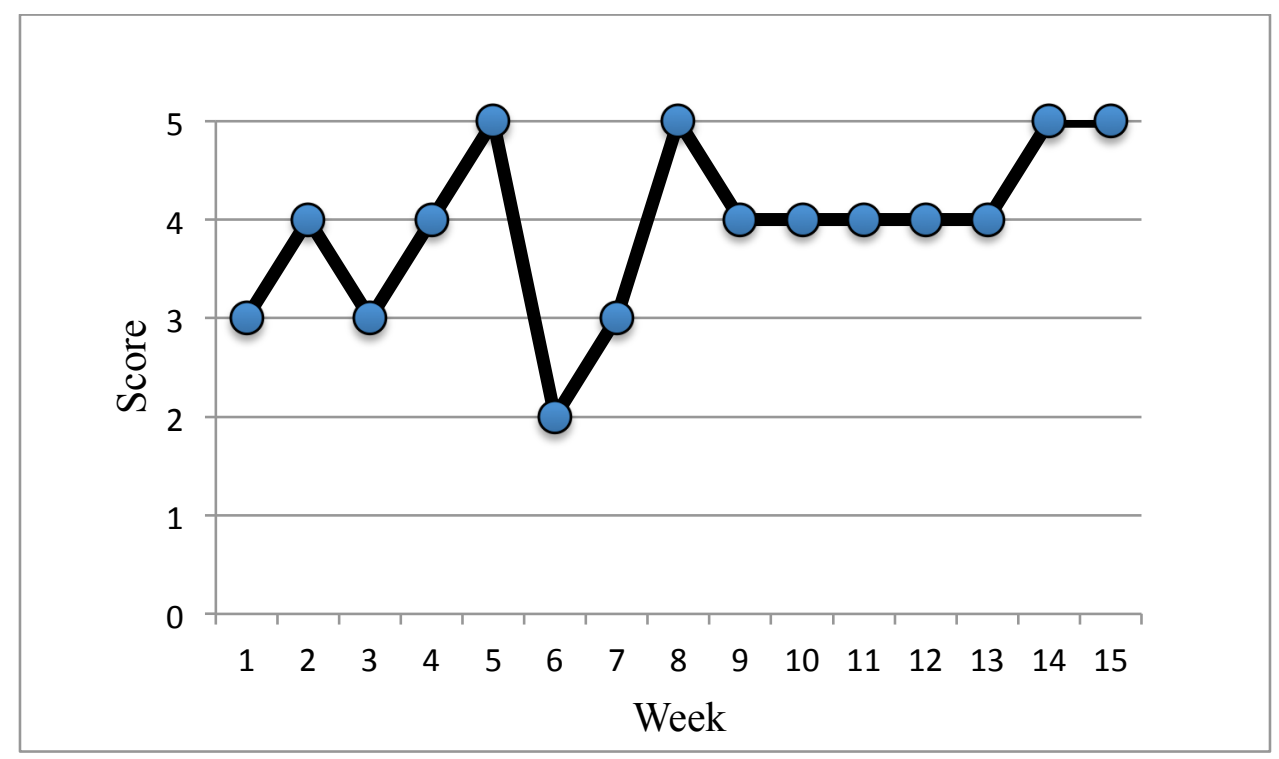

Figure 22. JJ-Attention. 


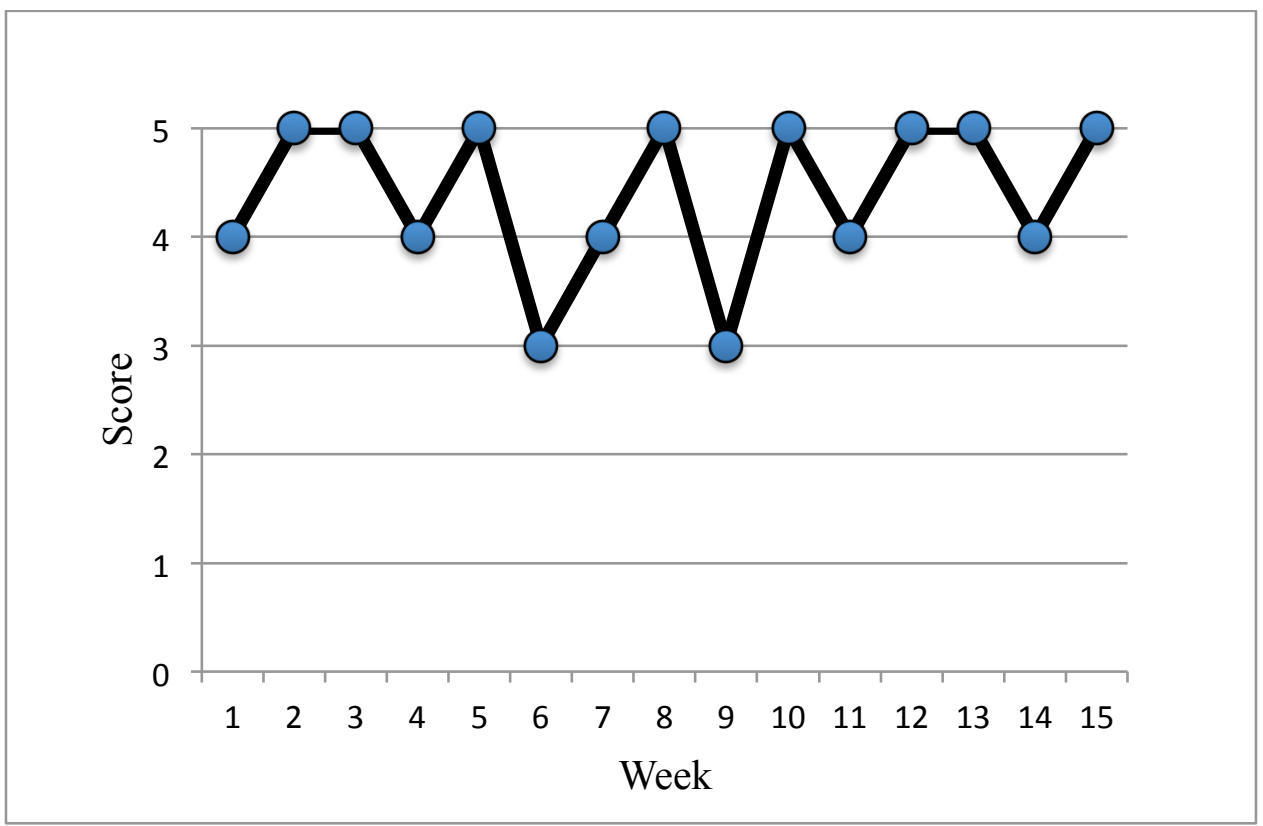

Figure 23. JJ_Engagement.

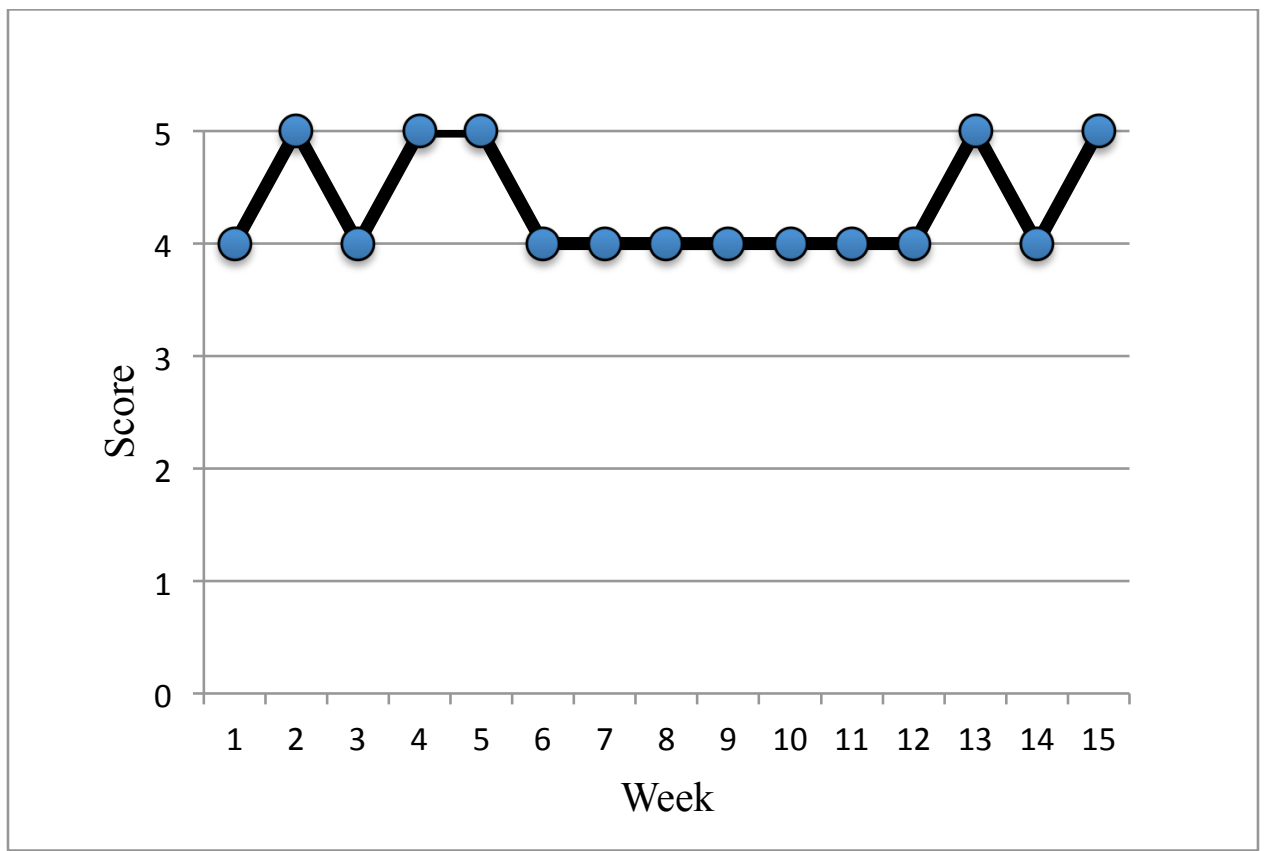

Figure 24. JJ-Emotional regulation. 


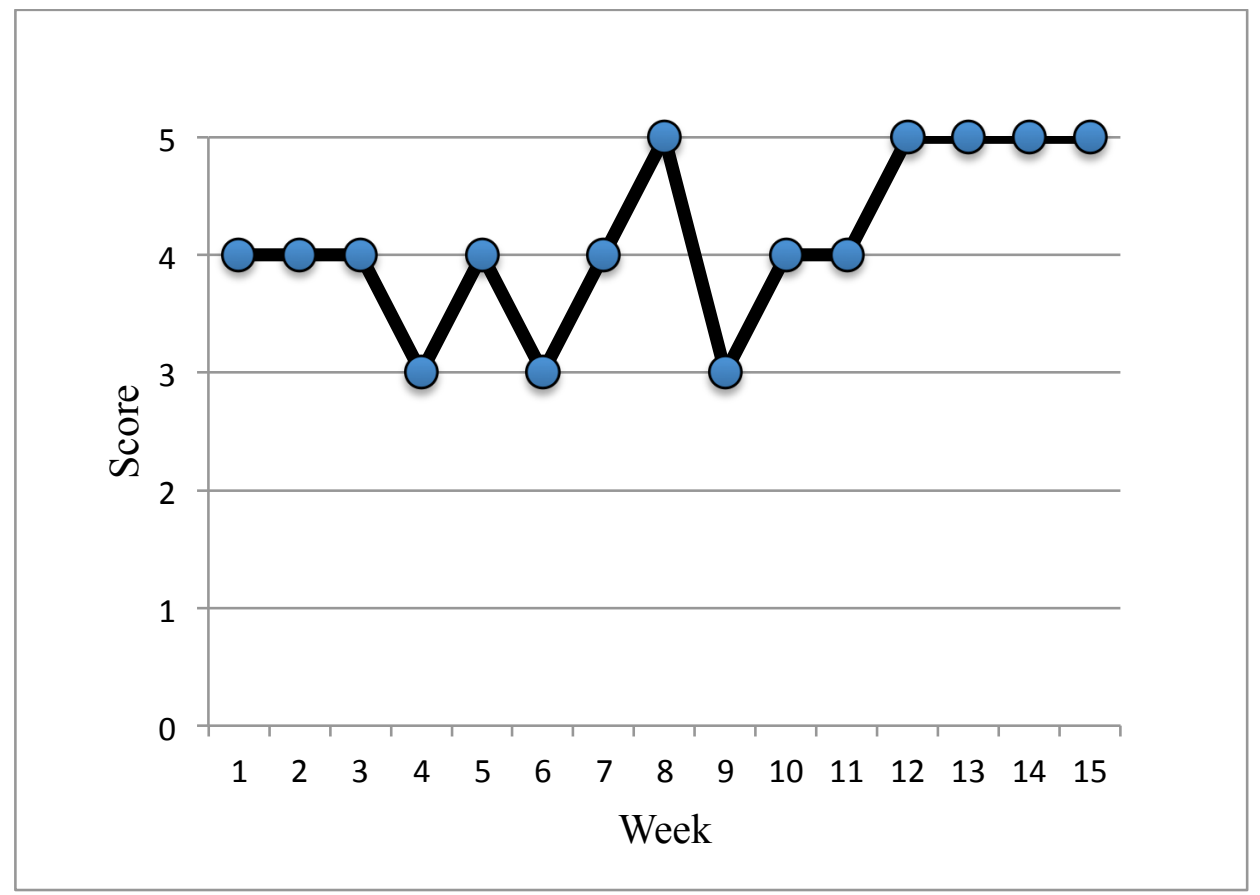

Figure 25. JJ-Age-appropriate behavior.

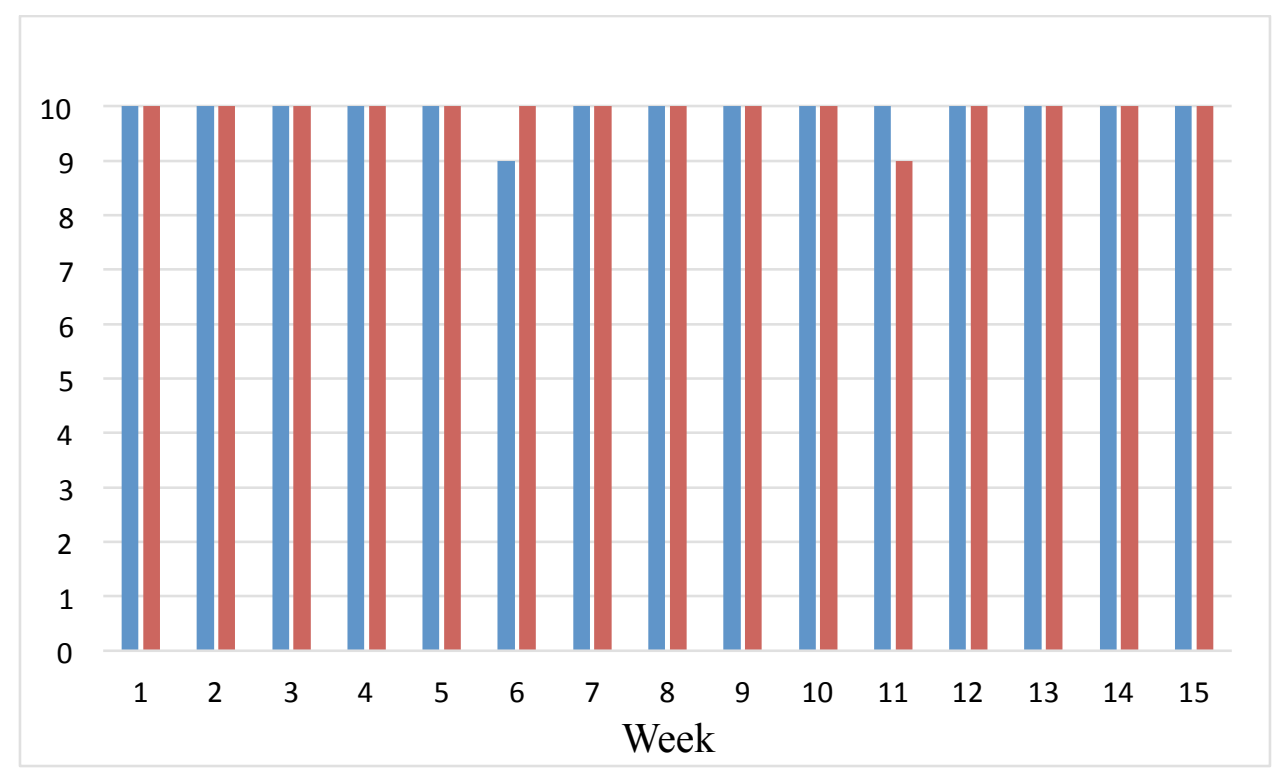

Figure 26. JJ—Cognitive "Yes" scores (Raters 1 \& 2). 


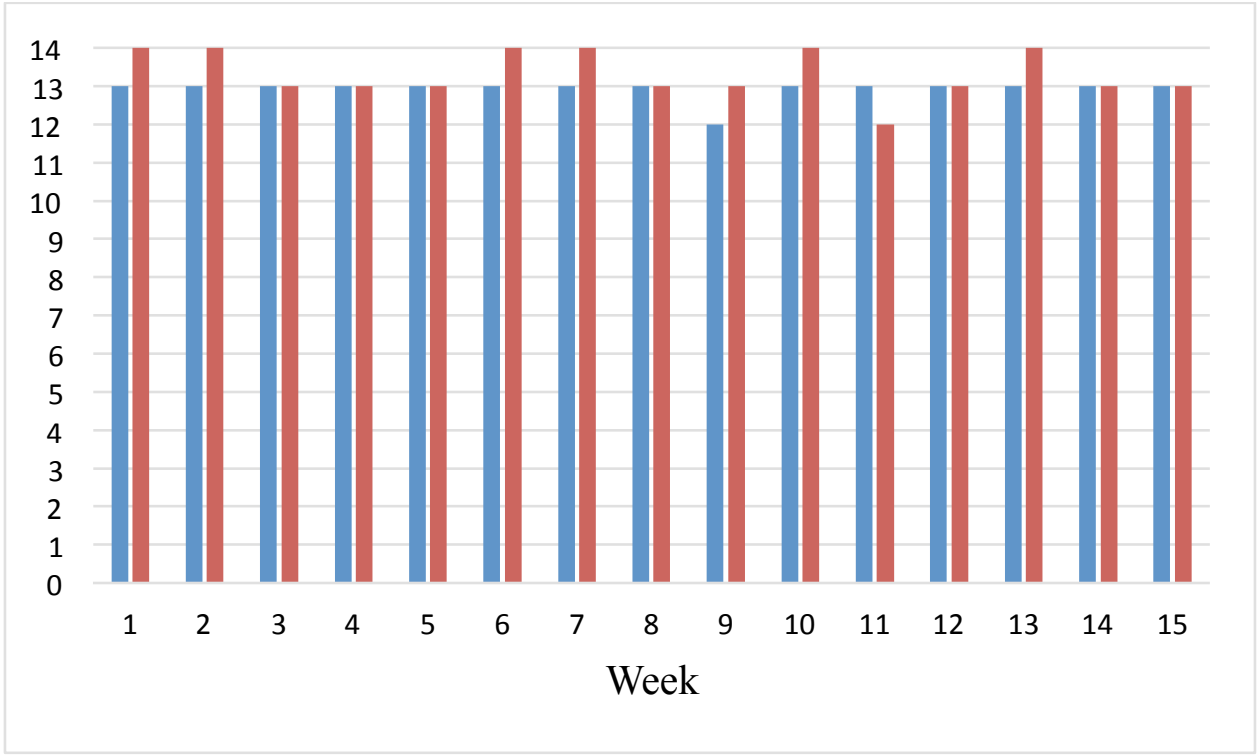

Figure 27. JJ-Social-emotional "Yes" scores (Raters 1 \& 2).

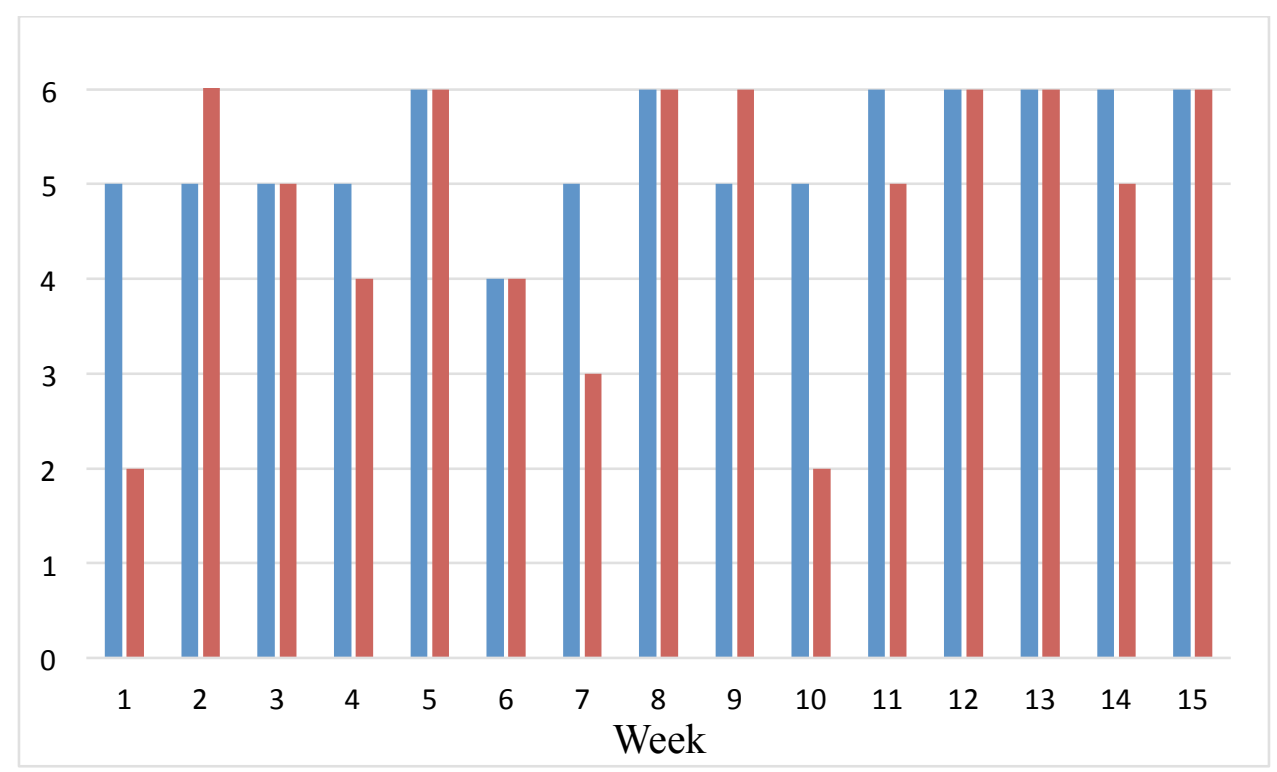

Figure 28. JJ-Verbal "Yes" scores (Raters 1 \& 2).

JJ's change score was four. Similar to Guy, his scores were consistently high throughout the course of AAT. 
Therapeutic impressions. This client's presentation from the start of AAT was unexpected. He was bold, comfortable, did not appear outwardly anxious (though distractibility and lack of focus may have been indicators) and was warm and affectionate. The concerns the program staff had for this client based on his classroom behavior and trauma history were not obvious in the treatment setting. The separation anxiety he had with his mother was not recreated in AAT; his attempts to delay the endings of session were age-appropriate and responsive to very typical approaches for children his age (using a transitional object, for example).

AAT for JJ, and perhaps for children with similar needs, appeared very effective. His gross motor skills improved and given his history, this should be considered therapeutic. In addition to improved motor control, this client's major growth area was in the area of emotional recognition and expression. He also consistently maintained composure during session, which was not typical for this child in other settings.

5. Jav. Jav was a 39-month-old male identified as being of "mixed" racial descent. He was referred to the Animal Assisted Therapy program by his classroom teacher and the agency case manager because they each had concerns about his emotional stability, ability to socialize with peers, poor relationship skills, difficulty trusting adults, and delayed communication skills.

This child had been in the community program for over one year at the time of referral. He was originally enrolled to TCP by a specialist from an early intervention team (outside of TCP), as he was still not using words or identifiable communication at 24 months of age. He was living in a low-income community with an unemployed single 
mother (age 20 at the time of this study), had no siblings, and had a history of involvement with Child Protective Services - he had been removed from his mother's care as an infant due to her homelessness and neglectful parenting. When he started TCP, Jav had been residing with his mother for past eight months and the case with Child Protective Services had since been closed.

Since he began attending the community program, Jav made little progress. His team reported that Jav's sporadic attendance at the program prevented him from benefiting from the services offered. His mother did not seem committed to bringing her child to the program except when she had other plans (she may have been using the services as a babysitting option rather than an ongoing source of support for her or her son).

His referral form noted that, compared to similarly-aged children, Jav was below average in: social functioning, emotional stability, appropriate behavior and language ability. Upon interviewing his case manager, she explained that Jav would isolate himself, fail to ask for help when needed, retreat from group activities, shy away from any new experiences and appeared withdrawn on most days.

This little boy had the appearance of a child who was not well cared for. He often wore the same clothes to the program, which appeared dirty and had a distinct odor. He had a lost look in his eyes and often appeared confused about what was going on around him, as if it took him a few extra seconds to process what was happening in the environment. Based on observation alone, it would appear as though Jav was cognitively delayed and/or had a sensory integration/processing delay. Unlike other children in the 
treatment group, this client was still experiencing various life instabilities that had yet to be resolved; in a sense, he appeared to have more acute stressors than other children, paired with less understanding of what he was experiencing at home.

Jav's mother had noted that he looked like his biological father, with whom she had a short-term abusive relationship; she resented Jav's appearance and called his face "lopsided." Indeed he did appear to have a droopy lip and chin, perhaps due to low muscle tone. He was small for his age and his clothes often slipped off his little body. It was not unusual for TCP to wash his clothes, send him home with extra food, and check in with his mother over the weekend. At the time of the AAT pilot, there was a great deal of concern about JJ and his mother; TCP was working closely with other community providers to put additional supports in place so that J would not have to return to foster care.

This child's exposure to pets was limited prior to AAT. He had never lived with any companion animals.

Course of treatment. Jav's first exposure to AAT was very difficult for him. He initially was introduced to the dog when his teacher brought him into the therapist's office. He appeared excited and eager to meet the dog; when she left, he began screaming and crying. He did not accept support from his therapist and the session ended early with him being carried back to his classroom. He could not calm down. Perhaps the novelty of the experience, paired with a new therapist and separation from his trusted teacher was too much to process. 
Jav missed his next session and when he returned (week three) he was again inconsolable. He stayed outside of the office and slapped his therapist when she tried to comfort him. Attempting to use a distraction, his therapist handed him a tennis ball to see if it might help him transition into the room and he screamed "give it to me!" when asked if he would to share with the dog. He refused to move and eventually started stomping his feet and flailing his arms. He was carried back to his classroom.

For his third and final session, Jav was again very emotional—crying, yelling, and eventually throwing his body on the ground. He could not express what he was feeling but it was obvious that he was highly aroused and distressed. Concerns about Jav were shared with his teachers and case manager. It was shared that Jav was fairly unpredictable and during times of stress, would use aggression and screaming. He seemed unable to regulate himself once overstimulated.

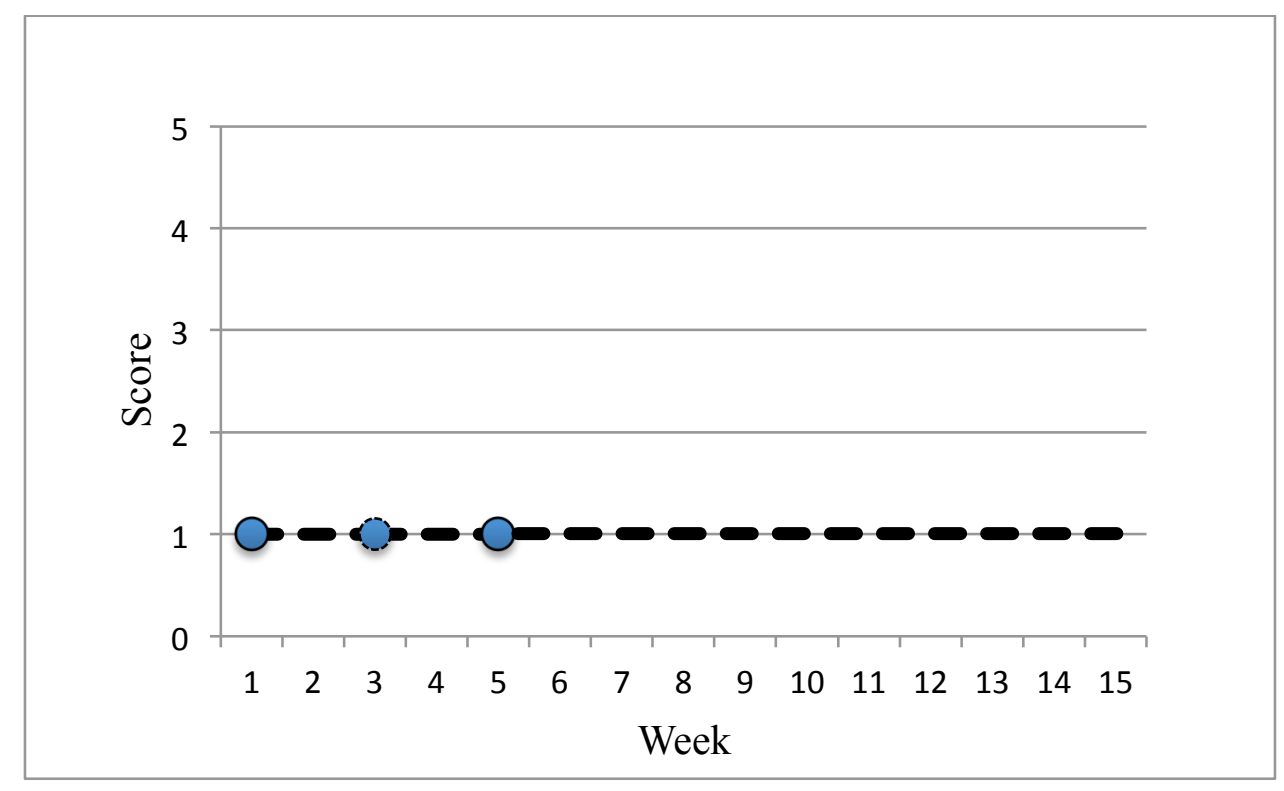

Figure 29. Jav-Attention. 


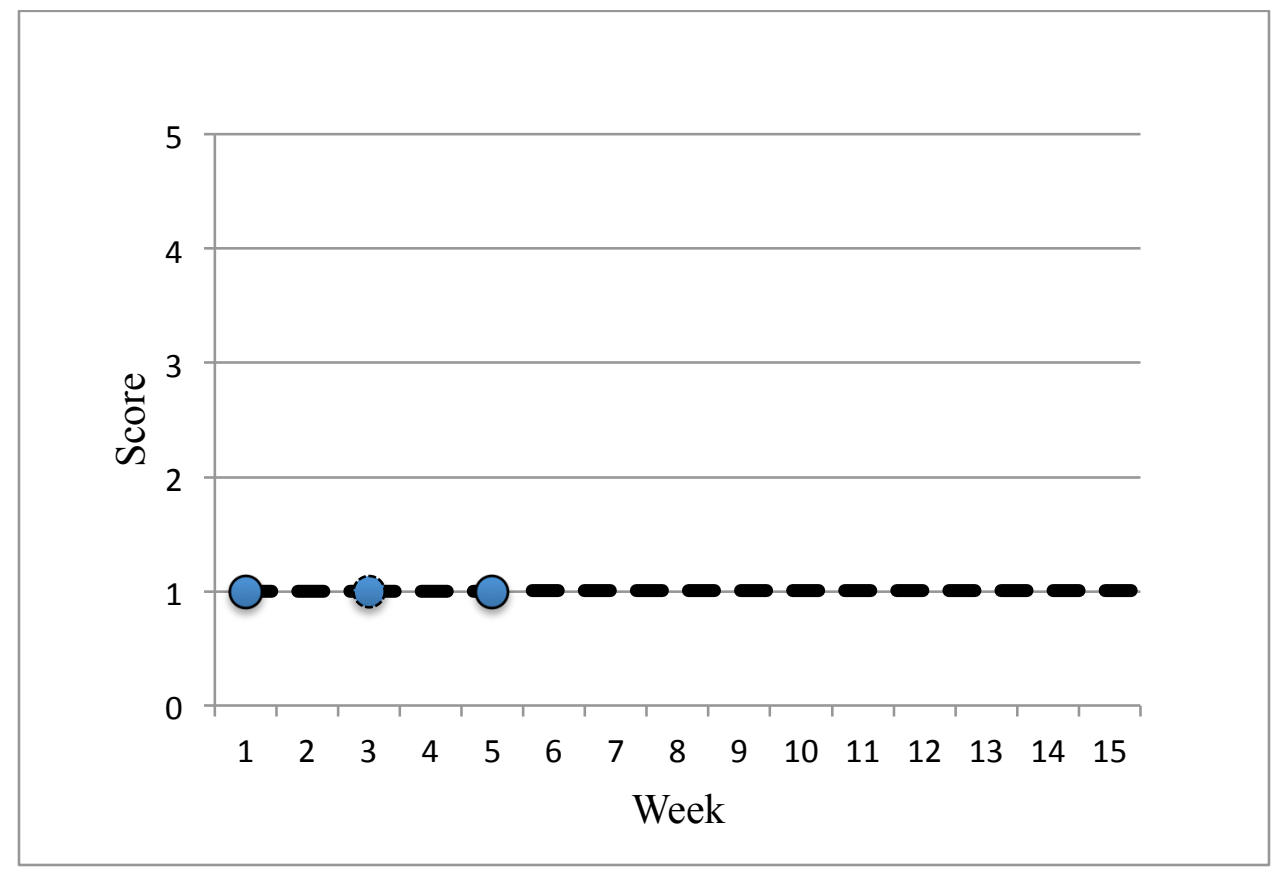

Figure 30. Jav-Engagement.

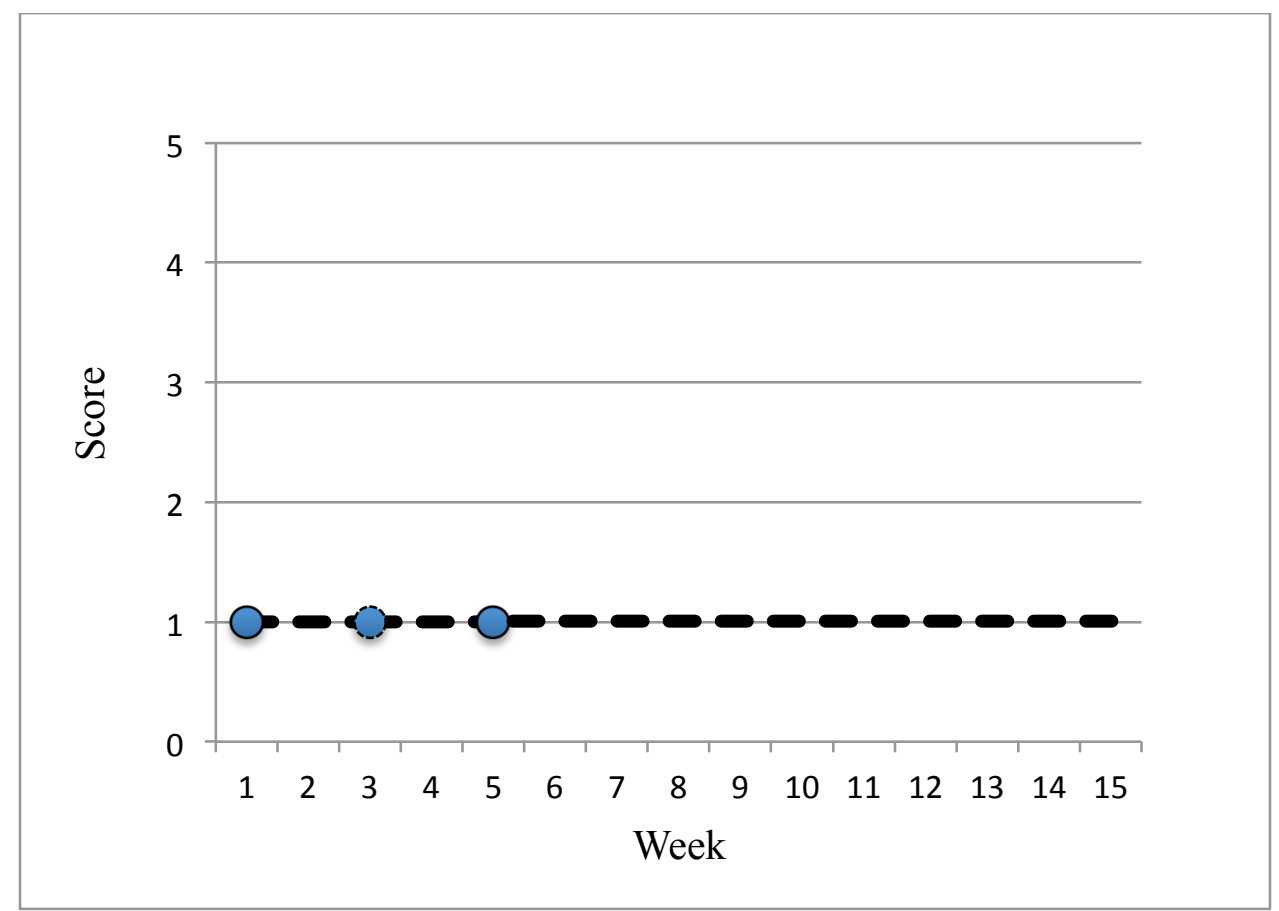

Figure 31. Jav-Emotional regulation. 


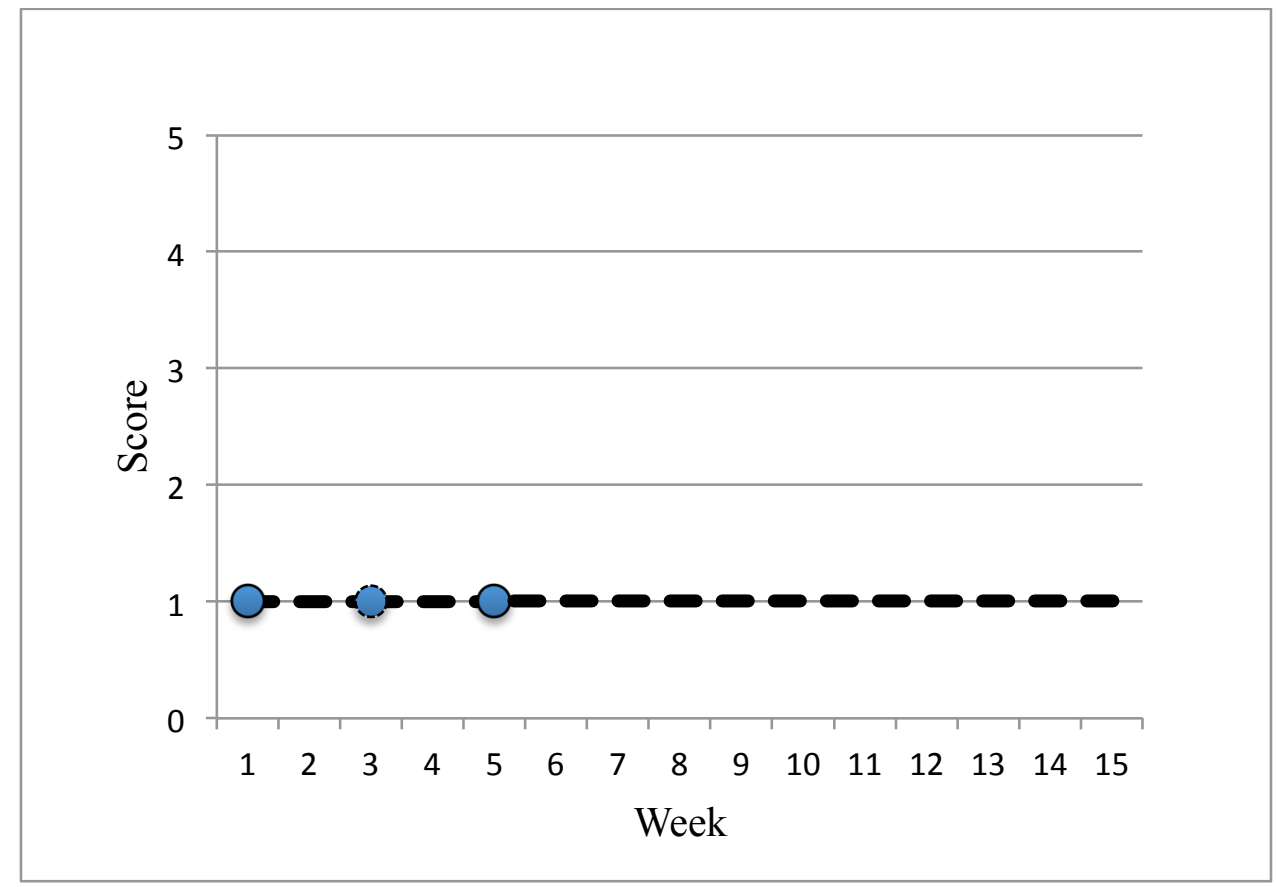

Figure 32. Jav-Age-appropriate behavior.

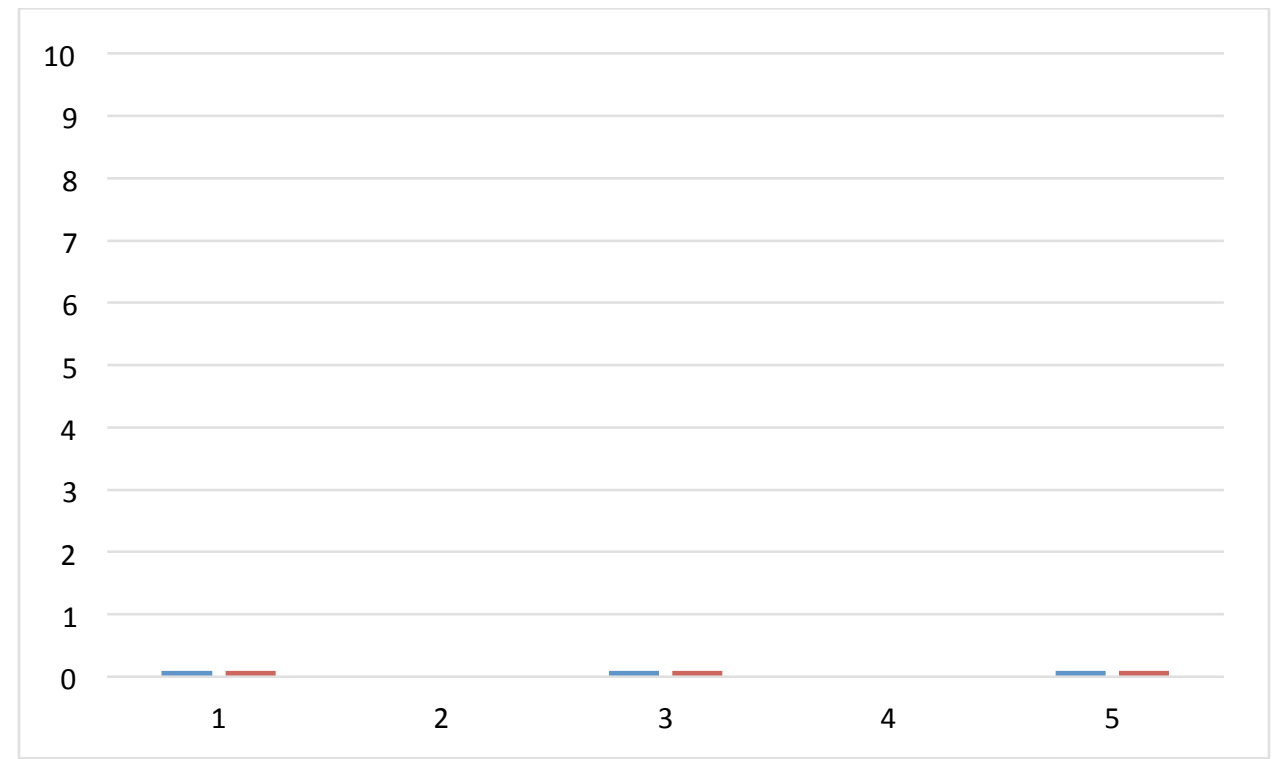

Figure 33. Jav-Cognitive "Yes" scores (Raters 1 \& 2). 


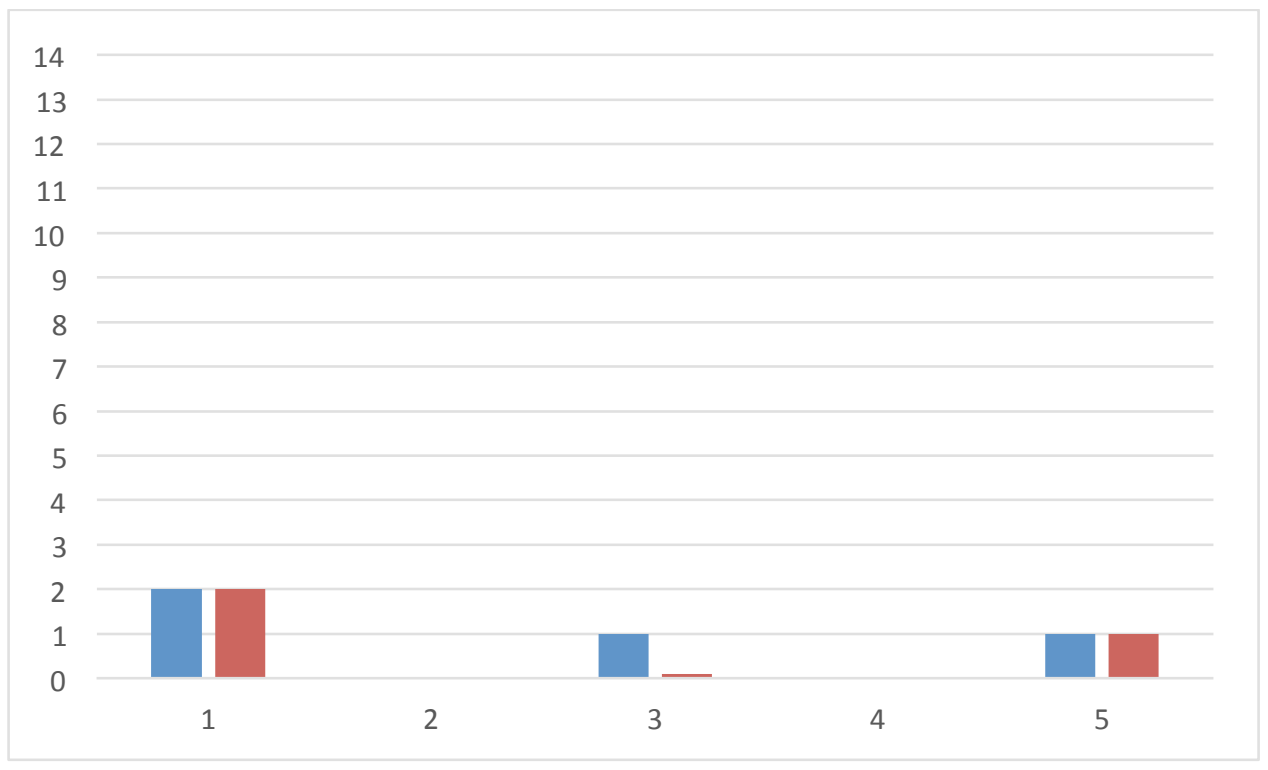

Figure 34. Jav-Social-emotional "Yes" scores (Raters 1 \& 2).

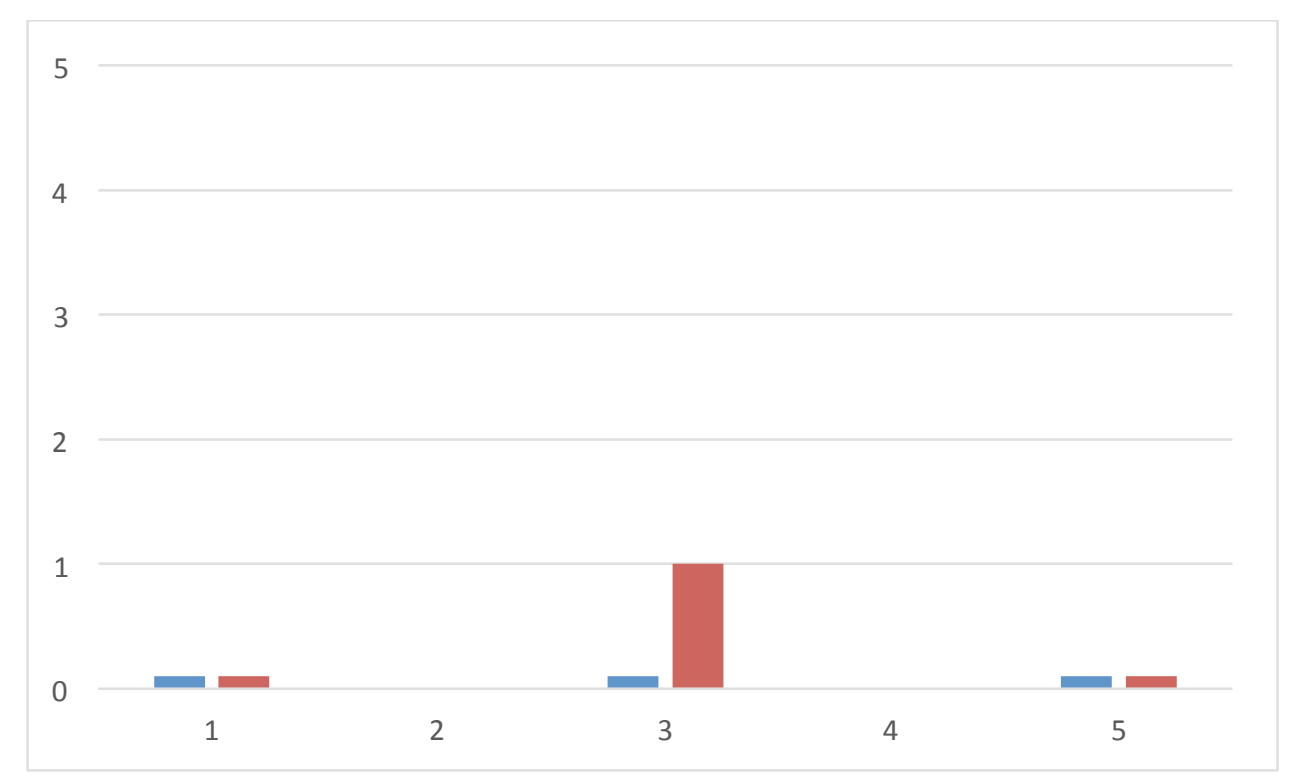

Figure 35. Jav_-Verbal "Yes" scores (Raters 1 \& 2).

Jav5's change score dropped two points between his first and last measurement.

He only attended three weeks of AAT, so these scores are rather unremarkable and seem 
to indicate virtually no change in observable, positive indicators during his brief involvement in AAT.

Therapeutic impressions. For a child like Jav, a slower introduction to a novel therapeutic environment would probably be beneficial. Perhaps building trust with his therapist in the classroom before transitioning into the office would have helped to decrease stress. Also, providing more physical space for this child could have allowed him the opportunity to "get away" from the dog and therapist while staying safe. It was clear that Jav was not feeling safe or supported by the environment, starting with his first session when his teacher left him. That departure experience alone may have set the tone for his remaining sessions.

This child participated in only three AAT sessions, the shortest attendance period of any of the children in the pilot. He stopped coming to TCP.

6. Kai. Kai, a Caucasian 15-month-old female, was referred to the program by her classroom teacher due to concerns that she was not meeting developmental milestones. Her teacher noted that her home lacked "environmental stimuli appropriate for her age" and that her caretaker (a foster mother) had multiple other young children in the home. Kai had lived in foster care since starting TCP four months ago. In her time at TCP, her team reported little progress or growth.

Little information was known about Kai's biological family. At the time of referral, she had no consistent contact with either biological parent. When asked, her foster parent reported that she couldn't share information about Kai's family because of a "federal investigation." The foster parent often seemed rushed during pick-up and drop- 
off times and then stated that if TCP couldn't provide transportation that she would no longer be attending the program. Ultimately, the program decided to provide the required transportation to keep the child in the program.

Though "easy" in the classroom, concerns about "what's really going on" with this child were noted on her referral form. Her teacher noted that he "felt sorry for her." She was rated as average in social functioning, appropriate behavior and language ability but below average in emotional stability. At times, she would sit quietly and cry, the reason unknown. She wouldn't reach out for help and did not typically ask for help or attention. New experience or stimuli cased Kai to retreat or appear withdrawn. Over time, she would "come around" and try new things but only when she was ready (support from adults did not seem to boost her confidence or comfort).

There were no pets in the foster home. Her history of pets in previous home/s is unknown.

Course of treatment. Kai missed the first week of AAT and officially began the pilot during week two. She experienced periods of crying followed by being comforted for her first four therapeutic sessions. She would also whimper and "shy away from dog" but be easily consoled and calm down quickly. This child did not use language or other communicators outside of crying to express her feelings or needs. She would vacillate between seeming unsure and afraid to steady eye contact and apparent interest in the therapy dog. Her first four weeks were marked not only by tearfulness but by focused attention on watching the dog closely; case notes indicate that she appeared "very interested." She would touch items belonging to the dog but resisted touching him 
directly. The therapist would encourage her to pet the dog briefly but only in week five did she agree to brush him. She touched the dog very briefly with her open hand.

This child required regular verbal reassurance in the therapy office. She sat in the therapist's lap during each session, with a decrease in crying and increase in verbalizations and interactions by week eight. She preferred hearing about the dog and looking at photos of him doing different things instead of touching or interacting directly. She regularly sought eye contact with her therapist after the dog would move to receive reassurance. Week 11 was Kai's last week in AAT (for reasons unknown) after missing five previous sessions. During week 11, Kai presented as tearful and upset when the dog came too close to her body, which was typical, but she used more gestures to communicate how she was feeling (she pointed at a toy for the dog, pointed to the door when she felt afraid and wanted to leave and shook her head "no" when asked if she wanted to offer the dog a treat). It appeared as though her ability to communicate in this setting, which was stressful for her, was beginning to increase. It also appeared as though she regularly sought comfort from the therapist, who was able to provide it, so she could regain emotional composure. As she was preparing to leave the office at the end of the session, she said "bye," which was her only word uttered through the course of the pilot. It was not known at the time, but this was to be her final session of AAT.

Brushing was the only physical contact this child had with the dog that did not bring about small bouts of crying. She would hold the brush and gently be in contact with the dog in this way; she was focused and maintained steady eye contact with the animal during these periods. Kai seemed to most enjoy watching the dog closely, looking at 
photos, staying seated on the therapist's lap in close proximity to the dog throughout the session, and listening actively to cross-talk between therapist and dog. These strategies and tools were enough to engage her throughout the full session, and although she didn't often demonstrate obvious behavioral responses, she was emotionally expressive and appropriately soothed in this setting. Her growth and progress seemed to be increasing subtly but she disengaged from the program/pilot after week 11. Based on data, it appears as though Kai's comfort seeking (through crying in previous sessions) was unique to this setting. She would cry in the classroom but not seek or accept comforting gestures; in AAT, she very obviously accepted comfort and regained composure as a result.

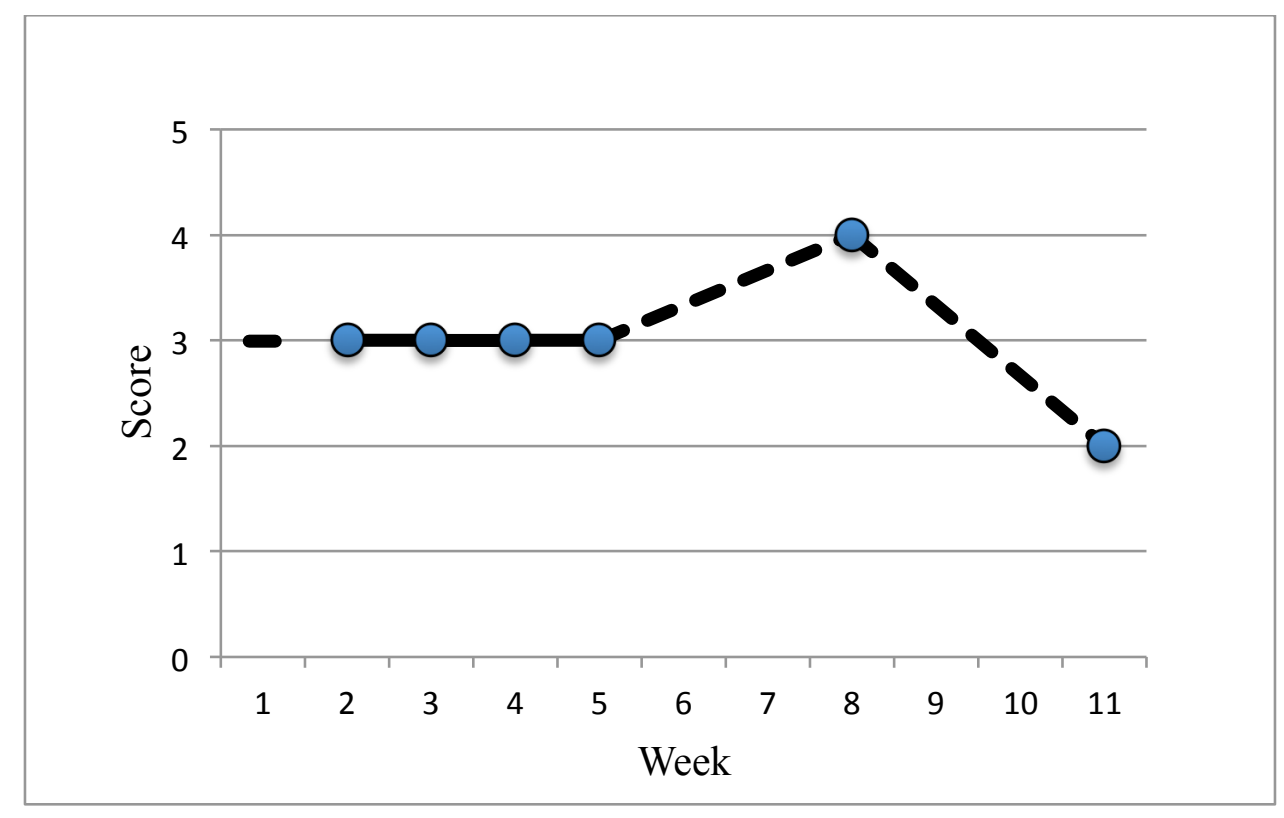

Figure 36. Kai-Attention. 


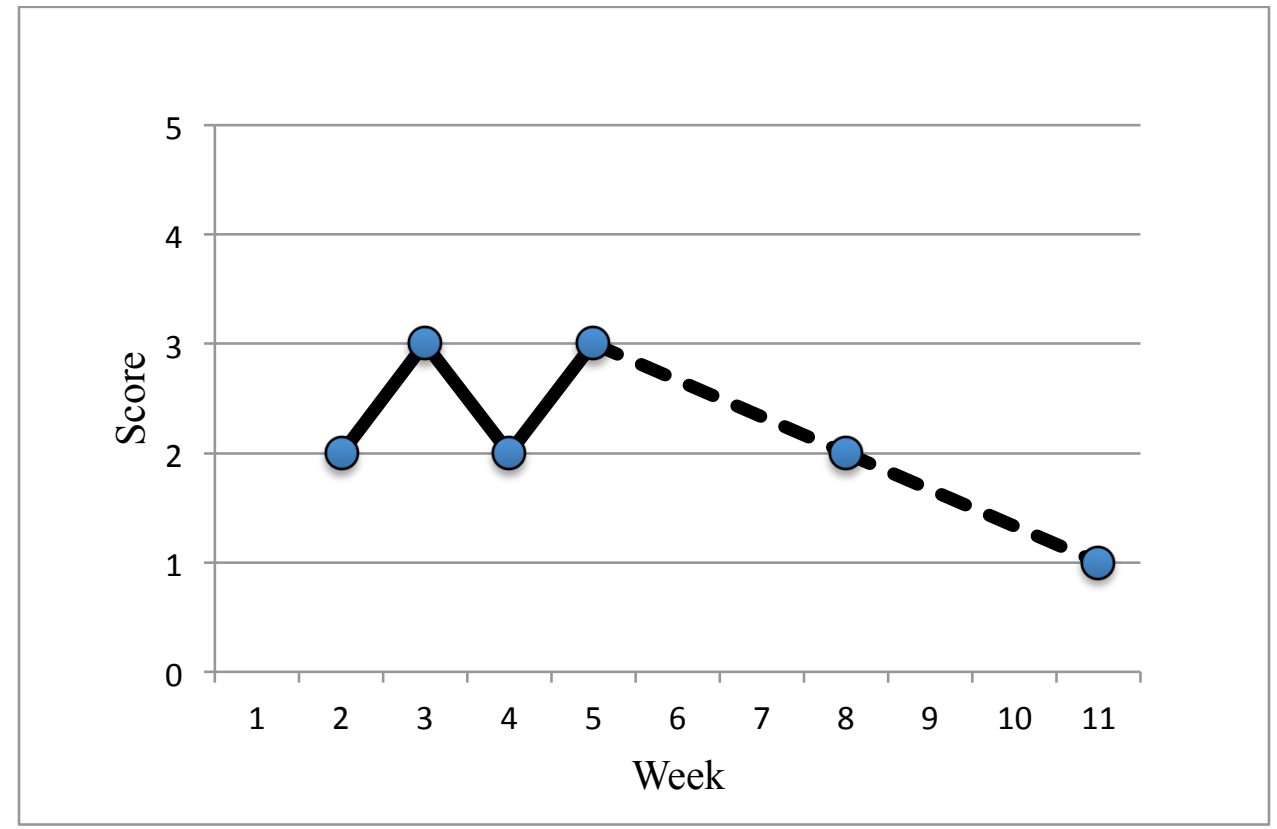

Figure 37. Kai—Engagement.

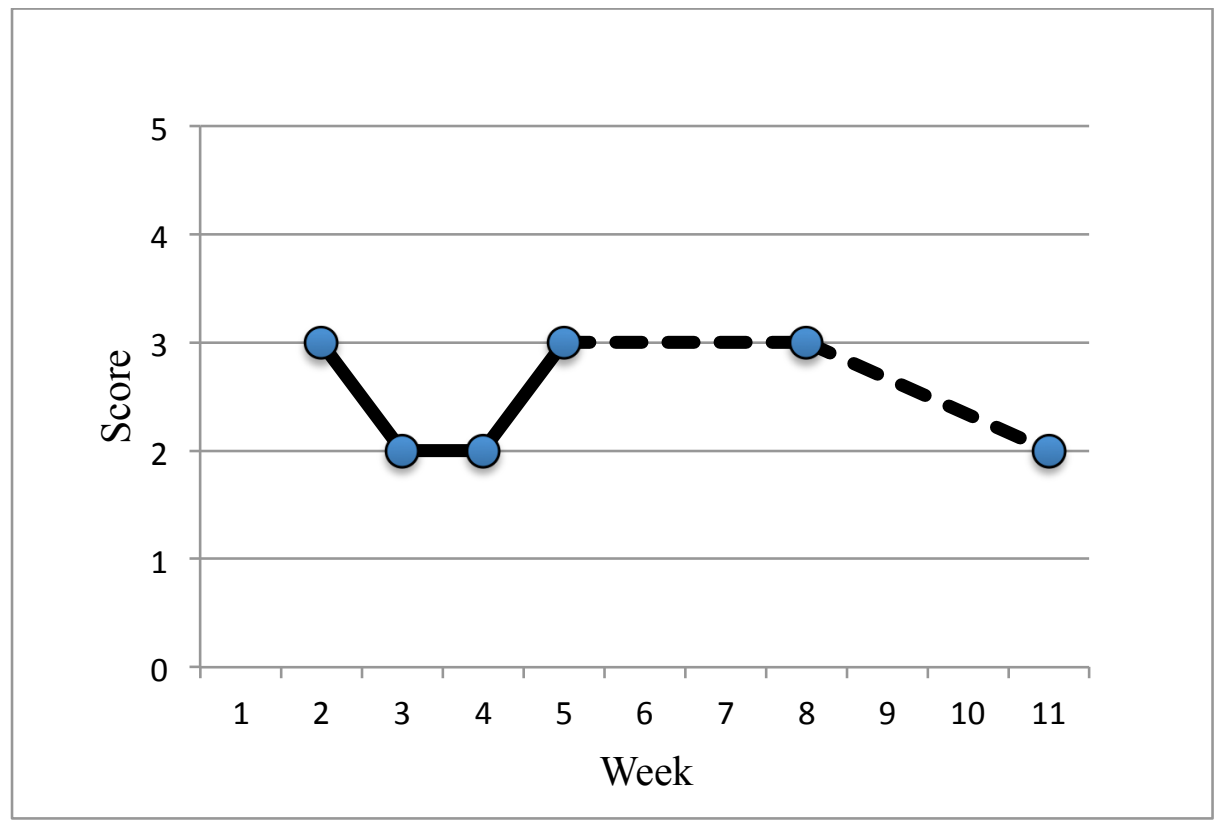

Figure 38. Kai-Emotional regulation. 


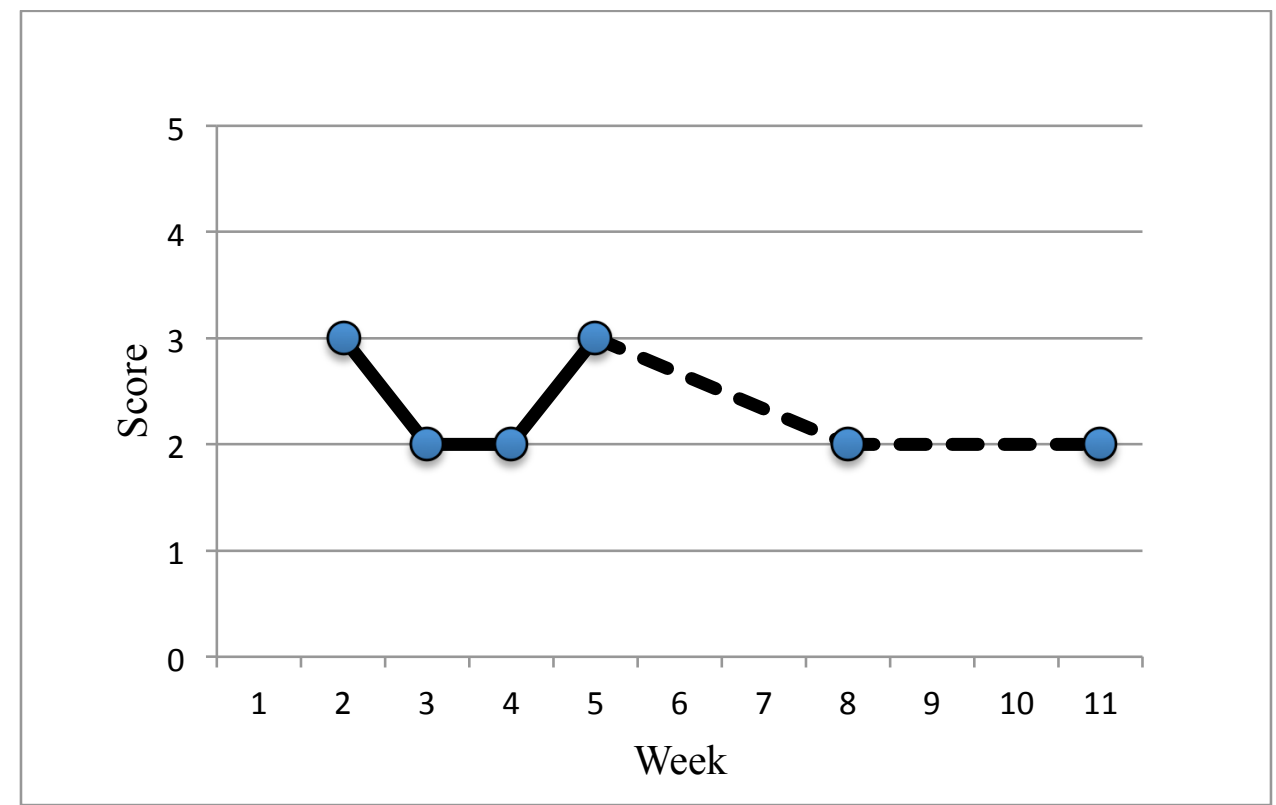

Figure 39. Kai-Age-appropriate behavior.

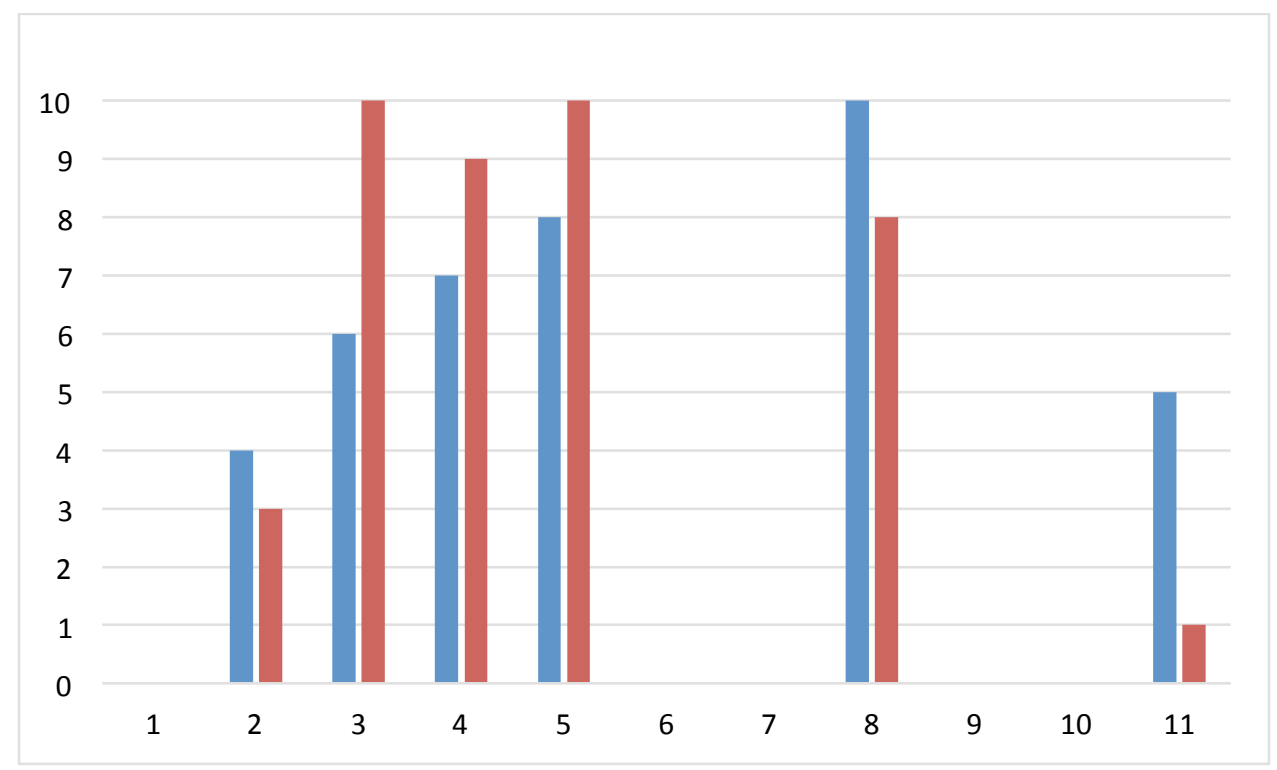

Figure 40. Kai-Cognitive "Yes" scores (Raters $1 \& 2$ ). 


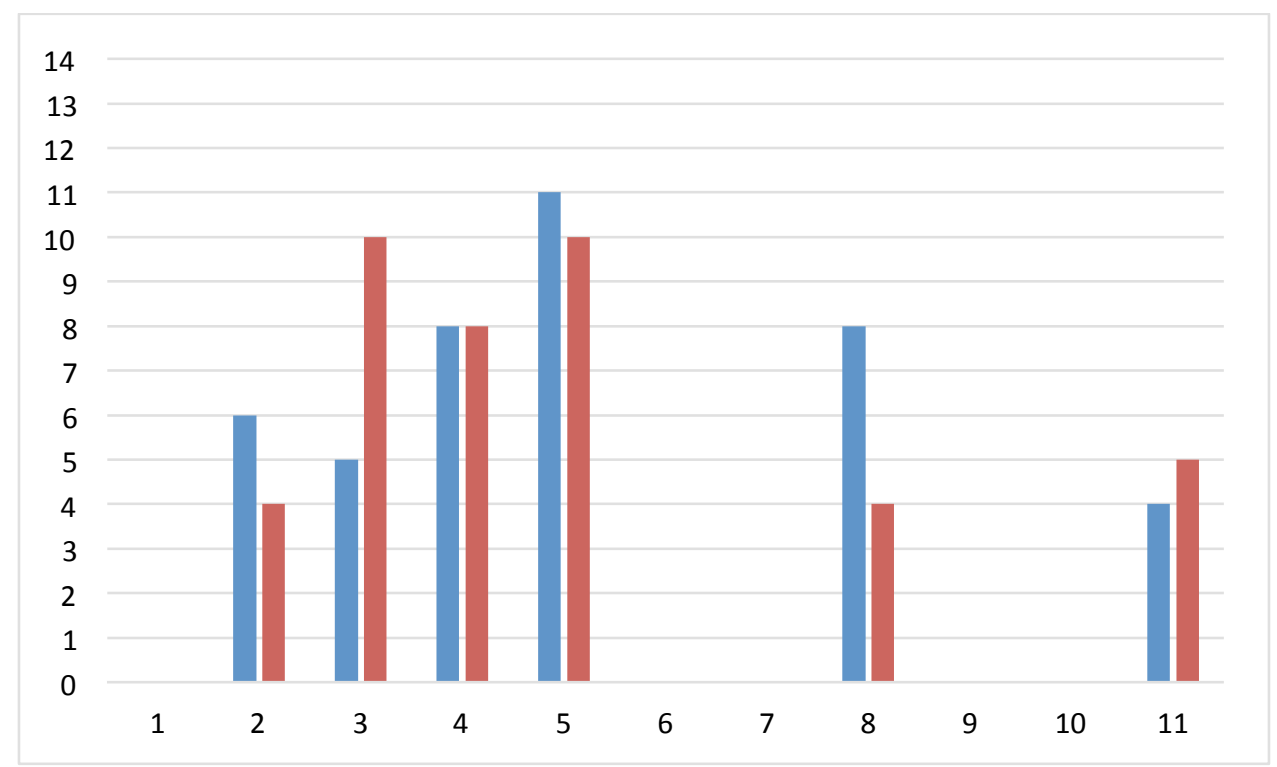

Figure 41. Kai-Social-emotional "Yes" scores (Raters 1 \& 2).

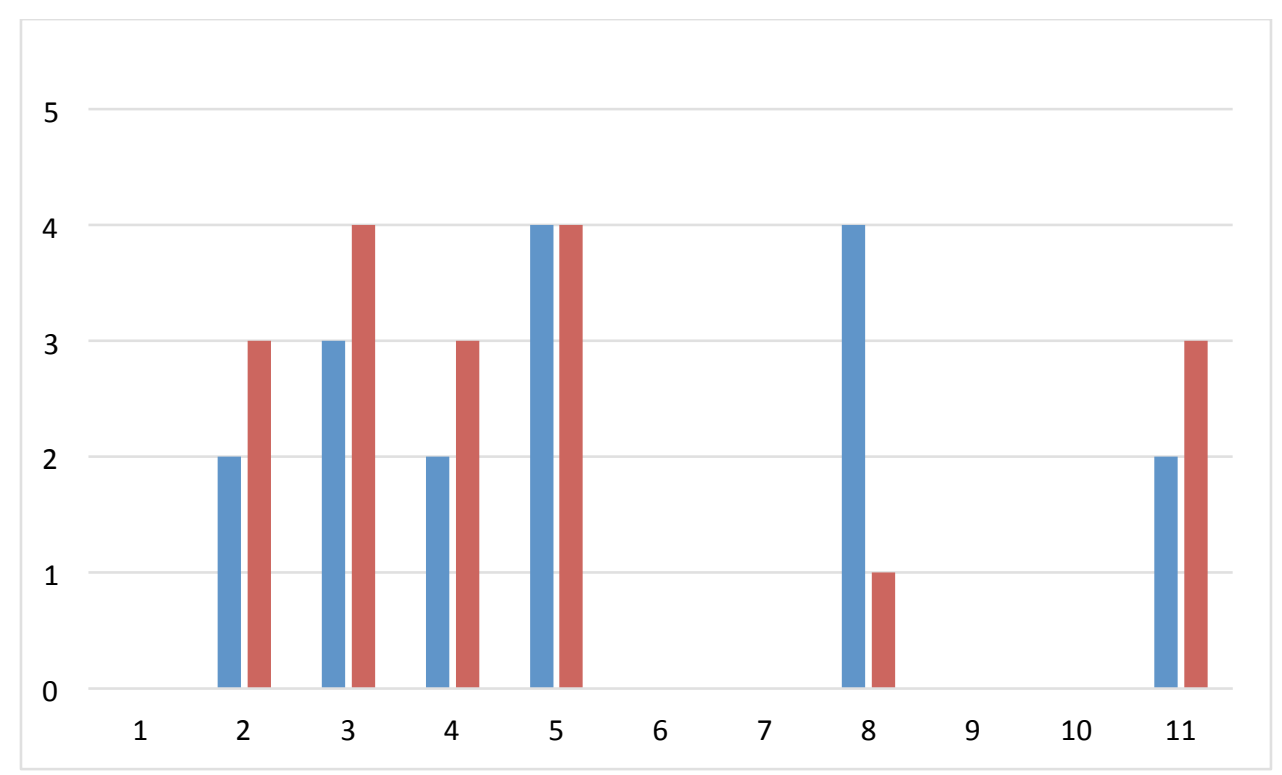

Figure 42. Kai-Verbal "Yes" scores (Raters 1 \& 2).

Kai6 had a change score of zero, despite some higher scores being recorded during the middle of the pilot period (weeks three, four and five were rated with more 
"yeses"). Due to missed sessions and an early termination, her scores dropped back down by the last session.

Therapeutic impressions. Kai was a child plagued by instability and disrupted attachment — this fact was confirmed by her sporadic attendance and inability to stay engaged in the full program. It is likely that she was moved out of her foster home during the period of this study. The program reported trying to reach her caseworker with no success. Her teacher stated, "She was here one moment and then, poof, she was gone!" A child with the presentation of detachment, emotional withdrawal and challenging family systems are potentially ideal candidates for AAT, because of its nonthreatening approach and the predictability, attention and affection given by the dog to client. This technique may have ultimately served Kai well, had she had the opportunity to continue. This child's use of crying as a communication tool was age-appropriate. When she felt unsure or afraid, she expressed that through cries and whimpers. She also accepted comfort from her therapist, with whom she had no previous relationship prior to this study, in a way that indicated she felt supported and safe. Research supports that AAT increases feelings of safety in certain children (Signal et al., 2017) and that seemed evident in Kai. Also, given the fact that she did not seek or receive comfort in this way from other staff in the program seems to indicate that this setting was unique and supported the rapport she was building with her therapist. It also provided the therapist with the opportunity to offer comfort and reassurance, which then reinforced and may have expedited the rapport-building process. 
7. May. May was a 28-month-old Hispanic female referred for AAT by her classroom teacher. May had a history of motor delays and tremors. Her pediatrician's referral to TCP qualified her for services there. May was living in a 2-bedroom apartment in a Section 8 housing complex with her biological mother, two older sisters, her mother's boyfriend and his infant son. The ages of her caretakers were unknown but it was presumed by the referral source that they were "very young." Neither was employed. It was suspected by program staff that May and her siblings were often left in front of a television for hours while her mother and mother's boyfriend either slept or attended to his infant son; this was based on reports from home visits.

In addition to her delays in gross and fine motor skills, May struggled to communicate her needs and engage with peers. She had difficulty with transitions and would often "melt down" when she was asked to shift activities or move between tasks.

Compared to similarly-aged children, May's referral source noted that she was average in the following areas: social functioning, emotional stability, appropriate behavior and language ability. When asked to explain further the areas in which May struggled, her case manager pointed out that "similarly-aged children" at TCP tended to be delayed in many of the same ways as May. And because she was only 28 months, her difficulty communicating may have been age-appropriate. Her "melt downs" were attributed to her age, the busy environment, and possible lack of similar stimulation in the home.

May was always dressed in pink from head to toe and her hair was always beautifully styled. It seemed as though her mother invested a great deal of time and effort 
into making May “cute.” Indeed, she was a very attractive little girl and received a lot of positive attention for the way she looked.

May cried and screamed a great deal—nearly every day and oftentimes three or four times throughout the day whenever there were transitions or she was asked to shift activities. May was a slow-to-warm-up child in most settings but did seem responsive to adult attention, especially from her mother. When her mother came to the program to pick her up, May would cling to her and often sit at her feet. May's mother would immediately straighten May’s clothes and redo her hair at the end of each day (when picking her up) before doing anything else. It was an obvious frustration to program staff working with May that her mother was so emotionally distant and preoccupied with May's appearance. There seemed to be very little vested interest in May's overall development.

It was reported that there was a small dog in May's home. There was no additional information available about her relationship with the dog or how long May had lived with it.

Course of treatment. May was brought into the therapy office by her mother, which was not a standard entry into the session for any of the participants. May was initially interested in the dog but then became highly distracted, looking out of the office to her mother who was standing just outside. When May's mother stepped back from the doorway, May cried loudly but the therapist was able to use simple distraction to help May with that transition. May enjoyed feeding the dogs small treats and would show excitement, but then remember that her mother was just outside and she would again 
become distressed. Given the atypical entry into her first AAT, it was decided to end the session a bit early and allow May to reconnect with her mother (who stood outside the doorway for the entire session). May's mother had expressed reservation that AAT might somehow ruin "her [May's] look” (clean, very sophisticated outfits and stylish hair-do) and wanted to observe the first session as a result.

May's second week of AAT showed markedly more interest and engagement with the dog and therapist. She easily transitioned into the room, fed the dog treats, interacted physically through petting and brushing and she appeared with a smile throughout the session. She was not verbally expressive but was otherwise positive in her interactions. She did not express or demonstrate distress and seemed very comfortable in this setting. May's third week included sharing toys with the dog, feeding treats and sitting very close to the dog while coloring with the therapist. Again, she appeared comfortable and emotionally stable (no signs of distress were noted). When the therapist attempted to guide the activity where May would identify similar body parts, May did not appear interested.

After a missed week, May came back to AAT and wanted to physically engage with the dog more than she had previously_-she enjoyed feeding treats, throwing a ball and sharing toys. During this session, she showed more interest in pointing to her body parts and then finding matching body parts on the dog. This was the first session when May used a word ("bye"). She appeared happy and interactive.

After another missed session, $\mathrm{M}$ showed a similar pattern of behaviors to the prior session. This time however, she also brushed the dog with support from the therapist. 
Again, she used just one word at the end of session ("bye") but appeared very focused and content during her time in therapy. During week eight, it was noted that May was excited and eager but also highly distracted; she looked around a lot and generally appeared distant. She interacted nicely with the dog (treats, petting and brushing) but only for brief periods. There were no verbalizations or attempts to communicate made.

Yet another missed session (week nine) followed by four weeks of very similar behavior patterns: May would show excitement and comfort when entering the therapy office. She would pet the dog and show interest initially; then, within about two minutes, she would shift her attention and play on her own with other toys in the room. She was quiet and focused. May would reengage with the therapeutic process with support from her therapist, and needed to be directed more than some other children. On her own, May would continue to look around the room and shift attention between objects quite frequently. With support, however, May would show increased focus in interacting with both the therapist and dog. At the end of this session, May said "bye, bye" and easily transitioned out of the room. Her affect was steady, though relatively flat, during these sessions.

By week 13, May appeared very comfortable with the dog. She was able to anticipate his behaviors (trying to lick her face, for example, which she would appropriately block and turn away from). When introduced to the ball, May seemed to not know what to do with it; when her therapist demonstrated how to throw and roll the ball, May instead gave it to the dog directly. She seemed unable to throw the ball and felt unsure about trying. She also tripped over the dog's tail a number of times during session, 
indicating some difficulty with motor control. The dog was unfazed and continued to interact with her in the way that she was comfortable (May handing toys and balls directly to him). May attempted to say the dog's name, which was a first, and showed spontaneous affection at the end of the session.

Due to concerns about motor control, the therapist attempted to have May take the dog on a short walk during week 14 . She was able to stay next to the dog, walking slowly, while holding his leash. She appeared pleased with herself during this activity but was otherwise distracted during the session. Her interactions with the dog and therapist were brief, followed by a period of distracted play with objects in the room. May's final session came after another missed week and she presented as unfocused and unresponsive. She did not greet the dog and chose not to engage in patterns of interaction that had been developed over the course of therapy. She looked away from the dog and almost appeared to not know where her therapist's voice was coming from. At the end of session, May said “Goodbye dog!” in a very loud and clear voice. 


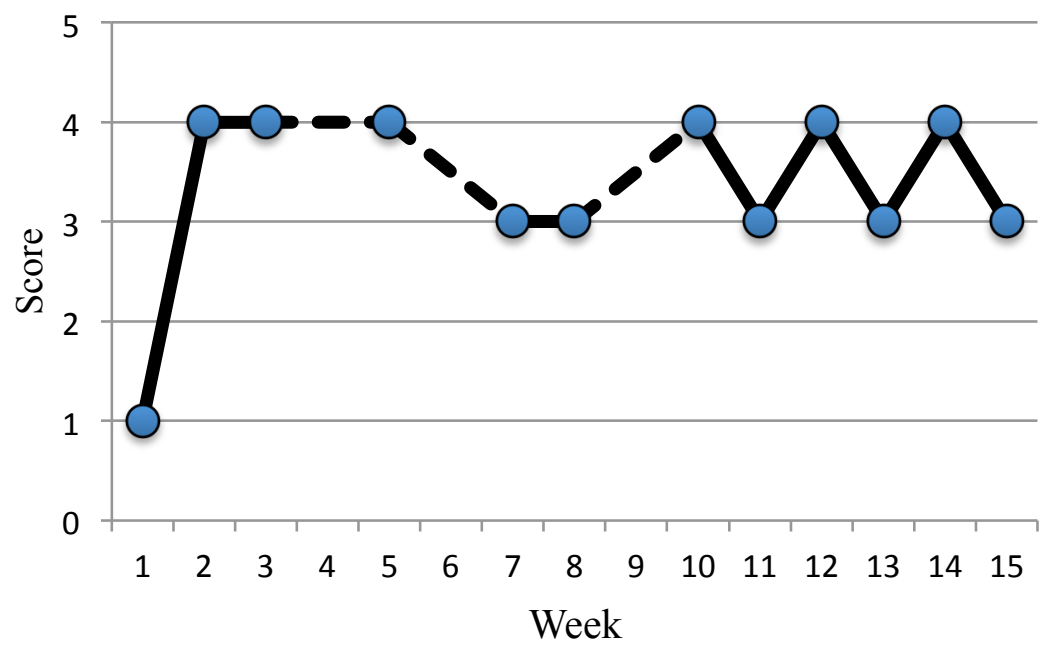

Figure 43. May-Attention.

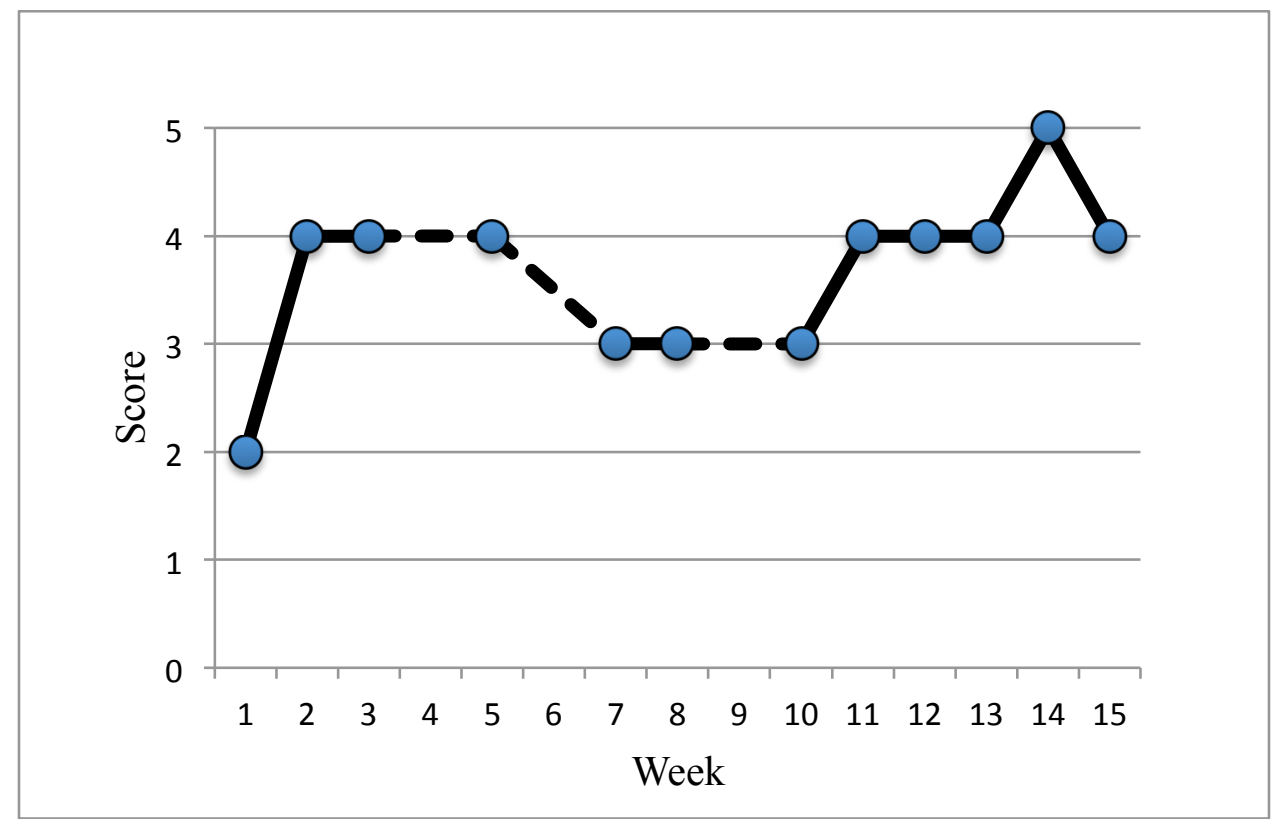

Figure 44. May_Engagement. 


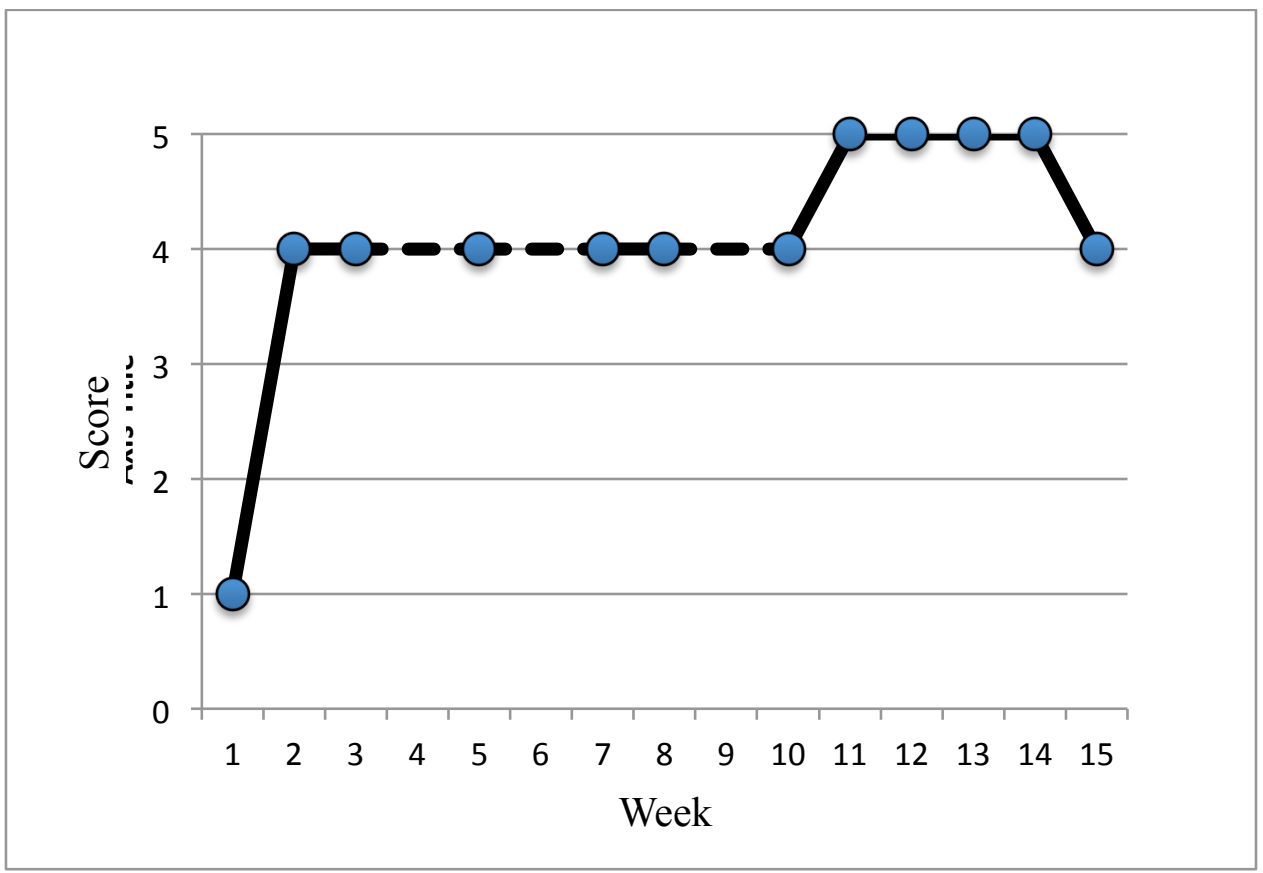

Figure 45. May_Emotional regulation.

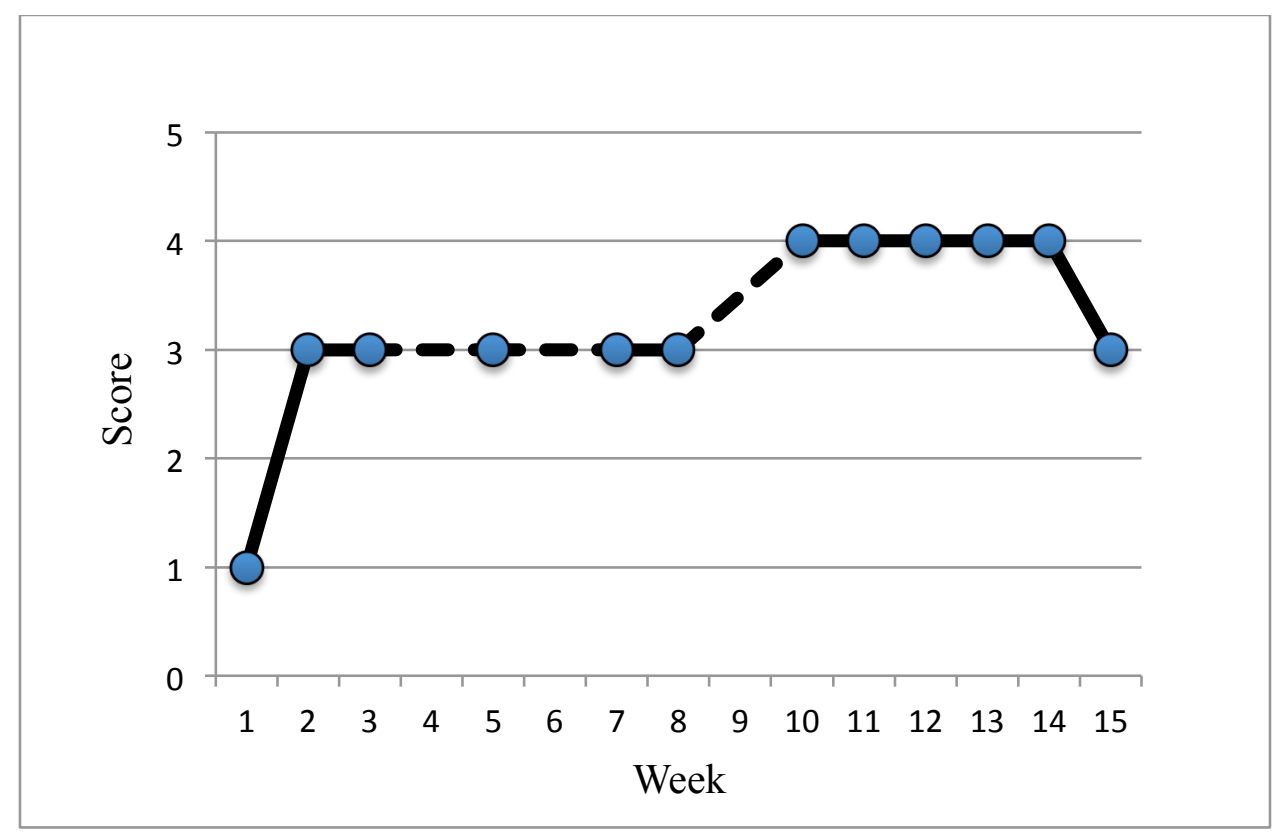

Figure 46. May-Age-appropriate behavior. 


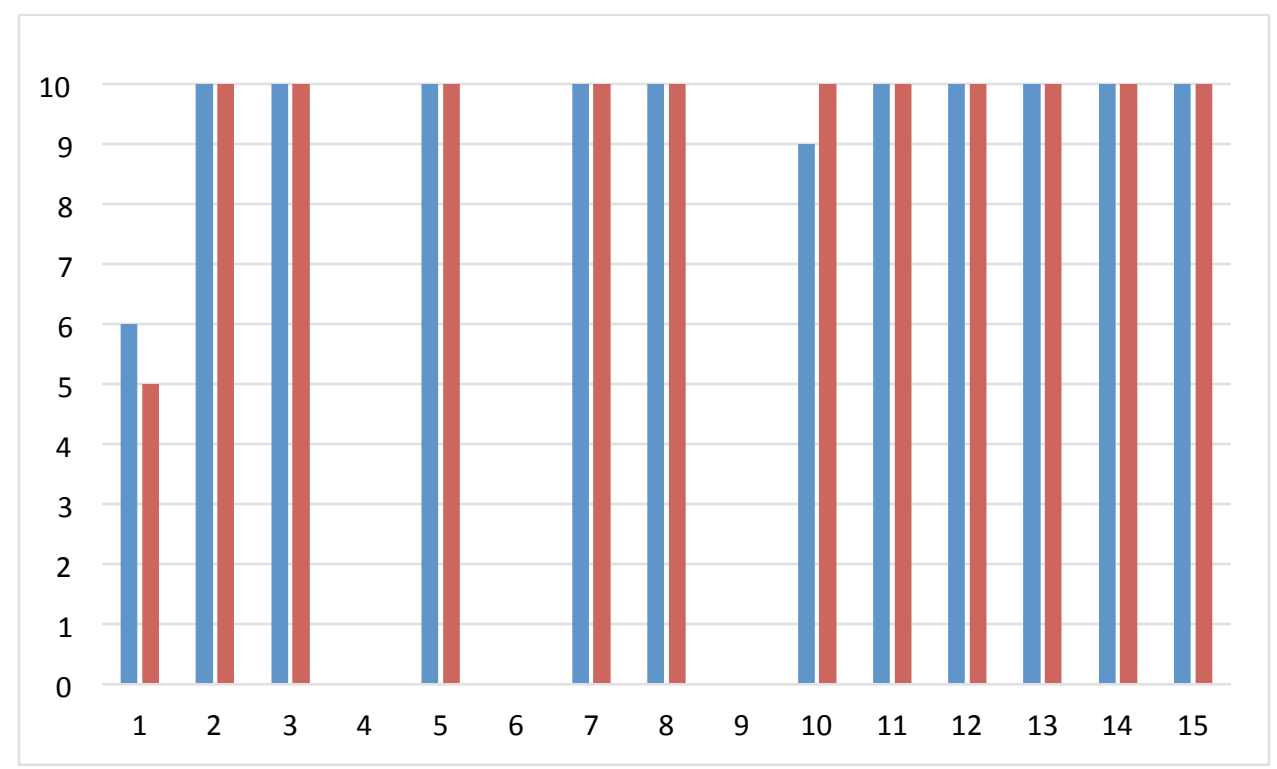

Figure 47. May-Cognitive "Yes" scores (Raters $1 \& 2$ ).

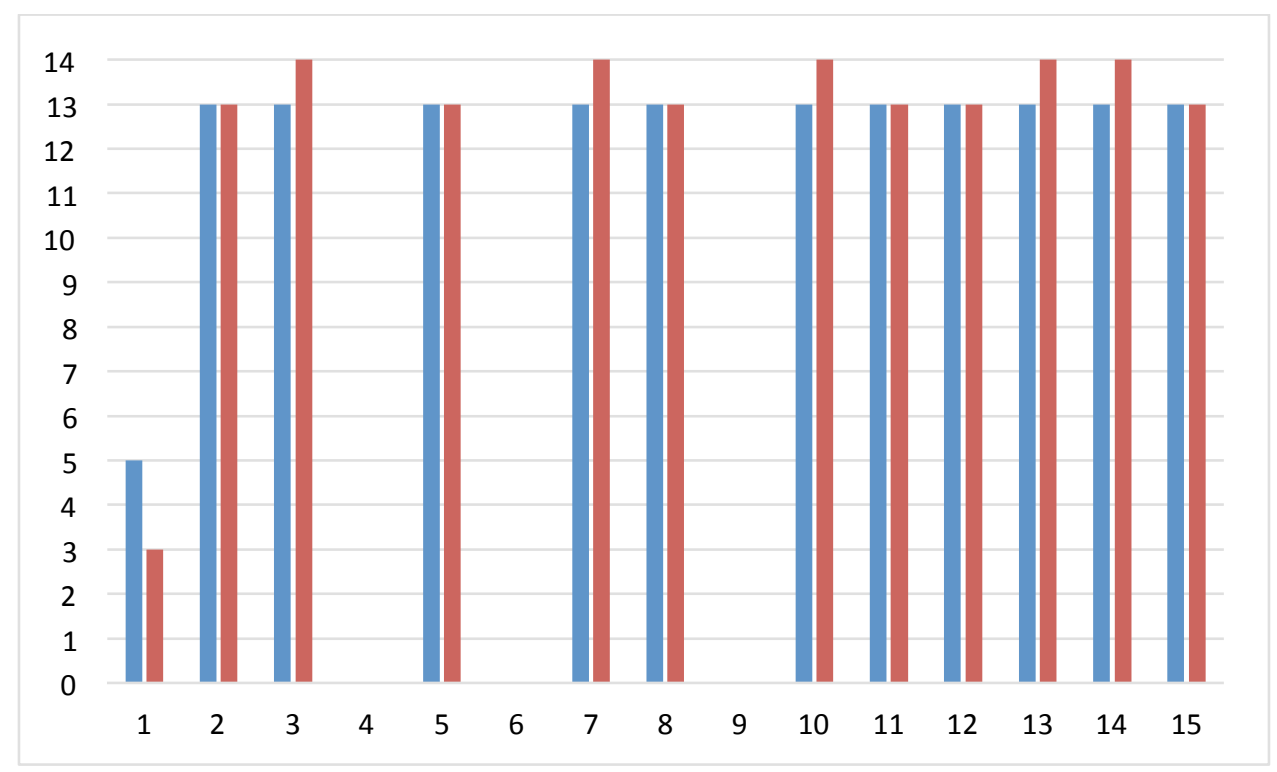

Figure 48. May—Social-emotional "Yes" scores (Raters 1 \& 2). 


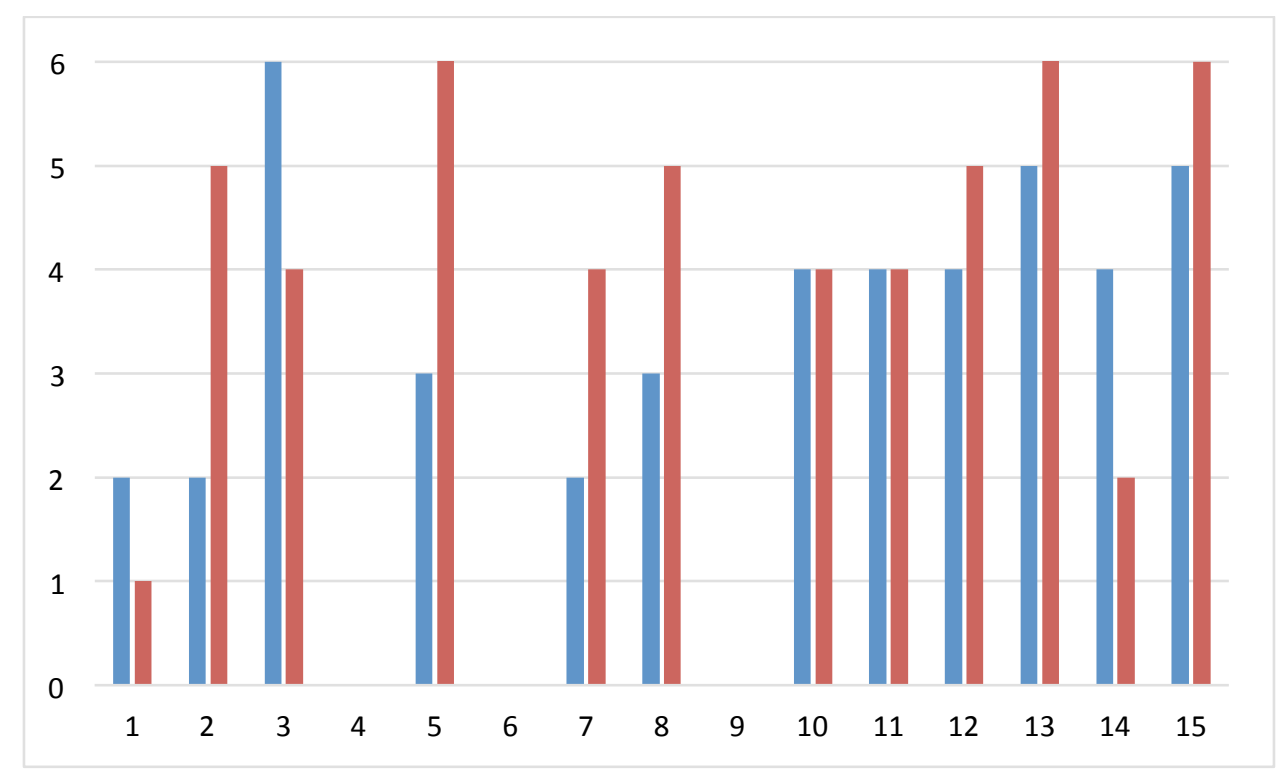

Figure 49. May_Verbal "Yes" scores (Raters 1 \& 2).

May7 has the second-highest change score of the sample group; she received 48 more "yes" indicators during her final week compared to week one.

Therapeutic impressions. Case notes indicate that she appeared "defiant" during this final session but perhaps she was more anxious and upset, knowing it was her final time with the dog. Further, the missed week prior to the final session seemed to impact the rhythm that had been established. Because of her inconsistent attendance, small markers of growth were often followed by regression. And because of the inconsistency, the therapist was not able to pursue one clear method or practice in treatment. Gross motor control and improved verbal expression were two key areas where M might have benefited from regular and structured therapeutic interventions (such as ball throwing, dog walking, command giving and body part identification), which she was able to do only inconsistently. 
8. Mik. Mik was referred for AAT by the program director at TCP; the organization had a "long history" with Mik’s family and their children. Mik was 30months-old at the time of referral and reported to be of Mexican descent. She lived in a home with her biological mother and father and five siblings, ranging in age from three months to eight years. Her father was a day laborer and her mother was unable to work due to severe respiratory problems and mobility issues (origin unknown). Her family lived in extreme poverty and risked deportation, though most of their children were born in the United States.

Mik, similar to her other siblings who had been through the program, was extremely quiet and communicated only using gestures and non-verbal behavior. She showed little interest in peers and appeared to want to avoid them when possible. Instead, she would "hover" close to adults in the classroom, though not engaging with them directly. Staff in the classroom found that Mik responded well to positive reinforcement and praise. She was identified as a "people pleaser" who "never gets in trouble." Instead, reports from the teacher stated that she "seemed to live in a little bubble" and showed little outward emotion.

Compared to similarly-aged children, Mik was reported to have below average social functioning, emotional stability and language ability; she was reported to have above average appropriate behavior. In contrast to her behavior at TCP, M's mother reported that $\mathrm{M}$ was talkative and social at home, regularly "misbehaved" and cried often. This clear disjunct between school and home was of concern to the educators at the program and something the director reported feeling "curious" about. The director 
wondered out loud about the culture in the home and how that impacted this child's functioning outside of the family system. It was typical for a child placed in the program for such a long period of time to have "warmed up" or settled in more. The worry and curiosity expressed by the staff were the main motivators for her referral to AAT.

Noted on her referral form was the following: "Mik is socially quiet and prefers her own space. AAT may help her make other connections and perhaps provide ways to build self-esteem and positive interactive skills because our traditional approach has not been successful." Most individuals working with this child agreed that she was "easy" and had no behavioral needs, though it's clear that they were referring to difficult-tomanage or externalizing behaviors, which were not ever observed.

Mik was reportedly "fearful" of animals and had never had a pet.

Course of treatment. Mik was observably very fearful at the start of AAT. She refused to enter the therapist's office and instead stood outside, looking through the window. Her teacher accompanied her to the appointment, knowing that she would present with reluctance and need extra support. The therapist walked into the office to pet the dog, modeling for Mik and showing that the dog was safe. Mik watched closely but stood firmly outside of the office. She had tears in her eyes while she watched her teacher inside the office but never overtly cried. The therapist offered Mik a stuffed dog to hold, which she took and held onto tightly. The session ended with her being escorted back to her classroom after approximately 15 minutes of looking into the therapist's office while the dog sat, chewed on a bone, lied down and rolled over. 
Mik's second session (week four, since she missed week one and three) started much like her first — she was fearful, resisted entering the room, stayed completely quiet and had no facial expression. Because her teacher was not present, she instead stayed close to the therapist, who was able to pick her up and bring her into the room. This allowed for the opportunity to cross-talk with the dog. Mik continued to appear "blank" and stare at the dog without interacting. At one point, she said "out" and the therapist then ended the session slightly early to demonstrate that Mik was not trapped or being forced to engage when she was uncomfortable. Also, her attempt to communicate was important to honor, especially given her relative silence and inability to self-advocate.

Mik continued to appear very flat and "shutdown" as weeks progressed. She entered the therapist's office with more ease but would keep her distance from the dog. She had no facial expression and made no efforts to communicate. She also resisted trying new activities like drawing or petting. Instead, she would watch her therapist interact with the dog and listen to cross-talking.

During week six, a subtle improvement was recorded in case notes: Mik brought a sticker of a happy face into the office to show the dog. When her therapist talked about feeling happy and looked more closely at the sticker, it was noted that the sticker and the dog's fur were matching colors. This seemed to help Mik relax; she then gestured that she wanted the dog to have a sticker too. This was the first session where Mik smiled. She continued to keep her distance but observe the therapist's closely. This session simply focused on the "happy sticker" and what it was like to feel happy. 
Future sessions built off Mik's previous interest in the happy face sticker. The therapist had a stack of stickers with various facial expressions available. Mik would pass stickers of her choosing to the therapist and indicate through non-verbal behaviors that she wanted the dog to have the stickers. The dog passively let the therapist put stickers on his fur and Mik watched. This activity presented an ideal opportunity to discuss each of the feelings depicted on the stickers. Mik appeared more comfortable in the therapeutic setting but remained quiet, though focused, throughout. Mik touched the dog for the first time during week seven. Prior to reaching out and touching him, she had brought objects to him and set them near his paws. When the dog demonstrated that he would not react, it seemed to help her feel more at ease and ready to interact. When given the choice of going back to her classroom early, she shook her head no and said "play more." She spent the remaining time brushing and feeding treats to the dog (using the therapist's hand as a "buffer" of sorts. She would place her hand on top of the therapist's so as to not directly come into contact with the dog). Mik whispered some words but they were not intelligible to the therapist or handler. At the end of the session, Mik peeled each of the stickers off the dog's body; she looked at them closely and then stuck them onto her shirt. This activity was accidental and one that had not been implemented with any of the other children; however, its value for this client seemed significant and certainly helped to make the transition into and out of the session.

Guided touch began to happen regularly by week eight (after she showed increased comfort during the previous week). She would touch the tips of the dog's fur on her own but go back to holding the therapist's hand, keenly watching each interaction. 
When the idea of throwing the ball was introduced, she showed great interest but would not actually do the throwing herself; instead, she would pick up the ball as it was dropped by the dog and transfer it into the therapist's hand. The case notes after this session note that "Mik would do this forever if she could." She appeared regulated, far more comfortable (perhaps standing up instead of sitting next to the dog helped, or she found a more open environment comforting). An "obvious raise in comfort level" was recorded. She was still quiet and relatively flat but no longer fearful or tearful. She made her interests known through clear non-verbal gesturing and pointing.

Mik's ability to enter the room increased as sessions continued, though once in the room she would move as far away from the dog as possible. She would then use the dog's objects or the face stickers as "bridges" to get closer. She continued to improve in her ability to touch the dog without needing the therapist's hand to support hers. She attempted to copy the actions of her therapist, such as feeding treats independently, and would almost complete the act before pulling her hand away and averting her gaze briefly. Her insecurity continued to manifest, though clearly progress and confidence were building.

Interestingly, Mik "froze” during week 11 after slow and steady progress. She recoiled from the dog, showed no interest or expression and did not communicate in the small ways that she had previously. She simply watched and listened without demonstrating any particular interest in skill building or activities. Later that day, it was reported to her therapist that Mik was sick and left the program early due to a fever. Her apparent reluctance or regression during this session may be linked to her not feeling 
well. Since this child was one to internalize and not communicate her needs, she was unable to tell her therapist or others that she wasn't feeling well. Mik then missed the following week of treatment.

When Mik returned (week 13), she walked confidently into the room and sat right down on the therapist's lap. Clearly, she had become accustomed to her routine during AAT and seemed to pick up where she left off. She participated in guided petting and brushing, picked up toys and placed them in front of the dog and chose which treats to have her therapist's feed the dog. Mik appeared to feel comfortable leading the therapist but remained reluctant to do any of the activities herself. When asked, she pointed to the dog's body parts. She also made faces for different emotions (just like the faces on her stickers). She was focused and attended carefully to each activity but was always about “one step away" from truly "being present with the dog."

Mik continued to show an increase in happiness and comfort, entering the room confidently, but staying a short distance from the dog. She was close and able to physically interact with her therapist without hesitation (sitting on lap, holding hands). Eventually, by week 14, Mik agreed to try and take the dog on a walk, which required holding his leash. This was a first-time experience for her, as she had shied away from this activity in the past. She walked slowly while holding the leash and looked to her therapist for encouragement. At the end of the walk, Mik smiled openly and again smiled when saying goodbye.

Week 15 was Mik's last week in AAT. Her pattern of entering the room and then creating space between herself and the dog appeared to have become engrained. During 
this final session, she was less expressive than those prior. She appeared "sad" and "almost tearful." When her therapist began talking about what makes children feel sad, she nodded her head yes and remained silent. When happy stickers were brought out, her mood lightened a bit. She did not want to touch the dog but did want her therapist to again place stickers on his fur. Her need to control the interactions with the dog were captured in her case notes, and repeated themselves from week to week. The more control she felt she had, the more expressive Mik would become.

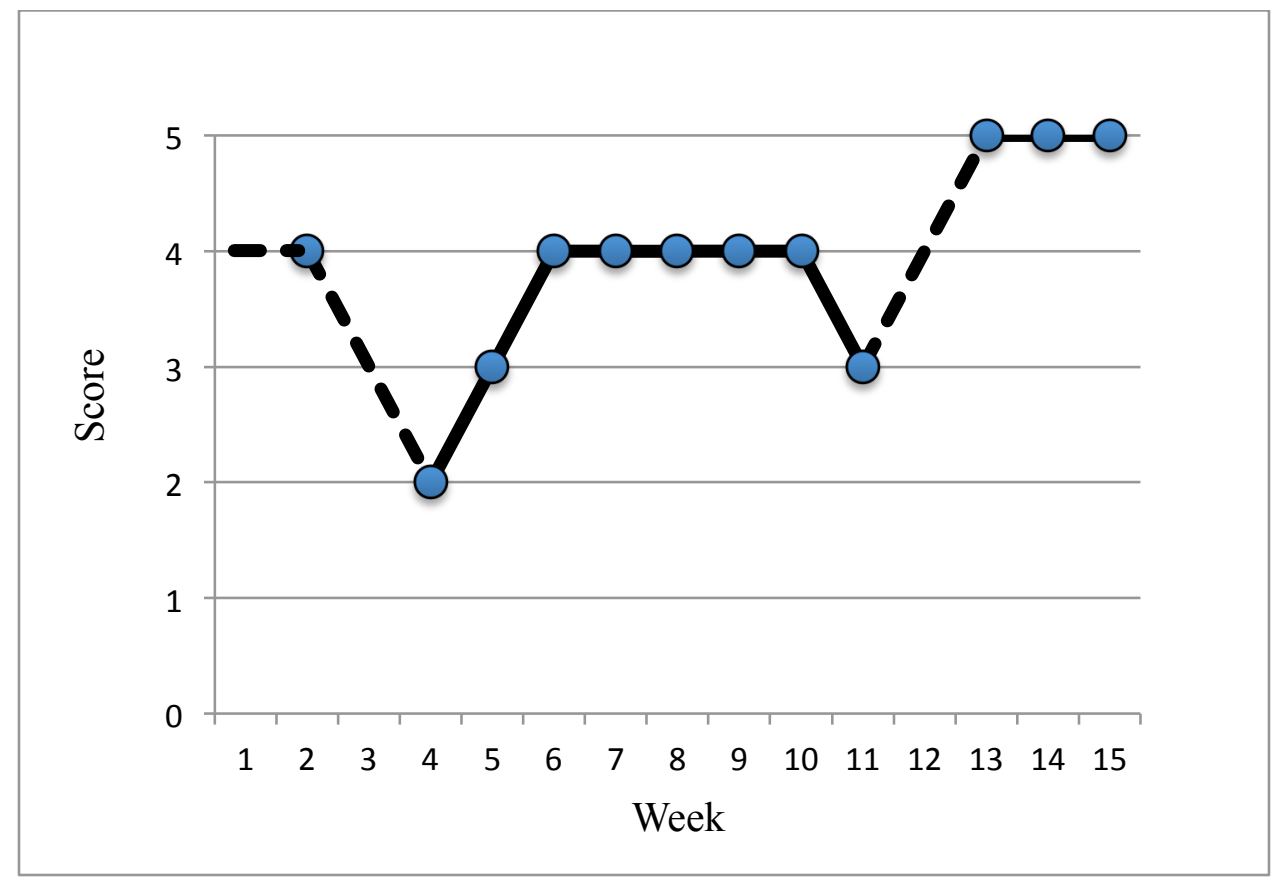

Figure 50. Mik-Attention. 


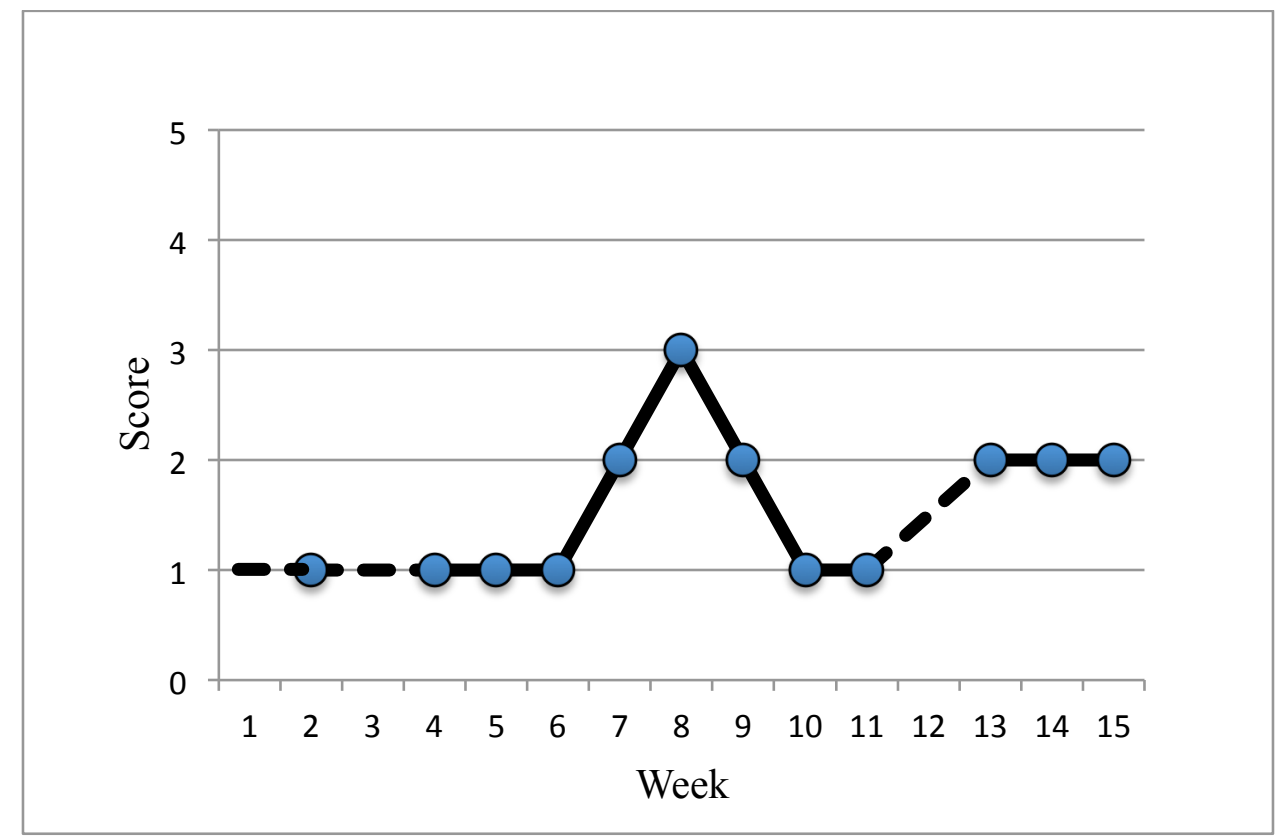

Figure 51. Mik-Engagement.

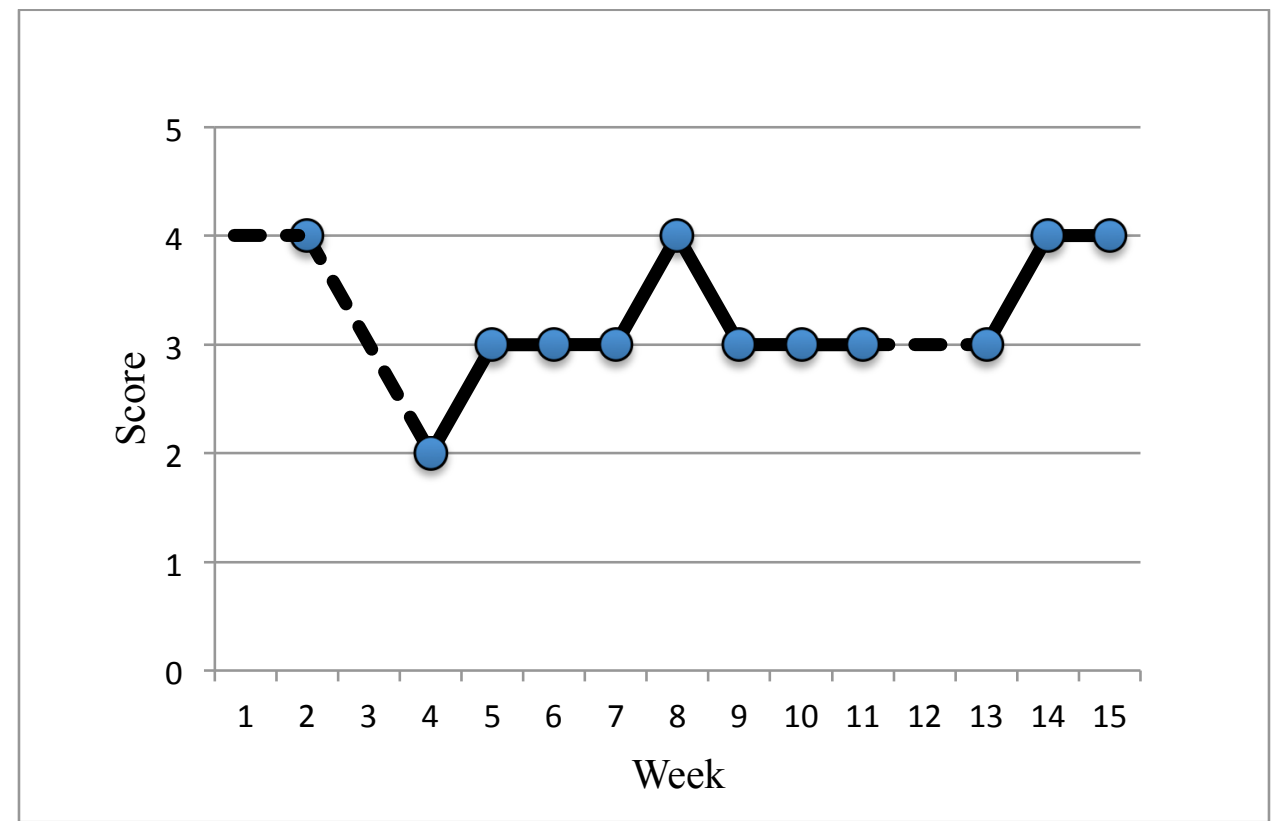

Figure 52. Mik-Emotional regulation. 


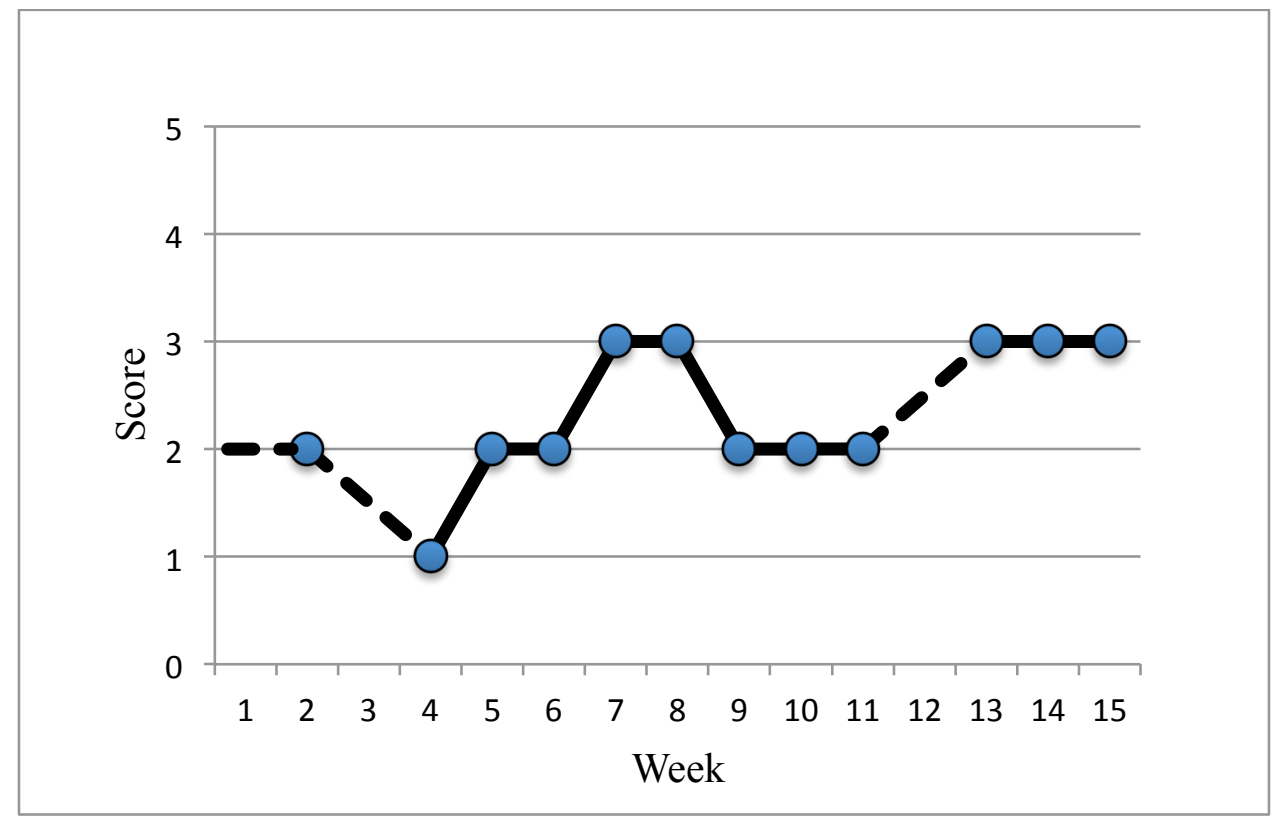

Figure 53. Mik-Age-appropriate behavior.

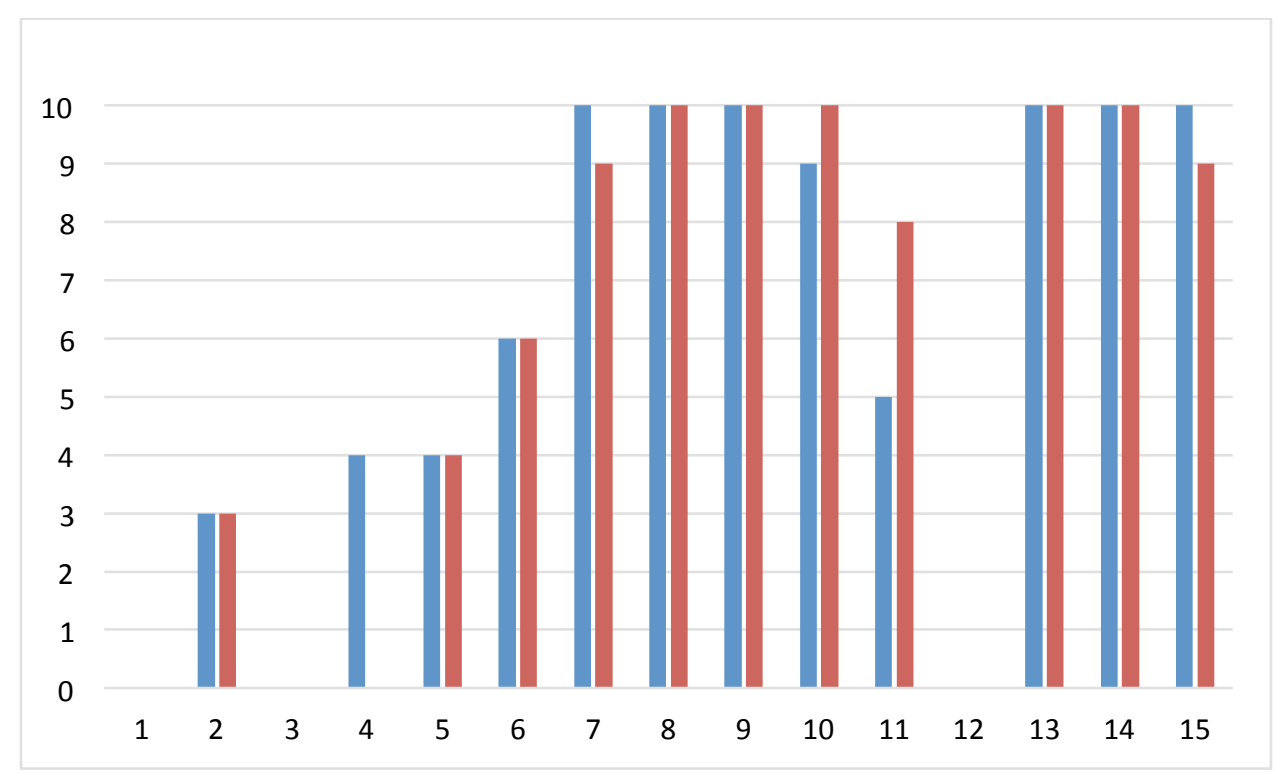

Figure 54. Mik — Cognitive "Yes" scores (Raters 1 \& 2). 


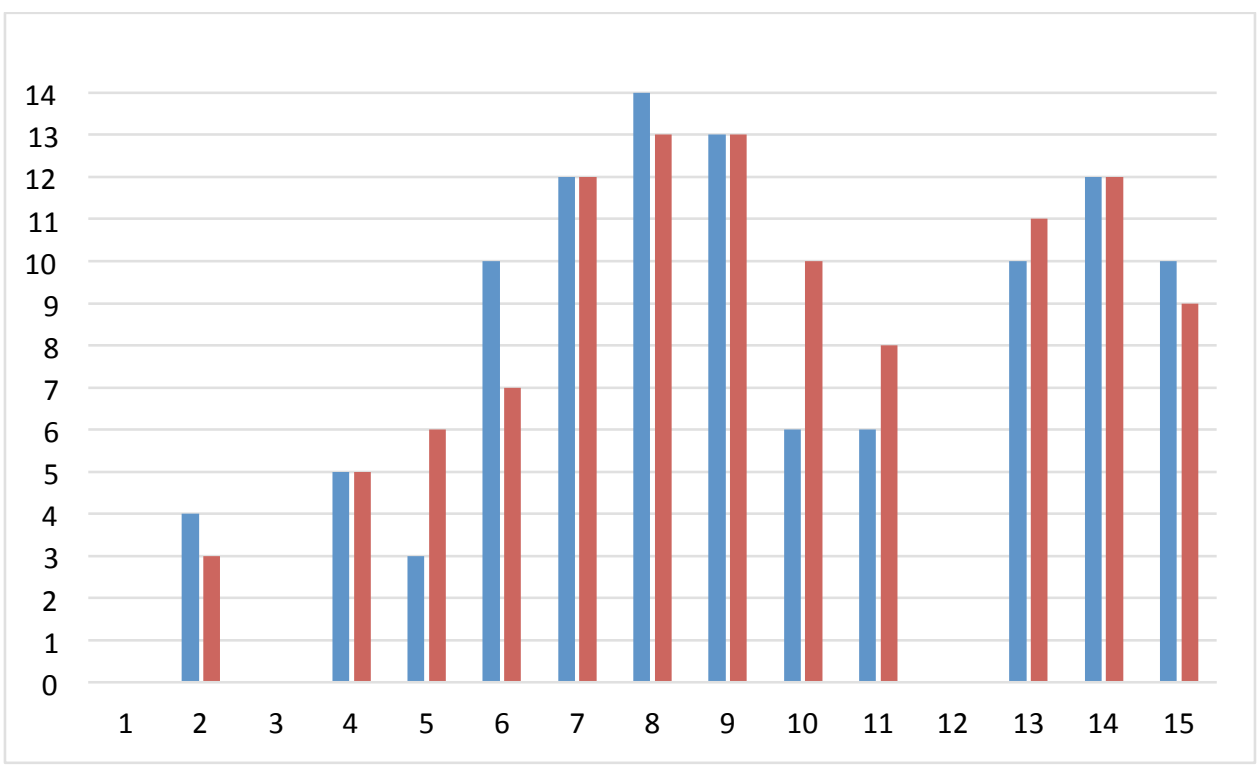

Figure 55. Mik-Social-emotional "Yes" scores (Raters 1 \& 2).

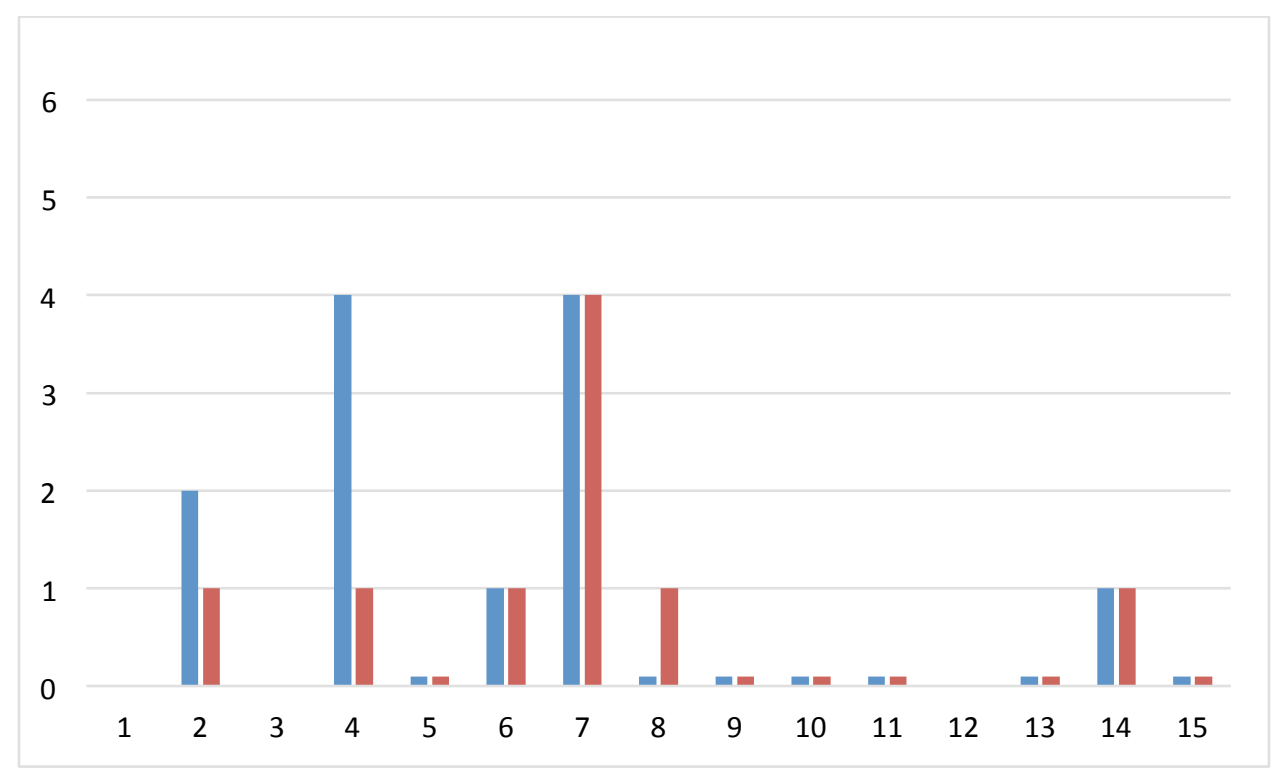

Figure 56. Mik—Verbal "Yes" scores (Raters 1 \& 2).

Mik8's change score was 28. 
Therapeutic impressions. It's clear that Mik needed a lot of opportunities to control and have power in her therapeutic work. Her physical and emotional distancing became more obvious when she was pressed to do something. This internalization was present in the classroom and persisted there, despite the genuine interest her teachers had in supporting her and her length of time in the program. It may be that chaotic environments, like home and school, did not present Mik with opportunities to exert her desire for control. She had little power in those settings. As a result, she retreated into her "bubble" when feeling overwhelmed or overstimulated. Slowly, Mik started to display attributes that had not been seen in other settings. Interestingly, she cried often at home and was reported to "misbehave." With more of a family-centered approach, additional information about Mik's behaviors at home would be elucidated. In the therapist's final case note, she wrote; "It is very possible that if the program lasted longer, Mik would have had a breakthrough..."

9. Nai. Nai, the youngest child in the treatment group, was a 13-months-old, African American female. She was extremely withdrawn at TCP and presented with a flat affect in most situations. Per her appearance, it was suspected that Nai had Fetal Alcohol Syndrome although this was not confirmed by diagnostics. Nai had been placed in foster care with a distant relative at the time of her birth; she had no contact with her biological mother or father. She was small, with only irregular patches of hair and seemed to have limited mobility (no crawling or exploring her environment). The program director reported Nai's case as one of "classic neglect." The foster family had not engaged in services, other than to drop-off and pick-up, since starting the program. 
Her case manager referred AAT to the program because of concern that "standard approaches don't reach her" and her home environment was lacking in appropriate stimuli. Nai did not express emotion and her needs were unclear-program staff had a hard time reading her due to her lack of expression and flat affect.

She was rated as below average in social functioning, emotional stability and language ability; and average in appropriate behavior. Her case manager felt that Nai would "slip through the cracks" because she just "melted into the landscape." There was additional concern that Nai's true needs were still undiscovered. A referral for an assessment of her developmental delays was pending at the time AAT commenced.

No pets were reported in the foster home.

Course of treatment. Nai was the youngest child in the study and also the only child whose scores dropped throughout the course of treatment. She had no emotion and typically sat on the ground, wherever she was placed, throughout each session. She showed no responsiveness, either positive or negative, to touching the dog. The therapist would speak slowly and encourage Nai to explore the room; but from week to week, she sat with little movement and no communication.

Nai did not express distress but also did not show interest in any activities until week seven. After a period of guided touch, Nai reached out on her own to touch the dog's nose and later held his ball. She allowed the dog to rest his head on her lap, although she wasn't looking down at him and it's unclear if she was fully aware of what was happening. 
Nai seemed unable to act on her own accord. Over time, her therapist decided to focus sessions on sensory experiences that she could have using the dog. The different body parts and textures were explored; as she increased guided touching, Nai showed an interest in physical interaction through simple petting. Though she became able to interact a bit more, she continued to appear emotionless and without any observable attempts at communication.

On week 15, her last week, Nai reached out to touch the dog without prompting and before any guided touching. She initiated this and appeared comfortable. She then showed "a glimmer of something close to a smile," per her case notes. Perhaps Nai was able to feel and express some emotion, or maybe her therapist was improving in her ability to read into very small indicators of this child's affect.

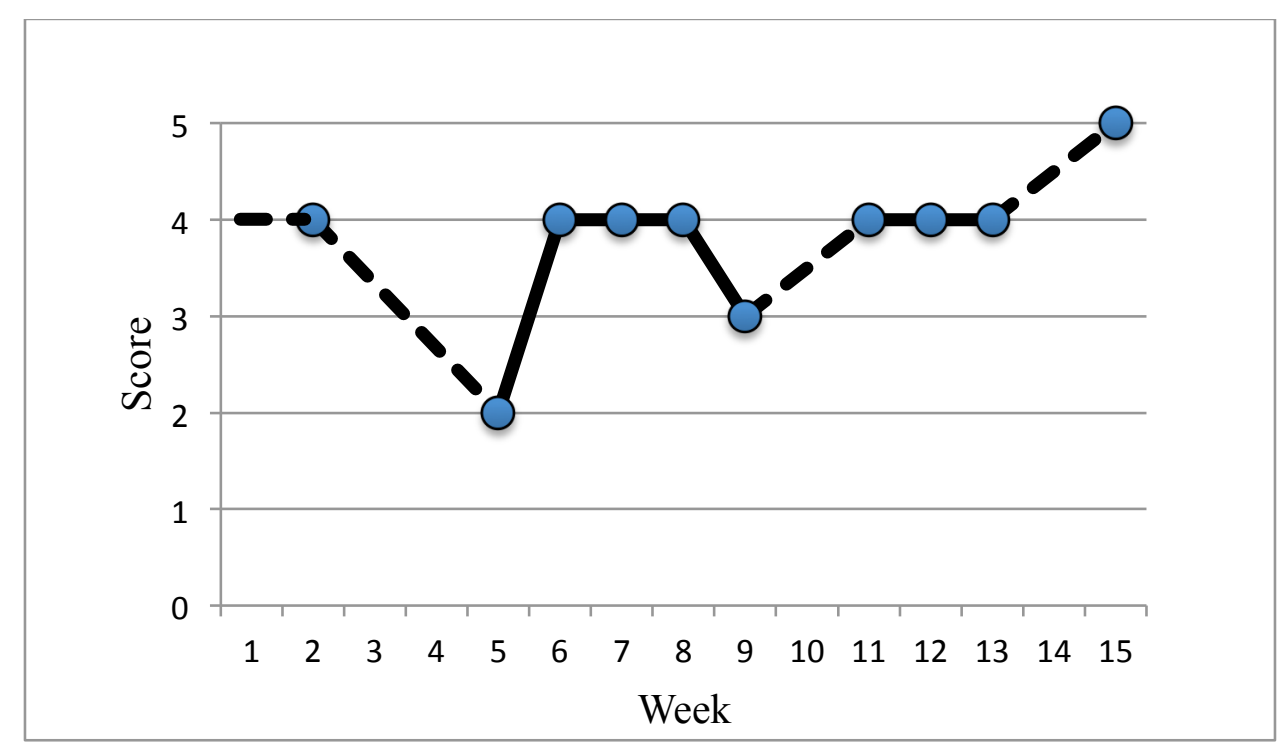

Figure 57. Nai-Attention. 


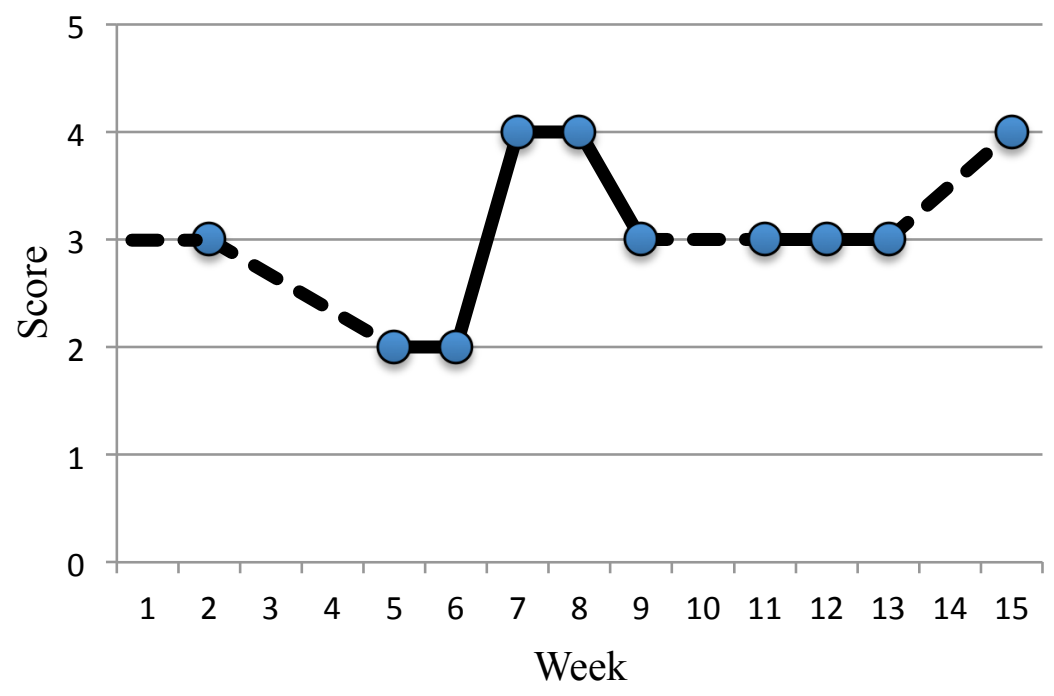

Figure 58. Nai—Engagement.

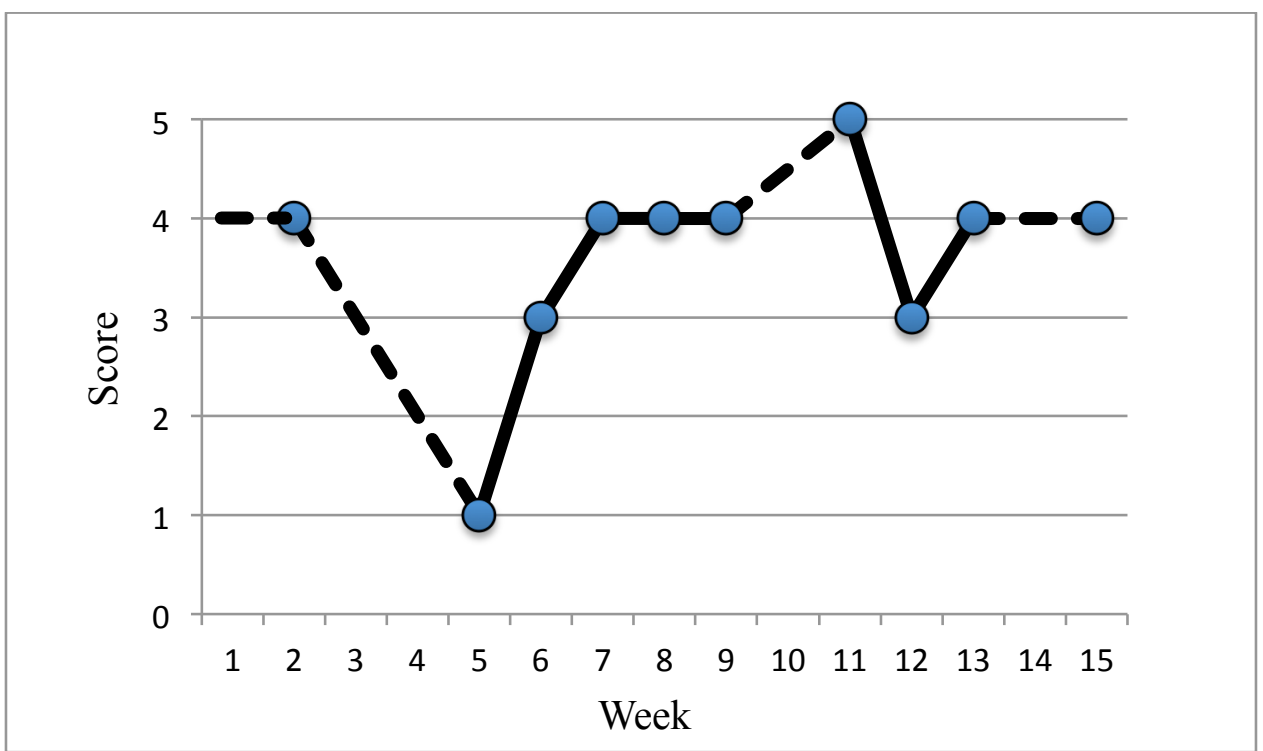

Figure 59. Nai-Emotional regulation. 


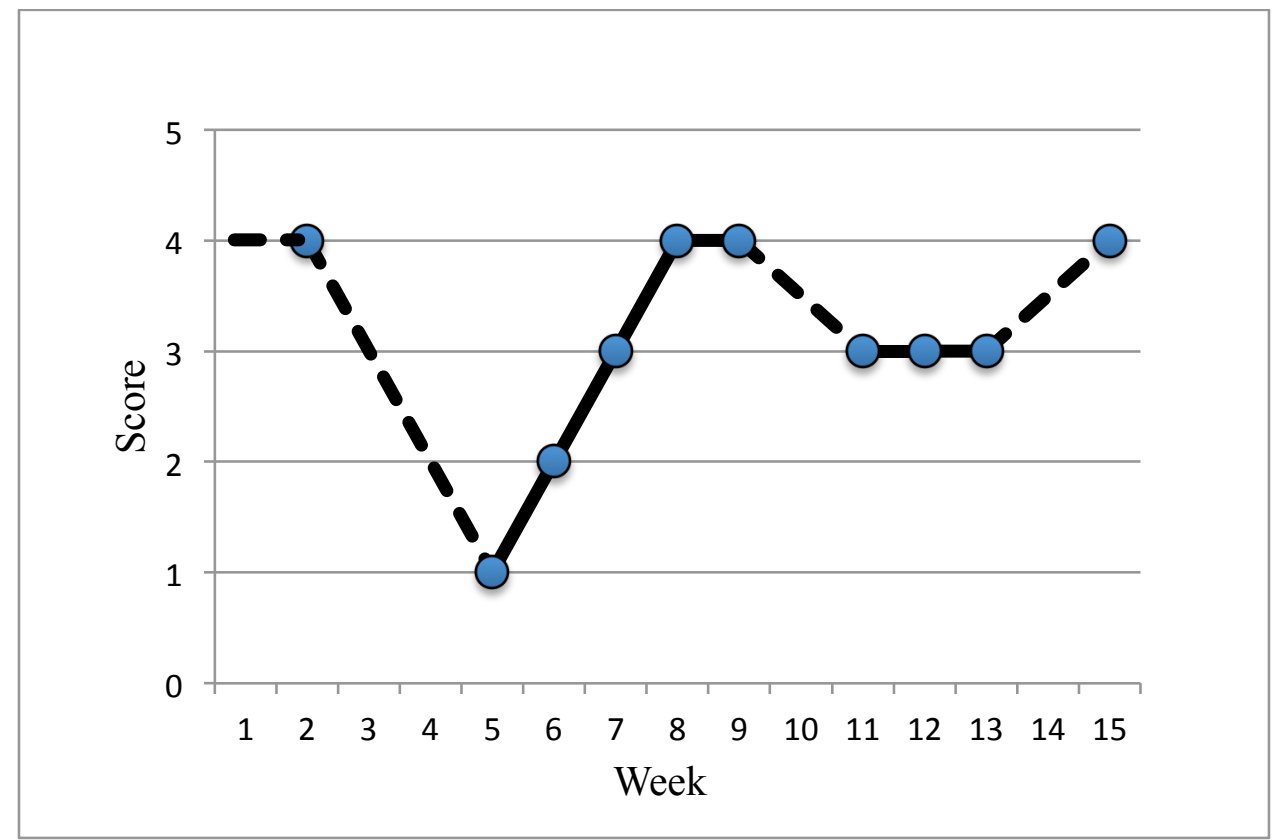

Figure 60. Nai-Age-appropriate behavior.

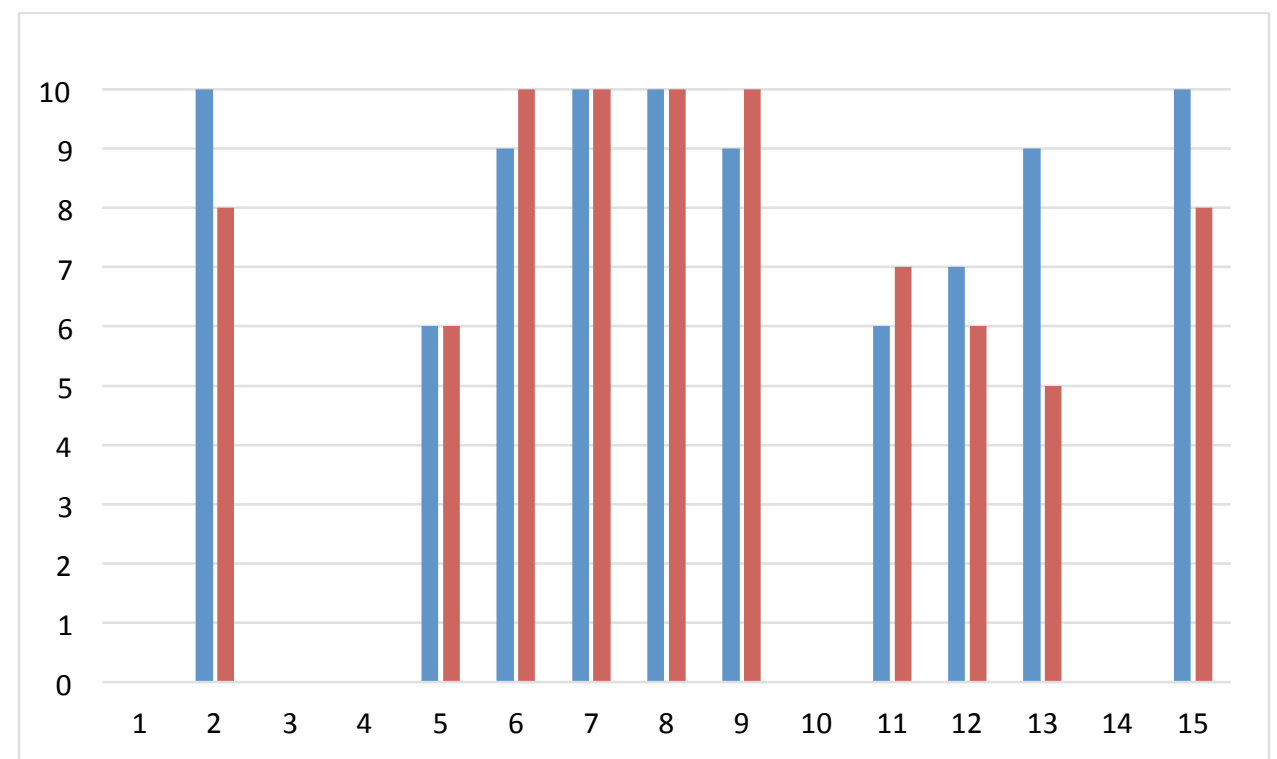

Figure 61. Nai-Cognitive "Yes" scores (Raters 1 \& 2). 


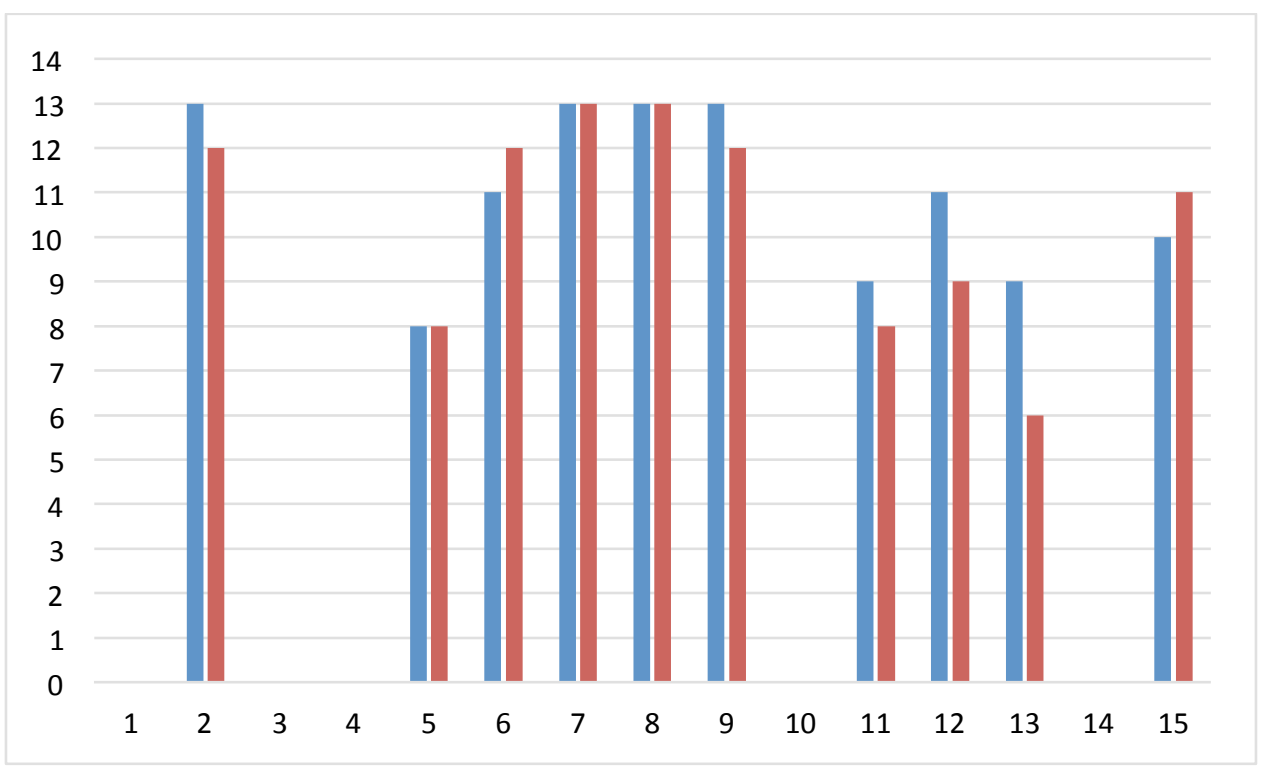

Figure 62. Nai-Social-emotional "Yes" scores (Raters 1 \& 2).

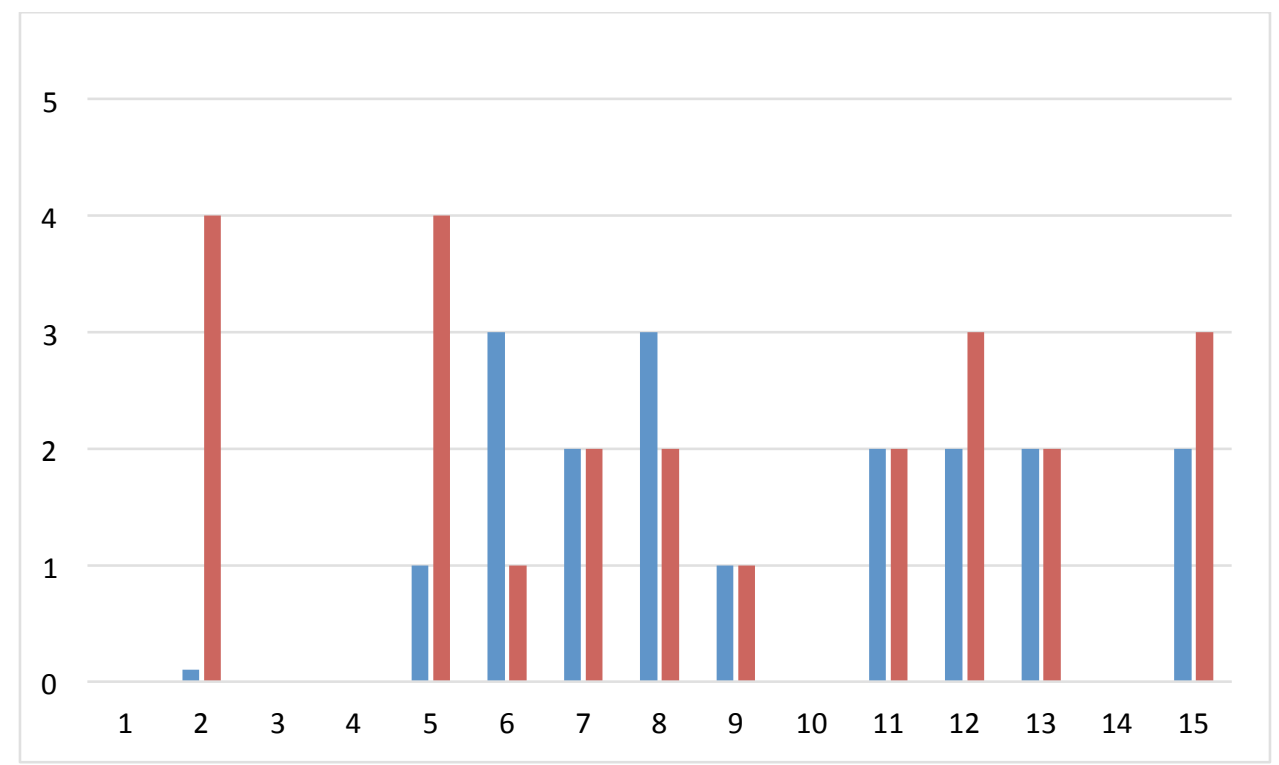

Figure 63. Nai-Verbal "Yes" scores (Raters 1 \& 2).

Nai9 had a total change score of -8 . She was the child who seemed least fit for this therapeutic intervention. 
Therapeutic impressions. For this particular client, AAT may have been overstimulating or simply not the right fit. She was also quite young and heavily impacted by trauma. For a child such as Nai, a more family-based approach could be useful to strengthen relationships and further explore what Nai would respond to. As a standalone treatment, AAT would not be ideal given the complexity of Nai's needs, her potential Fetal Alcohol Syndrome diagnosis and history of disrupted attachment.

10. Ren. Ren was a 28-month-old female Caucasian child referred to AAT by her classroom teacher and program supervisor due to concerns about pervasive neglect in her home, which impacted her in multiple ways. Ren was a friendly but unpredictable child. Some days she would demonstrate age-appropriate behaviors and appear stable; other days, she would weep for hours, aggress on children and adults, become non-responsive and "impossible to connect to" (per her teacher's report). Her mood and emotional instability were noted in her file and further assessment through the county's early intervention program were in process.

Ren lived with both of her parents in the basement of a friend's house. She had a younger infant brother. Both of her parents were unemployed, morbidly obese and had "mental health concerns" (unknown). She had recently had a bout of lice and her mother shaved her head bald because they could not afford treatment. Ren's parents rarely visited TCP and did not partake in any additional services that were offered. After the lice breakout, Ren was observed to wear the same exact outfit each day (always clean). When asked about it, her mother reported throwing out all the clothing, toys and "anything soft" in the home because she was afraid of lice and couldn't afford to treat it again. This 
prompted concerns that Ren had lost most of her belongings and was perhaps confused/upset about that. Her family refused donation of new toys or clothing.

Compared to similarly-aged children, Ren was rated as below average in social functioning and emotional stability; and average in appropriate behavior and language ability.

A dog was reported to be living in Ren's home. She had a history of being "rough" with the animal and could not be left unsupervised with it.

Course of treatment. Ren was immediately comfortable interacting with the therapy dog; she showed no fear or apprehension. She was affectionate and explored his body right from the beginning of the first session. She focused on the dog and his different body parts, by session two she was able to point to the parts of her body that matched the dog's. Ren's new occupational therapist observed her second session, which caused Ren to appear distracted and perhaps a bit confused. She was agreeable to sharing her toys with the dog and stayed close to the dog throughout the session. By session three, Ren developed a pattern of "teaching" the dog things about toys; and on session three, she brought a stuffed bear from her classroom to show him. She played catch with the dog and laughed each time he brought the ball back to her. Her emotional expression was appropriately varied during the session — she was gentle and then could easily shift into physical interactions that involved more gross motor movements.

From the first session, case notes indicate that Ren had very few verbalizations but was able to communicate and be expressive non-verbally. Quantitative markers indicate consistently high scores in all domains across most weeks but qualitative reports 
show that she struggled with periods of distraction and limited speech. Also noted by week four was Ren's struggle to perform fine motor skills. Week five was the first session where Ren spoke, she practiced repeating words and said "bye" at the end of session.

Ren began sitting on her therapist's lap during week six; she had not done so previously. She would interact with the dog but move into and out of the therapist's lap throughout the session. She seemed not to recognize basic cues in the dog's behavior but once it was explained what the dog was doing or feeling, she responded appropriately. For example, when the dog stood up and wagged his tail, Ren looked puzzled. When the therapist explained that the dog might be feeling happy or excited, she also stood up and appeared happy. The dog, in this case, was acting as a social model for the child; she was learning about her own feelings by seeing them demonstrated by the dog. As a result of this, the therapist decided to incorporate photos of dogs who were feeling different emotions - happy, sad, worried and sleepy. Ren was then able to demonstrate how she might look if feeling those same emotions. This activity was repeated during weeks seven, eight and nine. By week nine, Ren was observably excited when she walked into the therapist's office. She would seek out the photos of dogs and became far more physically affectionate to the dog. She tried some new feeling words and they became more and more intelligible as she repeated herself. Toward the end of the session, she was brushing the dog who had long hair and then pointed to her own head and said "no hair." She pouted briefly but continued to brush the dog. 
Notes indicate that Ren made steady and consistent progress from week to week. Her therapist indicated during week nine that she was "progressing beautifully." Her last AAT session was week nine; she stopped coming to TCP and no further information was offered as to why. This abrupt ending was disappointing and concerning. This child was showing clear indicators of progress, especially in her ability to recognize emotions and then articulate them. It's impossible to know if progress would have continued and what sort of behavioral markers could have been observed. As Ren's familiarity with the therapist and therapeutic process increased, she appeared to open up and enjoy her sessions.

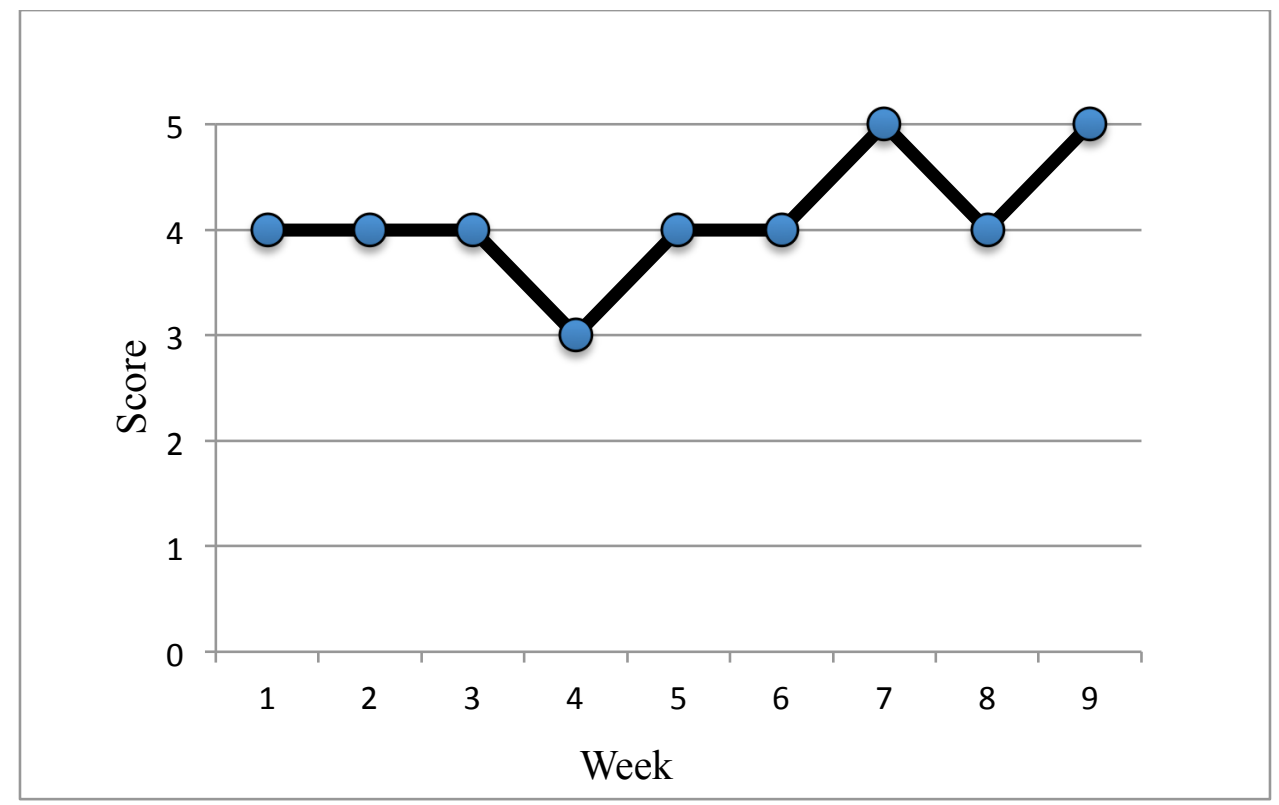

Figure 64. Ren-Attention. 


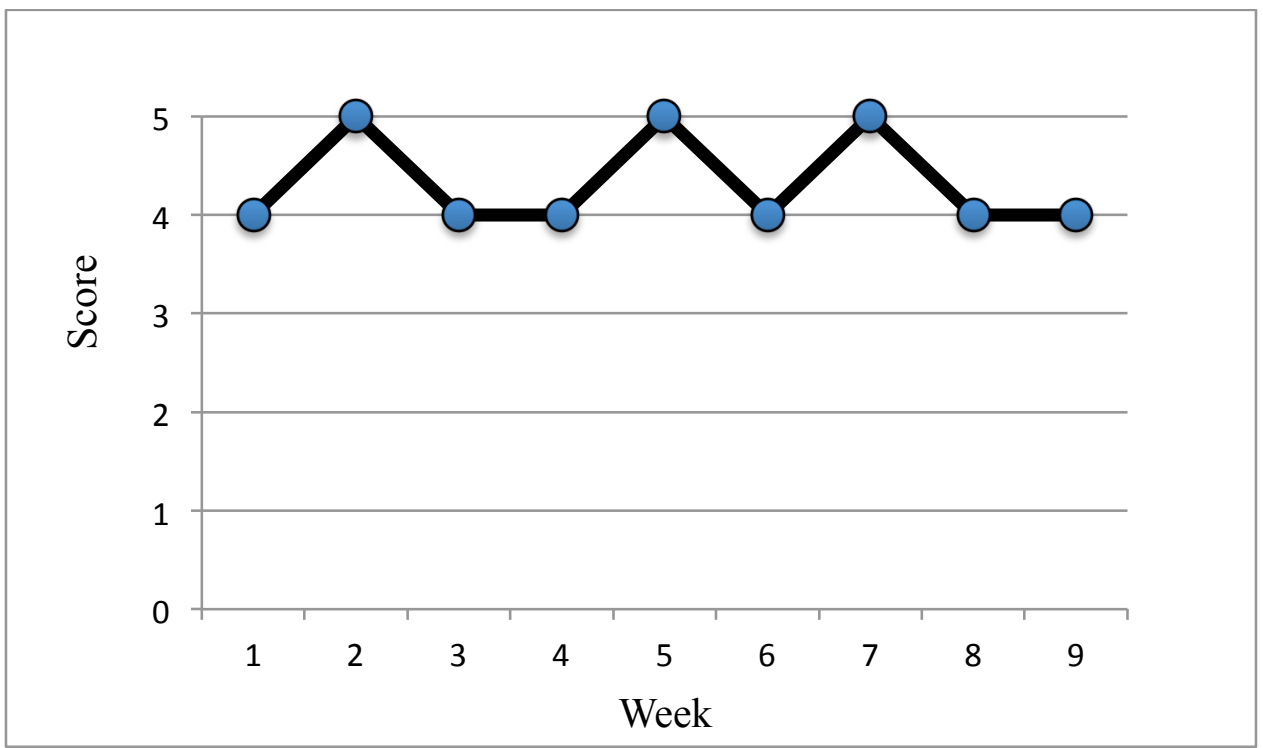

Figure 65. Ren-Engagement.

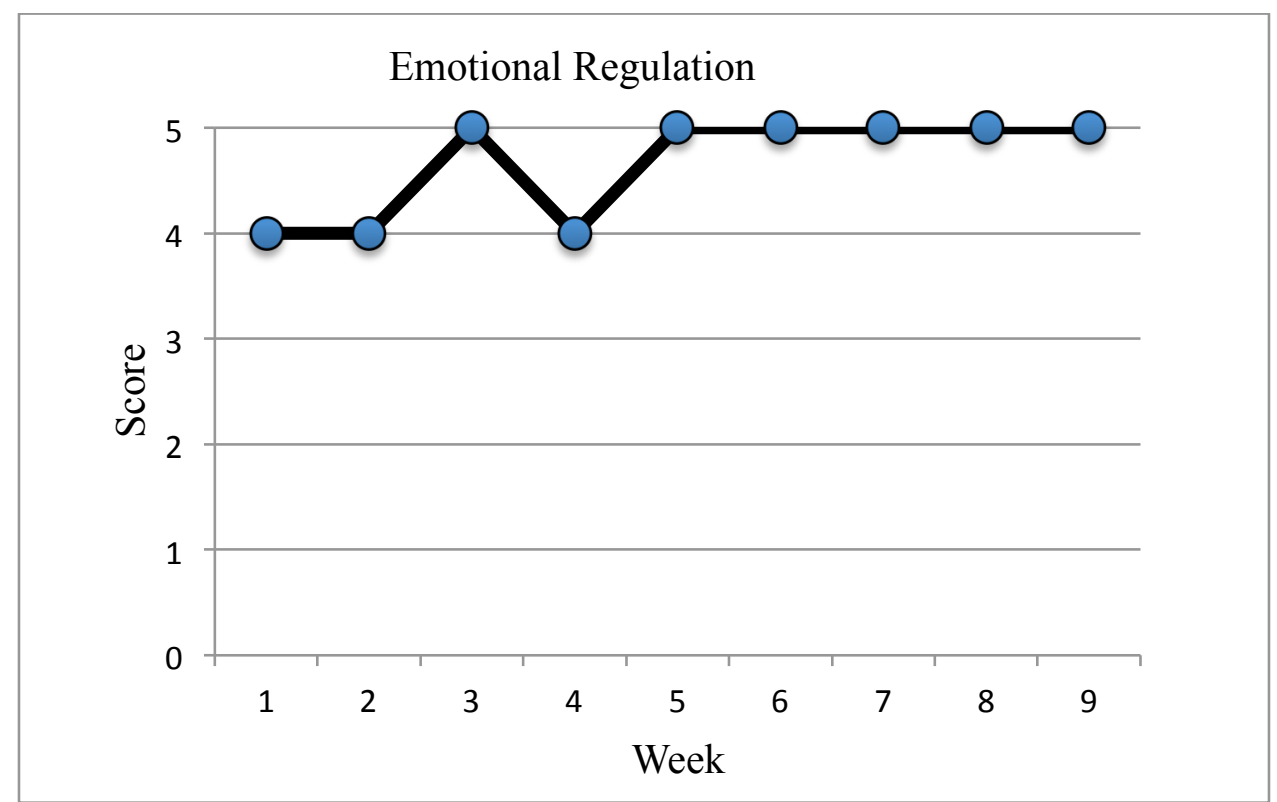

Figure 66. Ren-Emotional regulation. 


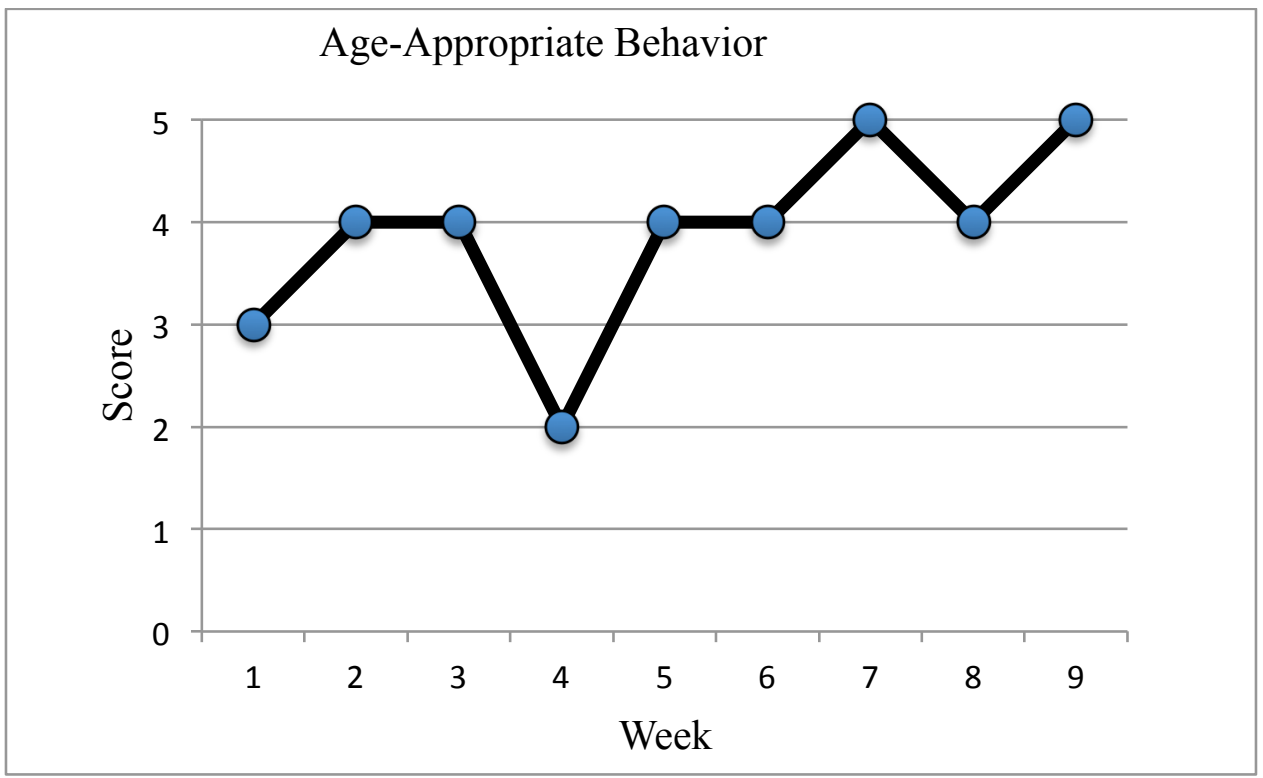

Figure 67. Ren-Age-appropriate behavior.

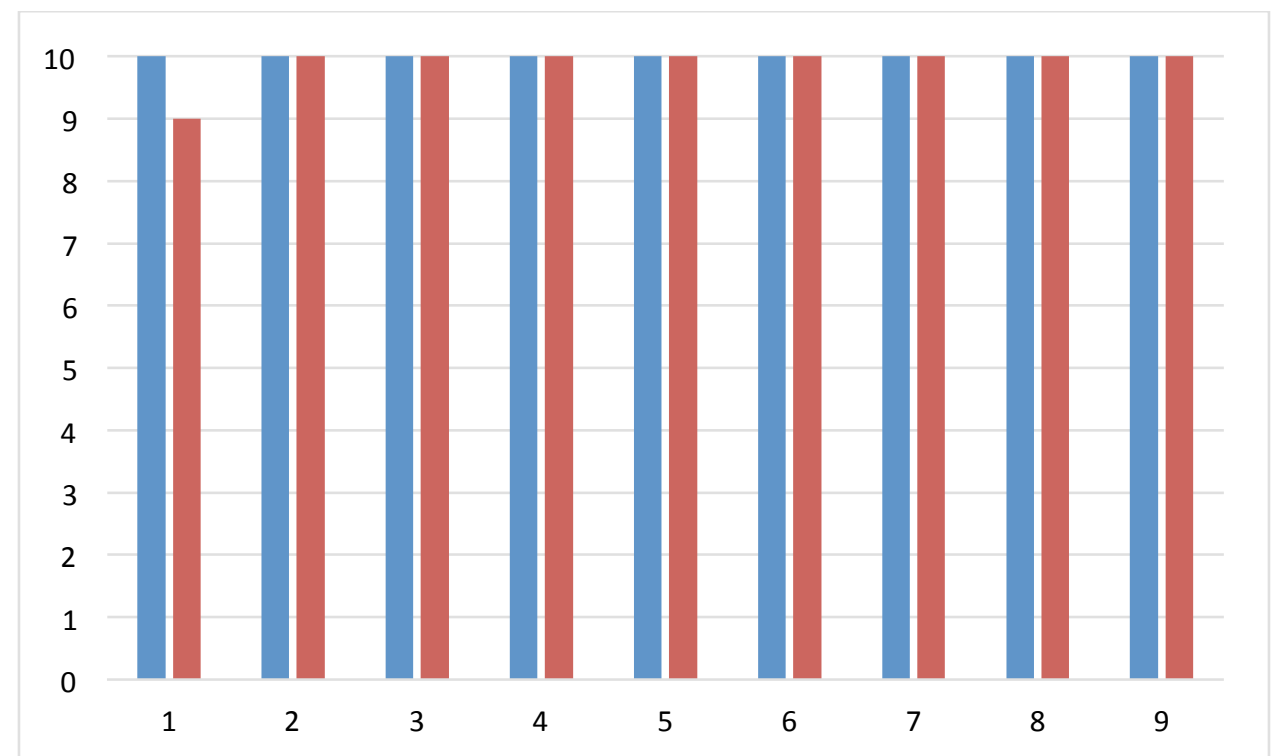

Figure 68. Ren-Cognitive "Yes" scores (Raters 1 \& 2). 


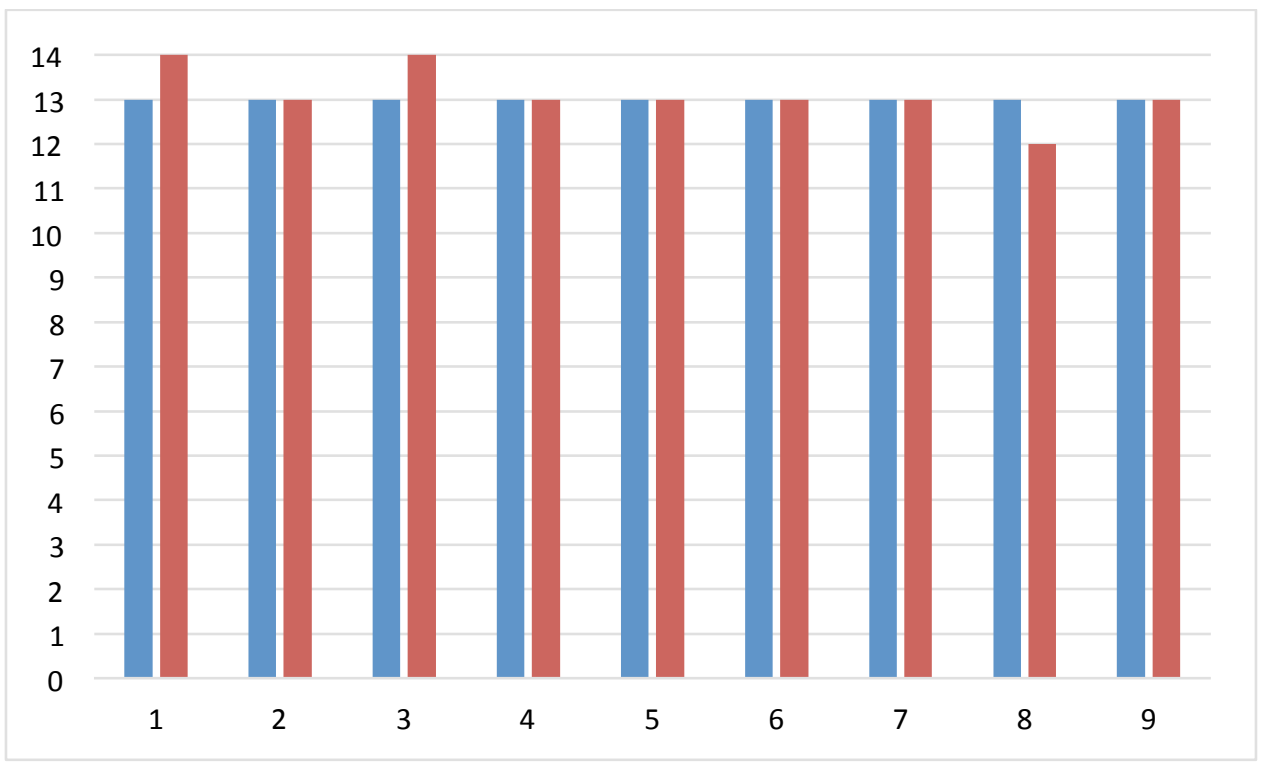

Figure 69. Ren-Social-emotional "Yes" scores (Raters 1 \& 2).

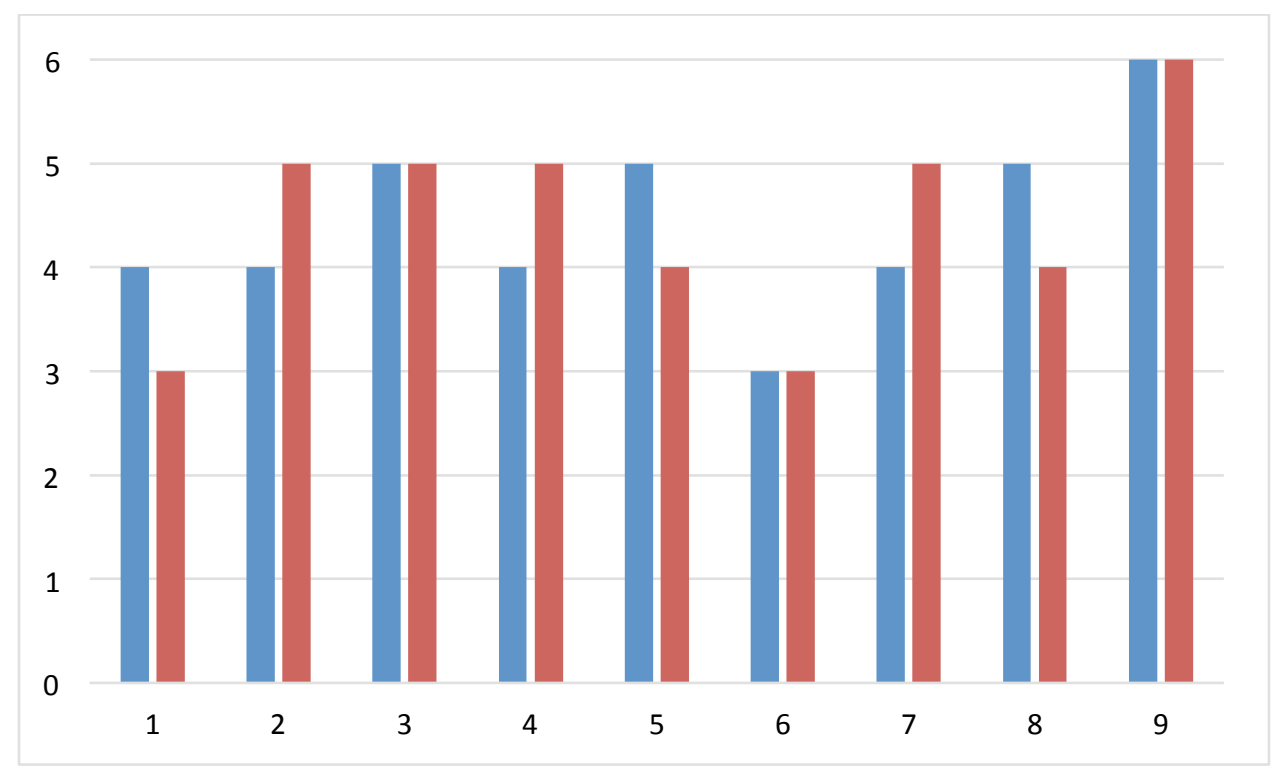

Figure 70. Ren-Verbal "Yes" scores (Raters 1 \& 2).

Ren10's change score was five. She had consistently high scores at the start of treatment but only had the opportunity to participate in nine of the 16 week program. 
Given that she was already receiving very high quantitative scores, her growth during the pilot is better measured using qualitative data. It appears as though she, as well as some of the other clients who received high scores during the first week of treatment, experienced a ceiling effect to their scores and there was a limit to measuring quantitative growth.

Therapeutic impressions. With more time, specific goals may have been set to help improve Ren's fine motor skills. Ideas for ways to help young children with that in an AAT-based setting include leashing and unleashing, buckling and unbuckling the dog's vest, brushing, texture identification (touching parts of the dog that are rough, such as its paws, or soft, such as its ears). Unfortunately, we can't predict how Ren might have responded to these guided activities. Based on what was observed, it is likely that Ren would have been comfortable trying new sensory activities and may have benefited in repeatedly engaging in those skills each week.

11. Tah. Tah was a 25-month-old Caucasian female referred to AAT by her case manager because of concerns that she was not getting enough attention in any of her daily settings (home or TCP). She was a quiet and reserved child who rarely communicated or expressed her needs. She was described as withdrawn but "easy to have in the classroom."

Tah was an only child living with her maternal grandparents; her parents' whereabouts were unknown. Her grandparents had recently relocated after being previously homeless in another state. Both grandparents had previous open cases with Child Protective Services when they were parenting their own children (included Tah's 
mother) but there were no safety concerns for Tah at the time of referral. Tah had limited social outlets outside of TCP; program staff believed she would benefit from a new experience (AAT) and that she needed additional stimulation. Her grandparents were reluctant to enroll their child in the program but ultimately decided they needed a break from daily care; they refused services or supports from any other community-based agency. Tah was reported to have very limited attachment to her grandparents and would not seek them out for comfort. Instead, she would self-soothe or cling to a doll (when hurt or confused). Staff at the program reported having to guess at what Tah might be feeling, because she would not express herself and her affect was so flat.

Compared to similarly-aged children, Tah's case manager rated her as average in social functioning, emotional stability and appropriate behavior but below average in language ability.

There were no pets in Tah's home.

Course of treatment. Tah was very hesitant to enter the room. She needed to be carried. She initially resisted even looking at the dog and began crying. She hid her head in the armpit of her therapist and stayed that way for about five minutes. During that time, the therapist simply cross-talked to the dog about simple feelings that Tah might be experiencing. Messages of safety were also cross-talked ("you are a safe dog and we will always make sure that Tah is safe when she's in here."). Tah turned her body to face the dog and finally made eye contact with it. She continued to show nervousness but was able to touch the dog's fur very quickly when asked if she would like to know what it felt like. After a very brief touch, she giggled. When asked if she wanted to try and touch the 
dog again, she nodded "no" but did not cry or avert her attention. During her second session with the dog, Tah was again nervous upon entering and needed to sit on the therapist's lap. She cried very briefly, which alerted the dog who then licked her face. She looked at the dog with large open eyes and a startled expression, as if she didn't know a dog even had a tongue. She smiled and increased her level of interaction immediately afterwards, still seated on the therapist's lap. She didn't use words and appeared "introverted and withdrawn" but did have more emotional expression during session two. At the end, she waved goodbye and again smiled.

Tah missed her third session and her fourth session looked very much like her first. She was fearful, cried, did not want to touch or look at the dog and eventually moved off the therapist's lap to get further away from the dog. From across the room, Tah engaged in an activity where she colored in parts of a dog's body on paper. She glanced back at the dog multiple times while coloring. She used no words and appeared with flat affect. Upon leaving, she agreed to touch the dog three times; this gave the therapist the opportunity to talk about how the dog might feel when being pet nicely ("I bet that feels good for the doggy. I think you are making him feel happy.").

The next two sessions were started when Tah's teacher brought her into the session. Leaving the classroom with the therapist seemed upsetting so her teacher, with whom she was bonded, brought her in and sat for a while. Tah approached the dog voluntarily and pointed out the treats and toys to her teacher (as if to show off a bit). Tah was able to touch and explore the dog, even looking closely at the pads of his feet and feeling different parts of his tail. She became distressed when her teacher left but easily 
refocused on the dog and engaged with her therapist. Her therapist used a dog puppet to "practice" her interactions with the dog; she also looked at books of other dogs and colored pictures of dogs to aid in increasing her comfort in the room. Week six included walking the dog, she stayed right by his side; and later throwing the ball. She was much more engaged and expressive.

After missing week seven, Tah entered into the room with the therapist (no teacher) for week eight's session and appeared eager to greet the dog. She went right toward him and began to use appropriate words to identify the dog's body parts. She appeared pleased (smiling face, standing up tall) when she correctly labeled her own body parts that matched the dog's. This was, by far, the most verbal she had been in AAT and also the most emotionally composed. From this session (week eight) forward, Tah appeared comfortable, ready to interact with the dog, more verbal from week to week and far more expressive.

The focus of her therapy became centered on her ability to stay emotionally composed and comfortable and also on her engagement with dog and therapist. She seemed to test herself by getting closer and closer to the dog, who would then lick her until she moved away. By week 14, she would not move away and the licking would turn into an experience lasting minutes. She giggled and laughed. She began using verbal commands and praises for the dog, which in turn lead to her being praised for her clear communication. During week 14, she said "good doggy-dog" without any support from therapist. 
By her last session, Tah confidently walked into the room and verbally greeted the dog. When reminded that it was her last session, she was eager to lie next to the dog and draw a picture for him (which she then gave to the dog's handler). The dog again spent some time licking Tah's face and hands, which she enjoyed. She walked the dog, as had become routine, threw the ball and then offered treats. She received a polaroid photo of her with the dog, which she looked at closely and held to her chest when it was time to say goodbye. Tah easily transitioned out of the room, offering the dog a hug followed by a big wave. She was very verbal throughout her last session and seemed to understand it would be her last time in AAT. Her final case note closes with: "Wow! She is a lot more comfortable and happy..." and "she has immensely increased her confidence and comfort level."

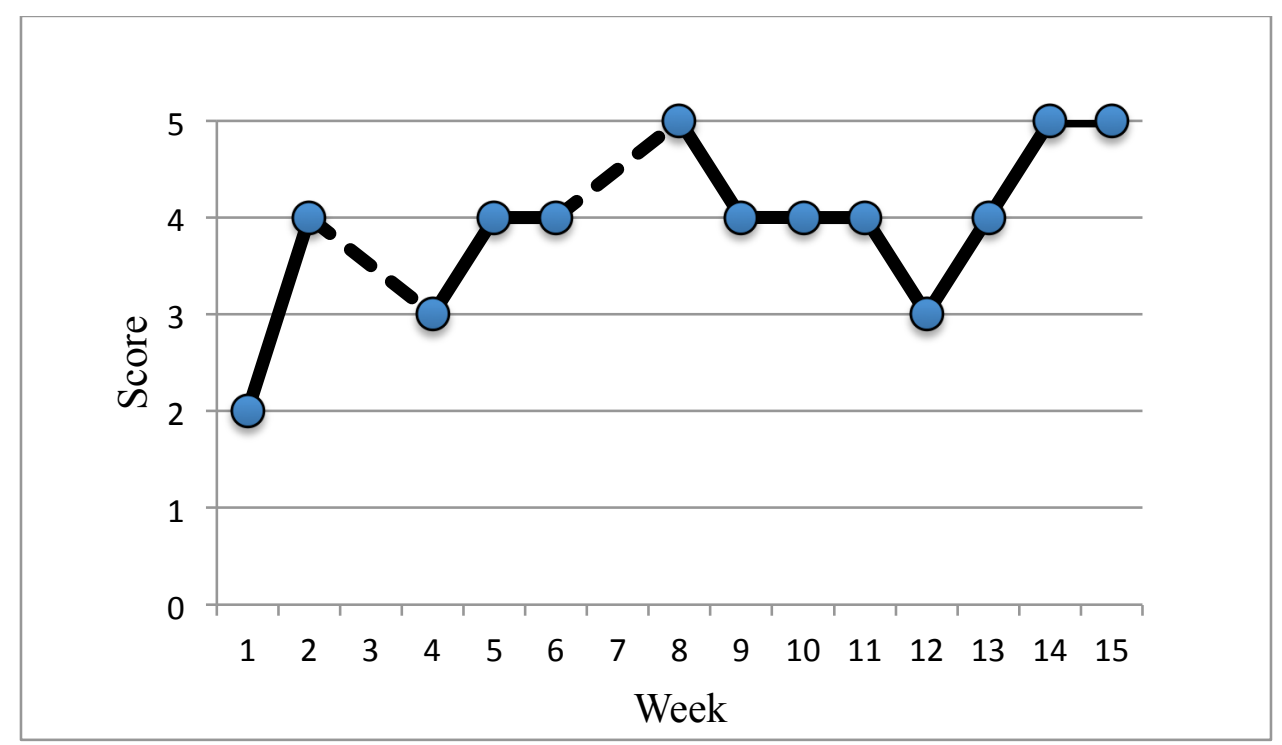

Figure 71. Tah-Attention. 


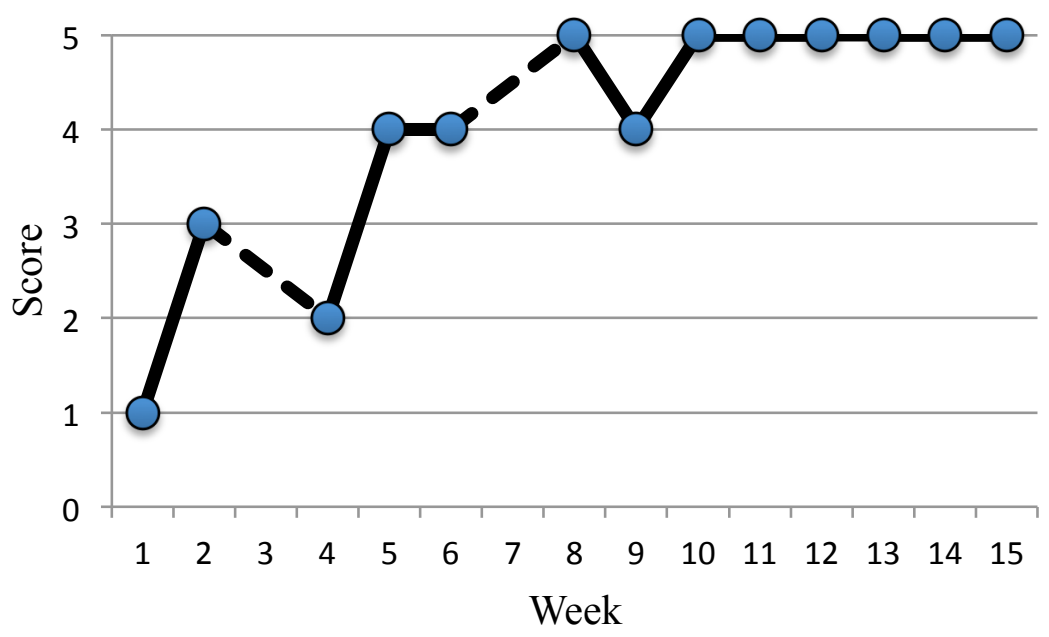

Figure 72. Tah-Engagement.

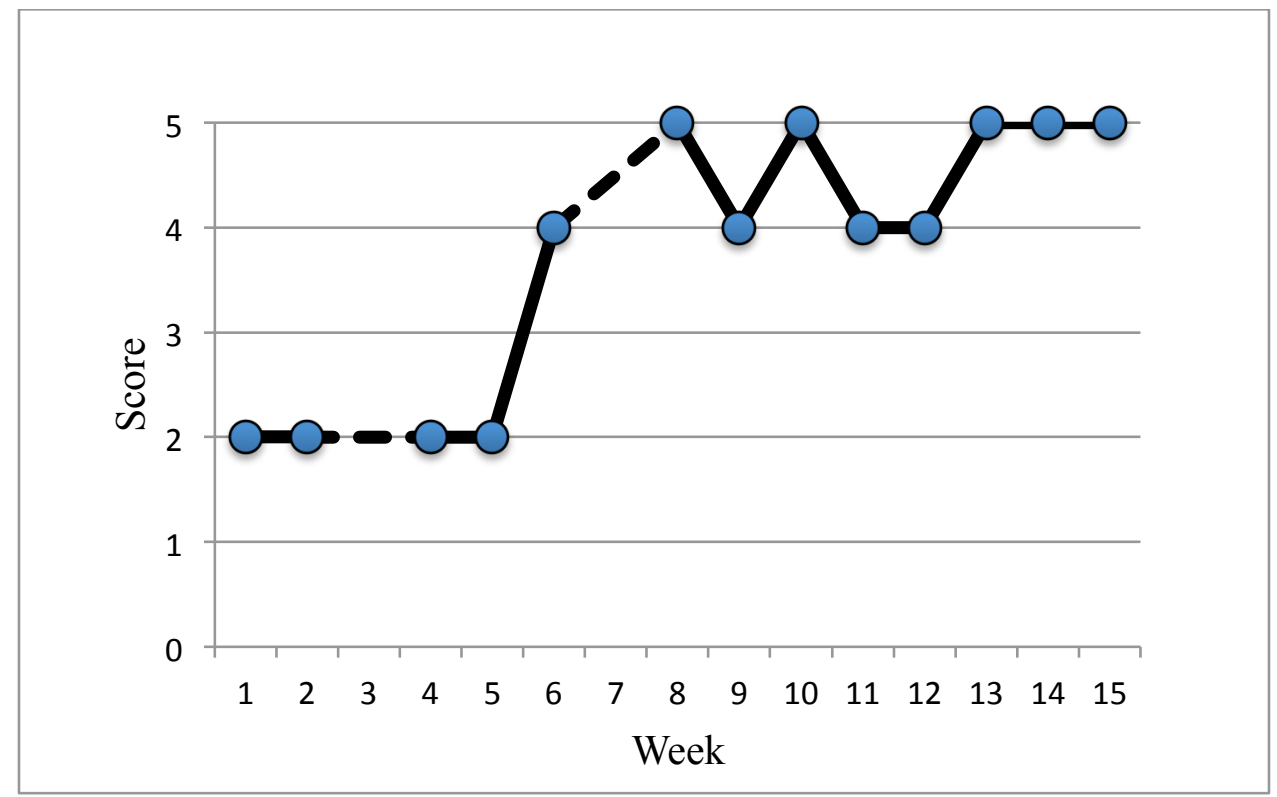

Figure 73. Tah-Emotional regulation. 


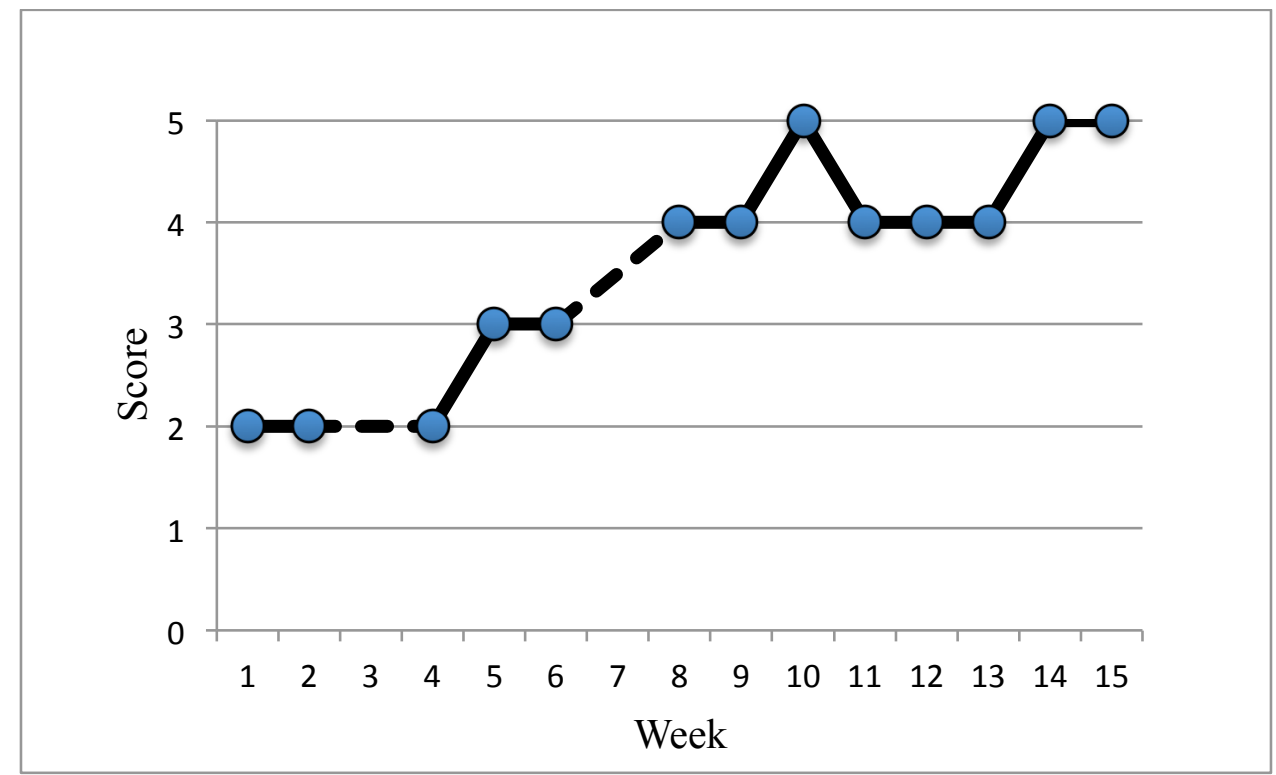

Figure 74. Tah-Age-Appropriate behavior.

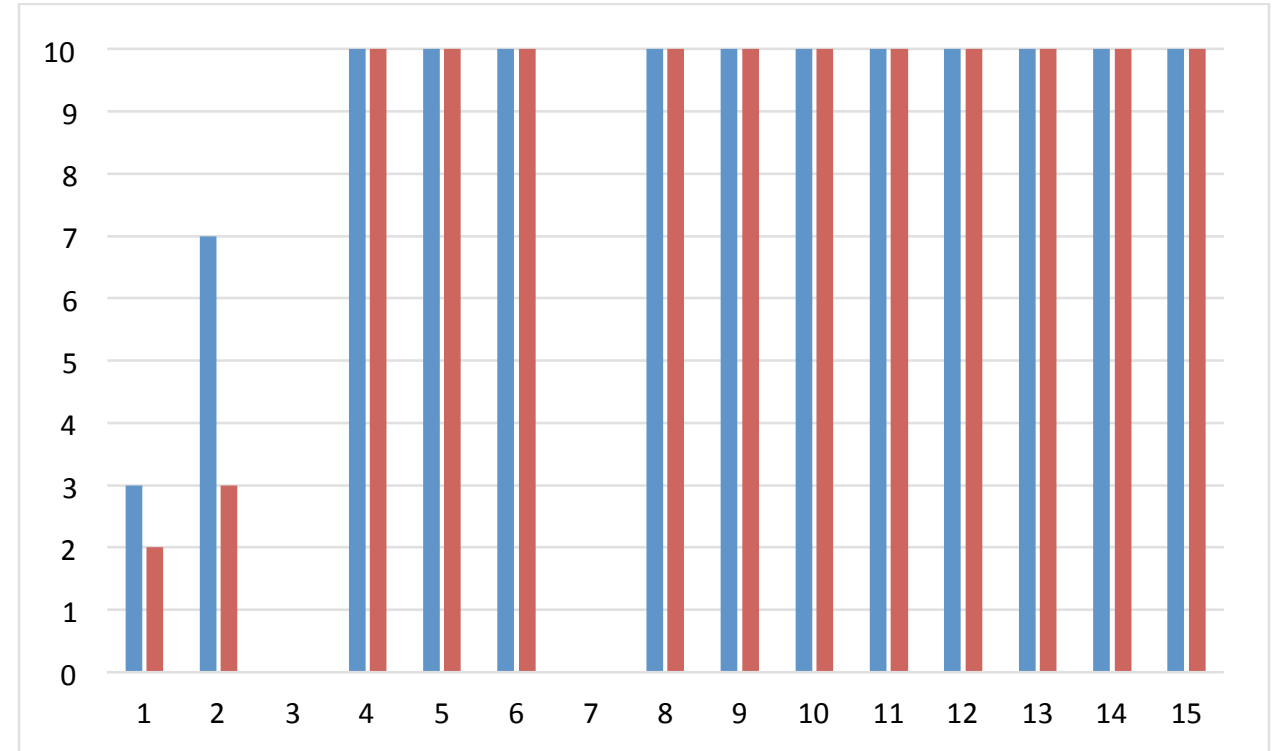

Figure 75. Tah-Cognitive "Yes" scores (Raters $1 \& 2$ ). 


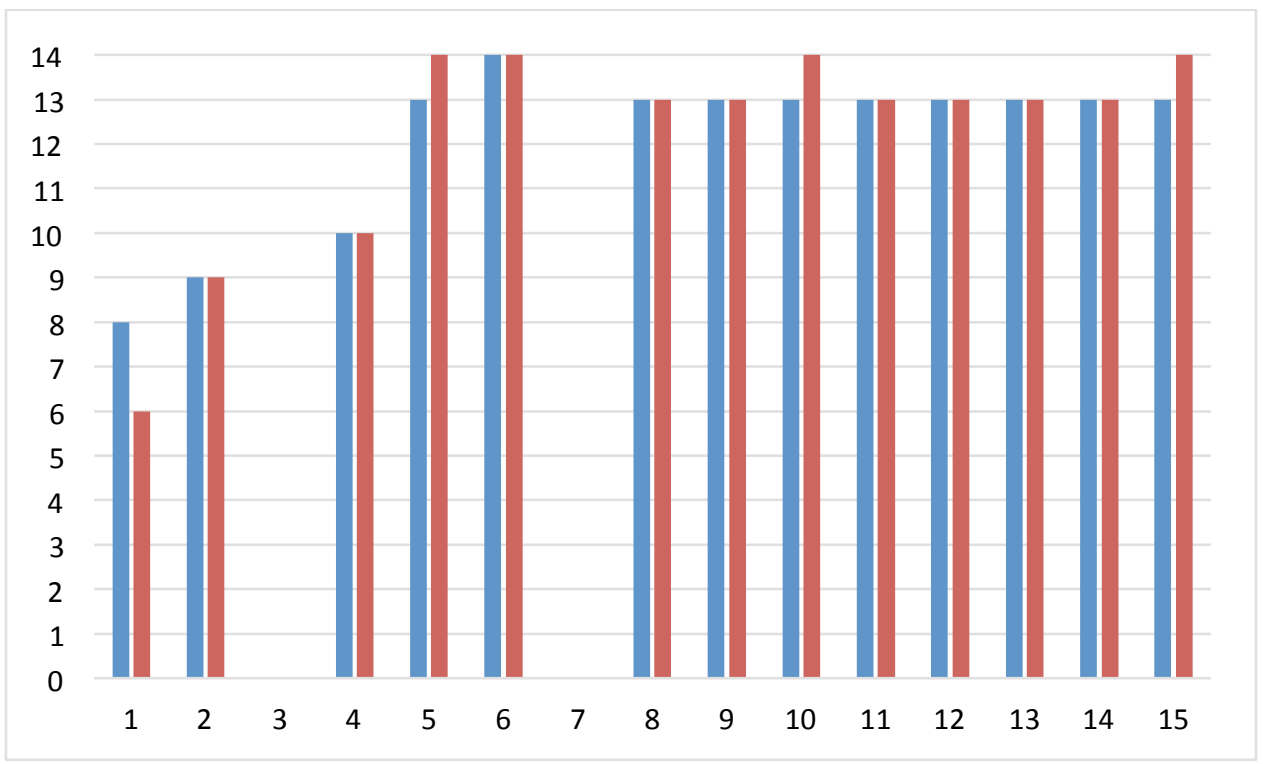

Figure 76. Tah-Social-emotional "Yes" scores (Raters 1 \& 2).

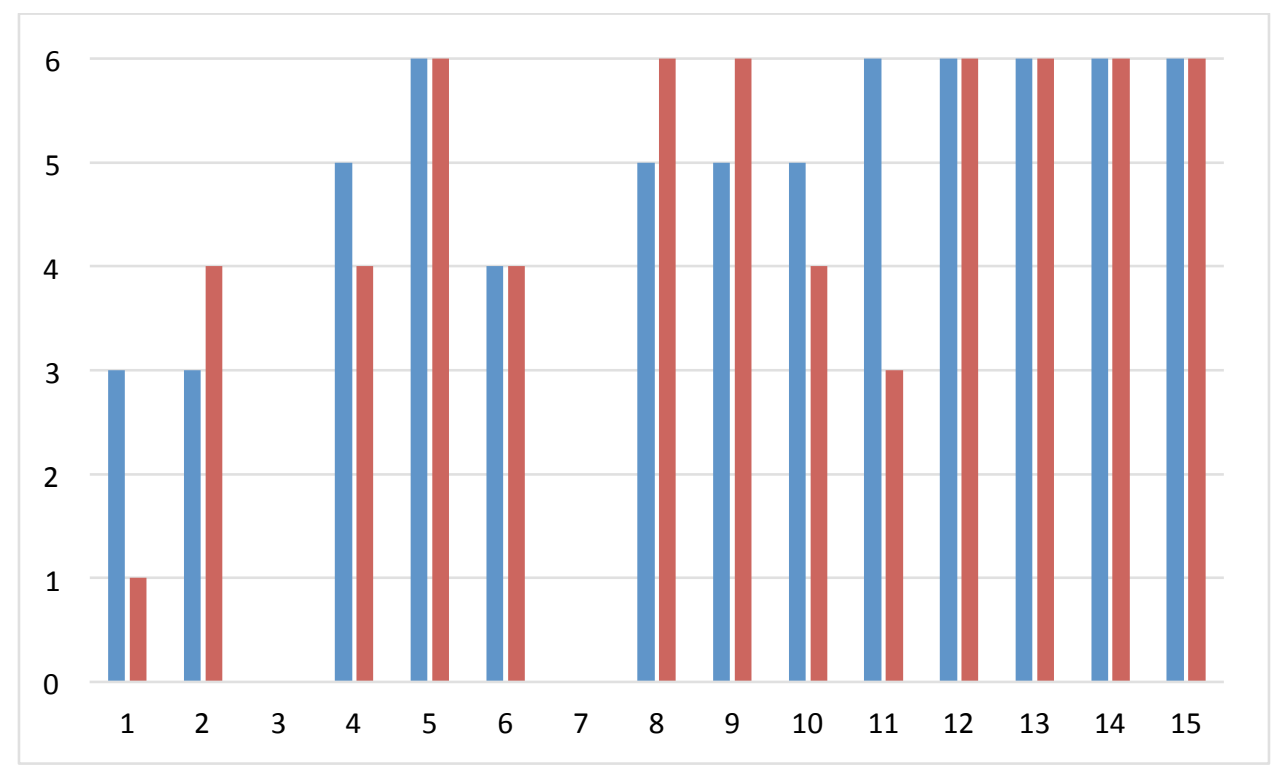

Figure 77. Tah—Verbal "Yes" scores (Raters 1 \& 2).

Tah11 has the third highest change score in the sample group: 46. 
Therapeutic impressions. For Tah, her experience in AAT was likely overwhelming at first. She had very few opportunities for socialization outside of her home and classroom. Her fear, tearfulness and reluctance were appropriate responses to such a novel experience and to be expected given the referral information provided prior to the pilot. For a child like Tah, new sensory experiences are valuable opportunities for exploration, emotional growth and confidence-building. In all measured areas, this child responded positively to AAT and maintained that progress during the last few weeks of treatment. Similar to Vivi (client \# 13), a family-focused approach could help to strengthen the positive impacts seen in the clinical setting. Helping to improve the attachment between Tah and her grandparents could be crucial in her long-term success. Also supporting the grandparents, who seemed reluctant and fearful as well, to explore a new setting and facilitate a relationship with a professional could be significantly beneficial to their role as Tah's caretakers. As shown in prior studies, rapport building may be increased with the presence of a dog in the treatment setting (citation here).

12. Vin. Vin, a 34-month-old Caucasian male was referred for AAT after showing increased aggression toward peers in his classroom. Vin has been at TCP for close to two years prior to the AAT pilot study and seemed very comfortable in the program setting. He had experienced housing instability and inconsistent parenting, witnessed domestic violence, had a short period in foster care (three months), and lived in extreme poverty during his enrollment at TCP. His referral source (program case manager) believed that Vin had experienced neglect from his caregivers but didn't have "proof." At the time of referral, Vin was living with his father, sharing a room with him in the home of a friend. 
Vin presented with very long hair, often in tangles, and would have various pieces cut out from week to week. He was often bathed while at the program because he was observably dirty, uncomfortable and was noted to "smell inappropriate" on most days. Vin's clothes generally did not fit and his pants were kept on his body with a thick piece of string that served as a belt. When the program sent home clothes in his size, he never returned wearing them. He continued to wear the ill-fitting or dirty clothes. He also appeared to have strabismus (crossed eyes) but his family had not followed up on referrals to ophthalmologists.

The referral source noted the following: "social-emotional concerns, high level of frustration, lack of problem-solving skills." Vin would hit others whenever frustrated and had difficulty expressing his feelings through words. He also appeared anxious when interacting with adults in his classroom. Vin would have bouts of screaming when his aggression was addressed; calming Vin down often involved moving him into a quiet space and assuring him that he was safe.

Vin's play was rife with anger and violence. He would "pretend" to kill his toys and always seemed to take on the role of aggressor. Professionals at TCP hoped that Vin might be able to express himself in AAT in a new/constructive way in order to process some of the experiences he witnessed. There continued to be concern that Vin's needs were not being adequately met in his home environment.

Compared to similarly-aged children, Vin's case manager reported that he had average social functioning but below average emotional stability, appropriate behavior, 
and language ability. He was receiving services through the county for delayed speech and language.

There was a dog in the home where Vin lived at the time of his referral. Due to his repeated moves and changes in caretaker, it was unclear how long Vin had lived with this pet.

Course of treatment. Vin presented as quite frantic, disorganized and unable to make eye contact. He also seemed small for his age but highly articulate and loud. He began acting out aggressively toward the dog during the very first therapeutic session. He was rough and often would push or hit the dog on the head. These behaviors were striking because, although noted in his referral information, it was evident from the first moment he walked into the office that he was unable to manage his outbursts and his acting-out was linked to feeling overstimulated. He would easily lose focus but when supported in reengaging with the dog, he would demonstrate happiness, comfort and communication. His body was often moving around the room, it was difficult for him to stay on any single task for more than a minute. He enjoyed physically interacting with the dog through petting, brushing, going on walks and giving commands. He would try and roll on or wrestle the dog, which was discussed with him by helping to identify how the dog might feel ("worried," "scared," "not sure" and "hurt"). In general, Vin seemed highly stimulated by not only the dog but by the level of one-to-one attention being offered.

By week three, Vin remembered the dog's name and became slightly less excitable. He appeared almost overly comfortable/no boundaries with the dog and the 
dog's belongings (toys, food, leash, treats) and would grab at them impulsively. Vin required a lot of redirection, which is often times counter-therapeutic, to stay safe in the session and not act out on the dog.

Case notes indicate Vin was often aggressive, highly distractible, aggressive, highly aroused and had difficulty calming down — these themes persisted into his last week (week 15). However, what was also noted was an increase in physical affection toward the dog, ability to speak clearly to the therapist and dog, identification of basic feelings in himself and the therapy dog, and the ability to link his behaviors with outcome (“He happy because I here.”). Areas of improvement: increased verbalization, feelings identification and cognitive skills (clear thinking, good memory). Though we did not see evidence of a decrease in aggression or impulsivity, the improvements in other areas were obvious. During his final session, Vin was able to dictate a social story to his therapist, which he made up largely on his own: "I am dog and I happy. Dog sad to get hurt. No hurts." 


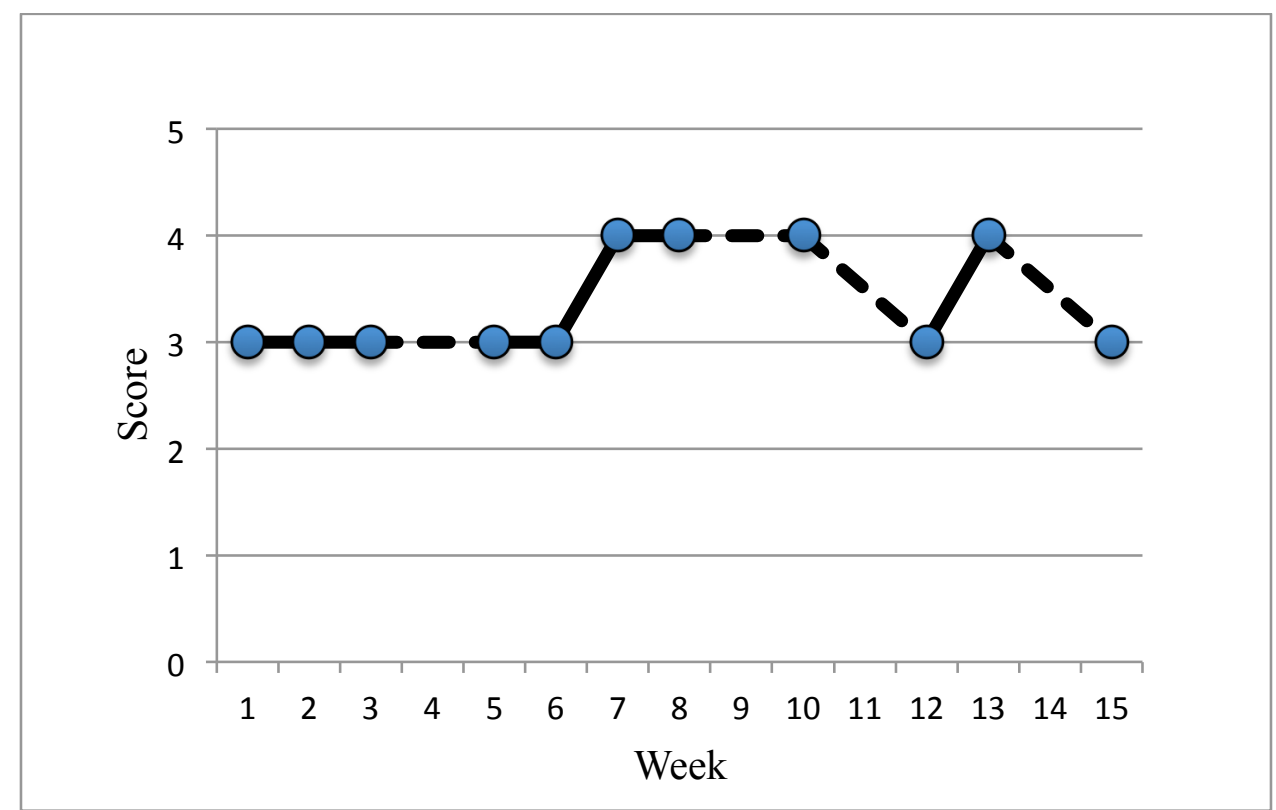

Figure 78. Vin-Attention.

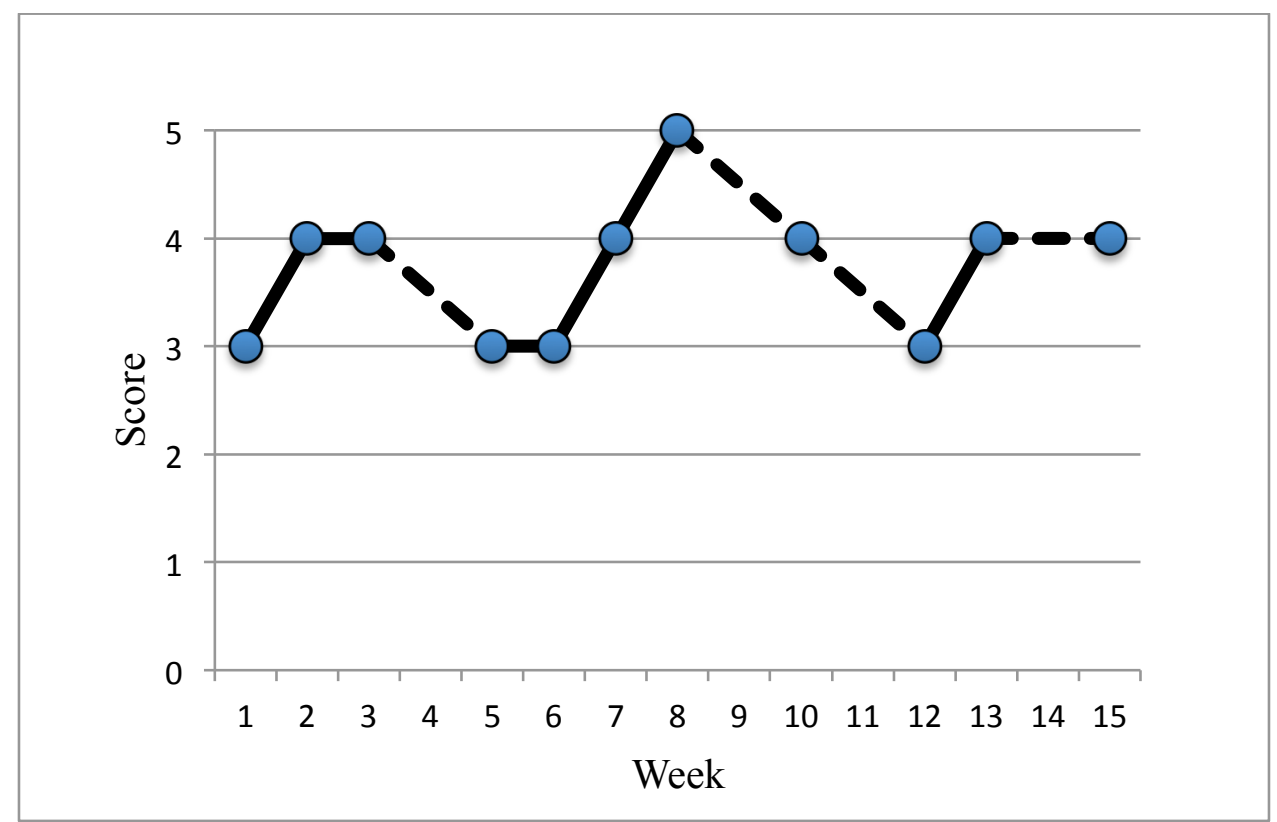

Figure 79. Vin-Engagement. 


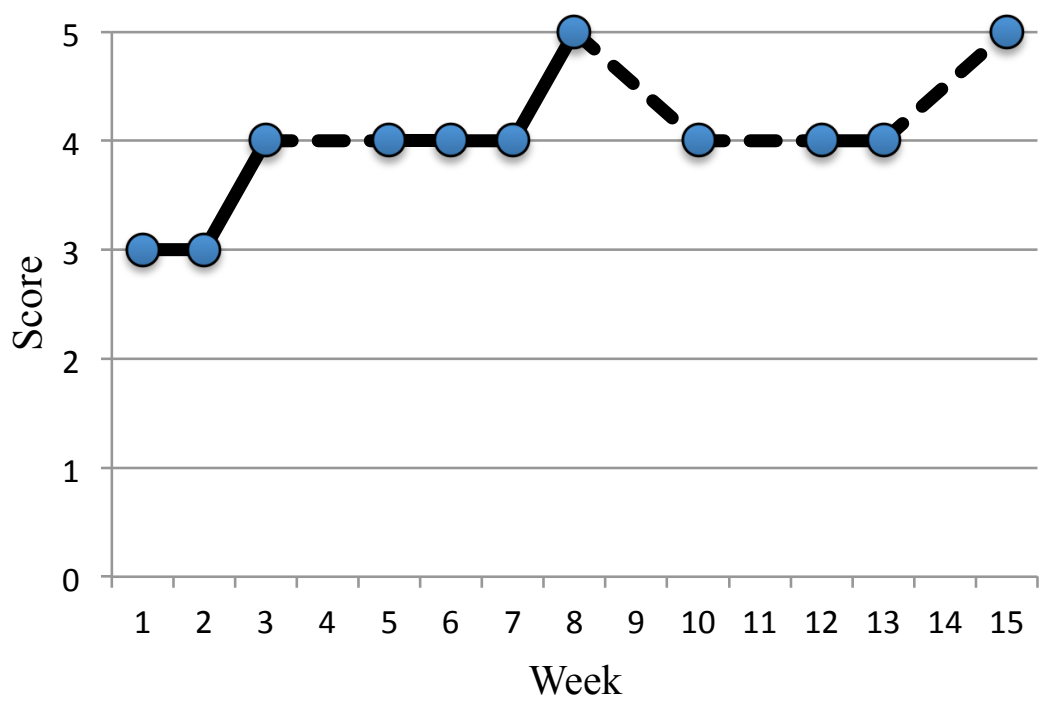

Figure 80. Vin-Emotional regulation.

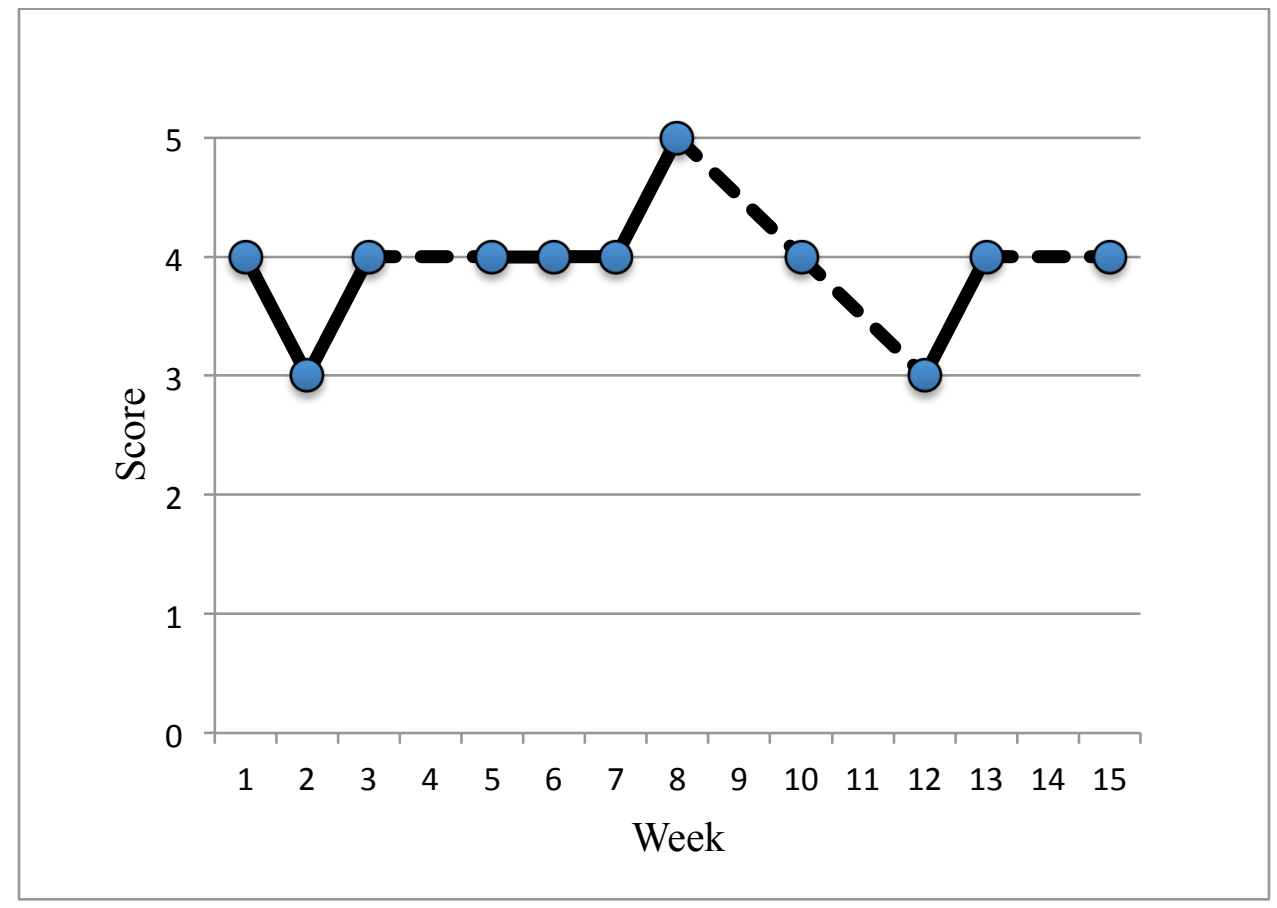

Figure 81. Vin-Age-appropriate behavior. 


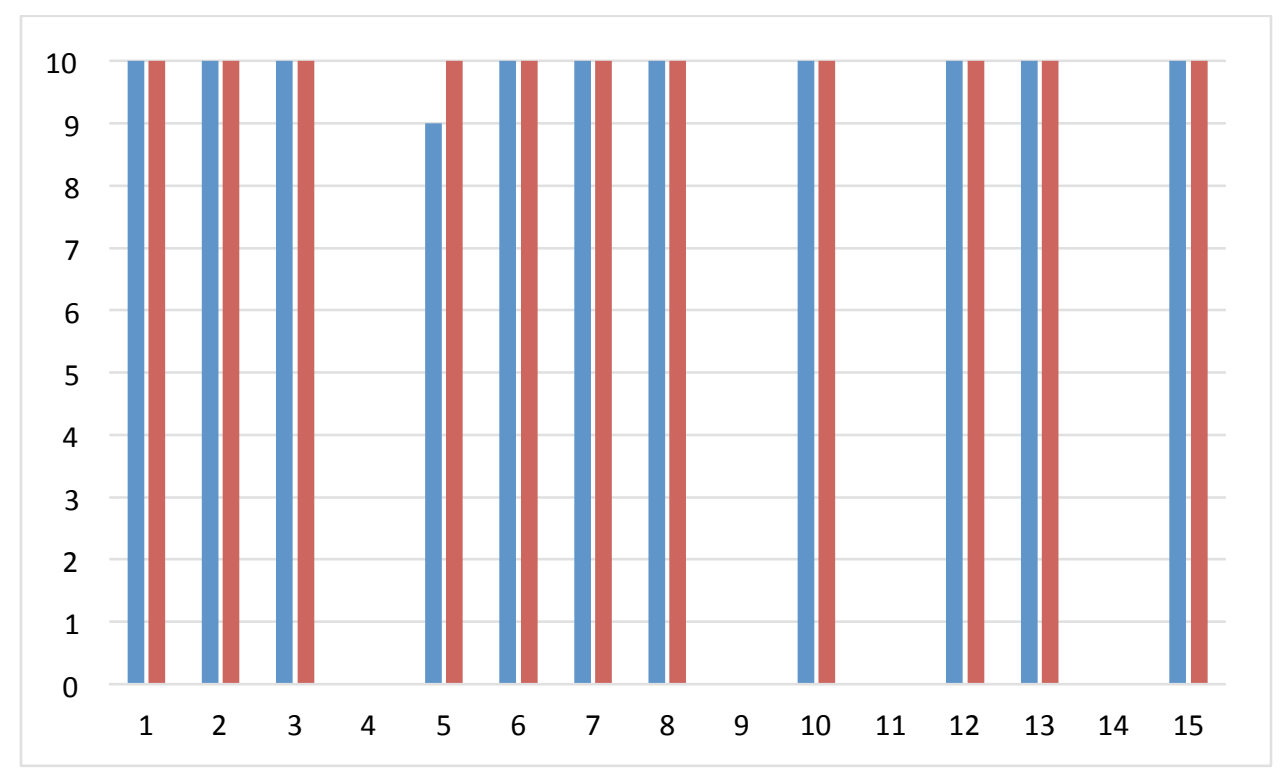

Figure 82. Vin-Cognitive "Yes" scores (Raters $1 \& 2$ ).

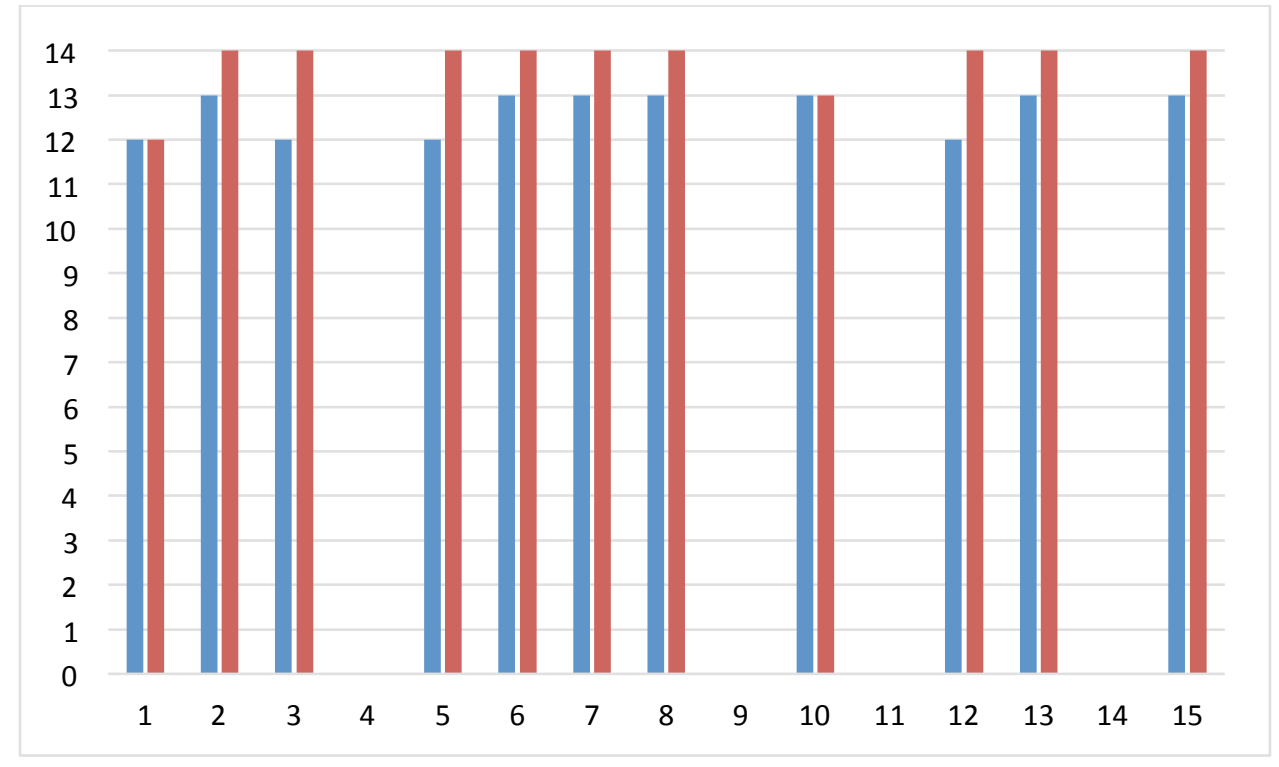

Figure 83. Vin-Social-emotional "Yes" scores (Raters 1 \& 2). 


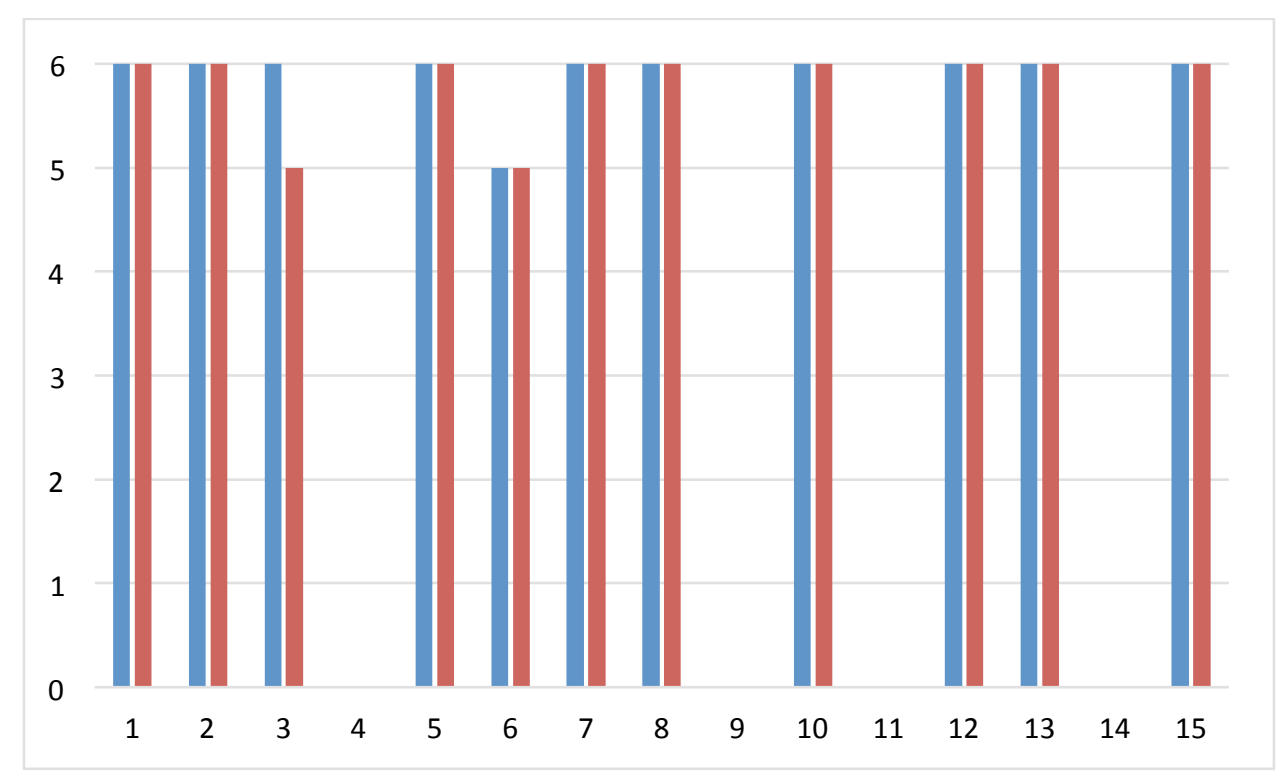

Figure 84. Vin-Verbal "Yes" scores (Raters 1 \& 2).

Vin12's change score was five.

Therapeutic impressions. This particular child demonstrated some classic symptoms of sensory dysregulation and anxiety. His diagnosis of Adjustment Disorder may capture some of the indicators of impulsivity, aggression and lack of focus. The therapeutic environment seemed to strengthen some skills in Vin that might help to balance or stabilize him, given his behavioral challenges; for example, understanding how his behavior impacts others would have clear benefits in social relationships. Also, understanding how he himself is feeling could help him to better regulate when overstimulated, anxious or excited.

This client, due to his need for physical activity and lack of prolonged attentiveness, received many opportunities to interact with the therapy dog: each session involved brushing, walking, throwing a ball, petting and giving treats. In many ways, Vin 
seemed to crave even more interaction-like wrestling and tickling the dog. Perhaps this was evidence of his need for more sensory input (he seemed to seek proprioceptive input from his environment, which often resulted in what was labeled "aggression" when, in fact, he was seeking contact and grounding).

Upon reflecting on this client, AAT might be best used as diagnostic support for identifying more clearly what his needs are. So much of his sensory seeking behaviors, which appear aggressive in nature, are typical for young children with sensory processing disorders. Allowing him opportunities for more "heavy work" may have calmed his body and allowed him more focus. A therapy dog is not necessarily the best fit for providing a child with the proprioceptive input he needs; but perhaps offering that input, either as an adjunct to AAT or before the therapy is introduced, would be beneficial.

In this case, the therapist learned much more about what needs this child was having and how the program might further support him outside of the pilot program. Opportunities to jump, crash, bump into, tug, climb, carry heavy things, squeeze and swing were all recommended as a result of his experiences in AAT and are supported in the literature on children with sensory needs.

13. Vivi. Vivi was a 31-month-old Hispanic/Caucasian female referred for AAT after a continued demonstration of aggression and noncompliance in the therapeutic classroom. She had been at TCP for one year and, though the aggression decreased somewhat, she continued to struggle with rule following and could not seem to engage in most activities. On most days, Vivi would run from activity to activity, never really focusing on any single task for more than a few moments. She was described to be "like a 
lit firecracker" and in need of constant "shadowing" to be sure she wouldn't hit, scratch or kick other children. The program had begun to provide Vivi with a one-to-one aide, though not necessarily staffed to provide this level of care, to keep her and the other children safe. Her dysregulation was consistent through the day.

Vivi lived with a single teen mother who was six months pregnant when AAT commenced. The family lived in a subsidized housing complex and received public assistance. Vivi's mother was involved with multiple service providers and had an open case with Child Protective Services, though Vivi was never removed from her mother's care and there was no record of abuse/neglect. Her classroom teacher believed that Vivi wasn't getting consistent attention at home and that her needs would be further ignored once her baby sibling was born. Vivi's mother admitted to being "scared" of what Vivi would do to her infant sibling.

Compared to peers, Vivi's referral form notes that she was below average in social functioning, emotional stability, and appropriate behavior but had average language ability. Her teacher noted that the child was one of the "most difficult kids" in the program because she seemed to have a constellation of needs that were not fully understood. Other service providers were regularly involved with this family, largely due to this child's mother being young and pregnant. Vivi "looked good" per a report from a case manager, which meant that she was well-dressed with no observable hygiene needs going unmet. She had huge, dark eyes, which were often complimented, and her mother often would tell people “don't be fooled, there's evil in there."

There were no pets in Vivi's home. 
Course of treatment. Vivi missed the first two AAT sessions (for reasons unknown). Her first session started with her rushing into the room, only briefly approaching the dog and then scattering the toys that were in the office. She appeared dysregulated and unfocused, perhaps this new setting was overstimulating. She needed repeated redirection and support to focus on one task at a time, she was distracted and impulsive. She showed sporadic interest in the dog and his toys and seemed to enjoy throwing them in his direction. Her time during the first session was spent exploring the room, touching items she could reach (including the dog) and rapidly shifting attention. She was encouraged to say goodbye at the end of her first session, which she was able to do; she said the dog's name (showing that she was paying attention to the information being shared by the therapist even though her attention seemed elsewhere).

Vivi's second session in AAT was far less impulsive and chaotic. She was more focused on the dog and was able to engage in simple direction-following: greeting the dog, feeding the dog, calling the dog by his name, and putting on the leash. She spontaneously began talking to the dog and babbling. Interesting to note: case notes indicate that when the therapist returned Vivi to the classroom, she was immediately impulsive and defiant; she began tumbling and running around the room. Her teachers needed to redirect her multiple times before she calmed down. Her emotional composure during the AAT session was met with dysregulation in the classroom setting immediately after. Perhaps this transition was too abrupt or she was aroused from AAT in a way that made it difficult to return to the classroom. 
After missing a week, Vivi returned (week six) and initially presented as shy and quiet, which had not been observed prior. She turned away from the dog and therapist briefly but was quickly engaged after being asked if she wanted to walk the dog. She was focused and calm throughout the session, far less impulsive, and stayed on task with coaching. She touched the dog and enjoyed receiving kisses from him, which was the most physical interaction they had had to date. She stayed primarily focused during the session on the dog, which was an improvement from prior sessions when she emptied toy bins, toppled small chairs and generally showed a lack of focus.

Vivi continued to present in a similar fashion for all sessions: she was aroused, moved quickly around the room, seemed to have more energy than she could channel and needed steady redirection from her therapist to focus on any one task. Despite her level of (over) stimulation, Vivi accepted direction and encouragement and always returned her focus to the dog. She engaged in a lot of pretend play with the dog (pretending to eat his treats and hiding things from the dog and asking him to find them). Her affect was always bright and appeared happy. She did not express or show distress.

Week 13 focused on helping Vivi to recognize her own feelings (happy, excited, ready-to-go) and then label feelings of experiences in the dog (fun, ready, happy). She continued to need a lot of support to regulate her behaviors and stay focused but she was affectionate toward the therapy dog and praised him when he did something she liked. Vivi communicated directly with the dog, both verbally and non-verbally, throughout the session. Vivi often needed visual cues to help with focus and her therapist kept pictures drawn during previous sessions. There was one picture, drawn early into the pilot, of Vivi 
and her "baby brother" (yet to be born); she rediscovered it during her session and pointed to the baby, calling him "Mac," the name of the therapy dog. When asked if she wanted to name her baby brother "Mac," Vivi enthusiastically gestured "yes" and jumped up and down. She repeated the dog's name many times. Due to reasons unknown, this was Vivi's last AAT session. She was not in the program for the remaining three weeks that the pilot was offered.

Program staff were not surprised when Vivi stopped attending and thought it might be due to the birth of her baby sibling; however, efforts were being made to contact the family and DHS caseworker. Clearly, there was a shared concern for this child shared by the program staff. One of her teachers stated, after she stopped coming to the program, that she "just needs so much" and was "only starting to get it."

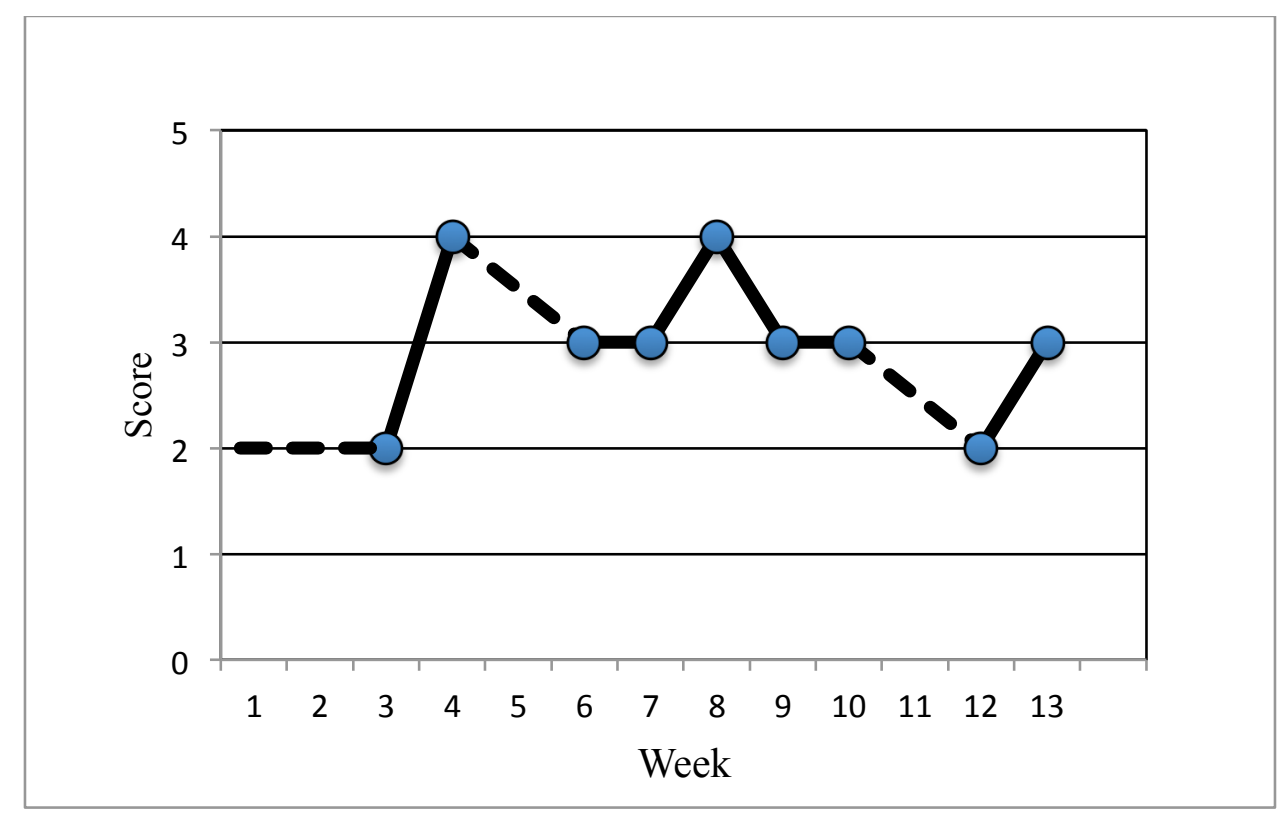

Figure 85. Vivi-Attention. 


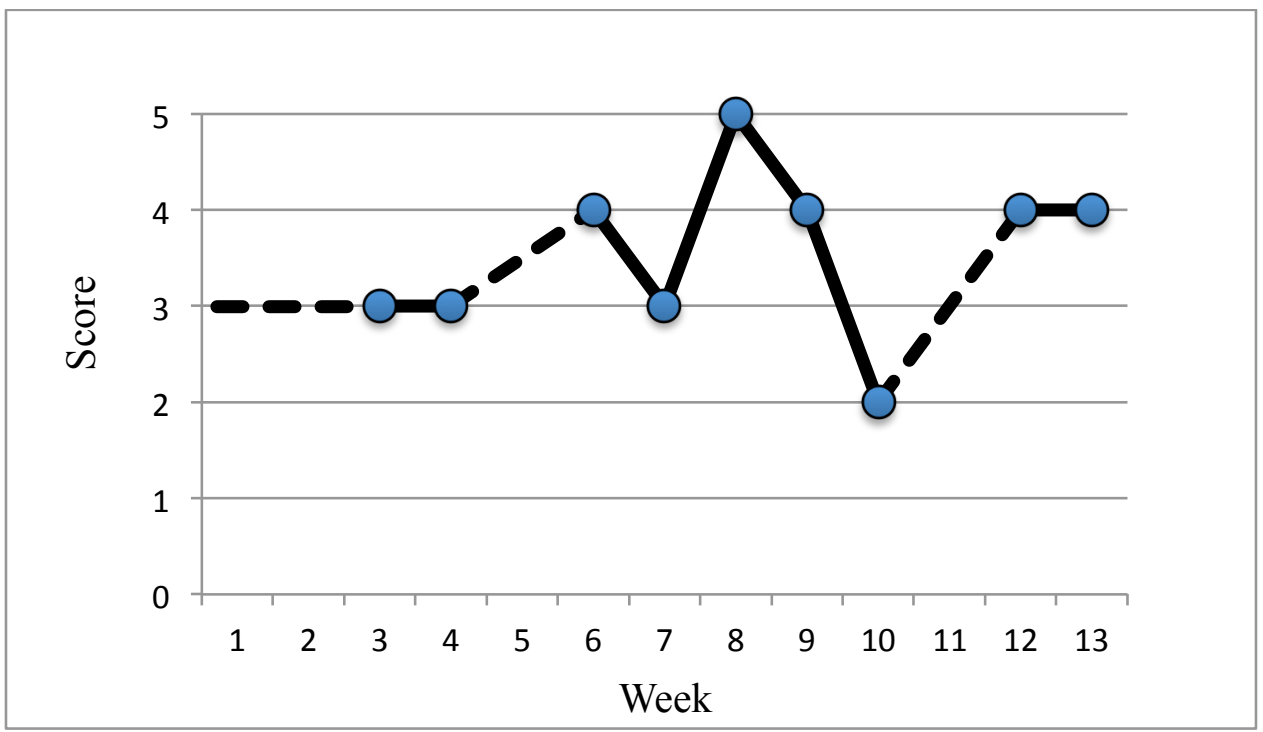

Figure 86. Vivi_Engagement.

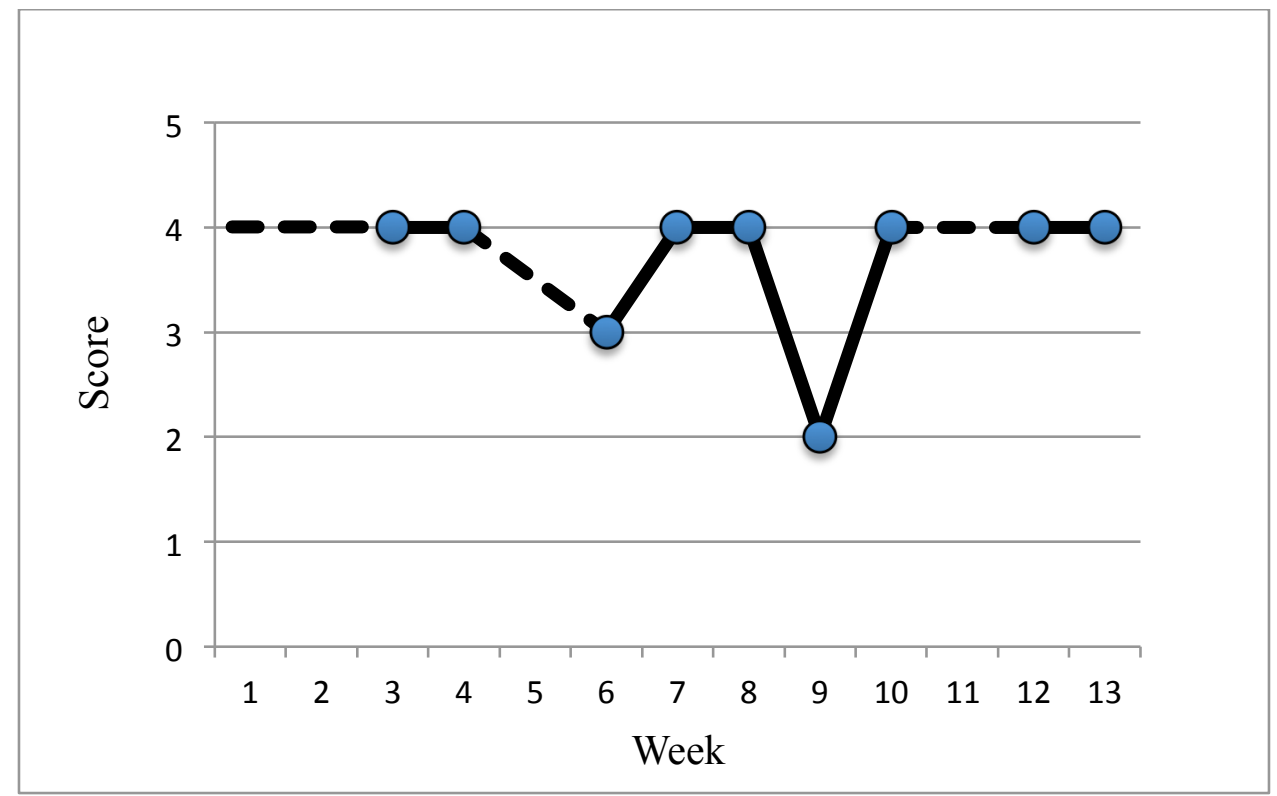

Figure 87. Vivi-Emotional regulation. 


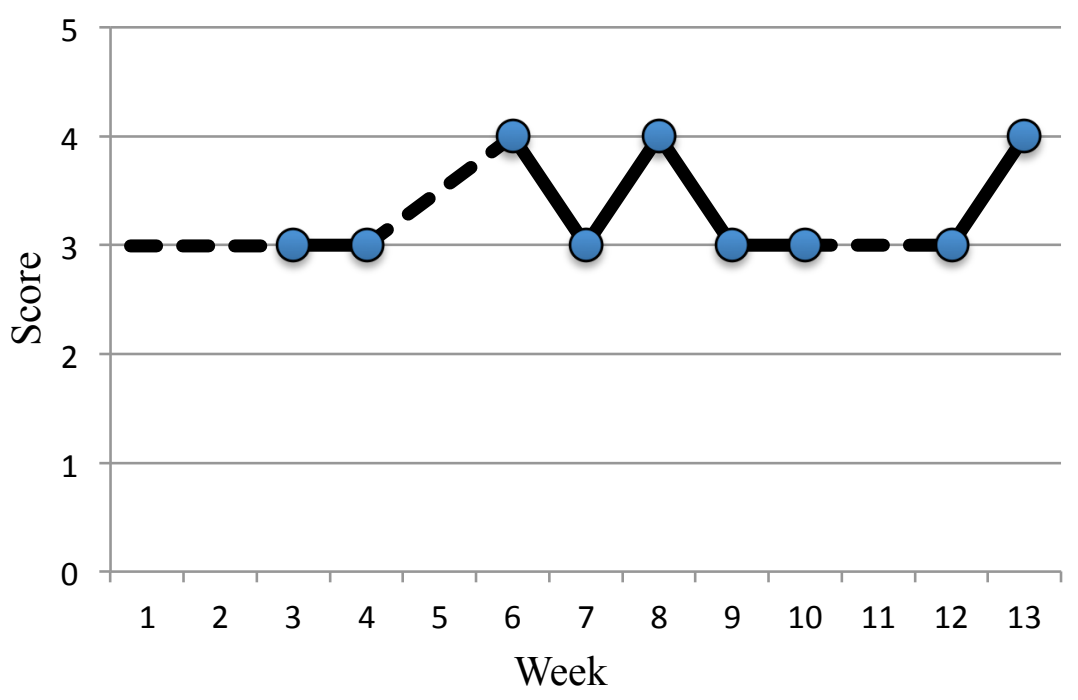

Figure 88. Vivi-Age-appropriate behavior.

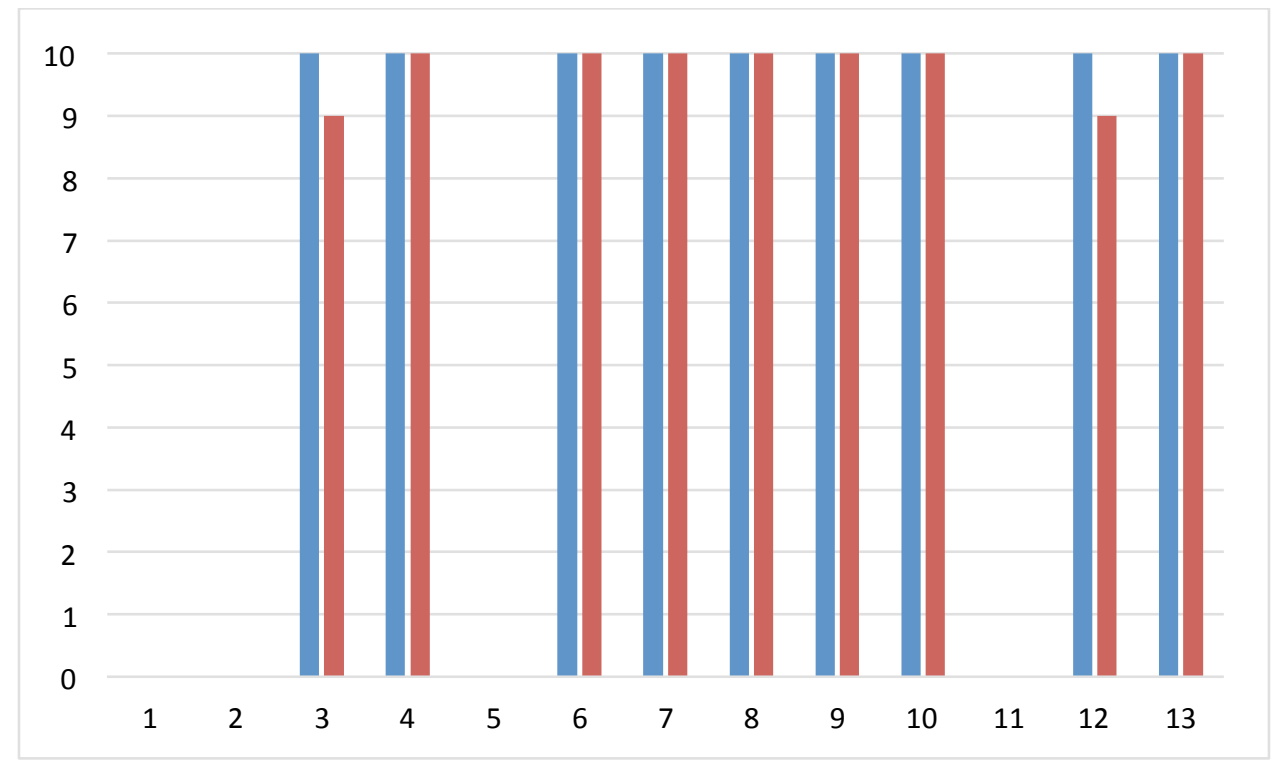

Figure 89. Vivi-Cognitive "Yes" scores (Raters 1 \& 2). 


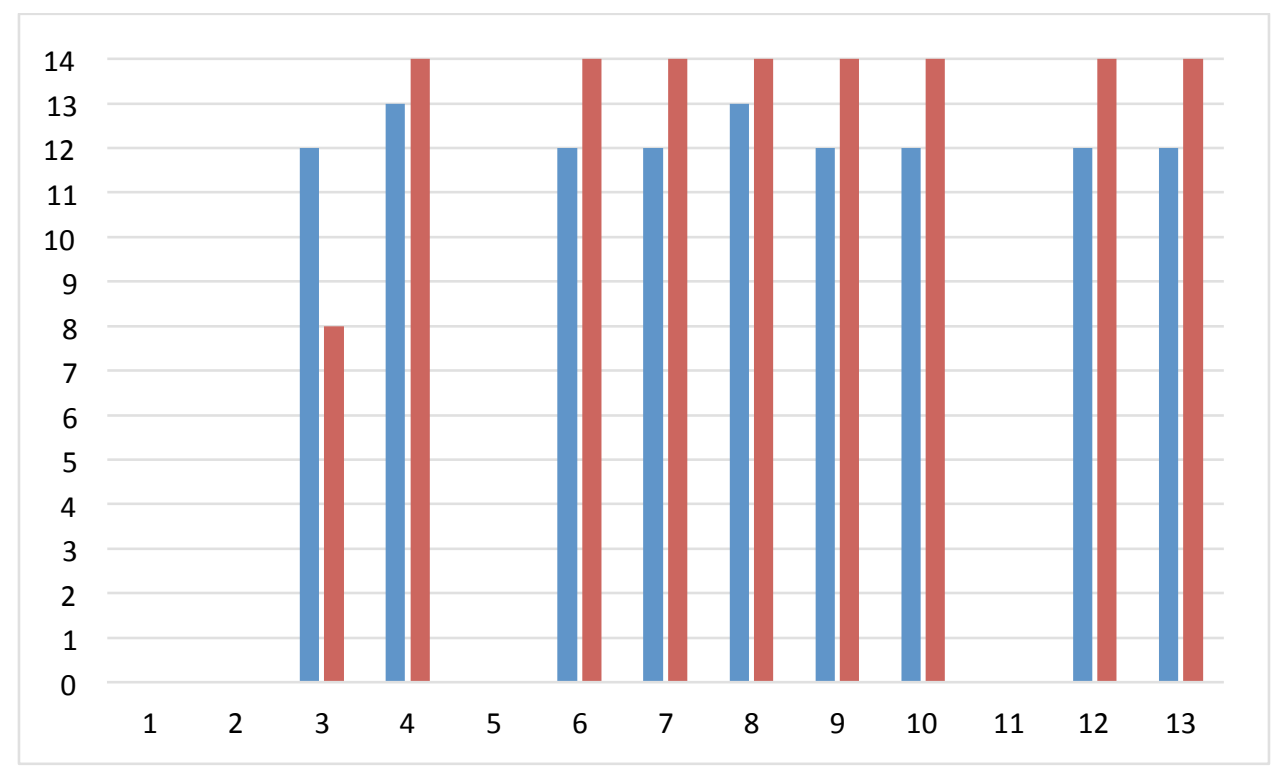

Figure 90. Vivi-Social-emotional "Yes" scores (Raters 1 \& 2).

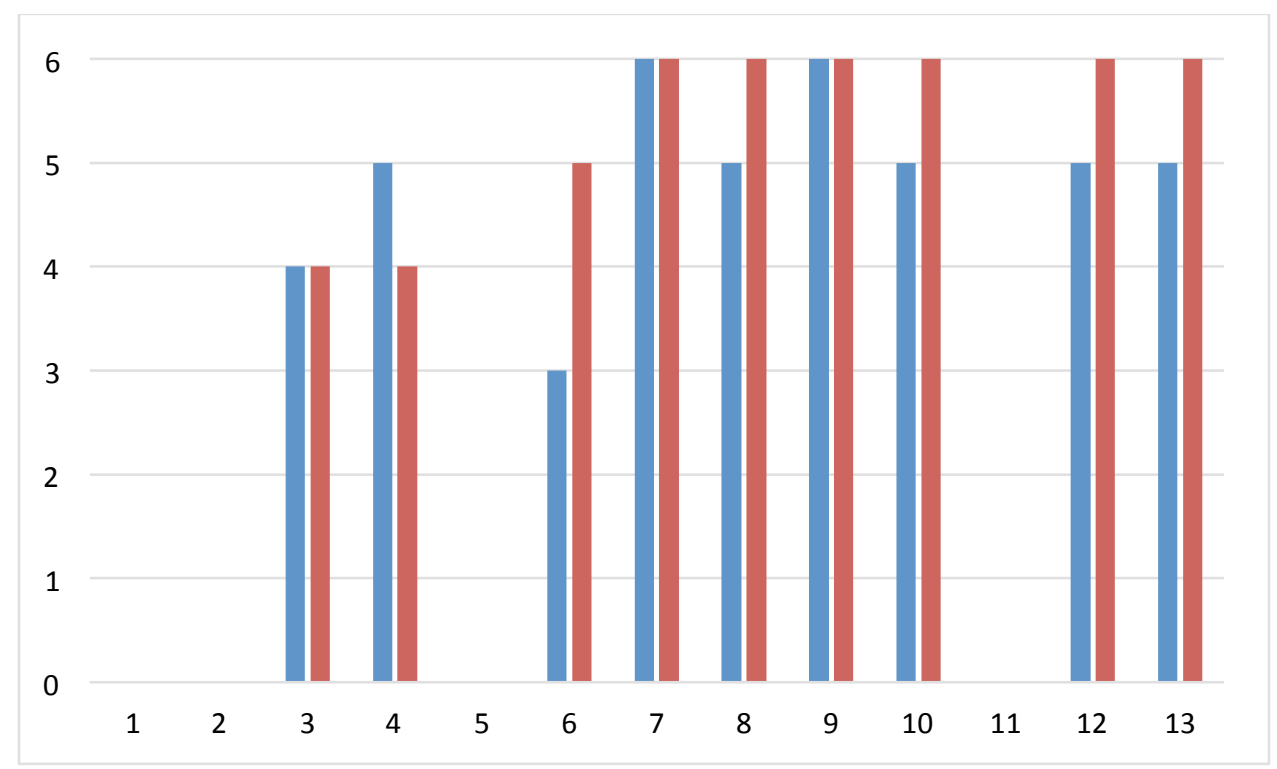

Figure 91. Vivi-Verbal "Yes" scores (Raters 1 \& 2).

Vivi13's total change score was 13. 
Therapeutic impressions. The dysregulation, hyperactivity (likely a result of anxiety), and disorganized behaviors seen in the classroom were also obvious in AAT; however, small indicators of improved focus and regulation were becoming obvious during the course of the pilot. Unfortunately, progress during AAT was obvious in short "bursts" and not typically maintained. It is obvious that Vivi was taking in new information during her sessions and demonstrated an ability to remember activities and routines from her sessions. She required a lot of coaching and support to regulate her behaviors in the clinical setting but with that support, she showed true interest in the dog and seemed to use him as a testing ground for emotional recognition.

This child was bright and highly capable but distracted by many of the stressors, some known and many unknown, in her environment. The instability at home and attachment with her mother, especially for a child this age, would be crucial to understand in order to best tailor the intervention in the best possible way. Perhaps the program and AAT were the most stable/predictable features of Vivi's environment, and provided the opportunity to begin to form some stable attachments. An opportunity to expand this service to include family-focused AAT would have been an ideal fit for her (and perhaps offer support to her young mother who was struggling). Research on familyfocused AAT (or family therapy using a therapy animal) is scant but for young children in complex family systems marked by trauma and separation, the most fitting therapeutic approach would include caretakers. Strengthening the relationship between child and parent is essential and the dog may help to defuse the tension in the room, act as a catalyst for engagement, provide a model for predictable and steady behavior and also 
decrease anxiety in both child and adult. This is especially relevant for child-welfare involved families.

The following table indicates the change scores for each client. These individual scores were calculated by comparing the "yes" ratings on the AATEI after the first session to the "yes" ratings after the last session. Higher scores indicate more observable change and improvement during the course of treatment.

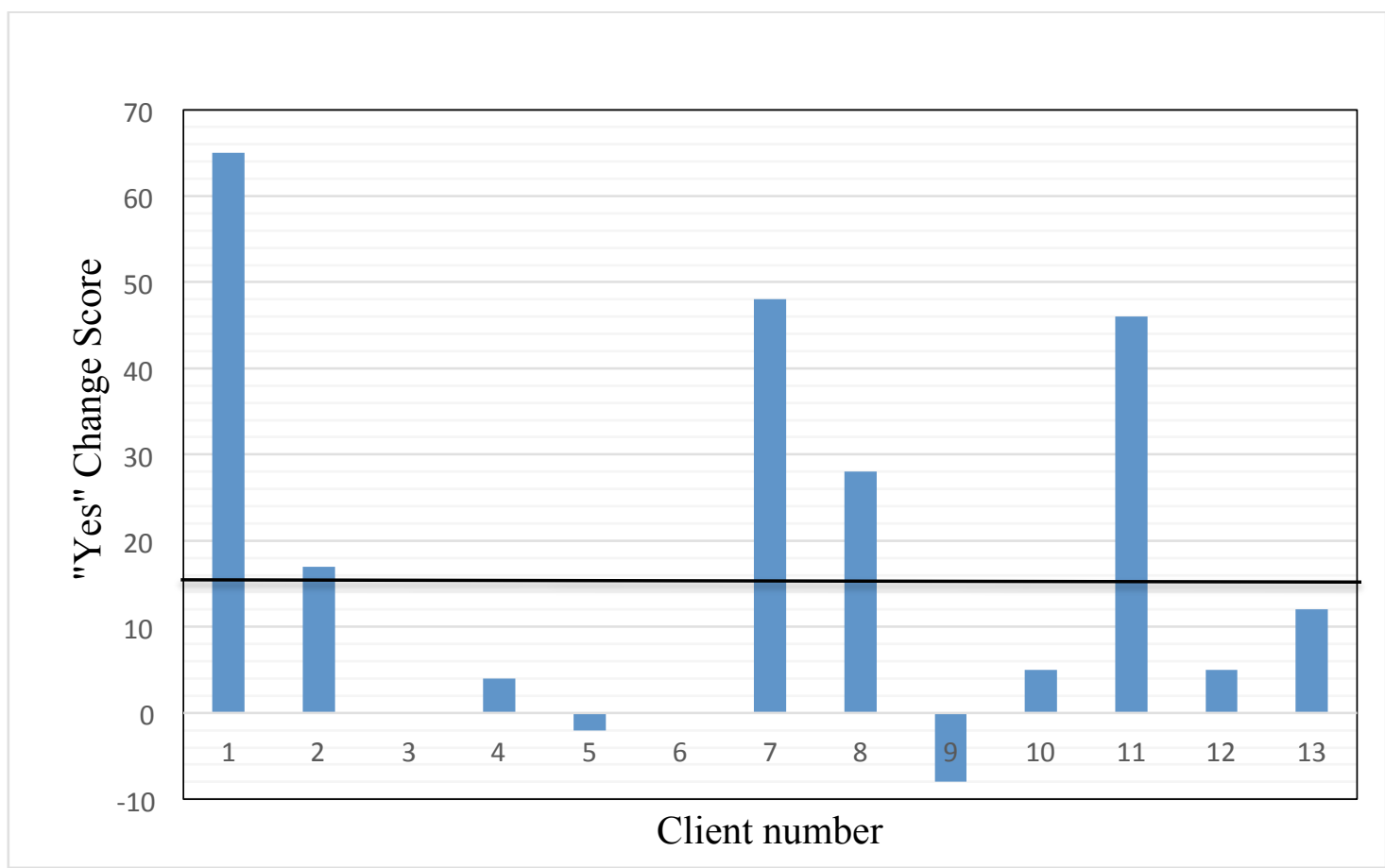

Figure 92. Individual change scores for each client (16.2 average score).

\section{Thematic Analysis}

Significant themes were discovered when applying a thematic analysis to the sample group as a whole and a number of important features and factors are highlighted 
below. To qualify as a "theme" for purposes of this thematic analysis, any code appearing three times or more was collated and considered (step three or the analysis plan as suggested by Braun and Clarke [2006]). The analysis plan was to code for (1) demographic data and (2) therapeutic data. Significant themes arising from the demographic data include:

- $100 \%$ of the children included in the sample were living below the federal poverty level.

- Seven out of 13 cases had either a prior or current open case with the Child Welfare system; six had been placed in foster care.

- Seven children had either suspected or confirmed diagnoses that impacted their daily functioning, such as physical impairments, pre-natal alcohol exposure or global developmental delays.

- $100 \%$ of the children had experienced trauma of some kind; all but one child with either suspected or confirmed neglect.

- Four children lived in homes where there were at least five other young children (either siblings or foster siblings).

- Four of the 13 children lived with both of their biological parents.

- All of the families of children involved in the study demonstrated some level of emotional distance, resentment or disrupted attachment. This feature was coded as "parental disdain" and is a fascinating feature of this specific sample group. Though not explored in depth due to limited data, this descriptor aids 
in understanding how pervasive trauma and relationship disruption are for these children.

- Ten cases were coded for "complex parent-child relationship" based on current challenges occurring at the time of the pilot (not just historically).

- Seven children were described as "flat," emotionally withdrawn, or expressionless.

- The remaining six children (not described as flat, withdrawn or expressionless) were impulsive, distracted, aggressive, and/or emotionally dysregulated to some degree.

- All of the children (100\%) were rated as "below average" on at least one four developmental domains (social, emotional, behavioral, and language/communication).

- Four of the children had pets; two of the four (50\%) had a history of "roughness" with those pets.

- All children experienced inconsistent attendance, ranging between just one absence for one client to 13 absences in another. The average number of sessions attended was 10 (out of 16 weeks offered).

The sample population is best described as a group impacted significantly by trauma, ongoing instability, family discord and disruption, and poverty. The case studies offer a rich description of the environmental contexts for these children. The developmental delays or dysmaturity observed in these children, and the reason for the referrals to the AAT pilot, were likely related to early relational trauma and poverty. The 
theoretical and practical implications of these findings will be examined in the Discussion section.

Additional themes were discovered during the coding process that elucidate the complexity and influence of the clients' families and family systems. This study does not attempt to correlate the various family stressors captured in the data with child functioning but it is important to recognize that such themes did arise in the coding process; additional themes were established based on the repeated observation of the following codes:

- "Outside services" - many of the children and families were connected to other support services, either voluntarily or involuntarily (such as in the case of child welfare involvement). Other examples of outside services include early intervention, job training programs, parental support groups, family therapy, and domestic violence intervention programs.

- "Parental medical illness" and "Parental mental health concern" were consistent themes for many of the families; suspected or confirmed diagnoses were coded the same since outside confirmation of illnesses could not be established for purposes of this study.

- Already mentioned, "parental disdain" was a theme discovered early into the coding process and the most unexpected discovery in the process of analyzing the qualitative data. Many parents reported either in intake paperwork or through conversation with staff at TCP that they resented, disliked or felt animosity toward their child. For example, when parents reported negative 
characteristics in their child (such as calling a child "lopsided," "weird," or "evil"), this was coded as parental disdain. In the sample group, this theme was recurring.

- "Long-term involvement" was established as a code for children in the program for a year or more. In many cases, the program made exceptions for families to continue enrollment due to lack of other consistent programs available to support the children. Approximately half of the sample group were children enrolled for over one year.

- "Parental (un)involvement"- this code denotes parents who were reluctant to engage or consistently refused to participate in the program's other support options (such as home visitation, family support groups and informal conversations with teachers and case managers). Based on limited data, approximately $75 \%$ of the children in the pilot group had uninvolved or disengaged parents; with additional data, the nuances of this phenomenon may have been worth exploring in more depth. However, because much of the data available for this study are based on secondhand information, this theme is considered one with limited application. It is still worth considering because whether or not a family was truly disengaged is perhaps less important than the fact the program staff, those working directly with the children, perceived the parents to be uninterested or indifferent and, as a result, that perception may have shaped the way services were offered and the sentiments staff held toward children and their families. 


\section{Therapeutic Themes}

In addition to better understanding the complexities and nuances of the sample group, this study aimed to identify the themes of intervention techniques and how clients responded to those attempts; ultimately, recognizing how and why certain children responded to varied approaches. The "Course of Treatment" sections within each case study were coded for types of therapeutic techniques and the responsiveness observed in clients. The goal of this portion of the study was to assess indicators of positive responses and link them to the features of children's clinical presentation. In essence, finding which children responded to what types of intervention techniques, and further, which children responded most favorably, and whether there was a relationship between the presenting clinical concerns and therapeutic techniques were the aims.

Children were grouped into one of three possible categories: Internalizers, Externalizers, and Typical Functioners. Groups were based on codes developed from the data that indicated traits, features and adjectives used in describing children before and during the initial treatment process. For purposes of this study, the terms Internalizing and Externalizing are not intended to convey clinical or diagnostic criteria; however, these labels are commonly used in practice and research with children who struggle with behavioral challenges. The Child Behavior Checklist (CBCL), for example, is a wellestablished standardized tool used to create a behavioral and emotional baseline for children as young as two years of age and to help providers in assessing what supports are services are necessary (Achenbach \& Ruffle, 2000). The CBCL tool classifies children based on domain areas into competencies and problem areas; those problem 
areas are then categorized into internalizing or externalizing behaviors. Internalizing behaviors include anxiety, social withdrawal and depressive symptoms while externalizing behaviors include aggression and impulsivity (Achenbach \& Ruffle, 2000). Though the CBCL was not used, Internalizers and Externalizers in this study appear to share many of the same qualities that the CBCL has identified as problem areas.

Therapeutic strategies were identified that were most common and seemed to positively impact children in their respective groups. This finding is significant because it links the traits of children prior to the intervention with potential intervention tools that may contribute to the increase in positive outcomes. And because there is no treatment manual for these types of interventions, and also because individual goals were not set prior to the pilot study, identifying the proper strategies for interventions is crucial.

The most commonly used intervention technique was cross-talking with children who were described as withdrawn, flat, "shut down," non-communicative, or internalizing; this technique was used as either the first or second intervention attempt in all of the cases where this theme was identified. For children who presented as remote and emotionally distanced, the cross-talking approach allowed the therapist to decenter the client by focusing on the dog and having a conversation where the child "overheard" what was being discussed. Rather than speaking directly to these children, cross-talking allowed the therapist to send messages of safety and encouragement while also setting boundaries, modeling appropriate behaviors and sharing emotions. 
Table 2

\section{Theme Groups}

\begin{tabular}{|c|c|c|c|}
\hline Group & Client & Interventions & Positive Outcome Areas \\
\hline \multirow[t]{6}{*}{ Internalizers } & Ay1 & Cross-talking & Improved emotional expression \\
\hline & Bri2 & \multirow[t]{5}{*}{ Physical touch } & Improved engagement \\
\hline & Kai6 & & Increased comfort \\
\hline & Mik8 & & \\
\hline & Nai9 & & \\
\hline & Tah11 & & \\
\hline \multirow[t]{4}{*}{ Externalizers } & $\mathrm{JJ} 4$ & Limit setting & Routine following/remembering \\
\hline & Jav5 & \multirow{3}{*}{$\begin{array}{l}\text { Feelings identification } \\
\text { (in dog) } \\
\text { Physical touch }\end{array}$} & Increased emotional regulation \\
\hline & Vin12 & & \\
\hline & Vivi13 & & \\
\hline \multirow{5}{*}{$\begin{array}{l}\text { Typical } \\
\text { Functioners }\end{array}$} & Guy3 & \multirow{2}{*}{$\begin{array}{l}\text { Body parts } \\
\text { identification }\end{array}$} & Increased communication \\
\hline & May7 & & Increased emotional expression \\
\hline & Ren10 & Physical touch & Expression of empathy \\
\hline & & $\begin{array}{l}\text { Feelings identification } \\
\text { in Dog \& Self }\end{array}$ & \\
\hline & & Playful interactions & \\
\hline
\end{tabular}

Six children were coded as "shut down" more than three times and therefore this theme was established; in all six cases, the chief therapeutic tool was cross-talking. Of these six children, three had the most significant change scores and evidenced the most growth or progress of the entire sample during the pilot period. Clients Ayl (change score 55), Tah11 (change score 46) and Mik8 (change score 28) began AAT as highly impacted by internalizing behaviors; common descriptors were "flat," "reluctant," 
"fearful," and "avoidant." Cross-talking seemed to positively impact these clients' comfort level in the treatment setting and allow them the opportunity to explore and express themselves emotionally. Each of the three most changed clients within this theme group demonstrated observable growth in emotional expression. Similarly, these same clients all improved in their ability to communicate during the session, either with the dog or directly with the therapist.

For children who showed significant internalizing behaviors, various forms of touch were used therapeutically. Guided touch, guided brushing, open-handed touch and petting were themes common in working with these clients. This group of children all demonstrated either increased comfort or engagement. Together, the techniques of crosstalking and physical touch appear to impact this portion of the sample population in positive ways.

A different group of three children showed behaviors that were considered typical in the clinical setting for their age and development. Descriptors for these children included "interested," "engaged," and "comfortable" or they demonstrated behaviors, such as reluctance or fear, that quickly subsided after the initial session of AAT. For these children, various therapeutic exercises were attempted, the most common being "body parts identification" (of self or dog), physical touch such as petting or brushing the dog, feelings identification in self or dog, and playful interactions. Playful interactions included: showing the dog something, teaching the dog (for example, when a child attempted to show the dog how a toy worked), reading to the dog, making up a story about the dog and playing fetch. This group of children tended toward more activity and 
therapeutic experiences during a single session; they had the opportunities to try more intervention strategies because they were more emotionally regulated and behaviorally stable. Interestingly, one client in particular was far more behaviorally stable during sessions than he was reported to be outside of the therapeutic setting.

Children grouped into the "externalizing" category were those who demonstrated significant inattention, impulsivity, physical aggression toward therapist or dog, dysregulation and overstimulation. As clients, they needed far more direction and limit setting than their peers. Physical safety was of utmost importance so that the sessions could continue; this required the therapists to continually set boundaries, reinforce limits, offers reminders and use praise to maintain safe behaviors. Often considered antitherapeutic, the therapists were required to be highly directive, especially during the first few weeks of treatment to ensure that the children could continue in the pilot. In this sample group, the children were responsive to limits, they required regular reminders, and all continued to participate. Client Jav5 attended only three sessions (the lowest attendance in the group) and therefore it was not possible to observe any indicators of his progress. For the other children in the group, the most consistent indicator of progress was in "routine remembering." This theme, especially as the one most consistently noted, was surprising given how distractible and inattentive the group appeared to be. Children showed clear indicators that they remembered the rhythms and activities from week to week despite what appeared to be lack of focus or engagement; they were being impacted by the therapeutic environment despite observations that indicated they might not be. Children demonstrated their routine remembering in various ways: recalling the dog's 
name without reminders, initiating activities that had been done the week prior, repeating words or phrases from past sessions, and looking for specific toys or books that had been explored previously.

Another important discovery was the theme of "feelings identification (in dog)." Children in this group were able to understand and identify certain emotions in the dog when prompted. This skill was likely learned through therapists explaining why and how safety was important in the therapeutic space; therapists also modeled this behavior. Children understood this message and though not consistently able to identify feelings in themselves, they could label certain emotions in the animal (like happy, sad and scared). Supportive tools for helping to identify feelings included stickers, story-telling, and identifying emotions in photos and drawings.

The following Thematic Web visually demonstrates the three groups and the intervention type or technique to which they responded most favorably. This style of presenting findings helps to clearly identify the ways in which theme groups are distinct and the ways in which they may overlap or share characteristics. The most noteworthy finding is that all three groups responded positively to physical touch (of the dog) and this intervention theme is therefore centered in the web below. Physical touch included petting, guided petting or guided touching, open handed touch, brushing, and guided brushing. 


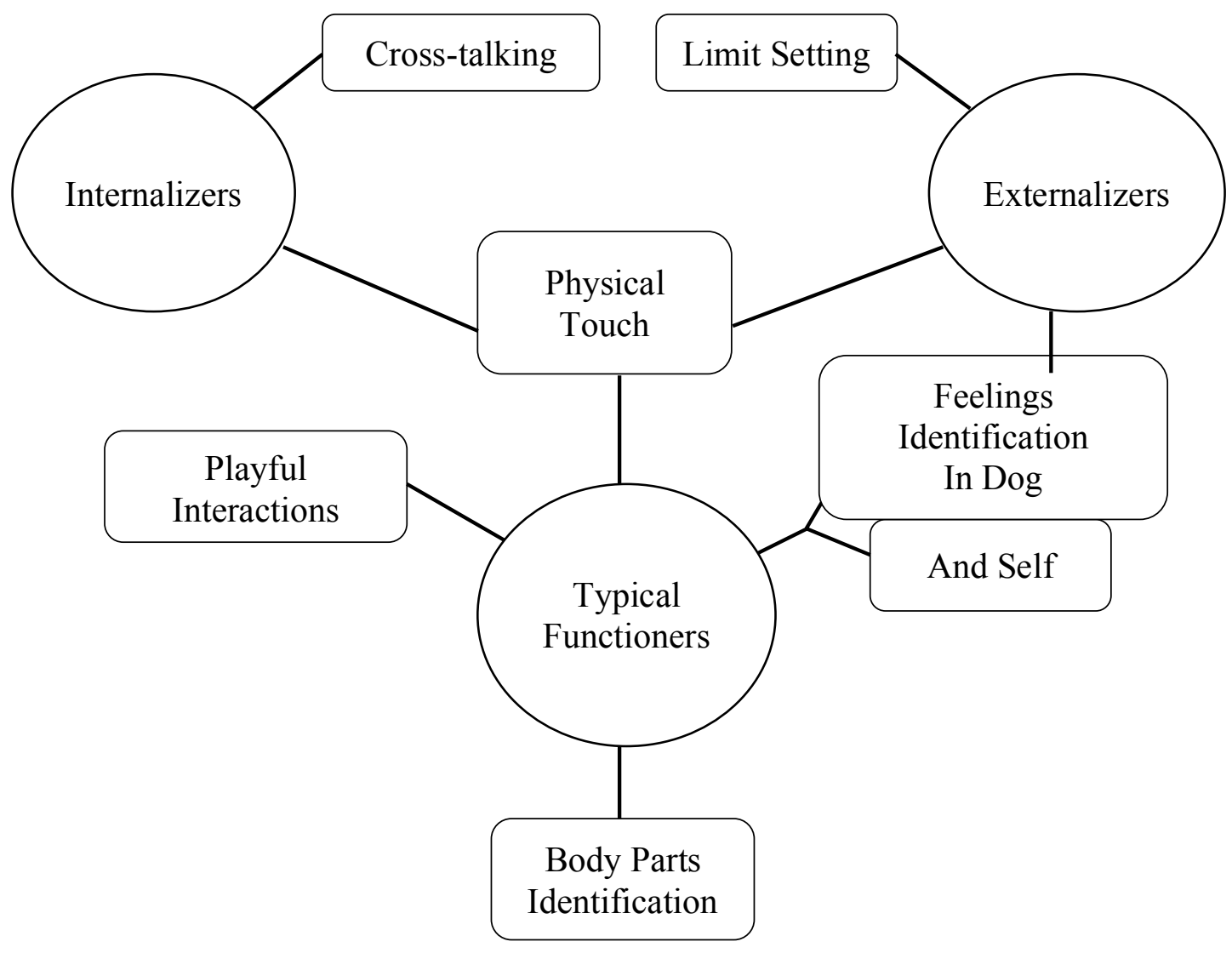

Figure 93. Thematic web for intervention type and technique.

All three groups of children showed positive responses to physical touch; this was the only consistently shared intervention theme amongst the three disparate groups. It is likely that this intervention had similar salutary effects for each group; for example, physically touching an animal, especially in a rhythmic or consistent pattern, has been repeatedly shown to help decrease anxiety and lower blood pressure and heart rate (Handlin et al., 2011; Levine et al., 2013) and decrease stress and lower cortisol levels (Vagnoli et al., 2015). Research on pet ownership shows complex and significant benefits 
to humans; children may benefit from a consistent relationship with an animal even if the animal is not their pet. Findings from this study indicate that the type of physical interactions shared with a pet are similar to the interactions had within the therapeutic setting (petting, brushing and touching).

In addition to discovering what interventions worked most consistently for which groups of children, additional findings about the children's characteristics were evaluated to assess how their demographic and personal information might be related to their responses to the intervention; this is discussed in the following section.

Findings indicate that the pre-treatment characteristics of children are important considerations when selecting types of interventions to incorporate into the therapeutic setting. Children within the identified theme groups share many pre-treatment demographic and clinical characteristics. Of the six children who showed internalizing behaviors, all were girls. Three had complex parent-child relationships (which included current or prior separation from parents, experience in foster care or parental disdain) and the other three came from families where at least five other young children were being raised in the home. Interestingly, the three children in the Internalizers group where there were many other children in the home were also Hispanic or Latina; perhaps the perception that they were withdrawn, expressionless or disengaged had to do more with culture or language barriers than clinical concerns. When considering sources of information, it is important to reflect that perhaps these children were misunderstood, uncomfortable or not considered typical from a dominant perspective; the impact of the 
children's culture was not adequately captured in the data. Also of note is that three (of the four) most outstanding change scores in the study were from this Internalizers group.

Three out of four Externalizers were boys. All four children had complex parentchild relationships and all had a history of open child welfare cases, with three of the four having been separated from their families and placed into foster care and then reunified. In their referral paperwork, all four in this theme group scored "below average" on emotional stability compared to their peers. As a whole, this group of children had consistently difficult and complex patterns of behaviors both at home and in TCP.

Children from the Typical Functioners group shared many of the same complex family dynamics and histories as the other two groups, however, all were in the current care of at least one biological parent and none had any known experiences in foster care. The one finding that separates this group from the others is that they had not been previously removed from living with a biological parent; though neglect and complex parent-child relationships were of concern for this group, as they were for the other two as well, the only identifiable was the finding that they had always lived with at least one parent since birth. Two clients in this group were expected, based on data collected prior to starting the intervention, to have very challenging behaviors and initially appeared to share many traits with the Externalizers. However, in the therapeutic setting, these two children (Guy and May) were more regulated and easy to work with than anticipated.

Based on this study alone, it is not possible to determine why these three children were more amenable to treatment or able to engage in more therapeutic activities; this is an area worthy of far more exploration. Given the theoretical underpinnings supporting 
this intervention, it may be that the children who have had lifelong consistent caregivers are better able to tolerate new situations and novel experiences; this may be evidence that their attachment history has provided them with the internal working model necessary to more readily form and trust new relationships and ultimately benefit from therapy. 


\section{Chapter 5}

\section{Discussion}

\section{My Role}

I served as one of the two therapists in the 2006 pilot program and now serve as researcher/principal investigator. My experiences, both personal and professional, led me to therapeutic work with animals and researching subsequent outcomes. When designing the AAT program, I did not necessarily seek to substantiate a preconceived notion or advocate for a particular service; my personal bias is that animals have worked to help me in various ways but I also recognized that I had a stable family, an idyllic childhood and experienced no remarkable trauma as a young person. I questioned if and how AAT would impact a population of children with whom I had little in common. I sought to learn as much about the population as I could while simultaneously exploring the components of the intervention. I have been open to discovering contrary findings. As with any research proposal, I increased my knowledge of salient issues throughout the process of reviewing literature and research. I know a great deal more about AAT, early intervention, HEP, and animal cruelty now than I did upon designing and launching the pilot program. In many ways, the study would have benefited from me knowing more ahead of time to help improve data collection (discussed in the Limitations section) and the outcomes may have been strengthened.

Strauss and Corbin (1998) discuss the difference between objectivity and sensitivity in qualitative research. As the therapist in 2006 and current principal investigator, I do not have the "ability to achieve a certain degree of distance" from the 
participants or the research; instead, I have the sensitivity to "respond to the subtle nuances of, and cues to, meanings in the data" (Strauss and Corbin, 1998, p. 42). Sensitivity is enhanced as the process of data collection continues (Padgett, 2004). Instead of eliminating bias altogether, it is important to both be aware of the impact it may have on the study or assessment of the data and to leverage its power to improve the quality and impact of the research.

It is important to note that the data analysis portion of this body of work was not completed until 2017, over 10 years after the collection of data. Given the amount of time between the delivery of services and the analysis of data materials, I as the principal investigator felt more distanced from the cases, the therapy and sheer memories than anticipated. Completing the case studies and analyses felt very much like a brand new project, so many years later. My objectivity, I believe, was increased by the time that lapsed between the service delivery and the analysis portions of the study.

Further, in the 10 years spanning from the delivery of the pilot program to the assessment of the data, very little new research and literature was added to the field of Animal Assisted Therapy for youth. A meta-analysis published in 2016 showed that although there has great interest in aligning research on AAT with supportive evidence, there has been little progress made (May et al., 2016). The barriers to effective research have been elucidated previously in this paper, however researchers (May et al., 2016) confirm that small sample sizes, lack of control groups, lack of randomization and inconsistent therapeutic strategies continue to negatively impact growth in this area of 
study. Certainly, those barriers are echoed in this study and discussed in the Limitations section below.

\section{Personal and Professional Interest}

Where exactly my profound and deeply-rooted respect for and interest in animals comes from remains somewhat of a mystery. As a young child, I ran out in rainstorms to collect the worms drowning in puddles. In middle school, I began feeding stray cats and bringing them home to beseech my parents to pay for veterinary costs. I remember rescuing animals throughout my childhood and adolescence- the plight of other species has always been at the forefront of my mind. Though I chose to focus my education and career on children's mental health, my continued passion for working with animals never faded.

As a professional, I have sought to somehow unify my two most significant areas of interest: children and animals. For years, I worked as a therapist in the field of child welfare while concurrently volunteering and advocating within the field animal welfare; I maintained a clear separation between those spheres. As my clinical work steered me toward prevention and early intervention, I began to seek out treatment alternatives to psychiatric medication for my clients after I witnessed a consistent reliance on psychotropic medications to treat behavioral problems in children aged 5 years and younger. It was at this point that I discovered the budding field of Animal Assisted Therapy; not only was this a novel and holistic non-invasive approach for children, but it also offered me the opportunity to fully align my two previously disparate areas of interest. 
As an MSW student at the time, I was fortunate to be associated with a number of child-serving organizations throughout the metro area that were eager to "test out" animal-based programs. I eagerly designed pilot programs, with support from supervisors and buy-in from the local organization certifying therapy dogs, and launched two AAT programs at agencies providing services to children and families. It is the pilot program at one of those agencies that, years later, I am researching. The population of children served in this pilot program had never before been targeted for a prevention model of AAT.

\section{Summary and Discussion of Findings}

Major findings from this study may be grouped into three conceptual categories: child and family characteristics that were based on assessment of data gathered before the treatment program was delivered; therapeutic tools that were identified during the treatment process to be beneficial to children; and distinct theme groups and their responsiveness.

- All of the children involved in AAT were currently living at or below the poverty level.

- All of the children involved in AAT had complex family systems where experiences of trauma were either current or historical.

- "Parental disdain" was identified as a relational characteristic between parents and their children. This is an area worthy of further study, as it indicates with more specificity the complex nature of the home environments in which these children were being raised. This finding also supports the importance of 
attachment in early relationships and sets a strong foundation for using AAT in a setting where families are included.

- Other themes, such as lack of parental involvement and medical or mental health concerns in caregivers, were discovered in most of the cases, again pointing to the complexity of family systems and the impact that these parents had on their children.

- All children, prior to commencing AAT, were either withdrawn, isolative and "flat" or impulsive, distracted, or aggressive — as a group, these children were acutely challenging to the professionals with whom they worked and were likely referred for the pilot program as a result.

- Based on membership into a certain theme group (Internalizers, Externalizers, or Typical Functioners), certain therapeutic interventions were more likely to be successfully applied and repeated throughout the course of treatment.

Cross-talking and physical touch were the most consistently used approaches with children in the Internalizers theme group; benefits shown by this group, as a whole, were improved emotional expression, increased indicators of engagement and comfort. Externalizers were also responsive to physical touch while also consistently responding to limit setting and feelings identification in the dog. As a group, Externalizers demonstrated an ability to remember routines and strategies from week-to-week, improved their ability to regulate emotions and limit physical roughness (aggression). The group most likely to respond to various therapeutic exercises was the Typical Functioners; they 
responded to the consistent delivery of physical touch (similar to the previous two groups) as well as body parts identification, feelings identification in the dog and in themselves, and playful interactions like fetch and taking walks. This group demonstrated an increase in communication scores throughout the treatment period as well as an increase in emotional expression and empathy toward the dog.

- The only therapeutic tool that children consistently responded to favorably was physical touch, which included petting, guided touch, brushing and guided brushing. Because of its cross-group positive impact, this specific intervention should be examined in more depth to better understand the nuanced impacts for children based on their respective group assignment. It is also suggested as a universal too for working with young children using AAT.

- Noteworthy differences between each of the theme groups were highlighted in this study. As a whole, the group shared many qualities but there are subtle yet important differences as well. All of the children in the Internalizing group were female. Three out of the six children came from large families where at least five other young children were being raised, and each of those three families was Hispanic or Latino. This finding has important cultural considerations not just in how treatment is offered but also in how data are gathered and assessed in the initial phases of program design. Children who are perceived to be "shut down" or emotionless may in fact be behaving within cultural norms; tools for gathering data should be culturally sensitive 
and far more strengths-based. All four children in the Externalizing group had either a history or current open case with the child welfare system; three out of the four were boys and all were considered "below average" in emotional stability by their referral sources. The only identifiable difference in Typical Functioners was the one finding that they, as a group, all lived with at least one biological parent since birth. All other influences were the same- trauma history, complex family systems, parental disdain, poverty—and the only feature of this group that was unique was that the children had experienced some level of parental consistency. This group was not higher functioning outside of the treatment setting than the other groups of children. Though based only on the data from the three children in this group, this particular finding is worthy of far more investigation in future research.

\section{Implications for Social Work}

The vital role that animals play in the lives of humans, and the important bonds that humans have with companion animals, has slowly gained more attention in social work practice and education since the very first known peer reviewed article was published on this topic in 1975 (Bikales, 1975). Culturally sensitive practice insists that social workers honor and respect the connections and supports within the lives of their clients; omitting the relationships that matter most to clients can become a barrier to treatment. Social work must widen its lens to better incorporate and value the roles that non-human animals serve to humans and the roles they could serve if better understood and supported. The importance of reciprocal relationships is understood in the field of 
social work, though often centered on human-to-human interactions. The primary mission of social work is to enhance human well-being and "helping to maximize the positive potentials of relationships between people and animals is a salient role for social workers" (Hoy-Gerlach \& Wehman, 2017). Social work must broaden its scope and center more attention on understanding how speciesism impacts human development and opportunities for change. It is incumbent upon social workers to continually challenge the established worldview (often considered oppressive and systemic) through the incorporation of new theory, knowledge and practice. Therapeutic interventions involving animals have continued to gain attention in the field of social work and substantial evidence has shown that additional attention is needed to further support the Human-Animal Bond and use this relationship to promote healthy development and healing.

Biophilia explains that it is inherent and essential that human beings are connected to the natural world around them; our evolution and socialization depended on this interconnection for millennia. Only since the rise of industrialization and technological growth have humans separated themselves so considerably from the natural features of their environment. This separation or disconnection has significant impact on human development and is a particularly important consideration when working with young people - how are their environments impacting their growth and how can these environments incorporate more positive influences to enhance their development? Biophilia posits that interspecies connection is one of the ways that children can reestablish this lost connection and Animal Assisted Therapy can help to "plug in" 
opportunities to foster deeply meaningful relationships. These relationships become especially important when working with children who are highly urbanized, don't have regular opportunities to explore their natural environment and have been socialized without contact with pets or other animals. Herein lies the connection between Biophilia and Ecological Systems Theory - the web of connections must not focus exclusively on human beings alone. A true "systems perspective" requires that social workers understand how and why interspecies connections matter, both in the historical and current contexts. Further, per Biophilia, children are essentially hardwired to seek out and accept relationships with animals so AAT as an intervention is developmentally appropriate. For children who do not have healthy opportunities to interact with natural features of their environment, especially animals, this intervention is promising. Most children in this study did not have consistent opportunity to engage with animals in a safe or supportive way in their home environments.

With trauma in early childhood being so pervasive, and with its potential to impact development across the lifespan, social workers should be exploring all opportunities to support clients in ways that have been previously labeled progressive or nontraditional (Dunlop \& Tsantefski, 2017). Findings from this study, as well as others, point to the importance of consistency in early attachment relationships. The impact of stable attachment patterns is profound and AAT should be one option for helping to build, reestablish or strengthen those connections.

There is much potential for social workers to embrace animal based interventions and services - it's an ideal field for promoting and delivering more progressive or 
experimental services while also researching and studying findings as they are discovered.

\section{Implications for Theory}

Theoretical support for interventions that incorporate animals in helping to promote a therapeutic effect is strengthened by this research. Attachment Theory continues to evolve: the source of one's attachment, especially in families where factors like poverty, mental illness and trauma impact the caregiver, need not always be a parent. In fact, children can often more easily attach to a non-threatening animal after experiences of abuse than they can to a human caregiver (Signal et al., 2017). The consistency of a pet, when other features of a child's home or life may be less consistent or safe, allows for the development of healthy patterns of attachment (which, in turn, promotes healthy brain development). Reciprocal relationships and mutual caretaking are critical aspects of healthy development, and central tenets in Attachment Theory. Those relationships and caretaking patterns can be practiced in a safe therapeutic setting where an animal serves as a consistent, nurturing and available attachment figure. In this study, many of the children experienced attachment disruptions and persistent trauma in their relationships with parents and caretakers; their ability to practice safe relationships with a non-threatening dog may have reparative value and offer opportunities to explore new patterns in give-and-take dyads.

Incorporating a therapy animal into family therapy holds significant promise, as parents who themselves may have experienced their own history of attachment disruption, can learn to meet the needs of a less demanding, less complex dependent. 
Parents might see how their unconscious strategies for caretaking play out in a therapeutic setting; perhaps this is the most promising area for future discovery-family therapy where both parents and children explore new relationship patterns in an effort to re-attach or build more secure styles of attachment. It does appear that all of the children in this study were heavily impacted by disrupted relationships and insecure patterns of attachment.

It appears as though Attachment Theory sets the strongest foundation for intervention with very young children who have experienced trauma and separation from important caregivers. Ecological Systems Theory, though not explicit in naming animals as important figures in relationships, leaves room to consider the ways in relationships are influenced by the environment. If one's environment changes to include a therapy animal, the web-like system then readjusts to allow for this new experience; the theory supports the idea that the more positive connections that exist within a child's life (the mesosystem), the more he or she will ultimately benefit. Through this study, children were offered an opportunity to explore a new and novel relationship (with the therapy dog) and various mesosystem connections resulted, for example: the relationship between child and dog, child and therapist, therapist and dog. Ecological System Theory posits that children are not passive recipients of environmental influences but instead active agents in their families, schools and communities. Animal Assisted Therapy offers children a chance to engage in ways where they are encouraged to be active, participatory, explorative and engaged in ways they might not otherwise. 


\section{Implications for Practice}

AAT is a promising intervention for many reasons, including its ability to be flexible in how the treatment is delivered, relatively low operational costs, growing acceptance of dogs in institutional settings and its effectiveness with diverse groups. The practical implications from this study are important to consider-young children benefit from AAT in various ways and the delivery of the intervention may be most optimal when first considering the demographic, familial, cultural and clinical features of a client. Children respond differently to certain intervention tools, with the exception of physical touch where all children appear to benefit to some degree. Cross-talking, for example, was found to be effective with internalizing children in particular; this is a simple and unscripted tool to support increasing a child's comfort in the treatment setting. This technique offers a good starting point for therapeutic interactions and pairs well with experiences of physically touching the therapy dog. In practice, this should be considered an ideal starting point. From this study, we now have an idea of which treatment techniques to to deliver consistently throughout the course of therapy.

Children who internalize, who don't express emotions or appear to have a flat affect were the most responsive to treatment in this study; in clinical settings, children who share these characteristics should be offered opportunities for AAT to broaden the scope of services. One of the goals of this research was to improve treatment options for very young, at-risk children and increase the referrals for children to this type of program. The study offers support for expanding the type of interventions available for "hard to reach" children to include AAT. Similar to findings from a 2017 study, children with a 
history of trauma showed a decrease in clinical symptoms and related symptomatology, specifically related to the reduction of "avoidance symptoms" (Signal et al, p. 88).

Clear goals can provide a direction for treatment and help to focus the intervention. Because this study was exploratory, it did not include pre-established goals for each client; however, future practice in the area may be enhanced by carefully constructed goals. The case studies indicated such complex home environments and parent-child relationships; including families would have not only garnered more information on the clients, it may have strengthened the impact of the therapy. The young children in this study were all greatly influenced by their environments; helping to improve those environments outside of the treatment setting is essential.

\section{Strengths of this Study}

This study explores a previously uncharted intersection between early identified at-risk children and Animal Assisted Therapy. This novel approach with a very young population is absent from literature and research in both early childhood development and animal based interventions. Using a blank slate approach, services were customized for children as the treatment progressed; and outcomes were unanticipated and unknown at the start of the study. The application of thematic analysis is an ideal fit for assessing program data at this stage of knowledge development, as it offers a bias-free strategy for developing themes. As an incipient area of study, this research endeavor recognizes the complexity of the population studied and invests in exploring the potential benefits offered by a novel therapeutic approach. 
This study included a diverse sample and focused on a group of children experiencing various risks. The intervention was carried out with attention to safety and functioned well within the larger intervention program.

The six randomized control studies in extant literature where dogs were used in a therapeutic capacity help to elucidate both the strengths and challenges in studying this type of intervention with youth. And though none of those studies focuses on pre-school aged children, the findings and benefits are shared-for example, a 2012 study compared AAT with alternative/other treatment options in working with traumatized youth and the benefits in reducing symptoms of trauma were most significant for those clients in the experimental (AAT) group (Dietz, Davis, \& Pennings). Another time-series RCT study assessed whether AAT was effective in reducing symptoms of ADHD and improving social skills compared to a control group where only toy dogs were used; again, findings indicate that the experimental group showed more benefits in reaching goals than the control group (Schuck et al., 2013). What this particular study demonstrates are various findings similar to previous studies where time-series randomized control group design were implemented and positive outcomes were demonstrated. However, replicating the programs or studies previously conducted is challenging given that a complete treatment manual or step-by-step program review were not included with the peer-reviewed publications.

This research, though not a RCT study, supports many of the findings from previous studies on populations of slightly older children. Given the complexity of the sample group and the positive responses recorded from nearly every client, this study 
offers a sound foundation for focus on specific groups of young children (for example, those with either externalizing or internalizing behaviors) to better understand the subtle ways AAT can be enacted to reach pre-established goals and lead to improved functioning.

Another important contribution of this study includes the detail to which the therapeutic processes were recorded. Published findings on AAT do not include the level of detail available within the case studies to understand which therapeutic techniques were applied and what reactions were observed in response. Replicating many of the therapeutic techniques included in this pilot study is possible because of the comprehensive week-by-week description of therapeutic sessions.

\section{Limitations}

Perhaps the most significant limitation of this study is that it did not include a randomized sample or control group. Children were selected for the pilot study by a professional working within the early intervention program and automatically qualified to participate. It is likely that the children referred were those who had the most severe or obvious indicators of delay or challenge. The sample group, then, presented with high needs and a multitude of concerns; it is unlikely that all children in the program had the same level of acuity. A control group would have provided a comparative sample to help better understand the complexities and severity of the treatment group. A control group where individualized therapy without a service animal was provided would have been most ideal in capturing the particular benefits of Animal Assisted Therapy. 
Additional limitations of this study include flaws in the selected instruments used to collect data. The tools were provided by the organization sponsoring the pilot study and have not been tested for validity or reliability. While the data extrapolated was useful and rich, more sound instruments would have not only increased the amount of data collected but also provided the opportunity to generalize findings beyond the scope of this sample. Pre and post-test measures would have added value to the study and offered a richer description of the sample and their respective outcomes. Also, tracking the clients beyond the 16 weeks would have offered more longitudinal data and helped to provide information about whether AAT is an intervention that has lasting positive impacts and promotes longer-term stability.

Setting clear goals for each client prior to offering the intervention may have helped to better tailor the intervention strategies or allowed for more focused attention on key "problem" areas. Instead, all clients were offered the same types of interventions and all clients were measured using the same markers for growth or success. Individualizing the treatment based on pre-established goals is an area for future study, especially based upon findings that certain groups of children respond differently to particular therapeutic tools.

As previously discussed, the family dynamics and community contexts in which these children were being raised have very important impacts and implications; including parents and caregivers into the study, either by intentionally collecting data from them (rather than including anecdotal information provided program staff or overheard in passing) or allowing them to participate in the therapy would have been beneficial. A 
more formal strategy to engage parents and caregivers may have offered a much richer description of the sample participants. Secondly, family participation in therapy is essential for young children; including family members in a follow-up study may provide valuable insights into the parent-child relationship and offer opportunities to develop more healthy patterns of attachment.

The line graphs and bar charts included within each case study have limitations in their applicability. The scaled quantitative data from progress notes offers little additional information about how children responded to sessions and there is often little change noted from week-to-week. An explanation for this is that the scales only measure certain aspects of observable behavior and do not include a wide enough range to capture subtle changes. The qualitative data does not always parallel the quantitative makers; though general trends are visible with certain clients, the mixed methods approach does not appear to have consistent benefits in this particular study.

This study did not explore in-depth the cases where change was not positive. It would be useful to understand more about the children, namely Jav, who did not respond well to treatment. Children who did not make observable improvements or increase scores are equally important to examine and, due to this study's emphasis on tools that were effective, they were not the focus of additional research attention.

I served various roles in this study - the program designer, therapist and researcher; this could be improved in the future by separating the individuals serving in those capacities. It is important to mention that the data collection is a bit dated; however, very few additional studies have been conducted in the time between the launching of the 
pilot study and the analysis of themes. Files and case notes maintained by the agency where the study was conducted appeared to, at times, include pathologizing language and often included blaming parents and families for their children's challenges. There were no sections on any of the case notes to include strengths or positive traits of the children, which is noteworthy. Perhaps in the last 10 years, record keeping and charting have better incorporated the assets and strengths of clients and their families, as this is an important consideration in working with any population.

\section{Future Research Directions}

This study and its findings pave the way for future research in a number of key areas. Although many children in the study share similar characteristics, it would be useful to for future studies to focus on children who present similarly in the treatment setting to better assess the delivery of intervention and the carefully measure the responses of each client. Findings from this study help to identify what particular interventions should be offered from the start of treatment; with more specific and sensitive instrumentation, outcome data would be far more detailed and applicable for quantitative analysis (something that continues to be lacking in this field of study).

Future research should focus on establishing a valid and reliable tool for gathering and assessing outcome data; specifically, one with quantitative measures to track incremental progress throughout the course of treatment. A 5-point scale is too narrow and does not capture the subtle ways that children respond to certain interventions. Further, completing evaluations after the therapy session often does not capture the therapeutic moments as they unfold; using supplemental qualitative data is useful, 
however, a more sophisticated tool to gather both quantitative and qualitative data is imperative.

In order to best substantiate AAT as a worthy intervention, a repeated measure experimental design with randomly assigned treatment and control groups is necessary; additionally, longitudinal data collection would offer insight into the lasting and transferable effects of the intervention. For many reasons, more rigorous methods of research design continue to be a challenge in this particular area of study.

Findings from this study show the complexity and comorbidity of all of the children in the sample group; one promising direction for AAT is that it may serve as an intervention in tandem with other services, such as occupational therapy or speech programs. Incorporating animals into other early intervention services may help to strengthen the impact of those services while also allowing for continued relationship opportunities between child and therapy dog. For children who interact with many services providers, the therapy dog could service as the constant and consistent figure of support. Another direction for future research based on this study is to attempt to include families and caregivers in the treatment process to some degree to understand how this changes the treatment process and influences the children; careful attention to how family engagement impacts treatment, and how to effectively compare individual treatment with family treatment is worthy of greater exploration.

Other important areas to explore in future studies are gender and culture, and how those constructs influence the children as well as the perception of presenting problems in those children. Findings from this study indicated that females were more likely to be 
considered Internalizers and males were more likely to be Externalizers based on information gathered from data sources. Children raised in non-English speaking homes were more likely to be considered "shut down," "flat," or non-verbal. The influence that gender plays in shaping behaviors for children, and how those behaviors are understood in a treatment setting, are complex and nuanced; so too is the powerful role that culture plays in affecting how children behave outside of their home environments. With all of the children so heavily impacted by inconsistency and trauma, their needs and behaviors can only be fully grasped with a better understanding of how macro-level influences their daily functioning.

Finally, there is reasonable potential for findings from this study to be incorporated into a treatment manual for AAT for young children. A more in-depth understanding of how therapeutic interventions were delivered, and the responses of each client, is possible due to the detailed description of each client's experience during the pilot. This level of detail offers future practitioners strong examples for the delivery of AAT. Additional research about intervention strategies and therapeutic tools, with similar and dissimilar sample groups, would yield many practical outcomes for social work and further substantiate AAT as truly therapeutic. Therapists would be able to replicate the techniques provided in the treatment manual and offer more consistent service delivery. The hope is that AAT can be standardized to some degree so as to gain more traction in various settings - knowing more about what consistently works will help direct future research into this promising intervention. 


\section{References}

Achenbach, T., \& Ruffle, T. (2000). The child behavior checklist and related forms for assessing behavioral/emotional problems and competencies. Pediatrics in Review, $21(1), 265-271$.

American Psychiatric Association. (2013). Diagnostic and statistical manual of mental disorders (5th ed.). Washington, DC: Author.

American Veterinary Medical Association. (1997). U.S. pet ownership \& demographics sourcebook. Schaumburg, IL: Center for Information Management, American Veterinary Medical Association.

Anderson, D. C. (2007). Assessing the human-animal bond: A compendium of actual measures. In D. C. Anderson (Ed.), New directions in the human-animal bond. West Lafayette, IN: Purdue University Press.

Anderson, P. E. (2008). The powerful bond between people and pets: Our boundless connections to companion animals. Westport, CT: Praeger.

Arluke, A., Levin, J., Luke, C., \& Ascione, F. R. (1999). The relationship of animal abuse to violence and other forms of antisocial behavior. Journal of Interpersonal Violence, 14(9), 963-976.

Armstrong, C., \& Hill, M. (2001). Support services for vulnerable families with young children. Child \& Family Social Work, 6(4), 351-358.

Ascione, F. R. (1993). Children who are cruel to animals: A review of research and implications for developmental psychopathology. Anthrozoos, 6(4), 226-247. 
Ascione, F. R., \& Weber, C. V. (1996). Children's attitudes about the humane treatment of animals and empathy: One year follow-up of a school-based intervention. Anthrozoos, 9(4), 188-195.

Attride-Stirling, J. (2011). Thematic networks: An analytic tool for qualitative research. Qualitative Research, 1(3), 385-405.

Bandura, A. (1973). Aggression: A social learning analysis. Englewood Cliffs, NJ: Prentice Hall.

Bandura, A. (1986). Social foundations of thought and action: A social cognitive theory. Englewood Cliffs, NJ: Prentice Hall.

Barker, S. B., \& Dawson, K. S. (1998). The effects of animal-assisted therapy on anxiety ratings of hospitalized psychiatric patients. Psychiatric Services, 49, 797-801.

Beck, A., \& Katcher, A. (1996). Between pets and people. West Lafayette, IN: Purdue University Press.

Beck, A. M., Seraydarianm L., \& Hunter, G. F. (1986). Use of animals in the rehabilitation of psychiatric inpatients. Psychological Reports, 58(1), 63-66.

Beirne, P. (2004). From animal abuse to interhuman violence? A critical review of the progression thesis. Society \& Animals, 12(1), 39-65.

Bemak, F., \& Keys, S. (2000). Violent and aggressive youth: Intervention and prevention strategies for changing times. Thousand Oaks, CA: Corwin Press.

Besthorn, F. H., \& Saleebey, D. (2003). Nature, genetics and the biophilia connection: Exploring linkages with social work values and practice. Advances in Social Work, 4(1), 1-19. 
Bikales, G. (1975). The dog as "significant other.” Social Work, 20, 150-152.

Bowlby, J. (1969). Attachment and loss. New York, NY: Basic Books.

Braun, V., \& Clarke, V. (2006). Using thematic analysis in psychology. Qualitative Research in Psychology, 3(2), 77-101.

Bretherton, I., \& Munholland, K .A. (1999). Internal working models in attachment relationships: A construct revisited. In J. Cassidy \& P. R. Shaver (Eds.), Handbook of attachment: Theory, research and clinical applications (pp. 226248). New York, NY: Guilford Press.

Bronfenbrenner, U. (1979). The ecology of human development: Experiments by nature and design. Cambridge, MA: Harvard University Press.

Brulliard, K. (2017, July 2). Therapy animals are everywhere. Proof that they help is not. The Washington Post. Retrieved from http://www.washingtonpost.com

Bulliet, R. W. (2005). Hunters, herders, and hamburgers: The past and future of humananimal relationships. New York, NY: Columbia University Press.

Burchfield, K. B. (2016). The sociology of animal crime: An examination of incidents and arrests in Chicago. Deviant Behavior, 37(4), 368-384.

Bustad, L. K. (1980). Animals, aging and the aged. Minneapolis, MN: University of Minnesota Press.

Bustad, L. K. (1990). Compassion: Our last great hope. Renton, WA: Delta Society.

Cloutier, A., \& Peetz, J. (2016). Relationships' best friend: Links between pet ownership, empathy, and romantic relationship outcomes. Anthrozoös, 29(3), 395-408. 
Cobb, S. (1976). Social support as a moderator of life stress. Psychosomatic Medicine, $38(5), 300-314$.

Cochran, M. M., \& Brassard, J. A. (1979). Child Development and Personal Social Networks. Child Development, 50(3), 601-616.

Cohen, S., \& Willis, T. A. (1985). Stress, social support, and the buffering hypothesis. Psychological Bulletin, 98(2), 310-357.

Cusack, O. (1988). Pets and mental health. New York, NY: Hawthorne Press.

Dadds, M. R., Whiting, C., \& Hawes, D. J. (2006). Associations among cruelty to animals, family conflict, and psychopathic traits in childhood. Journal of Interpersonal Violence, 21(3), 411-429.

Delta Society (2010). Delta society: The human-animal health connection. Retrieved from http://www.deltasociety.org

De Mello, M. (2012). Animals and society: An introduction to human-animal studies. New York, NY: Columbia University Press.

Dietz, T., David, D., \& Pennings, J. (2012). Evaluating animal-assisted therapy in group treatment for child sexual abuse. Journal of Child Sexual Abuse, 21(6), 665-683.

Duncan, A., \& Miller, C. (2002). The impact of an abusive family context on childhood animal cruelty and adult violence. Aggression and Violent Behavior, 7, 365-383.

Eisenberg, N. (1986). Altruistic emotion, cognition, and behavior. Hillsdale, NJ: Lawrence Erlbaum. 
Endenburg, N., \& Baarda, B. (1995). The role of pets in enhancing human well-being: Effects of child development. In I. H. Robins (Ed.), The Waltham book of humananimal interaction: benefits and responsibilities of pet ownership (pp. 7-17). Oxford, UK: Pergamon.

Eriksen, W. (1994). The role of social support in the pathogenesis of coronary heart disease: A literature review. Family Practice, 11(2), 201-209.

Esterling, B. A., Kiecolt-Glaser, J. J., Bodnar, J. C., \& Glaser, R. (1994). Chronic stress, social support and persistent alterations in the natural killer cell response to cytokines in older adults. Health Psychology: Official Journal of the Division of Health Psychology, American Psychological Association, 13(4), 291-298.

Fairchild, S. R. (2009). Introduction to a special edition: Attachment theory and its application to practice. Child and Adolescent Social Work Journal, 26(4), 287289.

Faver, C. A. (2010). School-based human education as a strategy to prevent violence: Review and recommendations. Children and Youth Services Review, 32, 365-370.

Faver, C. A., \& Strand, E. B. (2008). Unleashing compassion: Social work and animal abuse. In F. R. Ascione (Ed.), The international handbook of animal abuse and cruelty: Theory, research, and application (pp. 175-199). West Lafayette, IN: Purdue University Press.

Fine, A. H. (2000). Animal-assisted therapy: Theoretical foundations and guidelines for practice. San Diego, CA: Academic Press. 
Fine, A. H. (2006). Handbook on animal-assisted therapy: Theoretical foundations and guidelines for practice. Boston, MA: Elsevier/Academic Press.

Foer, J. S. (2009). Eating animals. New York, NY: Little, Brown and Company.

Friedmann, E., Katcher, A., Lynch, J., \& Thomas, S. (1980). Animal companions and one year survival of patients after discharge from a coronary care unit. Public Heath Reports, 95(4), 307-312.

Friedman, E., Thomas, S. A., \& Eddy, T. J. (2000). Companion animals and human health: Physical and cardiovascular influences. In A. L. Podberscek, E. S. Paul, \& J. A. Serpell (Eds.), Companion animals \& us: Exploring the relationships between people \& pets (pp. 125-142). Cambridge, UK: Cambridge University Press.

Friedmann, E., Katcher, A., Thomas, S., Lynch, J., \& Messent, P. (1983). Social interaction and blood pressure; influence of companion animals. Journal of Nervous and Mental Disease, 171(8), 461-465.

Friedmann, E., \& Thomas, S. (1995). Pet ownership, social support, and one-year survival after acute myocardial infarction in the cardiac arrhythmia suppression trial (CAST). The American Journal of Cardiology, 76, 1213-1217.

Friesen, L. (2010). Exploring animal-assisted programs with children in school and therapeutic contexts. Early Childhood Education Journal, 37(4), 261-267.

Garmezy, N. (1993). Children in poverty: Resilience despite risk. Psychiatry, 56, 127136. 
Garrity, T. F., Stallones, L., Marx, M. B., \& Johnson, T. P. (1989). Pet ownership and attachment as supportive factors in the health of the elderly. Anthrozoos, 3(1), 3544.

Greenwald, A. J. (2001). The effect of a therapeutic horsemanship program on emotionally disturbed boys. Dissertation Abstracts International, Section B: The Sciences and Engineering, 62(2-B), 1078.

Gullone, E. (2000). The biophilia hypothesis and life in the 21 st century: Increasing mental health or increasing pathology? Journal of Happiness Studies, 1(3), 293321.

Handlin, L., Hydbring-Sandberg, E., Nilsson, A., Ejdeback, M., Jansson, A., \& UvnasMoberg, K. (2011). Short-term interaction between dogs and their owners: Effects of oxytocin, cortisol, insulin and heart rate-An exploratory study. Anthrozoos, $24,301-315$.

Hanselman, J. (2001). Coping skills intervention with adolescents in anger management using animals in therapy. Journal of Adolescent Group Therapy, 11(4), 159-195.

Hargreaves-Cormany, H. (2017). Engendering empathic development and pro-social responses in elementary school students through a humane education program. Dissertation Abstracts International: Section B: The Sciences and Engineering, $77(8)$

Harm, N. J. (2005). Human-animal bond. Journal of Family Social Work, 9(4), 1-9. 
Hastings, P. D., Zahn-Waxler, C., Robinson, J., Usher, B., \& Bridges, D. (2000). The development of concern for others in children with behavior problems. Developmental Psychology, 36(5), 531-546.

Henderson, B. B. (2010). Childhood animal cruelty methods and their link to adult interpersonal violence. Dissertation Abstracts International.

Hensley, C., \& Tallichet, S. E. (2009). Childhood and adolescent animal cruelty methods and their possible link to adult violent crimes. Journal of Interpersonal Violence, $24(1), 147-158$.

Hensley, C., \& Tallichet, S. E. (2008). The effect of inmates' self-reported childhood and adolescent animal cruelty: Motivations on the number of convictions for adult violent interpersonal crimes. International Journal of Offender Therapy and Comparative Criminology, 52(2), 175-184.

Hensley, C., Tallichet, S. E., \& Dutkiewicz, E. L. (2009). Recurrent childhood animal cruelty: Is there a relationship to adult recurrent interpersonal violence? Criminal Justice Review, 34(2), 248-257.

Hines, L. (2003). Historical perspectives on the human-animal bond. American Behavioral Scientist, 47(1), 7-15.

Henry, B. C. (2006). Empathy, home environment, and attitudes toward animals in relation to animal abuse. Anthrozoos, 19(1), 17-34.

Hosey, G., \& Melfi, V. (2014). Human-animal interactions, relationships and bonds: A review and analysis of the literature. International Journal of Comparative Psychology, 27(1). 
House, J. S., Umberson, D., \& Landis, K. R. (1988). Structures and processes of social support. Annual Review of Sociology, 14, 293-318.

Hoy-Gerlach, J., \& Wehman, S. (2017). Human-animal interactions: A social work guide. Washington, DC: NASW Press.

Hughes, C. (2000). Animal-assisted therapy for children with pervasive developmental disorders. Western Journal of Nursing Research, 24, 657-670.

Jonson-Reid, M., Presnall, N., Drake, B., Fox, L., Bierut, L., Reich, W., Kane, P., Todd, R., \& Constantino, J. (2009). Effects of child maltreatment and inherited liability on antisocial development: An official records study. Journal of the American Academy of Child \& Adolescent Psychiatry, 49(4), 321-332.

Kahn, P. H. (1999). The human relationship with nature: Development and culture. Cambridge, MA: M.I.T. Press.

Kaminski, M., Pellino, T., \& Wish, J. (2002). Play and pets: The physical and emotional impact of child-life and pet therapy on hospitalized children. Children's Health Care, 31, 321-335.

Kamioka, H., Tsutani, K., Yamada, M., Park, H., Okuizumi, H., Tsuruoka, K., \& Mutoh, Y. (2014). Effectiveness of music therapy: a summary of systematic reviews based on randomized controlled trials of music interventions. Patient Preference and Adherence, 8, 727-754.

Katcher, A., \& Beck, A. (1983). New perspectives on our lives with companion animals. Philadelphia, PA: University of Pennsylvania Press. 
Kellert, S. R. (1993). The biological basis for human values of nature. In S.R. Kellert \& E.O. Wilson (Eds.), The biophilia hypothesis (pp. 49-69). Washington, DC: Island Press.

Kidd, A. H., \& Kidd, R. M. (1985). Children's attitudes toward their pets. Psychological Reports, 57, 15-31.

Knight, S., \& Edwards, V. (2008). In the company of wolves: The physical, social and psychological benefits of dog ownership. Journal of Aging and Health, 20(4), $437-455$.

Knight, S., \& Herzog, H. A. (2009). New perspectives on human-animal interactions: Theory, policy and research. Maiden, MA: Wiley-Blackwell Publishing.

Kogan, L. R. (2000). Effective animal-intervention for long term care residents. Activities, Adaptation and Aging, 25(1), 31-45.

Kohlberg, L. (1969). Stages in the development of moral thought and action. New York, NY: Holt, Rinehart, \& Winston.

Kruger, K., \& Serpell, J. A., 2006). Animal-assisted interventions in mental health: Definitions and theoretical foundations. In A. H. Fine (Ed.), Handbook on animalassisted therapy (pp. 21-38). New York, NY: Academic Press.

LaJoie, K. R. (2003). An evaluation of the effectiveness of using animals in therapy. Dissertations Abstracts International.

Lange, A. M., Cox, J. A., Bernert, D. J., \& Jenkins, C. D. (2006). Is counseling going to the dogs? An exploratory study related to the inclusion of an animal in group counseling with adolescents. Journal of Creativity in Mental Health, 2(2), 17-31. 
Levinson, B. (1972). Pets and human development. Springfield, IL: Charles C. Thomas Publisher.

Levine, G. N., Allen, K., Braun, L. T., Friedmann, E., \& Taubert, K. A. (2013). Pet ownership and cardiovascular risk: A scientific statement from the American Heart Association. Circulation, 127, 2353-2363.

Levinson, B. (1997). Pet-oriented psychotherapy for children. Springfield, IL: Charles C. Thomas Publisher.

Linder, D. E., Mueller, M. K., Gibbs, D. M., Alper, J. A., \& Freeman, L. M. (2017). Effects of an animal-assisted intervention on reading skills and attitudes in second grade students. Early Childhood Education Journal, 1-7.

Locke, J. (1699). Some thoughts concerning education. London, UK: Printed for A. and J. Churchill.

Louv, R. (2005). Last child in the woods: Saving our children from nature-deficit disorder. Chapel Hill, NC: Algonquin Books.

Macdonald, J. M. (1961). The murderer and his victim. Springfield, IL: Charles C. Thomas.

Macdonald, J. M. (1963). The threat to kill. The American Journal of Psychiatry, 120(2), 125-130.

Magadi, M. (2010). Risk factors for severe child poverty in the UK. Journal of Social Policy, 39(2), 297-316.

Main, M., \& Weston, D. (1982). Avoidance of the attachment figure in infancy: Descriptions and interactions. Tavistock Institute of Medical Psychology, 31-50. 
Marr, C., French, L., Thompson, D., Drum, L., Greening, G., Mormon, J., Henderson, I., \& Hughes, C. W. (2000). Animal-assisted therapy in psychiatric rehabilitation. Anthrozoos, 13(1), 43-47.

Matchock, R. L. (2015). Pet ownership and physical health. Current Opinion in Psychiatry, 28(5), 386-392.

May, D., Seivert, N., Cano, A., Casey, R., \& Johnson, A. (2016). Animal-assisted therapy for youth: A systematic methodological critique. Human-Animal Interaction Bulletin, 4(1), 1-18.

McCardle, P., McCune, S., Griffin, J., Esposito, L., \& Freund, L. (2011). Animals in our lives: Human-animal interaction in family, community and therapeutic settings. Baltimore, MD: Brookes Publishing Co.

McCulloch, M. J. (1981). Animal-facilitated therapy: Overview and future direction. Phi Kappa Phi Journal, 19-24.

McNicholas, J., \& Collis, G. M. (1995). The end of a relationship: Coping with pet loss. In Robinson (Ed.), The Waltham book of human-animal interaction: Benefits and responsibilities of pet-ownership (pp. 127-143). Oxford, UK: Pergamon.

McNicholas, J., \& Collis, G. (2000). Dogs as catalysts for social interactions: Robustness of the effect. British Journal of Psychology, 9, 61-70.

Melson, G. F. (2001). Why the wild things are: Animals in the lives of children. Cambridge, MA: Harvard University Press.

Melson, G. F. (2003). Child development and the human-companion animal bond. American Behavioral Scientist, 47(1), 31-39. 
Merz-Perez, L., \& Heide, K. M. (2004). Animal cruelty: Pathway to violence against people. Walnut Creek, CA: AltaMira Press.

Merz-Perez, L., Heide, K. M., \& Silverman, I. (2001). Childhood cruelty to animals and subsequent violence against humans. International Journal of Offender Therapy and Comparative Criminology, 45, 556-573.

Messent, P. (1983). Social facilitation of contact with other people by pet dogs. In A. Katcher \& A. Beck (Eds.), New perspectives on our lives with companion animals (pp. 37-46). Philadelphia, PA: University of Pennsylvania Press.

Miller, C. (2001). Childhood animal cruelty and interpersonal violence. Clinical Psychology Review, 21, 735-749.

Miller, P. A., \& Eisenberg, N. (1988). The relation of empathy to aggressive and externalizing/antisocial behavior. Psychological Bulletin, 103, 324-344.

Miller, K. S., \& Knutson, J. F. (1997). Reports of severe physical punishment and exposure to animal cruelty by inmates convicted of felonies and by university students. Child Abuse and Neglect, 21(1), 59-82.

Miller S. C., Kennedy C., DeVoe, D., Hickey M., Nelson T., \& Kogan L. (2009). An examination of changes in oxytocin levels in men and women before and after interaction with a bonded dog. Anthrozoos, 22, 31-42.

Mills, H., \& Dombeck, M. (2005, June 25). Emotional resilience. Retrieved from http://www.mentalhealth.net

Moore, K. A., Vandivere, S., \& Redd, Z. (2006). A sociodemographic risk index. Social Indicators Research Series, 27, 45-81. 
Muela, A., Balluerka, N., Amiano, N., Caldentey, M. A., \& Aliri, J. (2017). Animalassisted psychotherapy for young people with behavioural problems in residential care. Clinical Psychology \& Psychotherapy.

Muris, P., \& Ollendick, T. (2015). Children who are anxious in silence: A review on Selective Mutism, the new anxiety disorder in DSM-5. Clinical Child and Family Psychology Review, 18(2), 151-169.

Nagasawa, M., Kikusui, T., Onaka, T., \& Ohta, M. (2009). Dog's gaze at its owner increases owner's urinary oxytocin during social interaction. Hormones and Behavior, 55, 434-441.

Nightingale, F. (1860). Notes on nursing: What it is, and what it is not. New York, NY: D. Appleton and Company.

Nimer, J., \& Lundahl, B. (2007). Animal-assisted therapy: A meta-analysis. Anthrozoos, $20(3), 225-238$.

Onion, A. K. (2014). Humane education in an early childhood science education curriculum. In M. Renck Jalongo (Ed.), Teaching compassion: Humane education in early childhood (pp. 213-226). New York, NY: Springer.

Ostberg, V., \& Lennartsson, C. (2007). Getting by with a little help: The importance of various types of social support for health problems. Scandinavian Journal of Public Health, 35(2), 197-204.

Padgett, D. K. (2004). The qualitative research experience. Belmont, CA: Wadsworth/Thomson Learning. 
Parish-Plass, N. (2008). Animal-assisted therapy with children suffering from insecure attachment due to abuse and neglect: A method to lower the risk of intergenerational transmission of abuse? Clinical Child Psychology and Psychiatry, 13(1), 7-30.

Paxton, D. W. (1998). Urban animal management: A naturalistic perspective (Doctoral Dissertation, Australian National University). Dissertation Abstracts International.

Paxton, D. W. (2000). A case for a naturalistic perspective. Anthrozoos, 13(1), 5-8.

Peacock, C. A., \& McCulloch, M. J. (1981). Animals and mental health. Phi Kappa Phi Journal, 24.

Pew Research Center. (2006, March 7). Gauging family intimacy: Dogs edge cats (dad trail both). Retrieved from http://www.pewresearch.org

Porseky, R. H. (1996). Companion animals and other factors affecting young children's development. Anthrozoos, 9(4), 159-169.

Ptak, A. L., \& Howie, A. R. (2005). Providing the best quality of life during a difficult time: Pet partners helping hospice patients. Interactions, 23(1), 4-11.

Read, J., \& Bentall, R. P. (2012). Negative childhood experiences and mental health: Theoretical, clinical and primary prevention implications. British Journal of Psychiatry, 200, 89-91.

Reichert, E. (1998). Individual counseling for sexually abused children: A role for animals and storytelling. Child and Adolescent Social Work Journal, 15(3), 177185. 
Reynolds, A., \& Ou, S. (2010). Early childhood to young adulthood: An introduction to the special issue. Children and Youth Services Review, 32(8), 1045-1053.

Risley-Curtiss, C. (2010). Social work practitioners and the human-companion animal bond: A national survey. Social Work, 55(1), 38-46.

Rutter, M. (1987). Psychosocial resilience and protective mechanisms. American Journal of Orthopsychiatry, 57, 316-331.

Ryan, S., \& Ziebland, S. (2015). On interviewing people with pets: Reflections from qualitative research on people with long-term conditions. Sociology of Health \& Illness, 37(1), 67-80.

Rynearson, E. K. (1978). Humans and pets and attachment. The British Journal of Psychiatry: The Journal of Mental Science, 133, 550-555.

Schuck, S., Emmerson, N., Fine, A., \& Lakes, K. (2013). Canine-assisted therapy for children with ADHD: Preliminary findings for the positive assertive cooperative kids study. Journal of Attention Disorders, 23(13), 1-13.

Serpell, J. (1996). Evidence for an association between pet behavior and owner attachment levels. Applied Animal Behaviour Science, 47, 49-60.

Serpell, J. (1999). Guest editor's introduction: Animals in children's lives. Society and Animals, 7(2), 87-94.

Serpell, J. (2011). Historical and cultural perspectives on human-pet interactions. In P. McCardle, S. McCune, J. Griffin, L. Esposito, \& L. Freund (Eds.), Animals in our lives (pp. 7-22). Baltimore, MD: Brookes Publishing Co. 
Shaw, T. V. (2008). An ecological contribution to social welfare theory. Social Development Issues, 30(3), 13-26.

Sherbourne, C. D., Meredith, L. S., Rogers, W., \& Ware, J. E., Jr. (1992). Social support and stressful life events: Age differences in the effects on health-related quality of life among the chronically ill. Quality of Life Research, 1(4), 235-246.

Siegel, J. M. (1990). Stressful life events and use of physician services among the elderly: The moderating role of pet ownership. Journal of Personality and Social Psychology, 58(6), 1081-1086.

Signal, T., Taylor, N., Prentice, K., McDade, M., \& Burke, K. J. (2017). Going to the dogs: A quasi-experimental assessment of animal assisted therapy for children who have experienced abuse. Applied Developmental Science, 21(2), 81-93.

Slade, A. (2004). The move from categories to process: Attachment phenomena and clinical evaluation. Infant Mental Health, 25(4), 269-283.

Souter, M. A., \& Miller, M. D. (2007). Do animal-assisted activities effectively treat depression? a meta-analysis. Anthrozoos, 20(2), 167-180.

Sprinkle, J. E. (2008). Animals, empathy, and violence: Can animals be used to convey principles of prosocial behavior to children? Youth Violence and Juvenile Justice, $6,47-58$.

Strauss, A., \& Corbin, J. (1998). Basics of qualitative research (2nd ed.). Newbury Park, CA: SAGE Publications, Inc. 
Tallichet, S. E., \& Hensley, C. (2004). Exploring the link between recurrent acts of childhood and adolescent animal cruelty and subsequent violent crime. Criminal Justice Review, 29(2), 304-316.

Tallichet, S. E., Hensley, C., \& Singer, S. D. (2005). Unraveling the methods of childhood and adolescent cruelty to nonhuman animals. Society \& Animals, 14(3), $221-243$.

Taylor, A. F., \& Kuo, F. (2009). Children with attention deficits concentrate better after walk in the park. Journal of Attention Disorders, 12(5), 402-409.

Thyer, B. A. (2001). What is the role of theory in research on social work practice? Journal of Social Work Education, 37(1), 9-25.

Triebenbacher, S. L. (1999). Re-evaluation of the companion animal bonding scale. Anthrozoos, 12(3), 169-173.

Tucker, M. T. (Ed.). (2005). The pet partners team training manual: A Delta Society program for animal-assisted activities and therapy. Renton, WA: Delta Society.

Turner, W. G. (2005). The role of companion animals throughout the family life cycle. Journal of Family Social Work, 9(4), 11-21.

Vagnoli, L., Caprilli, S., Vernucci, C., Zagni, S., Mugnai, F., \& Messeri, A. (2015). Can presence of a dog reduce pain and distress in children during venipuncture? Pain Management Nursing, 16, 89-95.

Varese, F., Smeets, F., Drukker, M., Lieverse, R., Lataster, T., Viechtbauer, W., .. . Bentall, R. (2012). Childhood adversities increase the risk of psychosis: A metaanalysis of patient-control. Schizophrenia Bulletin, 38(4), 661-671. 
Vaughn, M. G., Fu, Q., DeLisi, M., Beaver, K. M., Perron, B. E., Terrell, K., \& Howard, M. O. (2009). Correlates of cruelty to animals in the United States: Results from the National Epidemiologic Survey on Alcohol and Related Conditions. Journal of Psychiatric Research, 43(15), 1213-1218.

Vilhjalmsson, R. (1993). Life stress, social support and clinical depression: A reanalysis of the literature. Social Science and Medicine, 37(3), 331-342.

Wachtel, M. (1999). Estimating interobserver reliability. American Journal of Clinical Pathology, 111(4), 567-568.

Walsh, F. (2009). Human-animal bonds I: The relational significance of companion animals. Family Process, 48(4), 462-480.

Watts, R. (2000). Techniques in marriage and family counseling, Vol. 1. Alexandria, VA: American Counseling Association.

Wax, D. E., \& Haddox, V. G. (1974). Enuresis, fire setting, and animal cruelty: A useful danger signal in predicting vulnerability of adolescent males to assaultive behavior. Child Psychiatry and Human Development, 4(3), 151-156.

Wenz-Gross, M., \& Siperstein, G. (1997). Importance of social support in the adjustment of children with learning problems. Exceptional Children, 63(2), 184-193.

Wells, D. L. (2009). The effects of animals on human health and well-being. Journal of Social Issues, 6(3), 523-543.

Wilkes, J. (2009). The role of companion animals in counseling and psychology: Discovering their use in the therapeutic process. Springfield, IL: Charles C. Thomas. 
Wilson, E. O. (1984). Biophilia. Cambridge, MA: Harvard University Press.

Wilson, E. O. (1993). Biophilia and the conservation ethic. In S. R. Kellert \& E. O. Wilson (Eds.), The biophilia hypothesis (pp. 31-41). Washington, D. C.: Island Press.

Wilson, C., \& Turner, C. (1998). Companion animals and human health. Thousand Oaks, CA: SAGE Publications, Inc.

Wolf, D. B. (2000). Social work and speciesism. Social Work, 45(1), 88-92.

Wright, J., \& Hensley, C. (2003). From animal cruelty to serial murder: Applying the graduation hypothesis. International Journal of Offender Therapy and Comparative Criminology, 47, 71-88.

Yin, R. K. (2009). Case study research. Thousand Oaks, CA: SAGE Publications, Inc.

Young, K. W. (2006). Social support and life satisfaction. International Journal of Psychosocial Rehabilitation, 10(2), 155-164.

Zilney, L. A., \& Zilney, M. (2005). Reunification of child and animal welfare agencies: Cross-reporting of abuse in Wellington County, Ontario. Child Welfare, 84(1), $47-66$.

Zimberoff, D., \& Hartman, D. (2002). Attachment, detachment, nonattachment: Achieving synthesis. Journal of Heart-Centered Therapies, 5(1), 3-94. 


\section{Appendix A}

\section{Animal Assisted Therapy}

Case Manager Referral Form

Child's name:

Referred by:

Basic reason for referral (why you selected this child to participate in Animal Assisted

Therapy, ie: emotional concerns, behavioral concerns, social delays, anxiety, etc...):

Compared to other similarly-aged children at the program -

(circle rating)

$\begin{array}{llll}\text { Social Functioning: } & \text { below average } & \text { average } & \text { above average } \\ \text { Emotional Stability: } & \text { below average } & \text { average } & \text { above average } \\ \text { Appropriate Behavior: } & \text { below average } & \text { average } & \text { above average } \\ \text { Language Ability: } & \text { below average } & \text { average } & \text { above average }\end{array}$

Does this child have a pet living in his/her home? YES

NO

Additional comments about this child or things for us to consider: 


\section{Appendix B}

\section{Animal-Assisted Therapy Evaluation Instrument (AATEI)}

Child's Name:

Date:

Evaluator:

\begin{tabular}{|c|c|c|c|}
\hline \multicolumn{4}{|c|}{ COGNITIVE } \\
\hline $\begin{array}{c}\text { SKILLS, } \\
\text { ABILITIES } \\
\text { AND } \\
\text { PERFORMANCE } \\
\text { (leave blank if N/A) }\end{array}$ & $\begin{array}{l}\text { OBSERVED } \\
\text { (check one) }\end{array}$ & $\begin{array}{c}\text { IF YES, } \\
\text { RATE } \\
\text { QUALITY* } \\
\text { (circle one) }\end{array}$ & $\begin{array}{c}\text { GOAL ACHIEVED / } \\
\text { RECOMMENDATION FOR } \\
\text { FOLLOW-UP (check one) }\end{array}$ \\
\hline $\begin{array}{l}\text { Attention to task at } \\
\text { hand }\end{array}$ & $\square$ Yes $\square$ No & $\begin{array}{llll}1 & 2 & 3 & 4 \\
& & 5 & \end{array}$ & $\begin{array}{l}\square \text { Needs improvement } \\
\text { No follow-up needed }\end{array}$ \\
\hline $\begin{array}{l}\text { Displays } \\
\text { concentration }\end{array}$ & $\square$ Yes $\square$ No & 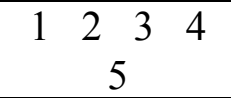 & $\begin{array}{l}\square \text { Needs improvement } \\
\text { No follow-up needed }\end{array}$ \\
\hline $\begin{array}{l}\text { Shows interest in } \\
\text { people and therapy } \\
\text { dog }\end{array}$ & $\square$ Yes $\square$ No & $\begin{array}{ccc}1234 & 3\end{array}$ & $\begin{array}{l}\square \text { Needs improvement } \square \\
\text { No follow-up needed }\end{array}$ \\
\hline Learns through play & $\square$ Yes $\square$ No & $\begin{array}{llll}1 & 2 & 3 & 4 \\
& & 5 & \end{array}$ & $\begin{array}{l}\square \text { Needs improvement } \\
\text { No follow-up needed }\end{array}$ \\
\hline $\begin{array}{l}\text { Learns through } \\
\text { using senses }\end{array}$ & $\square$ Yes $\square$ No & 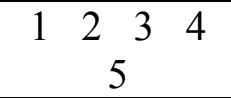 & $\begin{array}{l}\square \text { Needs improvement } \\
\text { No follow-up needed }\end{array}$ \\
\hline $\begin{array}{l}\text { Learns through } \\
\text { experimentation }\end{array}$ & $\square$ Yes $\square$ No & $\begin{array}{llll}1 & 2 & 3 & 4 \\
& & 5 & \end{array}$ & $\begin{array}{l}\square \text { Needs improvement } \\
\text { No follow-up needed }\end{array}$ \\
\hline $\begin{array}{l}\text { Notices routines / } \\
\text { follows routines }\end{array}$ & $\square$ Yes $\square$ No & 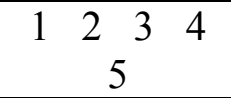 & $\begin{array}{l}\text { Needs improvement } \\
\text { No follow-up needed }\end{array}$ \\
\hline $\begin{array}{l}\text { Demonstrates } \\
\text { planned, deliberate, } \\
\text { and purposeful } \\
\text { response }\end{array}$ & $\square$ Yes $\square$ No & $\begin{array}{lll}1 & 234 \\
& & \end{array}$ & $\begin{array}{l}\square \text { Needs improvement } \square \\
\text { No follow-up needed }\end{array}$ \\
\hline Follows instructions & $\square$ Yes $\square$ No & $\begin{array}{lll}1 & 2 & 34 \\
& & 5\end{array}$ & $\begin{array}{c}\text { Needs improvement } \square \\
\text { No follow-up needed }\end{array}$ \\
\hline $\begin{array}{l}\text { Stays engaged } \\
\text { throughout session }\end{array}$ & $\square$ Yes $\square$ No & $\begin{array}{lcc}1234 \\
& 2 & \\
& & \end{array}$ & $\begin{array}{l}\square \text { Needs improvement } \\
\text { No follow-up needed }\end{array}$ \\
\hline
\end{tabular}




\begin{tabular}{|c|c|c|c|}
\hline \multicolumn{4}{|c|}{ SOCIAL / EMOTIONAL } \\
\hline $\begin{array}{c}\text { SKILLS, } \\
\text { ABILITIES } \\
\text { AND } \\
\text { PERFORMANCE }\end{array}$ & $\begin{array}{l}\text { OBSERVED } \\
\text { (check one) }\end{array}$ & $\begin{array}{c}\text { IF YES, } \\
\text { RATE } \\
\text { QUALITY* } \\
\text { (circle one) }\end{array}$ & $\begin{array}{l}\text { GOAL ACHIEVED / } \\
\text { RECOMMENDATION FOR } \\
\text { FOLLOW-UP (check one) }\end{array}$ \\
\hline $\begin{array}{l}\text { Appears happy and } \\
\text { content }\end{array}$ & $\square$ Yes $\square$ No & $\begin{array}{lll}123 & 3 \\
& 5 & \\
\end{array}$ & $\begin{array}{l}\square \text { Needs improvement } \\
\text { No follow-up needed }\end{array}$ \\
\hline Shows eye contact & $\square$ Yes $\square$ No & $\begin{array}{llll}1 & 2 & 3 & 4 \\
& 5 & \end{array}$ & $\begin{array}{l}\square \text { Needs improvement } \square \\
\text { No follow-up needed }\end{array}$ \\
\hline $\begin{array}{l}\text { Shows elevation of } \\
\text { mood }\end{array}$ & $\square$ Yes $\square$ No & $\begin{array}{llll}1 & 23 & 3 & 4\end{array}$ & $\begin{array}{l}\square \text { Needs improvement } \\
\text { No follow-up needed }\end{array}$ \\
\hline Expresses feelings & $\square$ Yes $\square$ No & $\begin{array}{llll}1 & 2 & 3 & 4 \\
& 5 & \end{array}$ & $\begin{array}{l}\square \text { Needs improvement } \square \\
\text { No follow-up needed }\end{array}$ \\
\hline $\begin{array}{l}\text { Shows interest in } \\
\text { exploring }\end{array}$ & $\square$ Yes $\square$ No & $\begin{array}{lll}123 & 23\end{array}$ & $\begin{array}{l}\square \text { Needs improvement } \\
\text { No follow-up needed }\end{array}$ \\
\hline $\begin{array}{l}\text { Actively responds to } \\
\text { the therapy dog }\end{array}$ & $\square$ Yes $\square$ No & $\begin{array}{llll}1 & 23 & 3 & 4\end{array}$ & $\begin{array}{l}\square \text { Needs improvement } \\
\text { No follow-up needed }\end{array}$ \\
\hline $\begin{array}{l}\text { Demonstrates } \\
\text { cooperation }\end{array}$ & $\square$ Yes $\square$ No & $\begin{array}{llll}1 & 2 & 3 & 4 \\
& 5 & \end{array}$ & $\begin{array}{l}\square \text { Needs improvement } \\
\text { No follow-up needed }\end{array}$ \\
\hline $\begin{array}{l}\text { Decrease in anxiety } \\
\text { / stress }\end{array}$ & $\square$ Yes $\square$ No & $\begin{array}{lcc}1 & 23 & 3 \\
& 5 & 4\end{array}$ & $\begin{array}{l}\square \text { Needs improvement } \\
\text { No follow-up needed }\end{array}$ \\
\hline Motivated by praise & $\square$ Yes $\square$ No & $\begin{array}{llll}1 & 23 & 3 & 4 \\
& 5 & \end{array}$ & $\begin{array}{l}\square \text { Needs improvement } \\
\text { No follow-up needed }\end{array}$ \\
\hline $\begin{array}{l}\text { Shows trust in staff } \\
\& \text { others }\end{array}$ & $\square$ Yes $\square$ No & $\begin{array}{llll}1 & 23 & 3 \\
& 5 & \end{array}$ & $\begin{array}{l}\text { Needs improvement } \\
\text { No follow-up needed }\end{array}$ \\
\hline $\begin{array}{l}\text { Demonstrates } \\
\text { emotional stability }\end{array}$ & $\square$ Yes $\square$ No & $\begin{array}{llll}1 & 2 & 3 & 4\end{array}$ & $\begin{array}{l}\square \text { Needs improvement } \\
\text { No follow-up needed }\end{array}$ \\
\hline Shows effect & $\square$ Yes $\square$ No & $\begin{array}{lll}123 & 4 \\
& 5 & \end{array}$ & $\begin{array}{l}\text { Needs improvement } \\
\text { No follow-up needed }\end{array}$ \\
\hline $\begin{array}{l}\text { Approached animal } \\
\text { voluntarily }\end{array}$ & $\square$ Yes $\square$ No & $\begin{array}{lll}123 & 4 \\
& 5 & \\
\end{array}$ & $\begin{array}{l}\text { Needs improvement } \\
\text { No follow-up needed }\end{array}$ \\
\hline $\begin{array}{l}\text { Uses touch to } \\
\text { express interest }\end{array}$ & $\square$ Yes $\square$ No & $\begin{array}{llll}1 & 2 & 3 & 4 \\
& 5 & \end{array}$ & $\begin{array}{l}\square \text { Needs improvement } \\
\text { No follow-up needed }\end{array}$ \\
\hline
\end{tabular}




\begin{tabular}{|c|c|c|c|}
\hline \multicolumn{4}{|c|}{ PHYSICAL } \\
\hline Moves to explore & $\begin{array}{l}\square \text { Yes } \square \\
\text { No }\end{array}$ & $\begin{array}{llll}1 & 2 & 3 & 4\end{array}$ & $\begin{array}{l}\square \text { Needs improvement } \\
\text { No follow-up needed }\end{array}$ \\
\hline Walks & $\begin{array}{l}\square \text { Yes } \square \\
\text { No }\end{array}$ & $\begin{array}{llll}1 & 2 & 3 & 4\end{array}$ & $\begin{array}{l}\square \text { Needs improvement } \\
\text { No follow-up needed }\end{array}$ \\
\hline $\begin{array}{l}\text { Displays } \\
\text { coordination }\end{array}$ & $\begin{array}{l}\square \text { Yes } \square \\
\text { No }\end{array}$ & $\begin{array}{lll}1234 \\
& 5 & \end{array}$ & $\begin{array}{l}\square \text { Needs improvement } \\
\text { No follow-up needed }\end{array}$ \\
\hline $\begin{array}{l}\text { Displays fine motor } \\
\text { skills }\end{array}$ & $\begin{array}{l}\square \text { Yes } \square \\
\text { No }\end{array}$ & $\begin{array}{llll}1 & 23 & 3 & 4 \\
& & 5 & \end{array}$ & $\begin{array}{l}\square \text { Needs improvement } \\
\text { No follow-up needed }\end{array}$ \\
\hline $\begin{array}{l}\text { Masters brushing } \\
\text { stroke (with dog) }\end{array}$ & $\begin{array}{l}\square \text { Yes } \square \\
\text { No }\end{array}$ & $\begin{array}{lll}1234 \\
& 5 & \end{array}$ & $\begin{array}{l}\square \text { Needs improvement } \\
\text { No follow-up needed }\end{array}$ \\
\hline $\begin{array}{l}\text { Maintains posture } \\
\text { with dog present / } \\
\text { desired posture }\end{array}$ & $\begin{array}{l}\square \text { Yes } \square \\
\text { No }\end{array}$ & $\begin{array}{lll}1234 & \\
& 5 & \end{array}$ & $\begin{array}{l}\square \text { Needs improvement } \\
\text { No follow-up needed }\end{array}$ \\
\hline $\begin{array}{l}\text { Displays visual- } \\
\text { motor skills }\end{array}$ & $\begin{array}{l}\square \text { Yes } \square \\
\text { No }\end{array}$ & 1234 & $\begin{array}{l}\square \text { Needs improvement } \\
\text { No follow-up needed }\end{array}$ \\
\hline
\end{tabular}

\begin{tabular}{|c|c|c|c|}
\hline \multicolumn{4}{|c|}{ VERBAL } \\
\hline \multicolumn{4}{|l|}{ (NON-VERBAL) } \\
\hline Makes noises & $\begin{array}{l}\square \text { Yes } \square \\
\text { No }\end{array}$ & $\begin{array}{llll}1 & 2 & 3 & 4 \\
& & 5\end{array}$ & $\begin{array}{l}\square \text { Needs improvement } \\
\text { No follow-up needed }\end{array}$ \\
\hline Responds to sounds & $\begin{array}{l}\square \text { Yes } \square \\
\text { No } \\
\end{array}$ & $\begin{array}{lll}1 & 23 \\
& 5 & 4 \\
\end{array}$ & $\begin{array}{l}\square \text { Needs improvement } \\
\text { No follow-up needed }\end{array}$ \\
\hline Babbles & $\begin{array}{l}\square \text { Yes } \square \\
\text { No }\end{array}$ & $\begin{array}{lll}1 & 23 & 3 \\
& 5 & \end{array}$ & $\begin{array}{l}\text { Needs improvement } \\
\text { No follow-up needed }\end{array}$ \\
\hline Makes gestures & $\begin{array}{l}\square \text { Yes } \square \\
\text { No }\end{array}$ & $\begin{array}{lll}123 & 23 \\
& 5\end{array}$ & $\begin{array}{l}\square \text { Needs improvement } \\
\text { No follow-up needed }\end{array}$ \\
\hline $\begin{array}{l}\text { Makes eye contact } \\
\text { when called }\end{array}$ & $\begin{array}{l}\square \text { Yes } \square \\
\text { No }\end{array}$ & $\begin{array}{lll}123 & 4 \\
& 5 & \end{array}$ & $\begin{array}{l}\square \text { Needs improvement } \\
\text { No follow-up needed }\end{array}$ \\
\hline \multicolumn{4}{|l|}{ (VERBAL) } \\
\hline Uses new words & $\begin{array}{l}\square \text { Yes } \square \\
\text { No }\end{array}$ & $\begin{array}{lll}123 & 23 \\
& 5 & \\
\end{array}$ & $\begin{array}{l}\square \text { Needs improvement } \square \\
\text { No follow-up needed }\end{array}$ \\
\hline $\begin{array}{l}\text { Uses appropriate } \\
\text { words }\end{array}$ & $\begin{array}{l}\square \text { Yes } \square \\
\text { No }\end{array}$ & $\begin{array}{lll}123 & 34 \\
& 5 & \end{array}$ & $\begin{array}{l}\text { Needs improvement } \\
\text { No follow-up needed }\end{array}$ \\
\hline $\begin{array}{l}\text { Attempts } \\
\text { communication with } \\
\text { therapy dog (verbal) }\end{array}$ & $\begin{array}{l}\square \text { Yes } \square \\
\text { No }\end{array}$ & $\begin{array}{llll}1 & 2 & 3 & 4 \\
& & 5\end{array}$ & $\begin{array}{l}\square \text { Needs improvement } \\
\text { No follow-up needed }\end{array}$ \\
\hline $\begin{array}{l}\text { Desires verbal } \\
\text { explanation }\end{array}$ & $\begin{array}{l}\square \text { Yes } \square \\
\text { No }\end{array}$ & $\begin{array}{lll}123 & 23 \\
& 5 & \end{array}$ & $\begin{array}{l}\square \text { Needs improvement } \\
\text { No follow-up needed }\end{array}$ \\
\hline Verbal interaction & $\square$ Yes $\square$ & $\begin{array}{llll}1 & 2 & 3 & 4 \\
\end{array}$ & $\square$ Needs improvement $\square$ \\
\hline
\end{tabular}




\begin{tabular}{|c|c|c|c|}
\hline with staff and others & No & 5 & No follow-up needed \\
\hline $\begin{array}{l}\text { Uses multi-word } \\
\text { sentences }\end{array}$ & $\begin{array}{l}\square \text { Yes } \square \\
\text { No }\end{array}$ & $\begin{array}{ccc}1234 \\
& 5 & \\
\end{array}$ & $\begin{array}{l}\square \text { Needs improvement } \\
\text { No follow-up needed }\end{array}$ \\
\hline
\end{tabular}

Additional Notes: 


\section{Appendix C}

\section{Animal Assisted Therapy Progress Note}

Child's name:

Date:

Completed by:

Scales:

- attention

low 1

2

3

4

5 high

- engagement

low 1

2

3

- emotional regulation

low 1

2

34

5 high

- age-appropriate behavior

low 1

2

3

$4 \quad 5 \quad$ high

23

34

$4 \quad 5 \quad$ high

1. Child's behavior was humane and appropriate at all times: $\mathrm{Y}$ or $\mathrm{N}$ as evidenced by:
( ) petting
( ) grooming
( ) talking/verbalization
( ) playing
( ) sharing
( ) other:

2. Child demonstrates bonding behaviors through:

( ) physical affection

( ) verbal interaction

( ) respecting animal's boundaries

( ) did not demonstrate bonding

3. Child sought contact with animals through:
( ) slowly approaching without prompting
( ) approaching with prompting
( ) eye contact
( ) guided touch
( ) petting
( ) grabbing/hitting 

( ) child avoided contact
( ) other:

4. Increased social relatedness:

( ) child attempted to engage with animal by:

( ) identified similar body parts with prompting

( ) gave appropriate attention to animal

( ) read animal's cues (body language)

( ) other:

5. Child exhibited the following attachment behaviors:

( ) acceptable physical touching

( ) appeared to recognize dog

( ) saying goodbye at end of session

( ) maintaining emotional composure throughout session

( ) child appeared nervous or anxious toward end of session

( ) child needed help transitioning out of session

6. Child was able to manage high levels of arousal:

( ) able to transition into and out of session without difficulty

( ) demonstrated hesitancy upon entering

( ) maintained emotional stability throughout the session

( ) demonstrated high levels of instability, as marked by:

7. Child's general affect was:
( ) content
( ) calm
( ) quiet
( ) curious
( ) disinterested
( ) excited
( ) frightened
( ) angry 
() distracted () other:

8. Additional notes: 


\section{Appendix D}

\section{Animal-Assisted Individual Therapy Program}

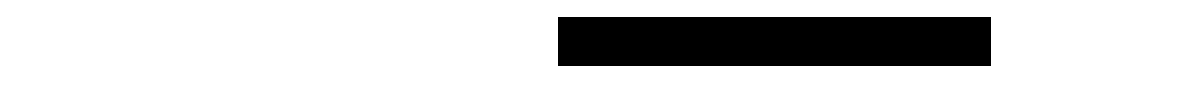

Dear Parent or Guardian,

will be offering a new and exciting program that involves incorporating certified therapy dogs with individual child therapy. Your child was chosen to participate! Recent research on the benefits of Animal Assisted Therapy has shown that children are able to learn impulse control, relaxation techniques, soothing skills, empathy building, and build respect for animals. All of the activities that children will be involved in will be guided by a therapist and supervised by the animal's owner.

Your child will be holding and petting an animal under the supervision of an Animal Assisted Therapist and other $\square$ staff. All of the animals have received physical and behavioral examinations by a veterinarian.

The dogs involved in this therapeutic program are certified and sponsored by the Dove Lewis Animal Clinic. They have undergone extensive training and have been fully screened by Dove Lewis as well as will take every precaution when working with your child, as all of the dogs have worked directly with children in the past. There are minimal risks associated with participating in the program (including biting, scratching, or other physical injuries) but these risks are unlikely.

Signing this form releases $\quad$ from liability should injury occur. Further, your signature certifies that you have granted permission for your child to receive Animal Assisted Therapy on a weekly basis. 
If you would like more information on Animal Assisted Therapy or the activities that your child will be participating in, please feel free to contact Leah Brookner or Lori

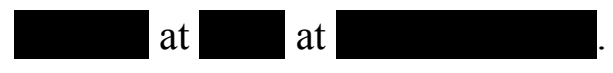

- Should your child be allergic to dogs, please check here ( )

Please comment on any special considerations or information that you think we should know:

I have read this consent form and understand its content. I give permission as the parent/guardian

of for him/her to participate in this

program.

Parent/guardian signature

Date 


\section{Appendix E}

\section{Photo/Media/Research Release}

\section{Child's Name}

Dear Parent or Guardian:

Please be advised that while participating in the Animal Assisted Therapy Program (AAT) your child may be photographed or video-taped during the session. Written data on your child's progress will also be recorded. The data, photograph or tape will be used for research purposes for data analysis. With your consent, the photograph or tape may be reproduced and released for use by _ including but not limited to use by Dove Lewis Animal Hospital and affiliates of Portland State University. Your child will remain anonymous; no name will be used outside of his/her classroom.

Please indicate your consent to use your child's photo by initialing the format/s you approve.

In-house: in and around building and classrooms

If yes, I consent to have my child's photo appear in the classroom with his/her

name

's Website: access through the internet; no name to appear Newsletter: mailed to community members and

donors; no name to appear

Fundraising: slide, video, PowerPoint presentations, print media including brochures, newspapers, magazines; no name to appear

Flyers: Information, announcements, and updates to $\square$ program participants; no name to appear 


\section{Appendix F}

\section{Human Subjects Review Committee Permission Letter}

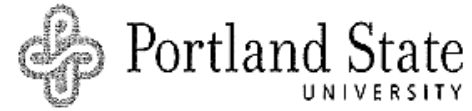

Human Subjects Research Review Committee Post Office Box $751 \quad 503-725-4288$ tel

Portland, Oregon 97207-0751 503-725-8170 fax

hsrrc@lists.pdx.edu

To: Leah Brookner

From: HSSRC 2012

Date: February 9, 2012

Re: HSRRC waived review of your application titled, "Is Therapy Going to the Dogs? Evaluating Animal Assisted Therapy for At-Risk Children" (HSRRC \#122037)

Your proposal is exempt from further Human Subjects Research Review Committee review, and you may proceed with the study.

Even with the exemption above, it was necessary by University policy for you to notify this Committee of the proposed research, and we appreciate your timely attention to this matter. If you make changes in the research protocol, the Committee must be notified in writing, and changes must be approved before being implemented.

If you have questions or concerns, please contact the HSRRC in the Office of Research and Strategic Partnerships (RSP), (503) 725-2243, Market Center Building, $6^{\text {th }}$ floor.

cc: Roxanne Treece

Maria Talbott 